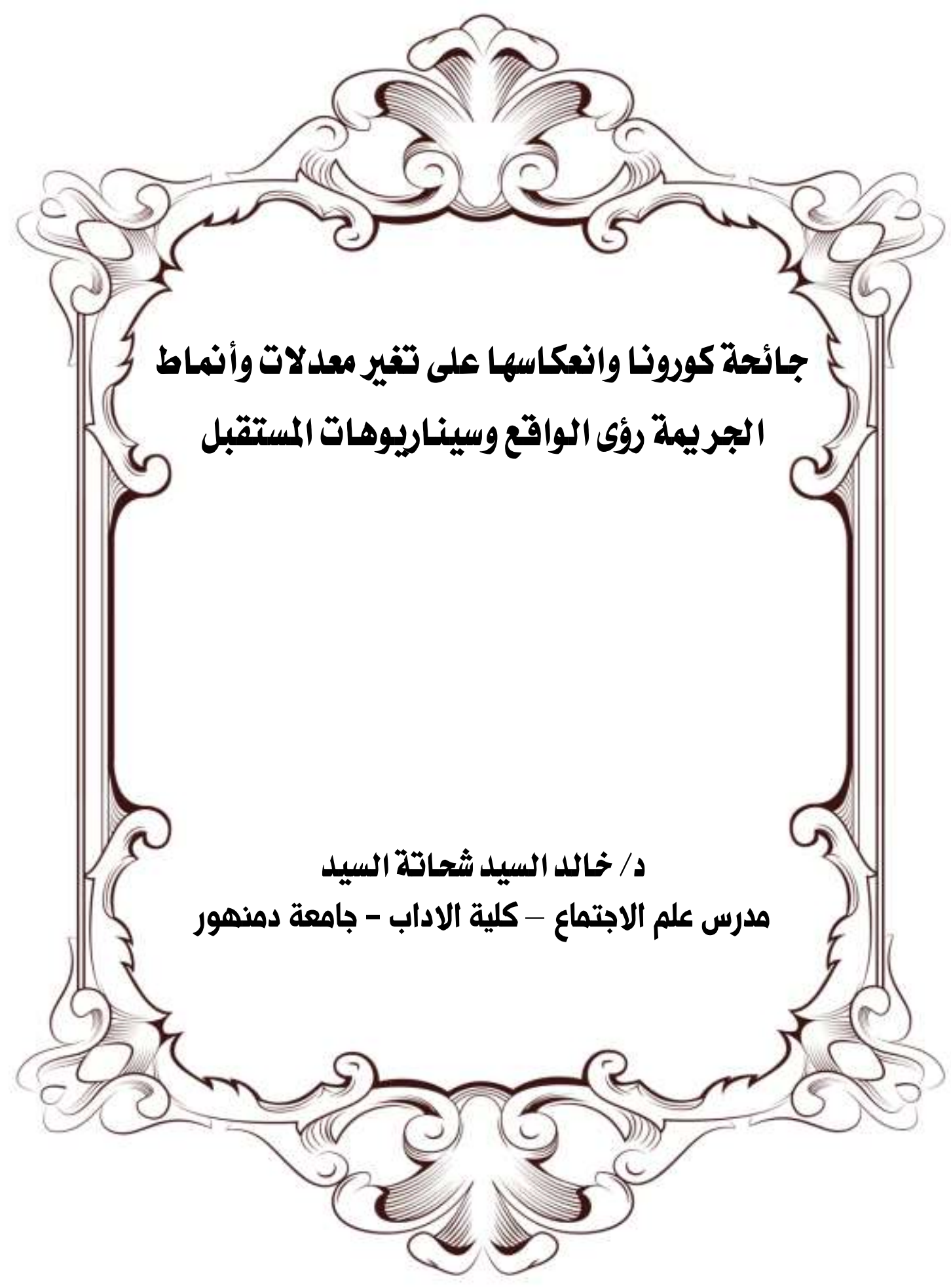


مجلة كلية الدراسات الإسلامية والعربية للبنات بدمنهور العدد الخامس الجزء الثالث عشر •r+rم

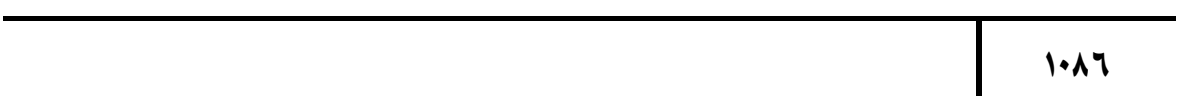


جائحة كورونا وانعكاسها على تغير معدلات وأنماط الجريمة رؤى الواقع وسيناريوهات المستقبل

خالد السيد شحاتة السيد قسم القانون - كلية الاداب - جامعة دمنهور khaled.shehata@art.dmu.edu.eg: البريد الإكتروني

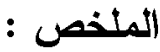

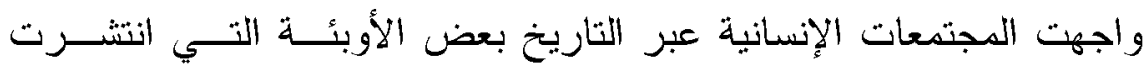

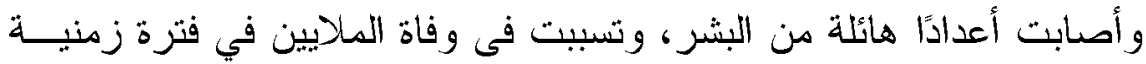

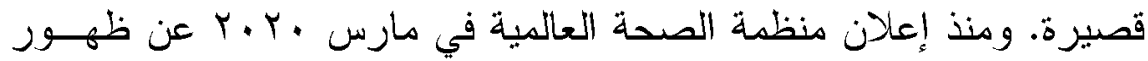

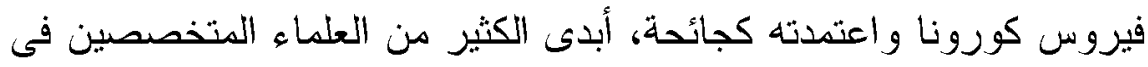

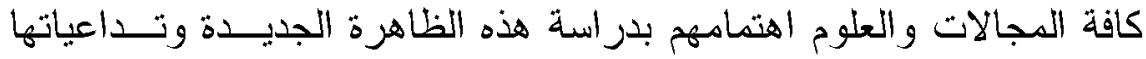

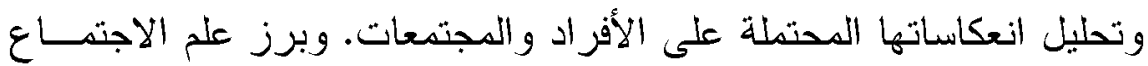

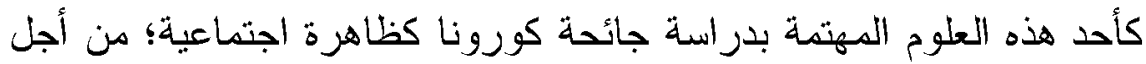

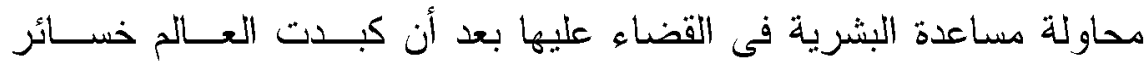
اقتصادية وبشرية هائلة.

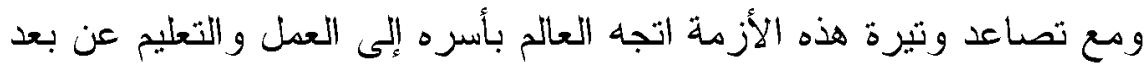

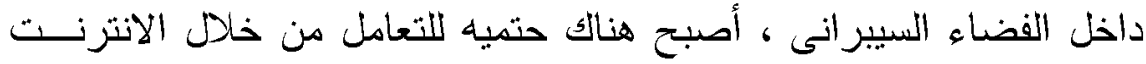
وهنتع المعلومات فى كافة مناحى الحياة، وضرورة تسريع وتيرة الانتقال

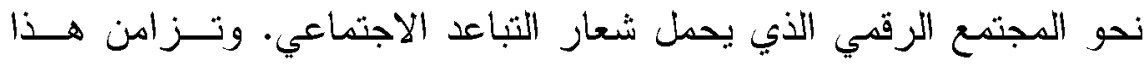

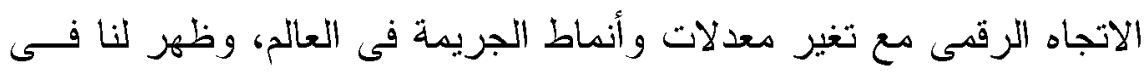

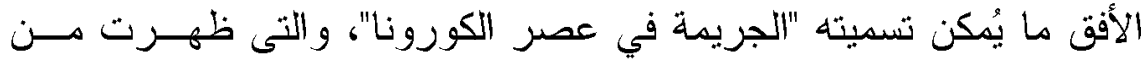

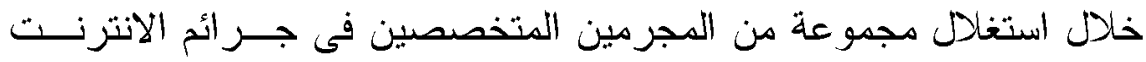
الفجوة المعرفية والتكنولوجية بينهم وبين ضحاياهم دن أفر اد الدجتمع، وشنوا حربًا صامتة مصعدين من أنشطتهج الخبيثة وجر ائمهر السيبر انية.

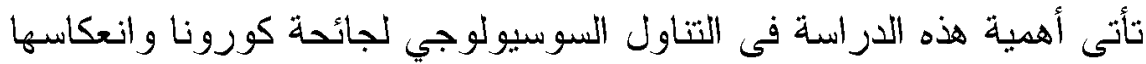

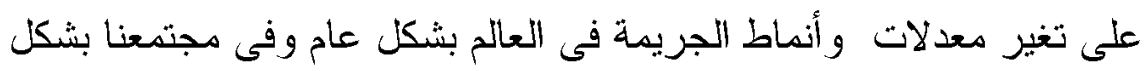


خاص، ودحاولة قر اهة و تحليل الو اقع المجتمعى وارتباطه بتتـامى أثـــال

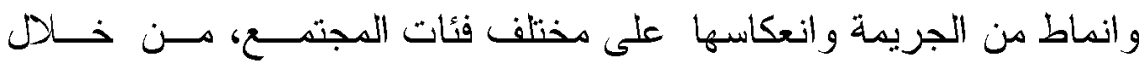

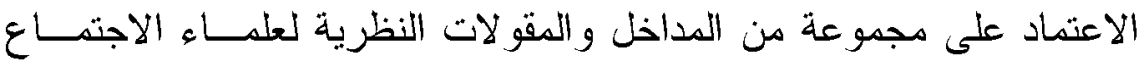

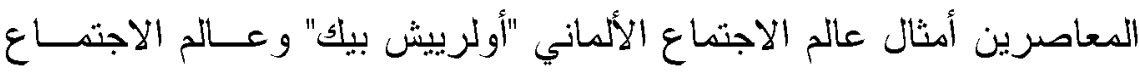

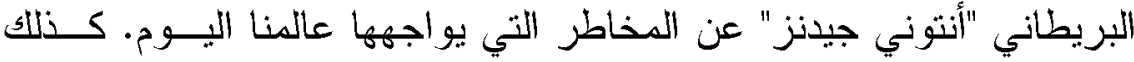

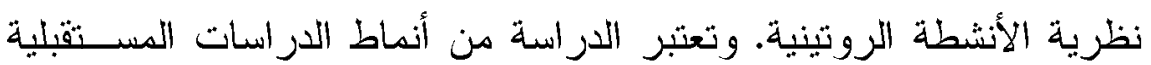

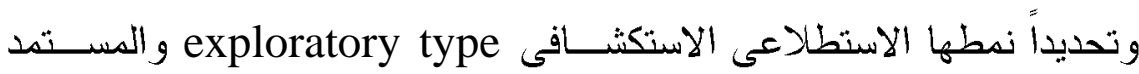
دنهجياً على البيانات الجاهزة والمعلومات و التقارير ومسح التراث الات النظرى.

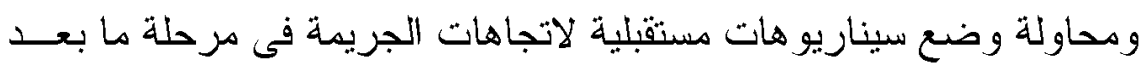
الجائحة، ووضع بعض وضع الحلول و المقترحات لمو اجهة هذه الأزمة.

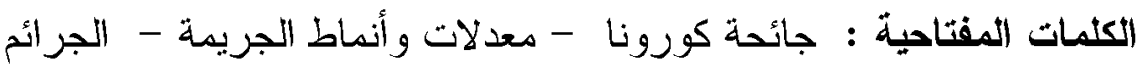
السيبز انية - سيناريو هات المستقبل 
جائحة كورونا وانعكاسها على تغير معدلات وأفماط الجريمة رؤى الواقع وسيناريوهات المستقبل

Corona pandemic and its reflection on changing crime rates and patterns Reality visions and future scenarios khalid alsyd shihatat alsyd

Law Department - Faculty of Arts - Damanhour University

\section{Email: khaled.shehata@art.dmu.edu.eg}

\section{Abstract :}

Human societies throughout history faced some epidemics that spread and infected huge numbers of people, and caused millions of deaths in a short period of time. Since the World Health Organization announced in March 2020 the emergence of the Coronavirus and adopted it as a pandemic, many scientists specializing in all fields and sciences have expressed their interest in studying this new phenomenon and its implications and analyzing its potential repercussions on individuals and societies. Sociology emerged as one of these sciences that are interested in studying the Corona pandemic as a social phenomenon. In order to try to help humanity eliminate it after inflicting enormous economic and human losses on the world.

With the escalation of this crisis, the entire world has turned to work and education remotely within the cyberspace, there has become an imperative to deal through the Internet and the information society in all aspects of life, and the need to accelerate the pace of transition towards a digital society that bears the slogan of social distancing. This digital trend coincided with the changing rates and patterns of crime in the world, and on the horizon appeared what could be called "crime in the era of corona", which appeared through the exploitation of a group of criminals specializing in Internet crime the knowledge and technological gap between them and their victims of society, and launched a war Silent elevated from their malicious activities and their cybercrimes.

the importance of this study in the sociological approach to the Corona pandemic and its reflection on the changing 
rates and patterns of crime in the world in general and in our society in particular, and an attempt to read and analyze the societal reality and its connection with the growing forms and patterns of crime and its reflection on various groups of society, by relying on a set of approaches And the theoretical quotes of contemporary sociologists such as the German sociologist "Ulrich Beck" and the British sociologist "Anthony Giddens" about the dangers our world faces today. Also the theory of routine activities. The study is considered one of the types of future studies, specifically its exploratory type, which is systematically derived from ready data, information, reports and a survey of theoretical heritage. And trying to develop future scenarios for crime trends in the post-pandemic stage, and to develop some solutions and proposals to confront this crisis.

Key words: Corona pandemic - Crime rates and patterns Cybercrime - Future scenarios 


\section{أولاً - المقدمة}

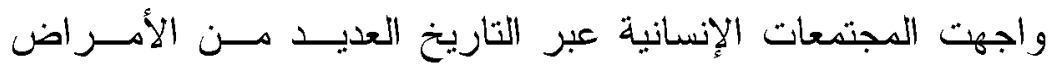

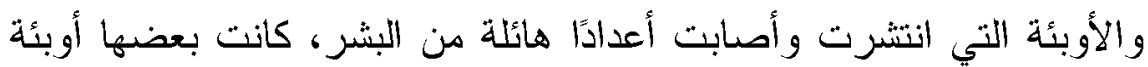

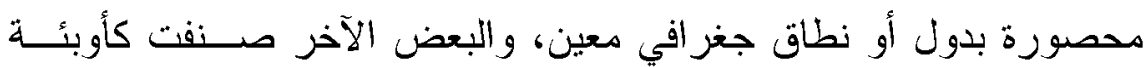

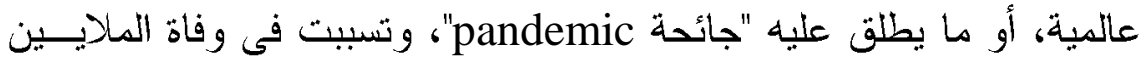

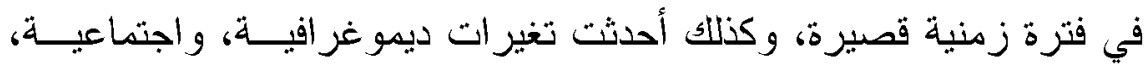

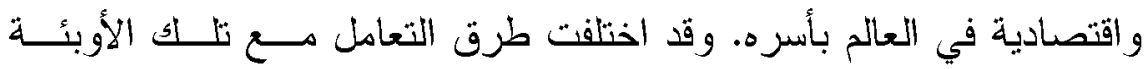
و التصدي لها باختلاف الحقبة الزمنية، والإككانات الكتاحة، كما تباينت الآثار

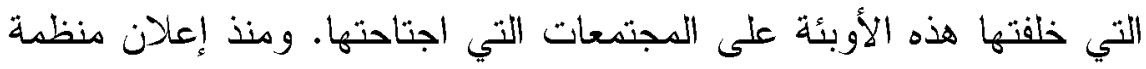

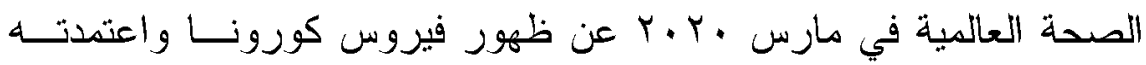

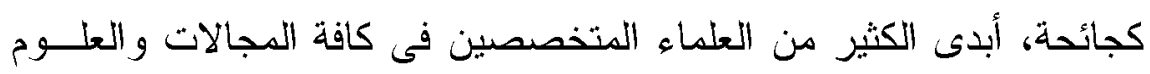

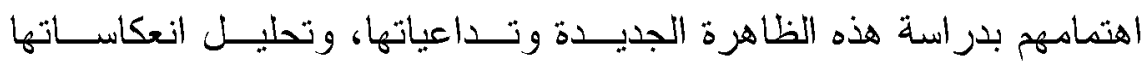

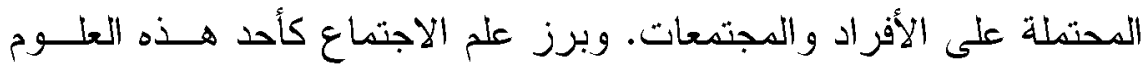

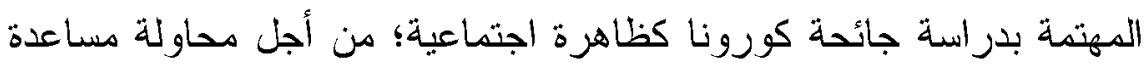

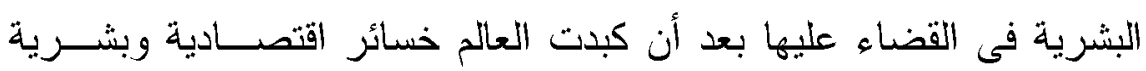
هائلة.

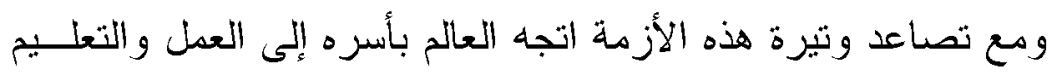

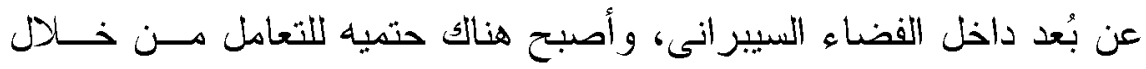

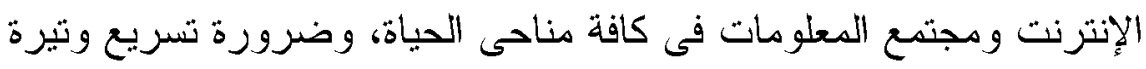

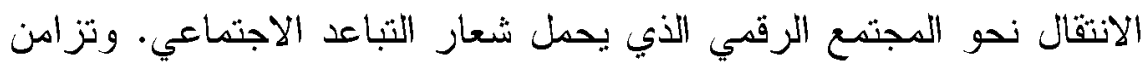

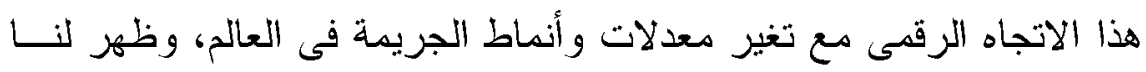

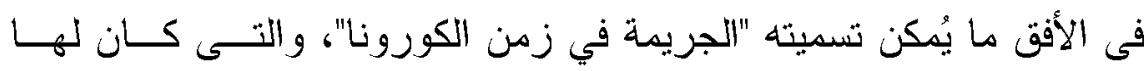

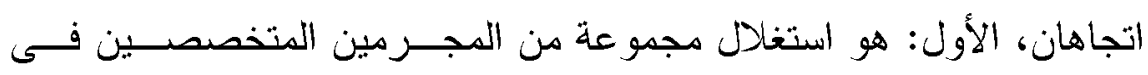

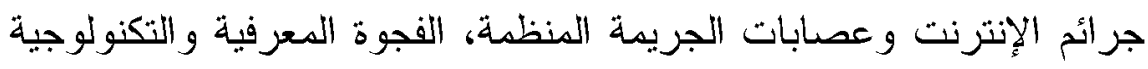

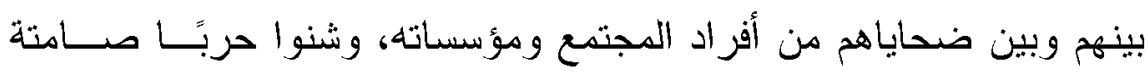

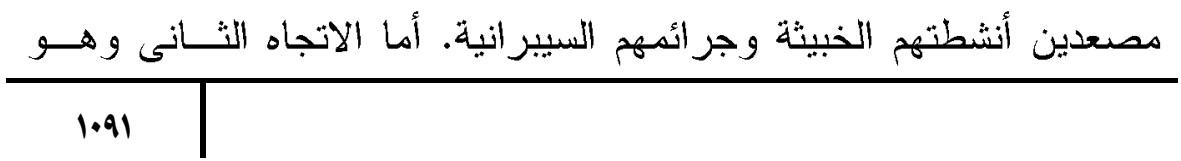


الخاص بالفئات المهمشة والعمالة غير المنتظمة و أفراد المجتمع الذين فقدوا

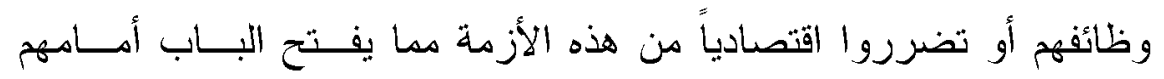
لارتكاب الجريمة.

ومن هنا تأتى هذه الدراسة لتتناول فى محورها الأول تعريف جائحة

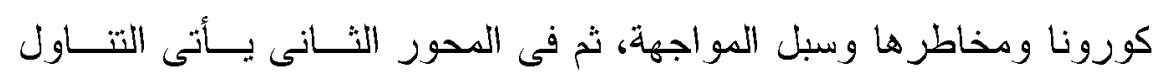

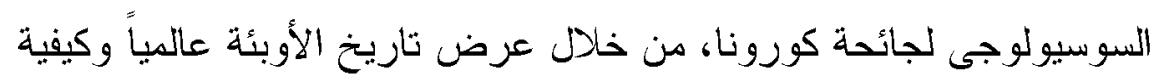

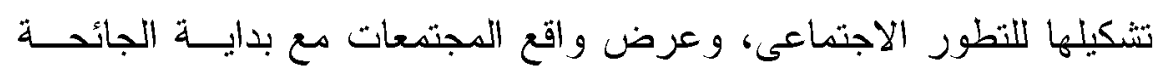

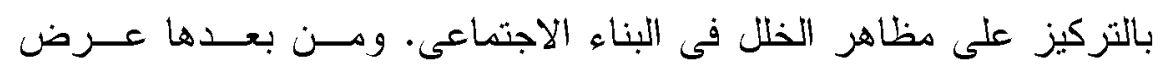

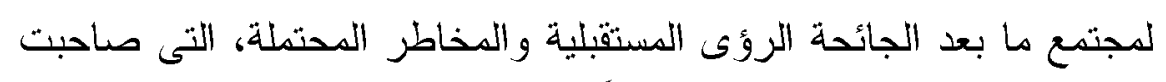

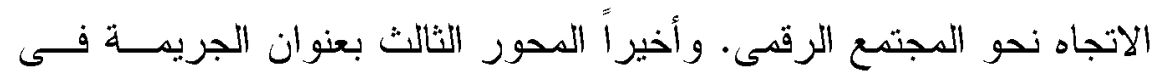

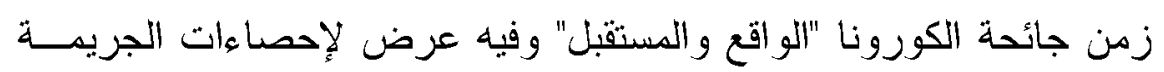

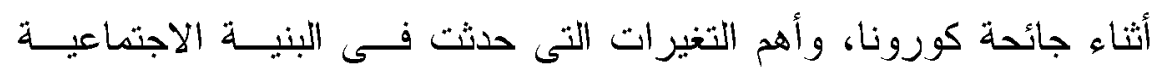

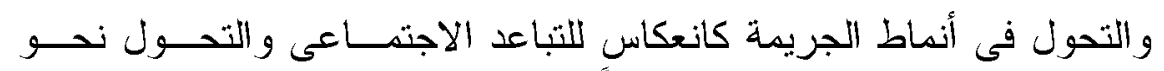
المجتمع الرقمى، ثم سيناريوهات دستقبل الجريمة بمر احلها الثلاثة. وأخيراً

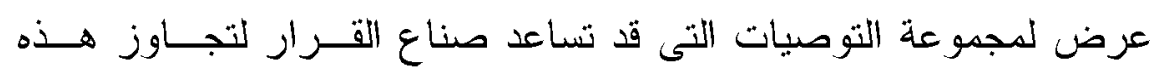
الأزمة.

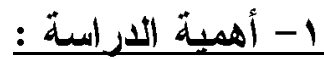

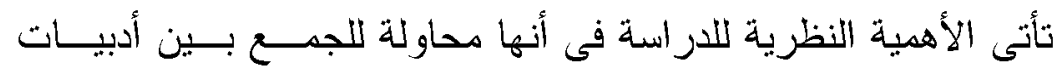

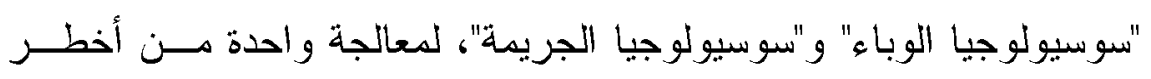

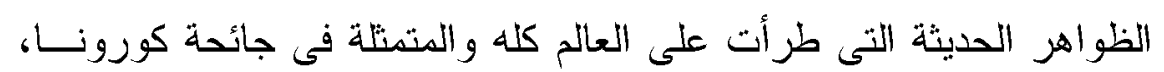

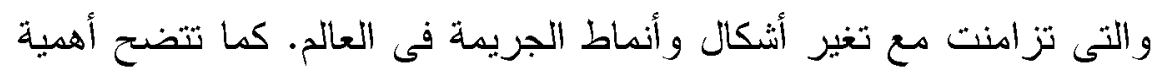

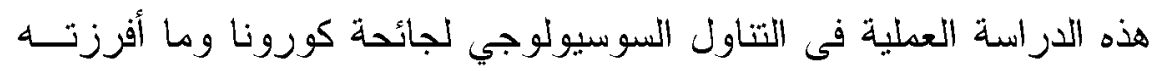

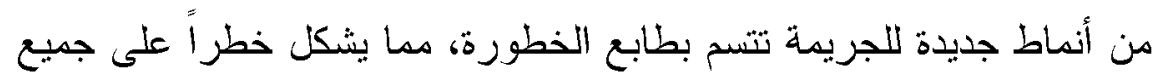

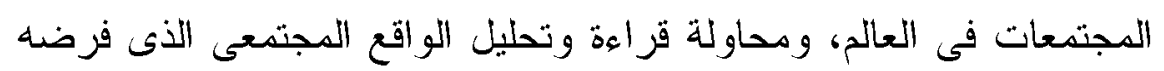

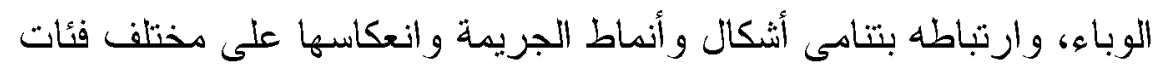

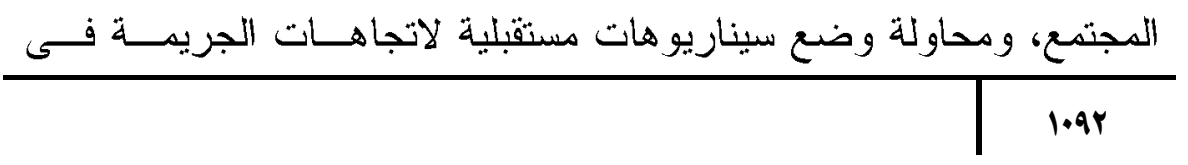


درحلة دا بعد الجائحة، ووضع بعض الحلول و المقترحات لمواجهـة هـــهـ الأزمة.

r- أهداف الارسة

يتجلى الهدف الرئيسي للار اسة فى محاولة التعرف على طبيعة جائحة

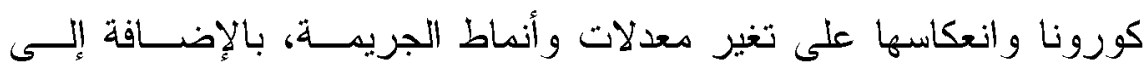

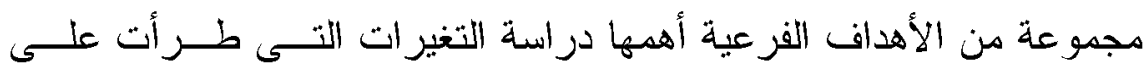

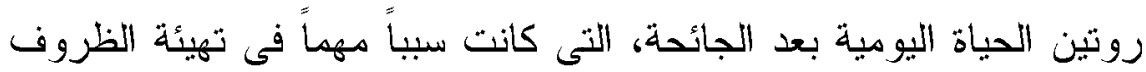

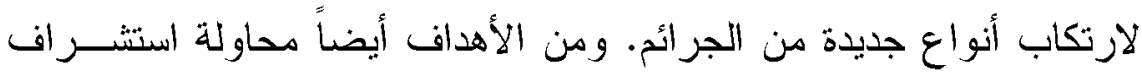

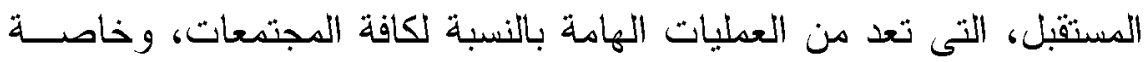

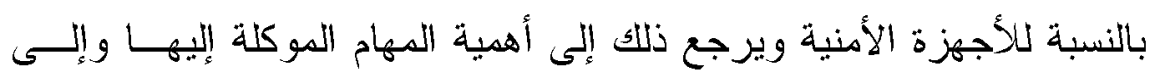

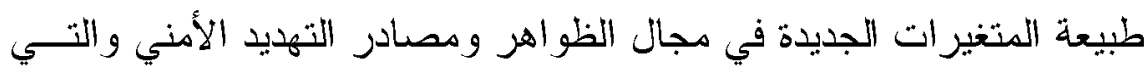

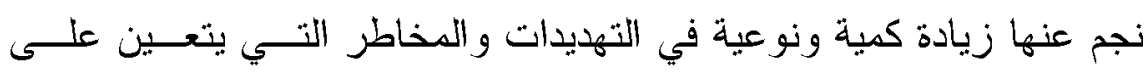

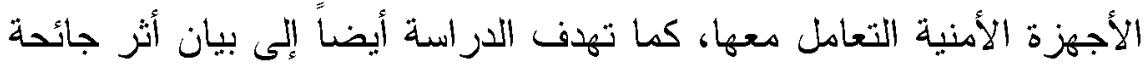

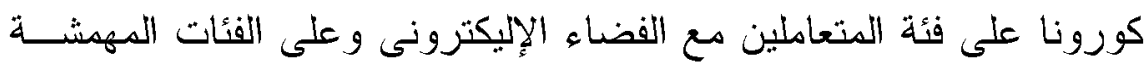

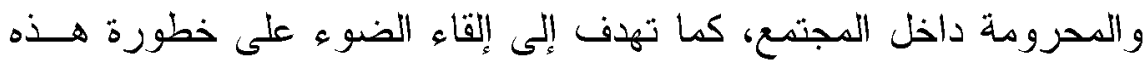

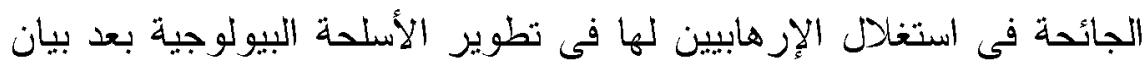

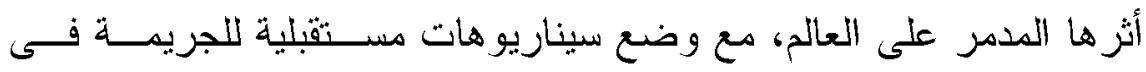
مجتمع ما بعد الجائحة وطرق مواجرنها.

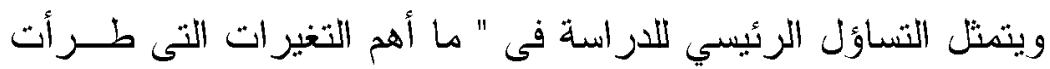

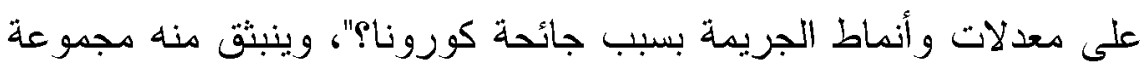

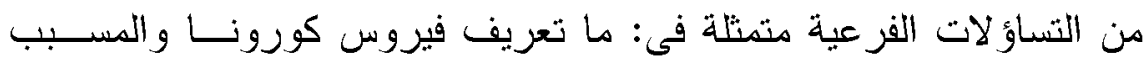

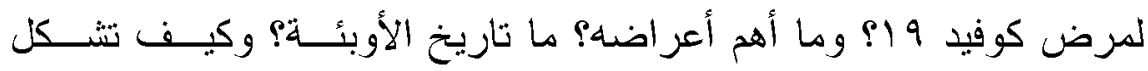

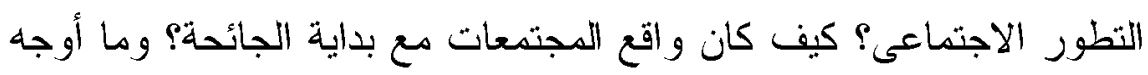
هظاهر الخلل فى البناء الاجتماعى التى حدثت هع الجائحة؟ ها أهم التداعيات

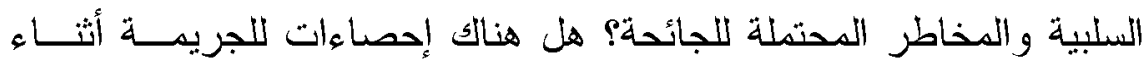

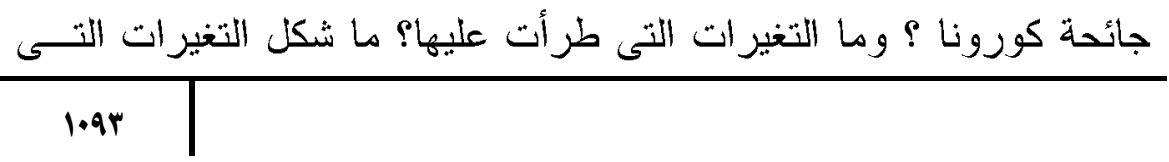


حدثت فى البنية الاجتماعية وأنماط الجريمة كانعكاس للتباعــــ الاجتمـــى و التحول نحو المجتمع الرقمى؟ ما هى السيناريو هات الاقتصادية والاجتماعية

$$
\text { وسيناريو هات مستقبل الجريمة فى مجتمع بعد الجائحة؟؟ }
$$

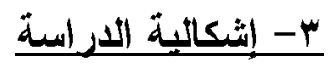

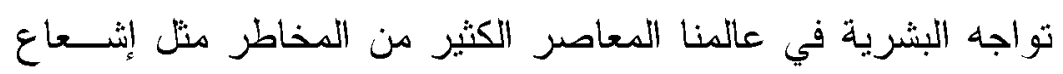

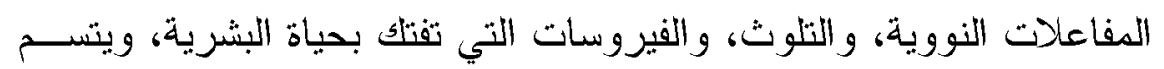

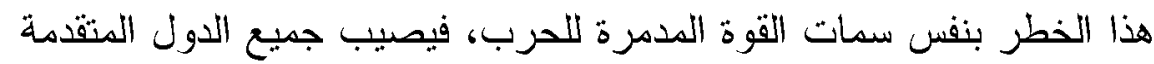

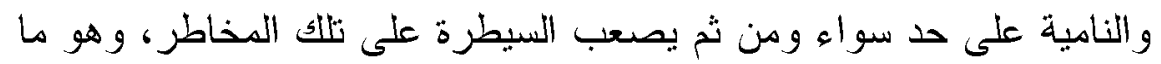

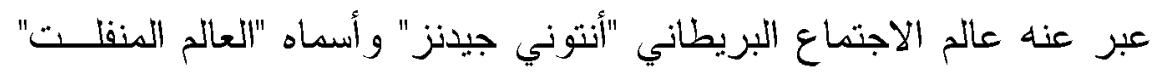

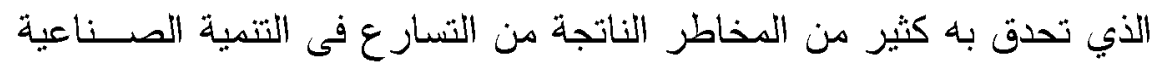

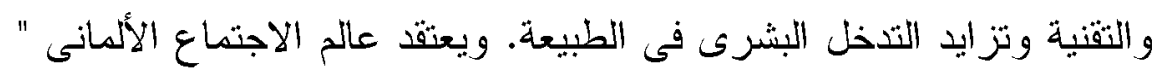

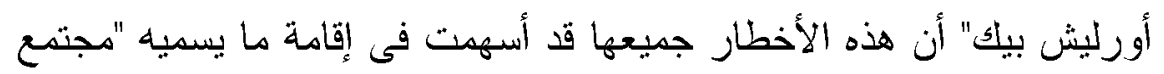

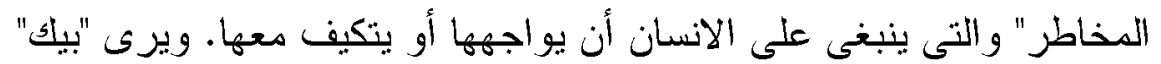

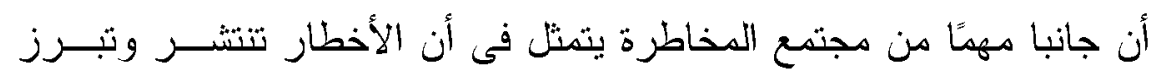

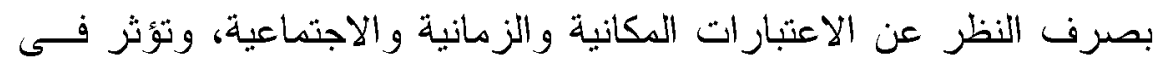
جيع البلدان و الطبقات الاجتماعية. ومن هنا يجد العالم اليوم نفسه في ظل الأزمة الصحية الراهئه اهنة بـين

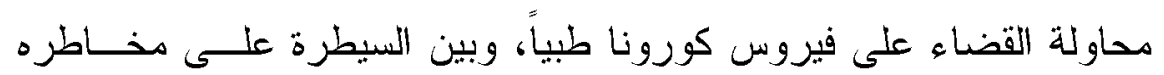

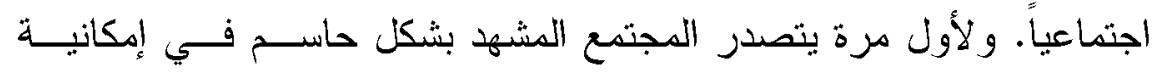

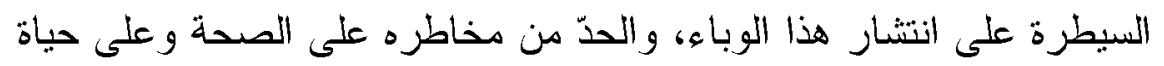

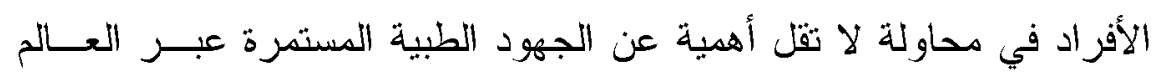

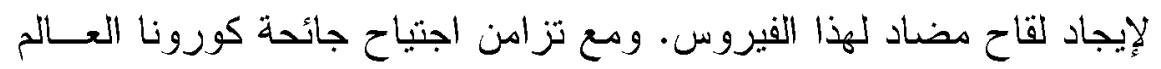
بأسره، وإجبار سكان العالم جميعا لأخذ إجازة إجبارية والمكوث في المنزل، الهئ

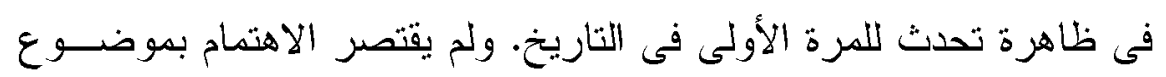

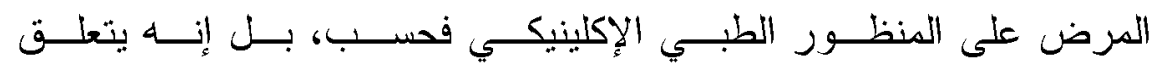

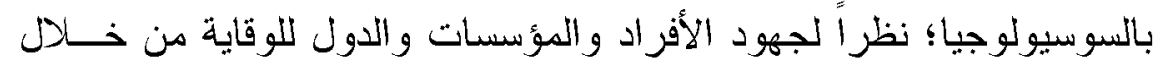


الإجراءات الاحترازية المتمتلة بالحجر والعزلة والتباعد الاجتماعى، وهـي

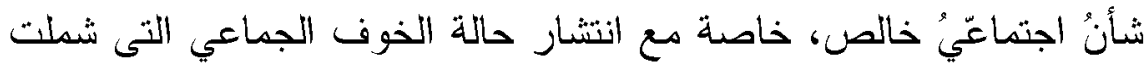

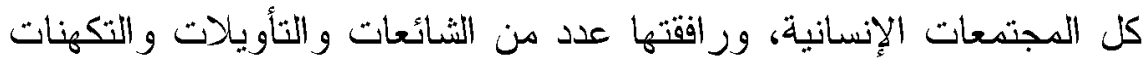

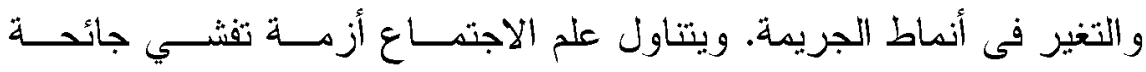

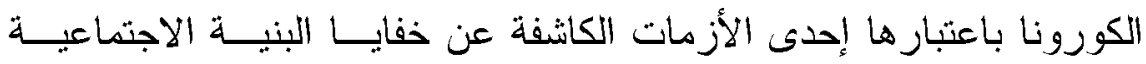

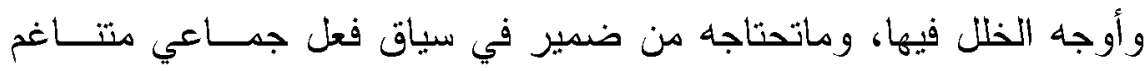

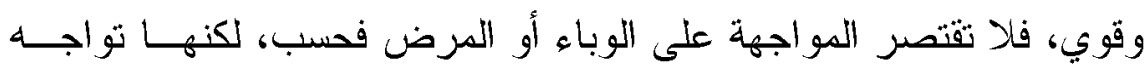

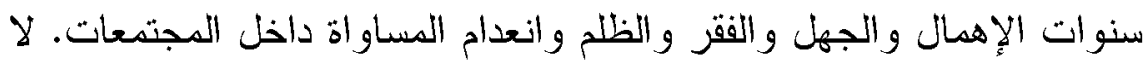

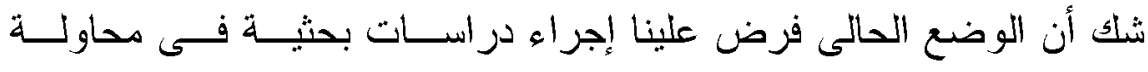

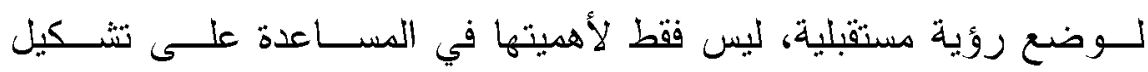
الاستجابات الحكومية والمجتمعية الفعالة للنسخة الحالية من وباء كورونــا،

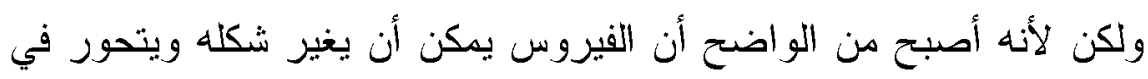

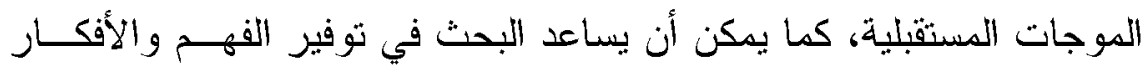
المهية للتعامل دع التعقيدات الوبائية وتداعياتها.

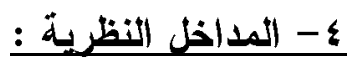

تعتمد هذه الدراسة على مجموعة من المداخل و المقــولات النظريـــة

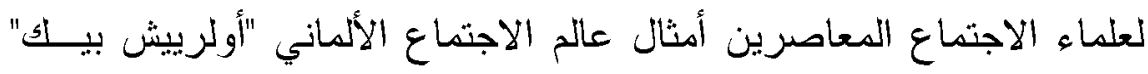

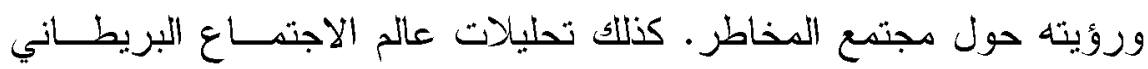

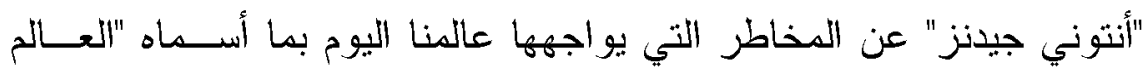

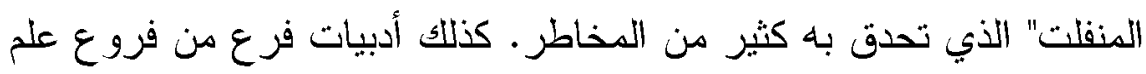

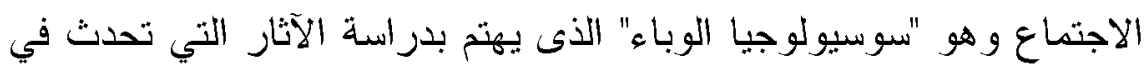

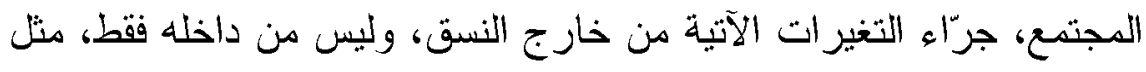

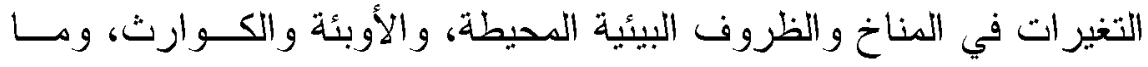
تحدثه في الحياة الاجتماعية دن أزمات مختلفة. كما تقدم الجائحســة فرصدً

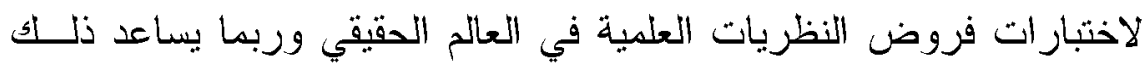
على توقع ما قد يحدث في ظروف وبائية أخرى مداتلة فى المستقبل. وهــن 
النظريات الإجرامية الر ائدة والتى اعتدثت عليها الدراسة "نظرية الأثشـــة

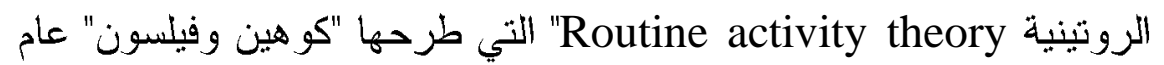

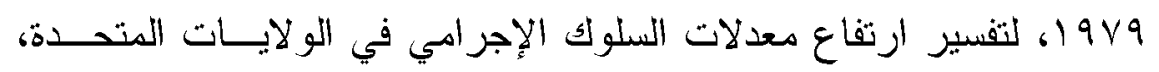

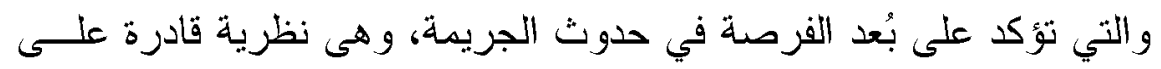

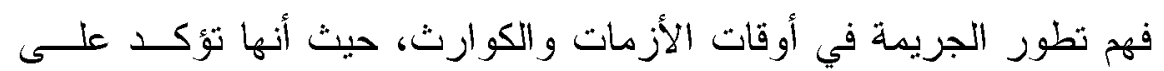

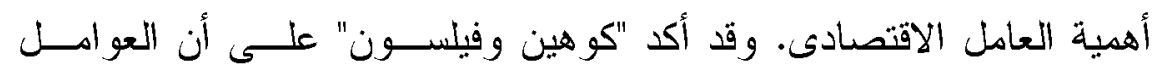

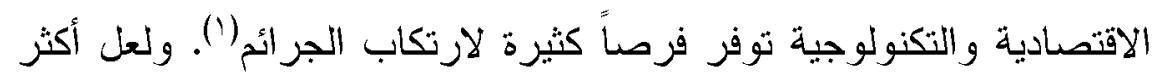

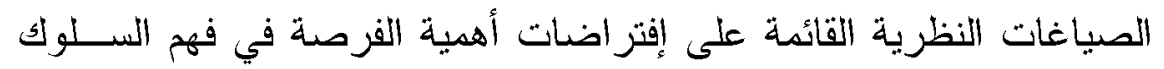

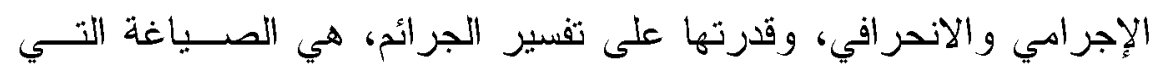

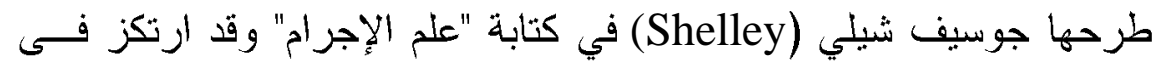

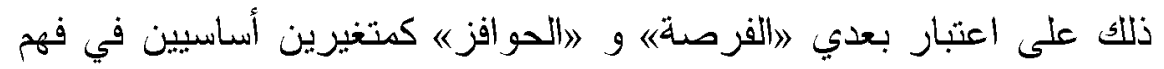

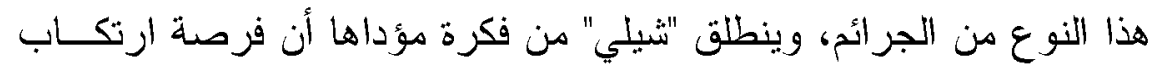

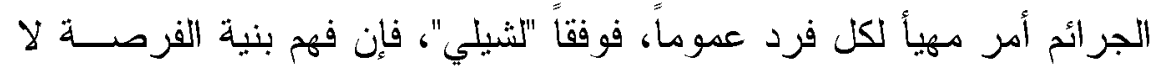

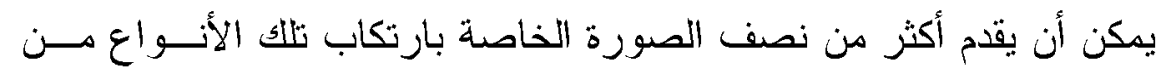

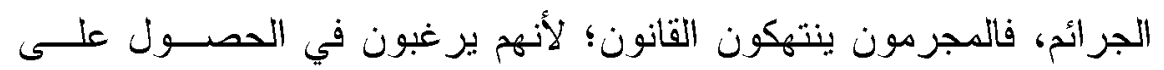

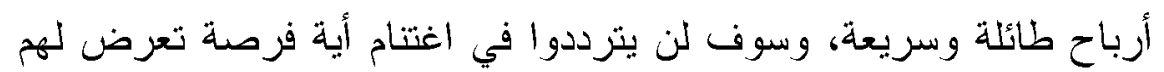

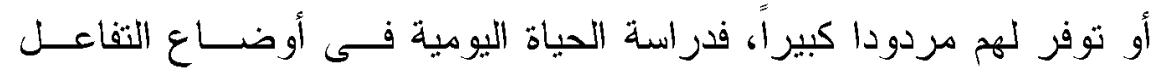

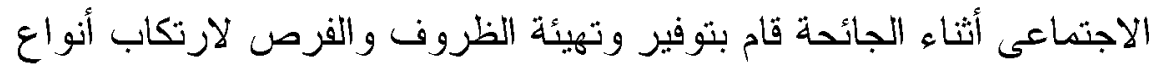

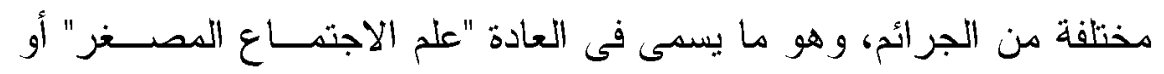

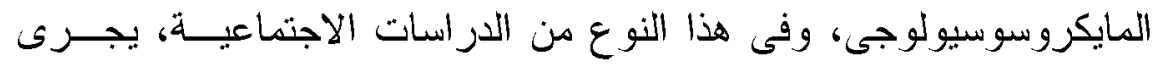

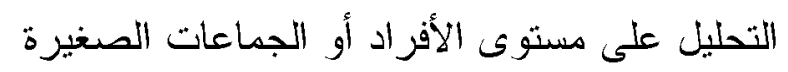

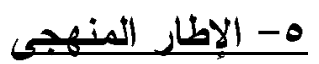

تعتبر بحوث المستقبل محاولة لاستقراء المستقبل أكثر دنها تخطيطـاً

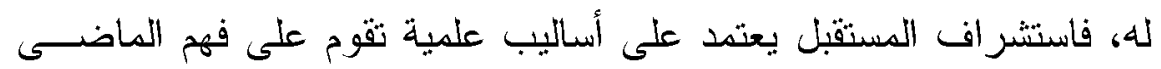

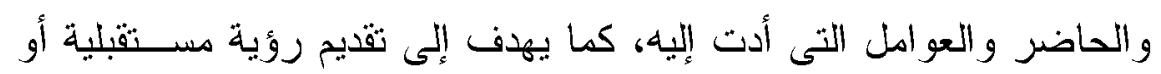

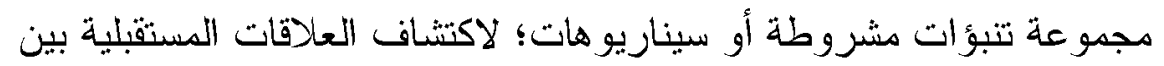


الأشياء و النظم والأنساق الكلية والفرعية التى يموج بها المجتمع. كما تهـتـ

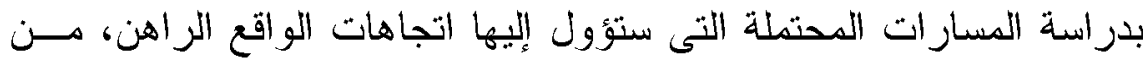

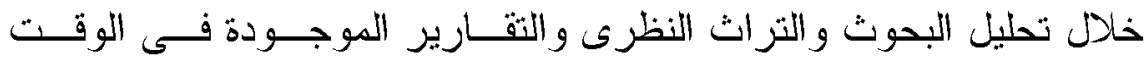

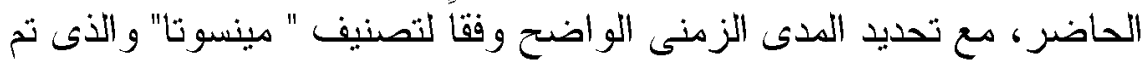

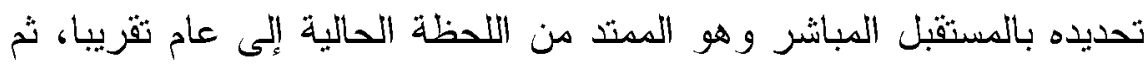

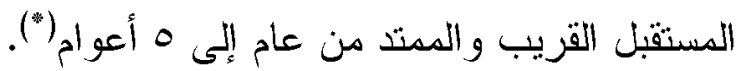

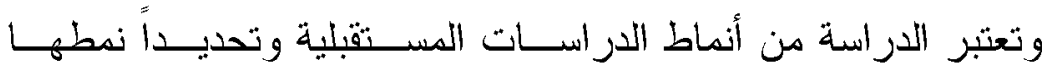
الاستطلاعى الاستكثافى exploratory type. وتبدأ خطو اتها المنهجية من ون

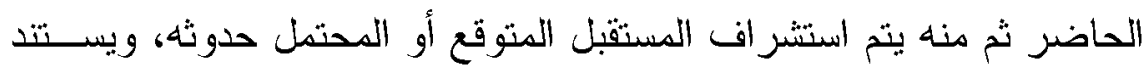

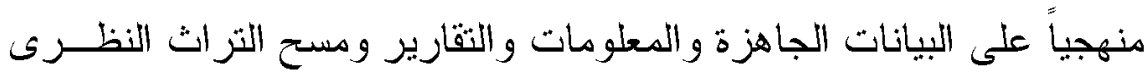

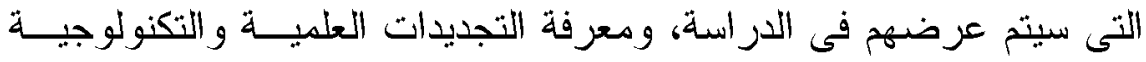

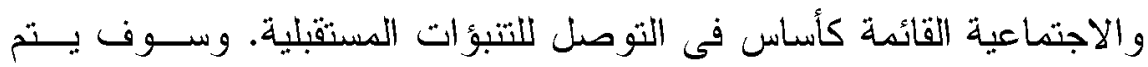

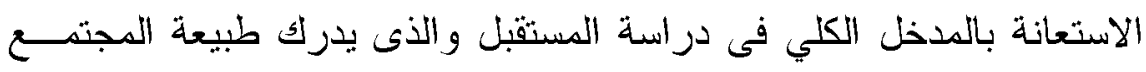

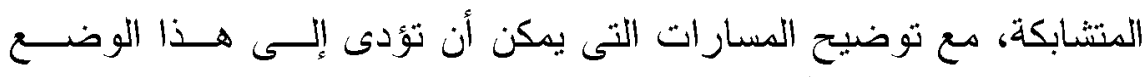

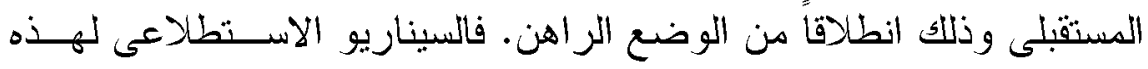

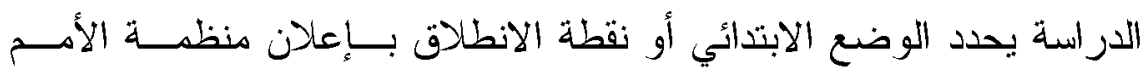
المتحدة فيروس كورونا كجائحة، التى من بعدها ستتشكل الصورة المستقبلية.

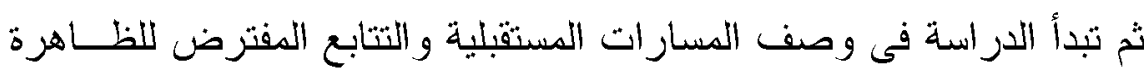
كحل الدراسة عبر الزمن، عن طريق تحليل مجموعة من الأحداث و البيانات

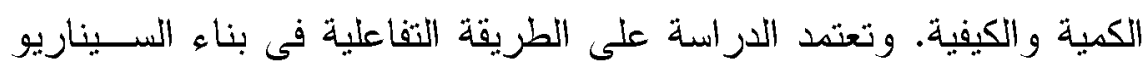

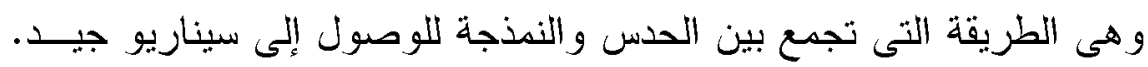

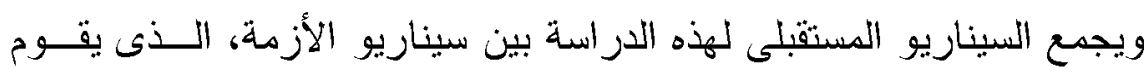

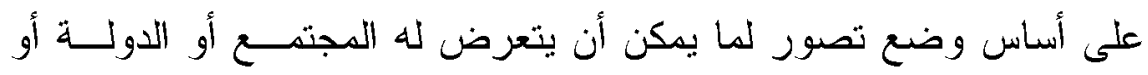

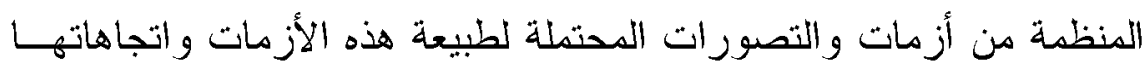

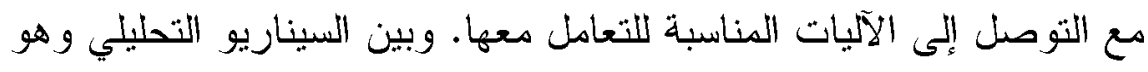

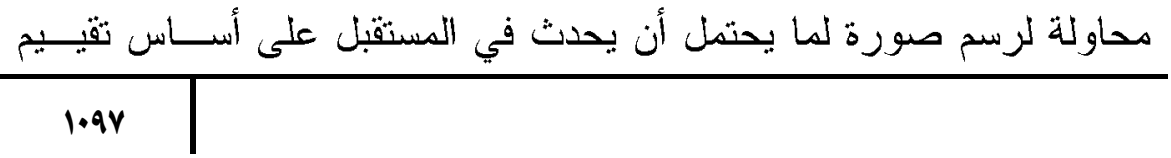


موضوعي وتحديد احتمالات الأوضاع المستقبلية لأن تقييم سياسة أو خطـــة

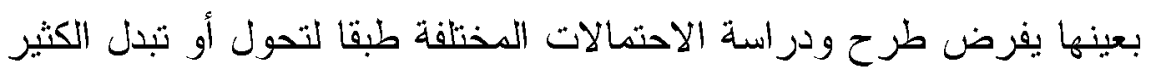

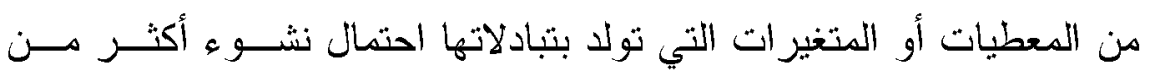
سيناريو للمستقبل.

\section{المحور الأول : جائحة كورونا......التعريف والمخاطر والمواجهية}

تتاولت العديد من المواقع الحكومية والطبية الرسمية كـلـ هـايخص

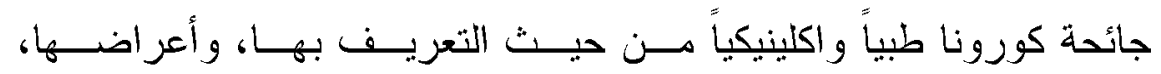
وخطورتها، و سبل التصدى لها. وخصص موقع منظمة الصحة العالمية على والى

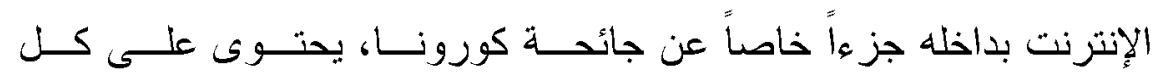

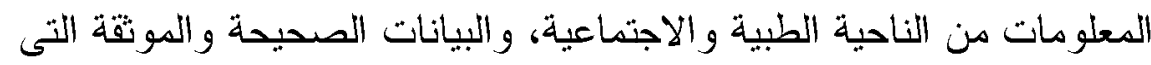

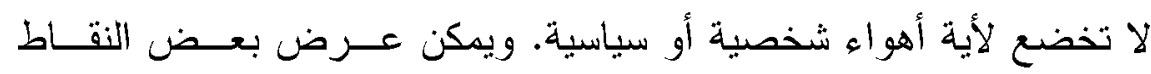
التعريفية منها على النحو التالى (r)

\section{1 - تعريف فيروس كورونا و المسبب لمرض كوفيد 19}

تعد فيروسات كورونا سلالة و اسعة من الفيروســات التـي تصــيب

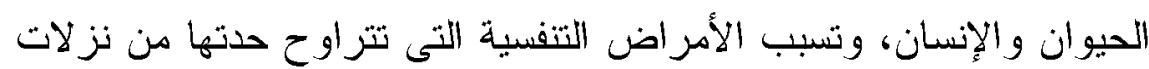

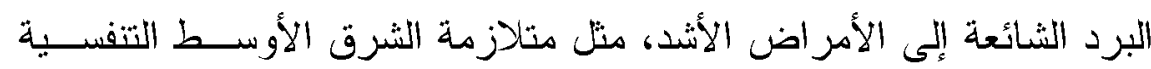

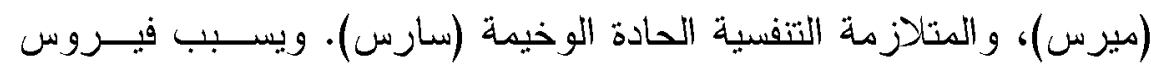

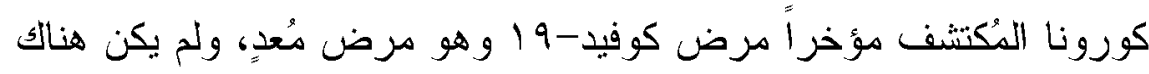

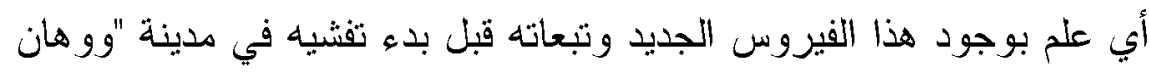

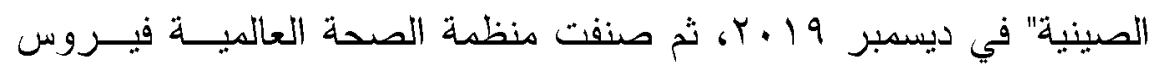

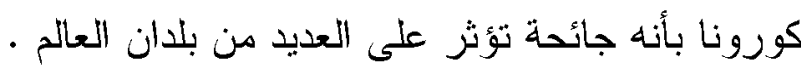

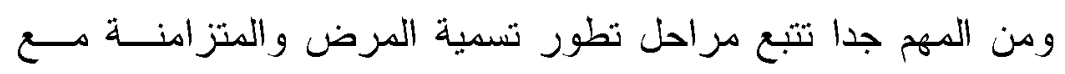

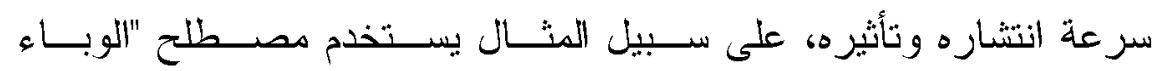

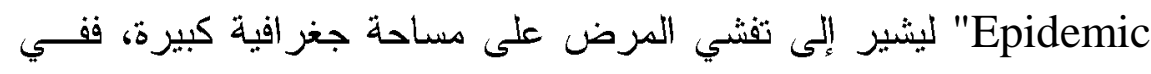

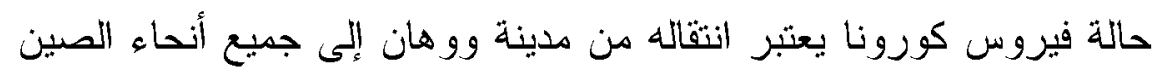
تعني أنه قد تطور من مجرد مرض منتشر كمرحلة أولى إلى وباء كمرحلة 
ثانية. أما المرحلة الثالثة "الجائحة pandemic" فهــو مصــطلح يســتخدم

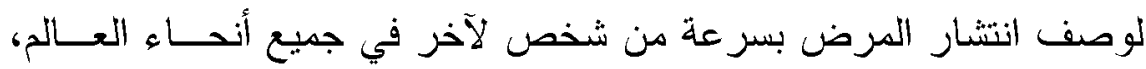

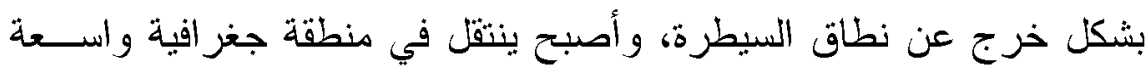

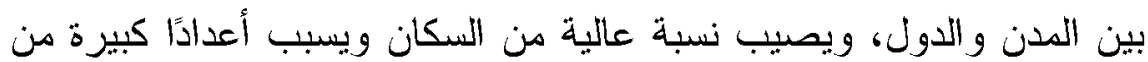

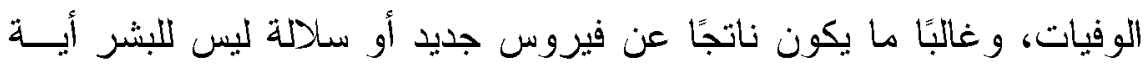

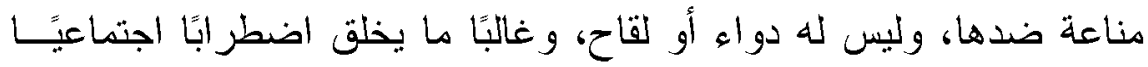
وخسائر اقتصادية.

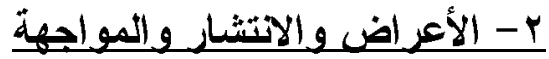

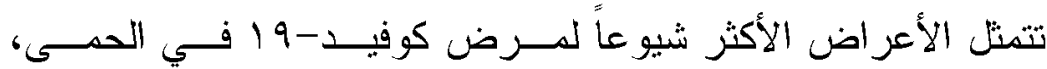
والإز هاق، و السعال الجاف، و آلام الجسم، واحتقان الأنف، و الصداع، وفقدان

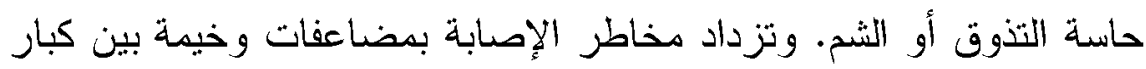

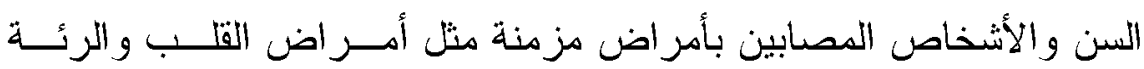

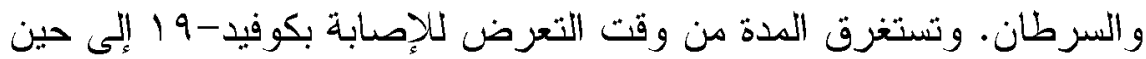

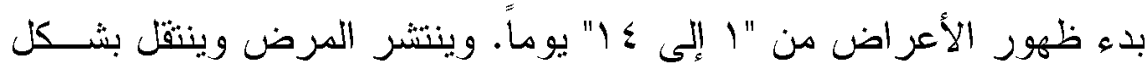

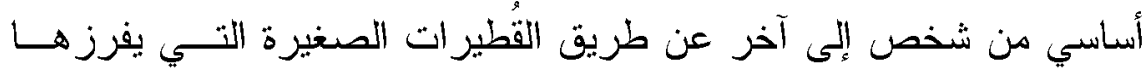

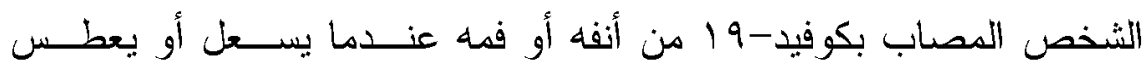

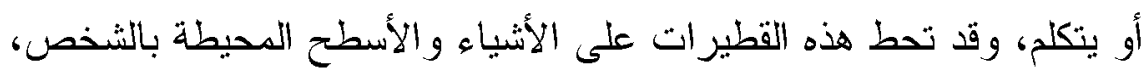

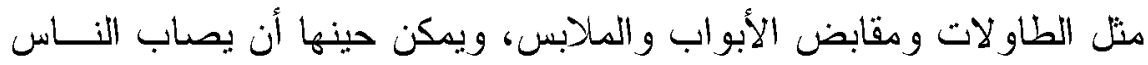

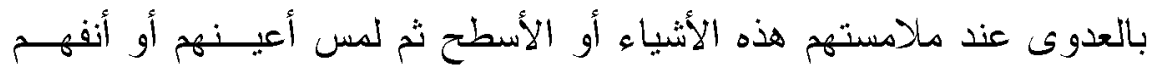

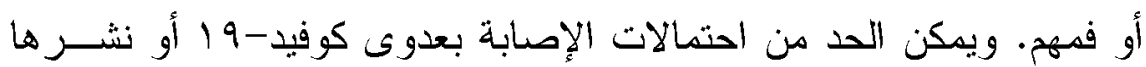

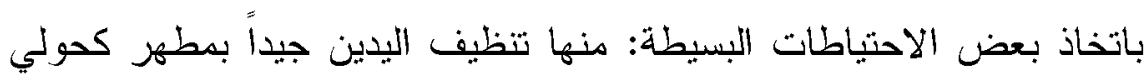

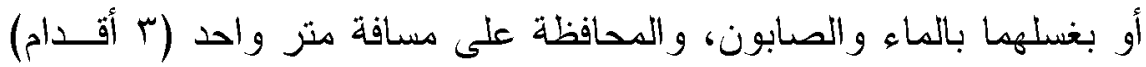

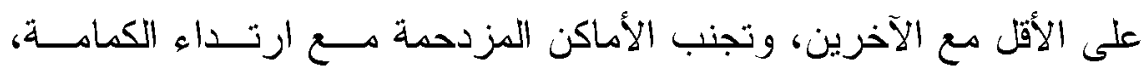
و تجنب لمس العين و الأنف و الفم. 


\section{المحور الثانى : التناول السوسيولوجي لجائحة كورونا}

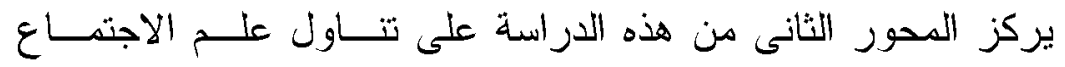

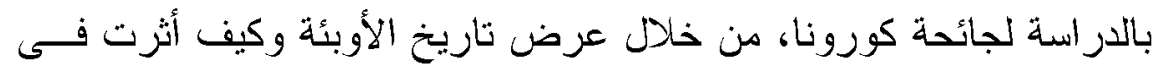

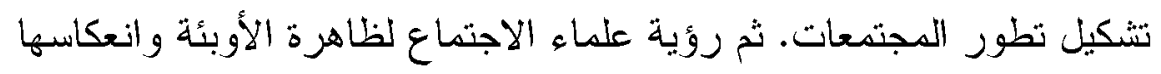

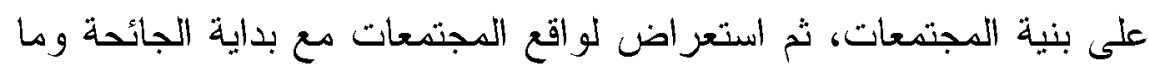

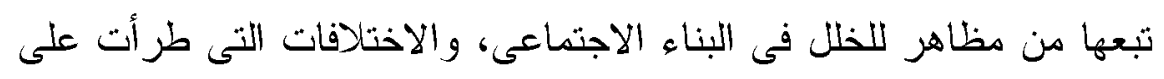

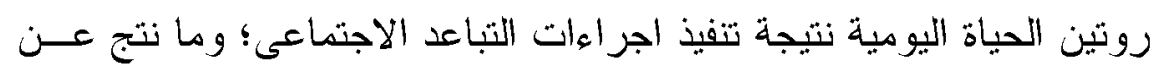

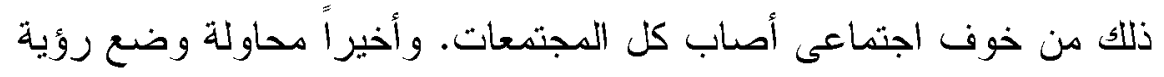
مستقلية لدجتمع ها بعد الجائحة.

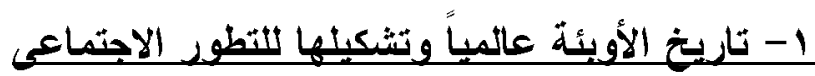

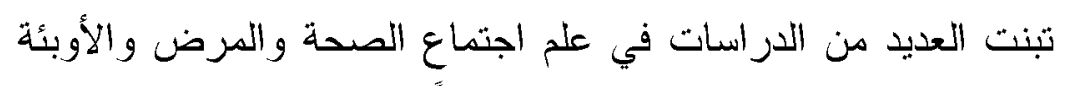

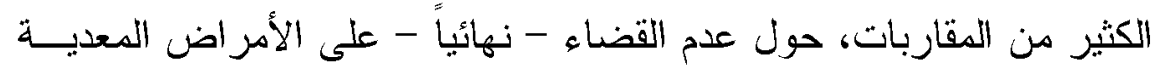

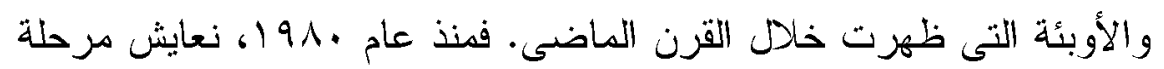

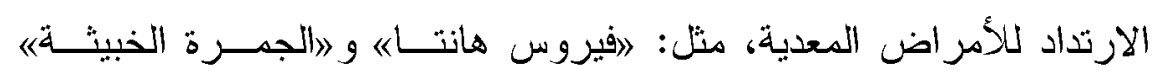

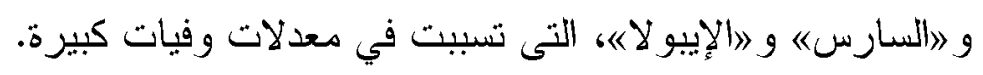

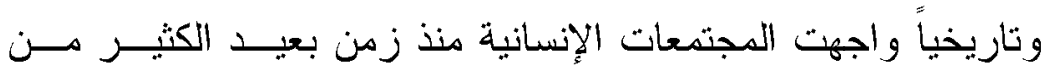

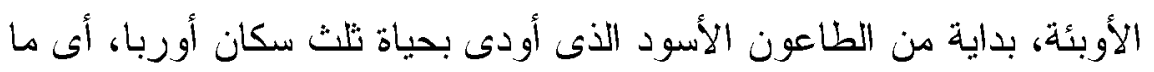

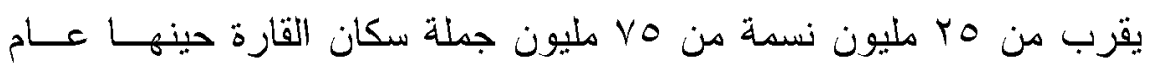

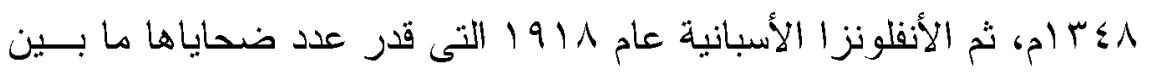

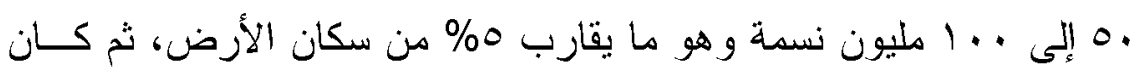

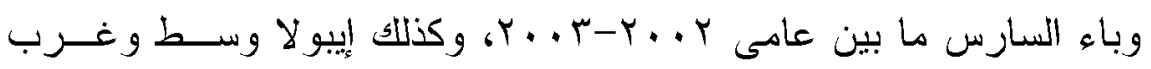

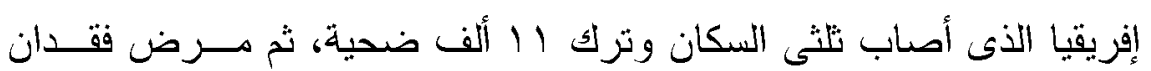

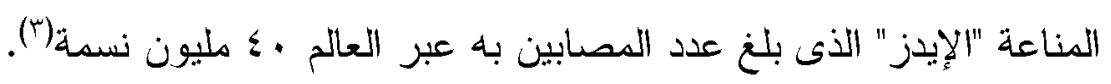

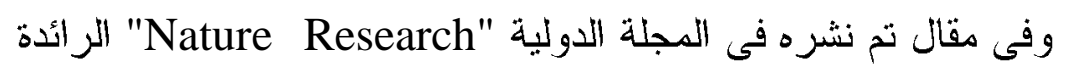

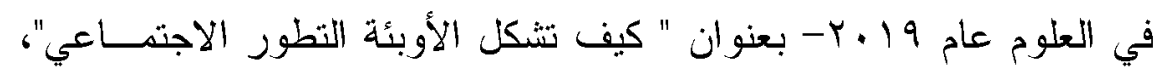

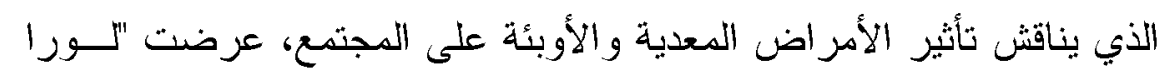


سبيني" در اسة "فرانك سنودن" حول الأوبئة و المجتمع، التى أكـــد فيهــا أن

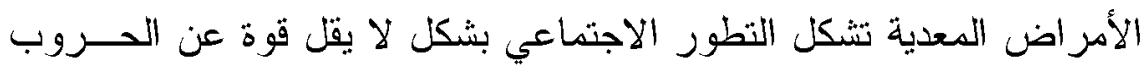

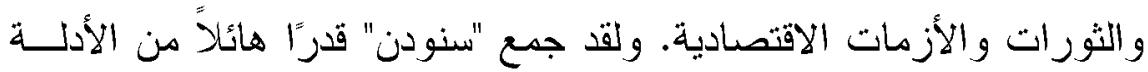

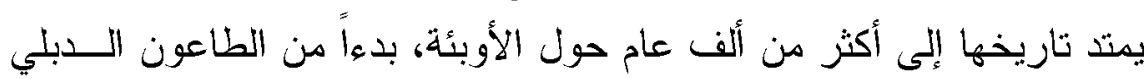

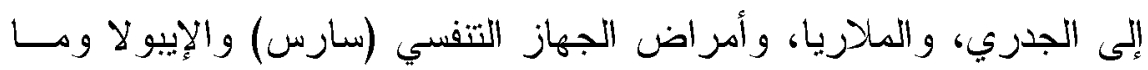

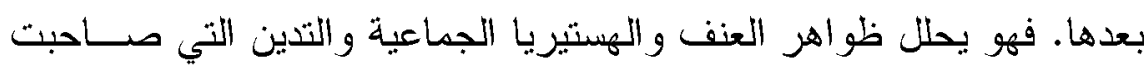

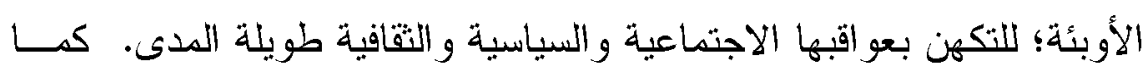
استعرض "فرانك سنودن" في كتابه "تاريخ الأوبئة عبر التاريخ" انتثار وباء ولهاء ولئه

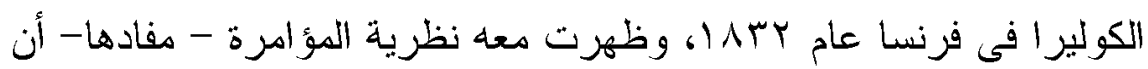

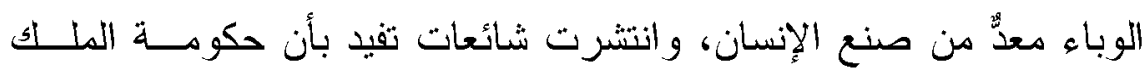
"لويس فيليب" تضع مادة الزرنيخ في آبار المياه لتسمهها. وهع انتثار الوباء

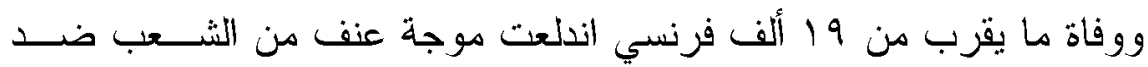

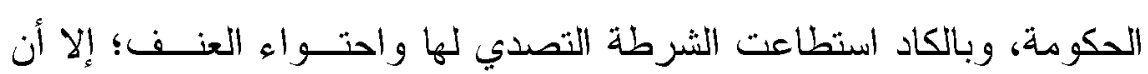

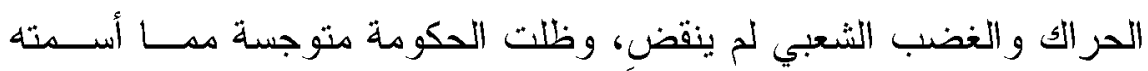

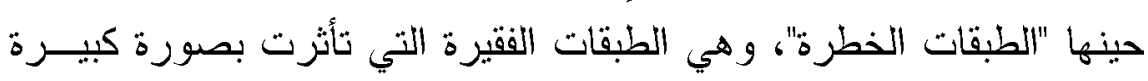

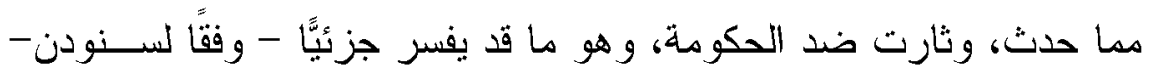
أحداث "القهع الطبقي" التي شهدتها العاصدة الفرنسية بعد هذا الوباء بسنوات هات

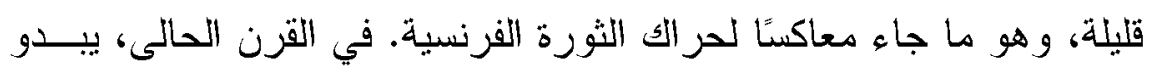

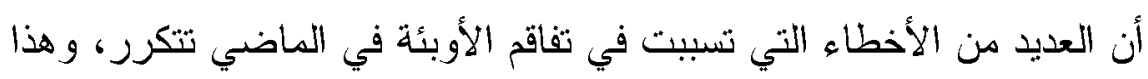
هو السبب الذي جعل "سنودن" يشير بشكل ينذر بالسوء إلى استمرار انتشار

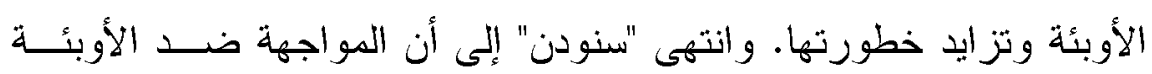

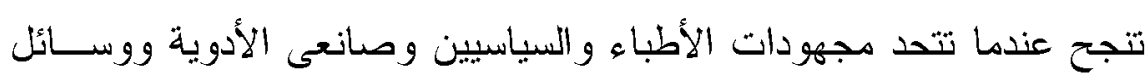

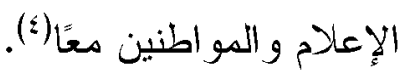




\section{r- التناول السوسيولوجى للأوبئة}

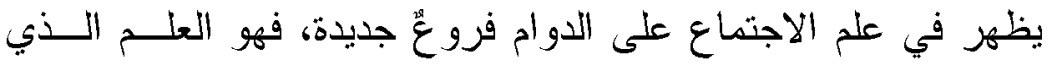

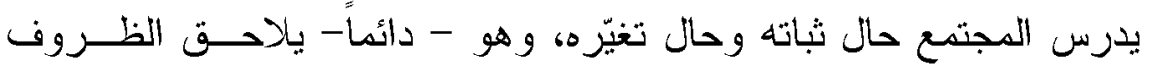

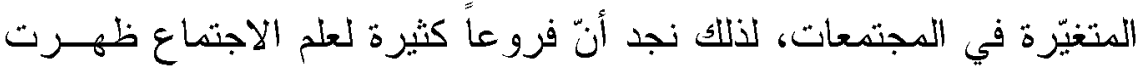

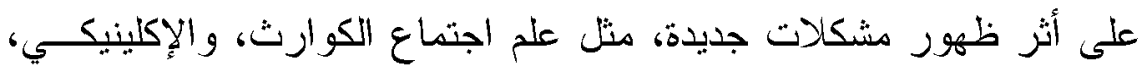

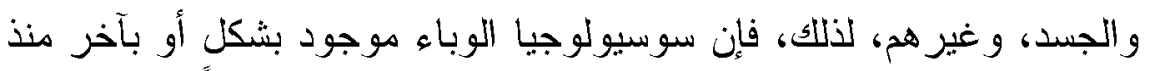

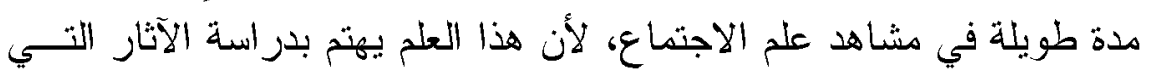

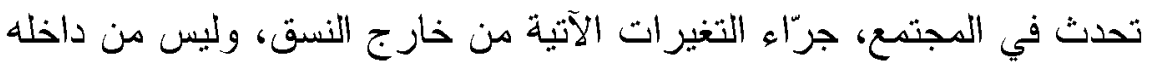

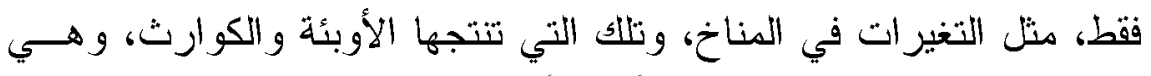

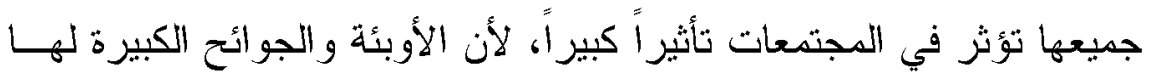

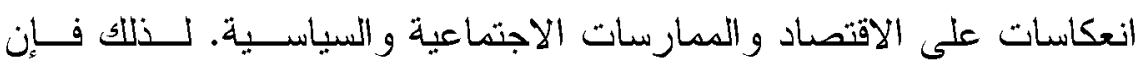

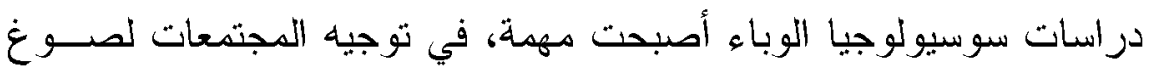
سياسات جديدة متجددة للتعامل مع الأوبئة(').

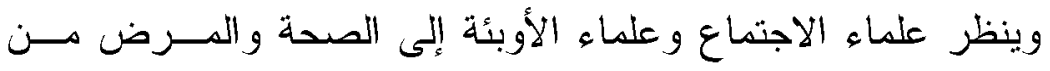

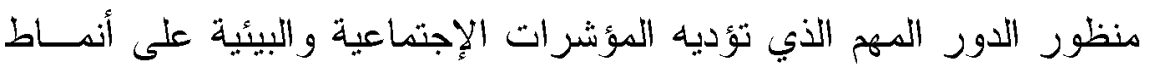

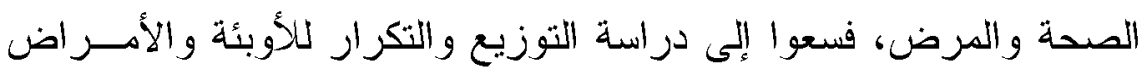
بين السكان، و إلى تفسير الصلة بين الصحة هن جهة و وعدد من المتغيــرات

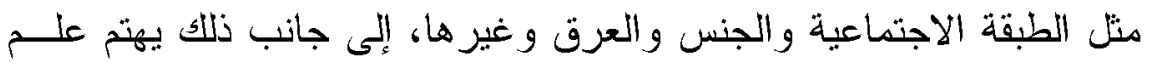

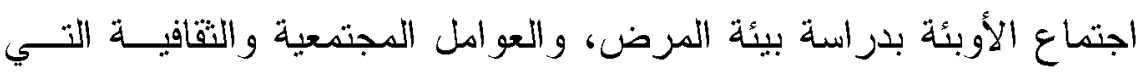

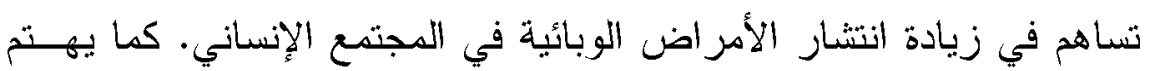

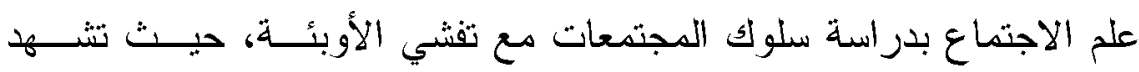

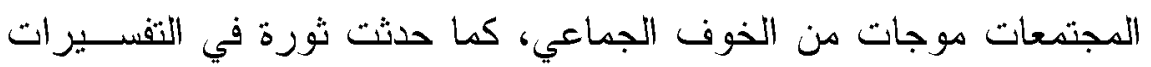
المرتبطة بأسباب هذه المعاناة الجماعية جراء الوباء، وتسببت في موجة هن

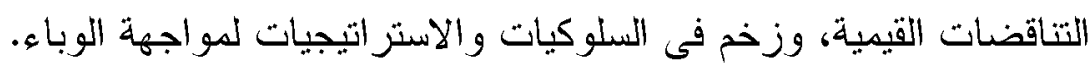

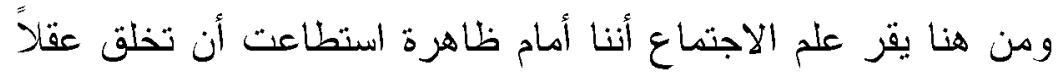

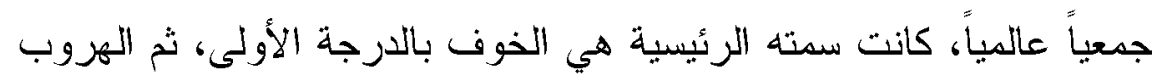


من خطر الفيروس غير المرئي. فثمة أمور يمكن ملاحظتها في سياق تفتي

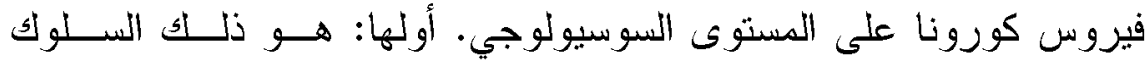

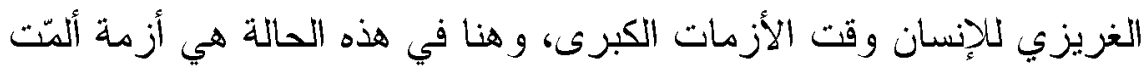
بكل المجتمعات على اختلاف تصنيفاتها، فقد بات هدف الحفاظ على الحيــاة الهدف الأول للفرد، ويبدو أن النظرية السوسيولوجية سوف تهتم الآن بالعودة

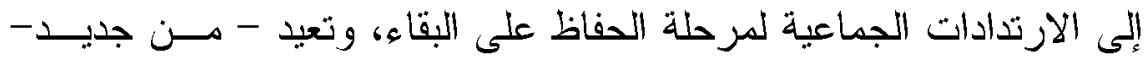

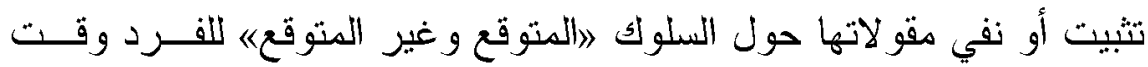

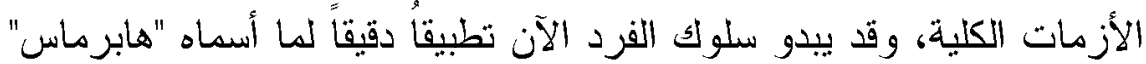
بسيادة العقل الوظيفي على هقدرات الحياة اليودية. ثانيها: التوازن الوظيفي

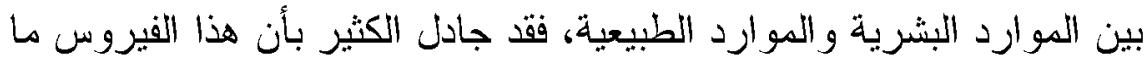

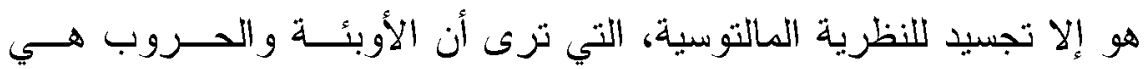

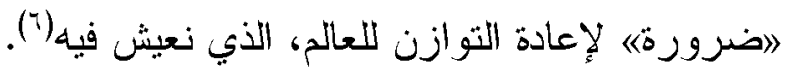

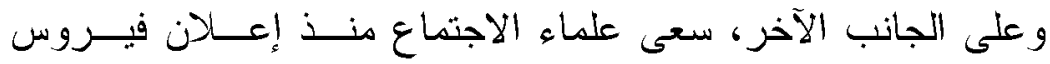
كورونا كجائحة من طرف منظدة الصحة العالمية في مارس الماضي، إلى

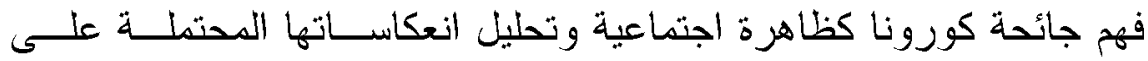

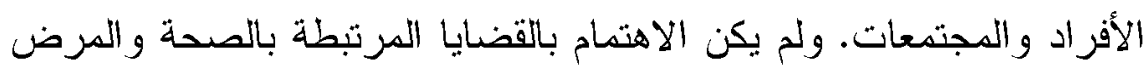

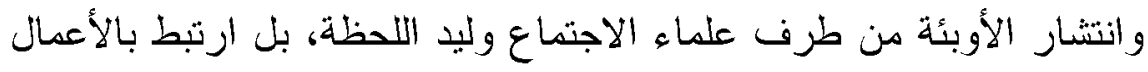

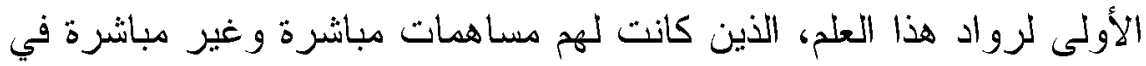

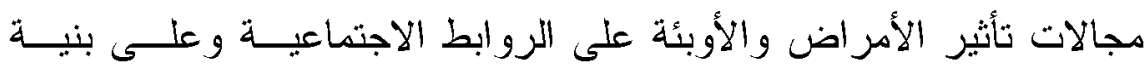

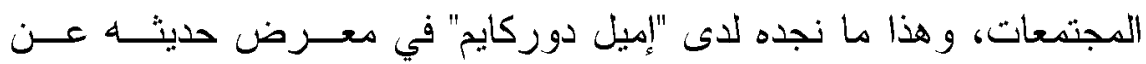

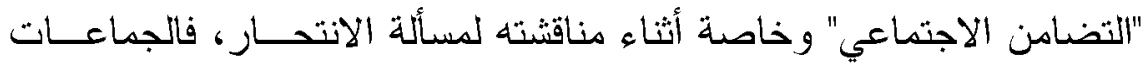

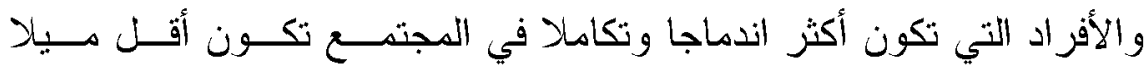

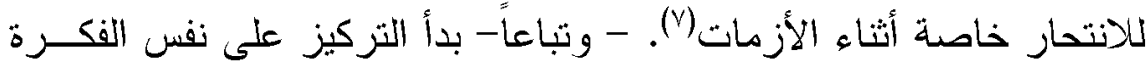

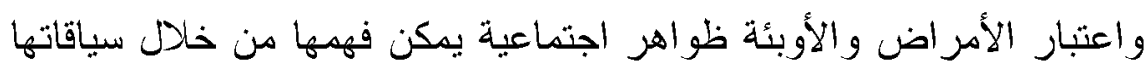

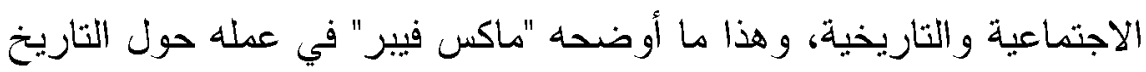
و السوسيولوجيا، وكيف يمكن تقديم تحليل مقارن بين نفس النوع من الأحداث 
خلال فترات تاريخية متفاونة "، وتظهر كذلك مساهمة "مارسيل موس" حول

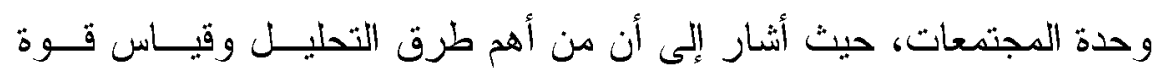

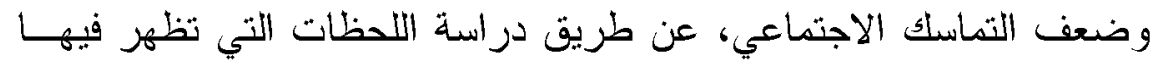

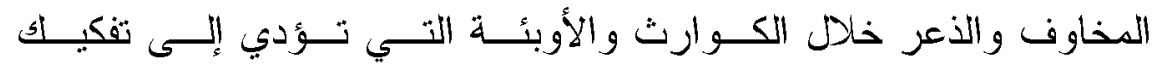
أو اضمحلال المجتمعات.

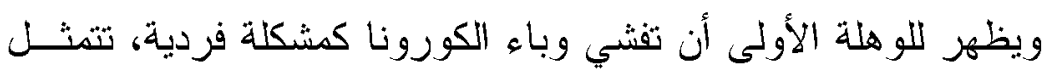

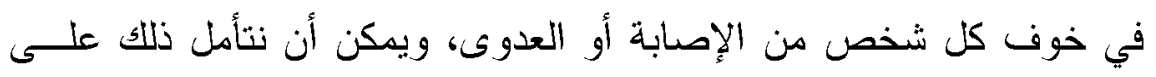

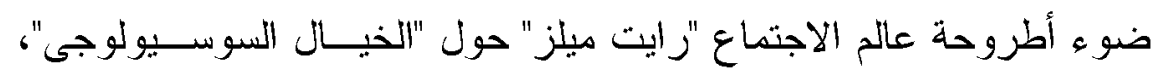

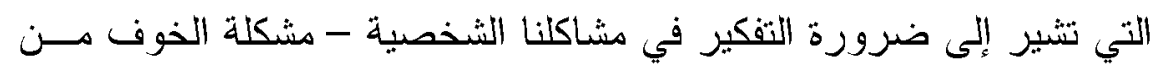
الإصابة بفيروس الكورونا - وفههها فى ضوء القضايا الكبرى، خاصة وأننا

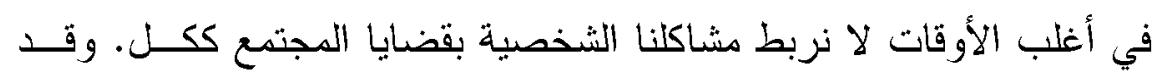
نعتقد أن مشاكلنا الثخصية يمكن حلها من خلال آليات التأقلم الفردية وحدها.

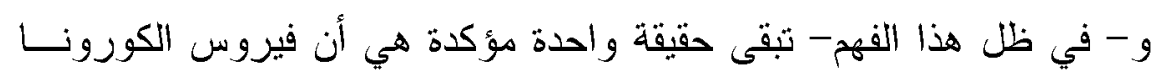

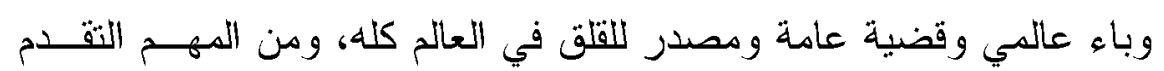
نحو فهم هذه المشكلة والكثف عن جو انبها الأخرى( (^).

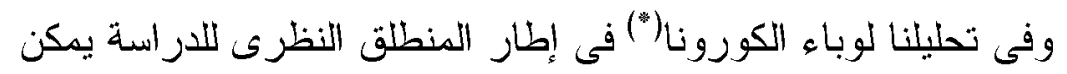

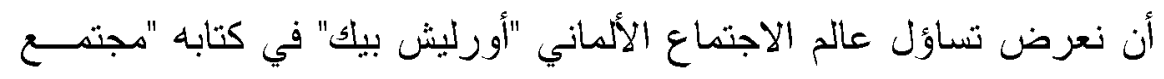

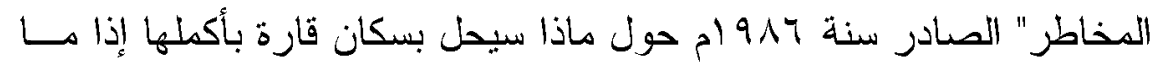

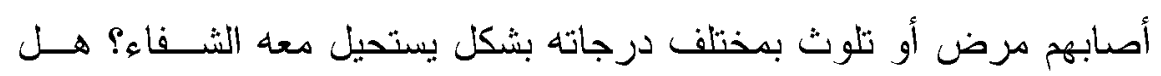

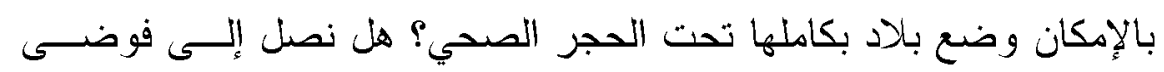

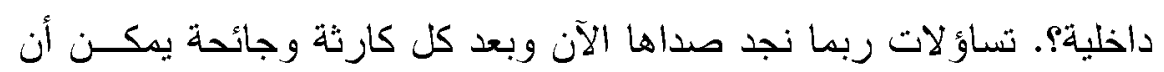

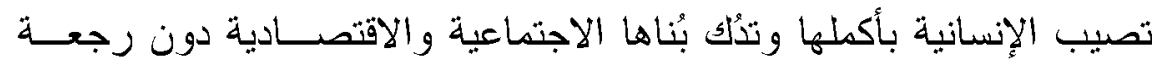

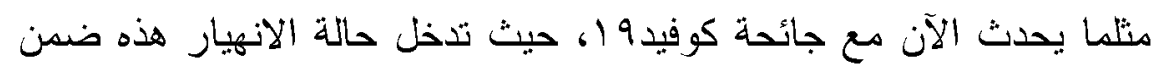

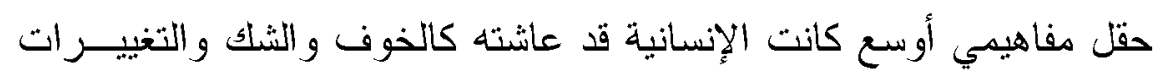

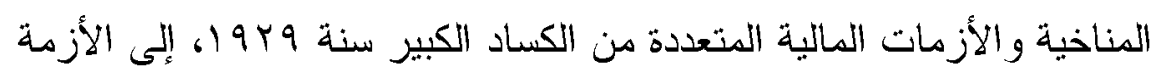

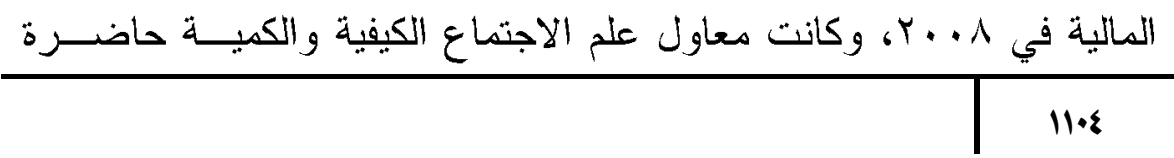


وبقوة في كل هذه الدحطــات، مسـن زاويسـة الفهـم و التحليـل و التفسـير والاستتر اف.

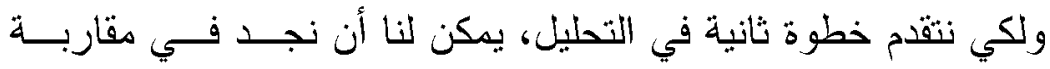

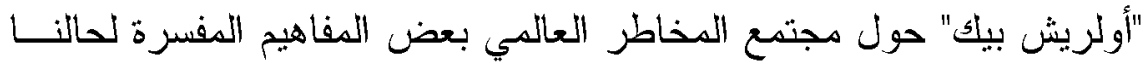

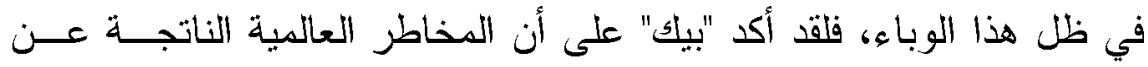

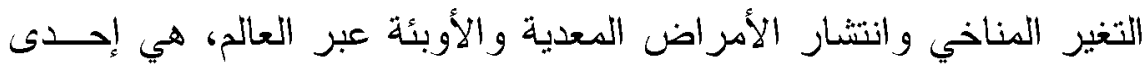

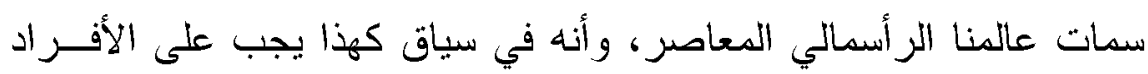

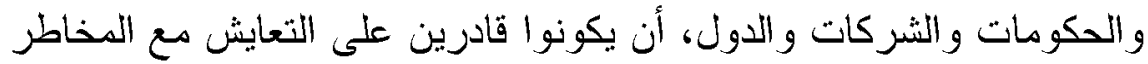

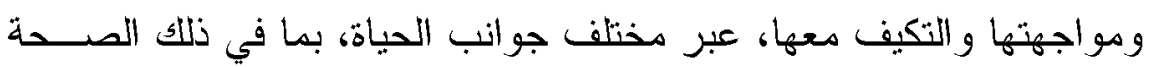
و المرض. ولقد أكد "بيك" على أنه في حال حدوث أية كارثة أو وباء عالمي،

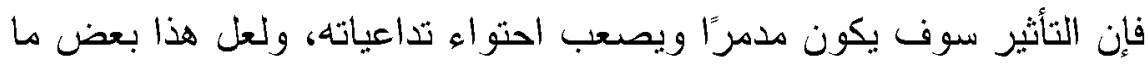

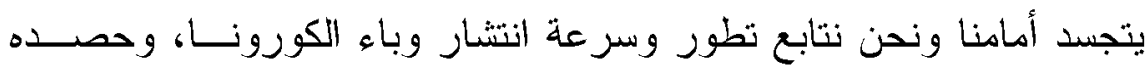

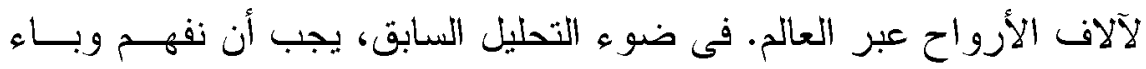

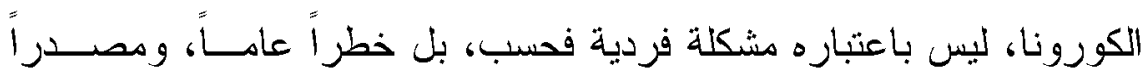

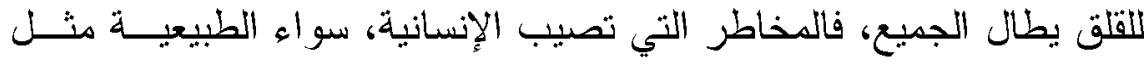

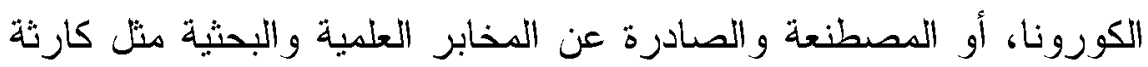
تشرنوبيل أو هيروشيها، تؤثر بدور ها على المجتمع في كليته وفي تفاصيله،

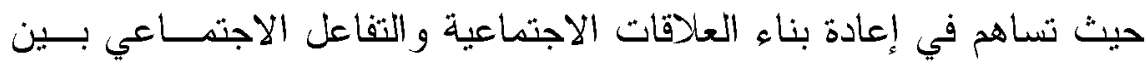
الأفراد وفي تغيير أنماط العيش. وبالفعل وجد سكان العالم أنفسهر - فعليا-

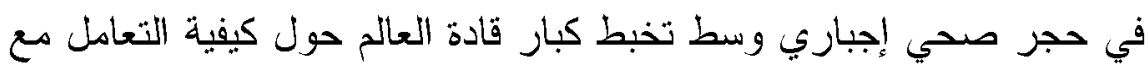

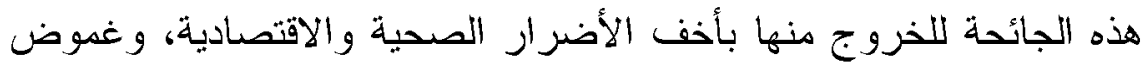

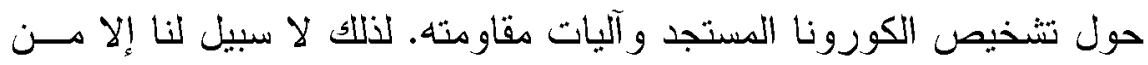
خلال التغيير، فمن خلاله يجب على كل شخص إعادة النظر في تصرفاته،

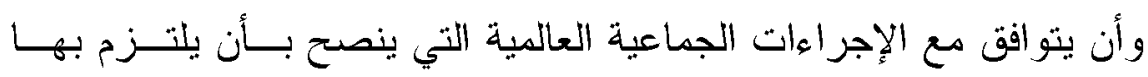
الجميع؛ لاحتو اء الوباء ووقف الاهر اهنت اهناره. 


\section{r- واقع المجتمعات مع بلابة الجائحة اولاً : مظاهر الخلّ في البناء الاجتماعى}

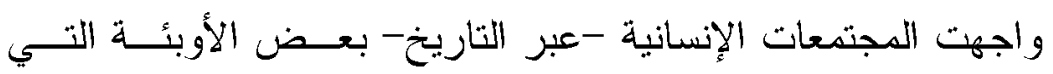

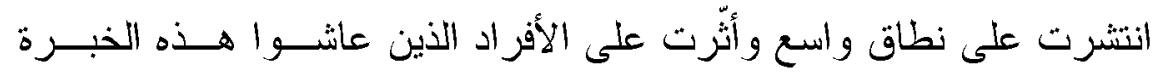

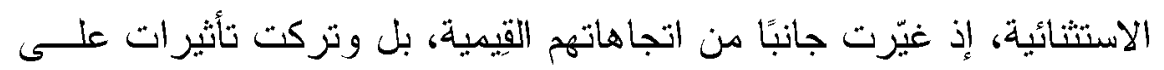

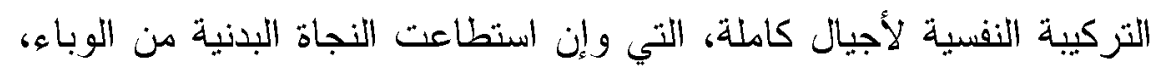

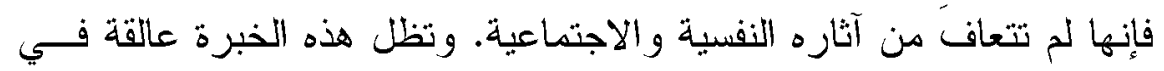

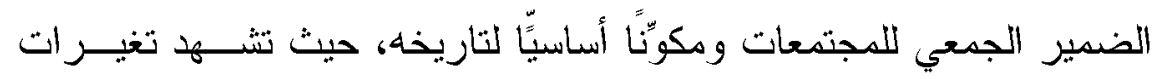
جذرية في نمط حياتها اليومية، وتتنهي التجربة بخلق معان وفئيم و أفكـار

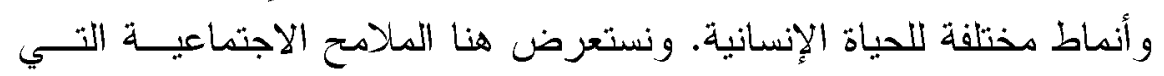

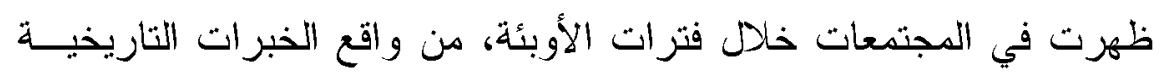

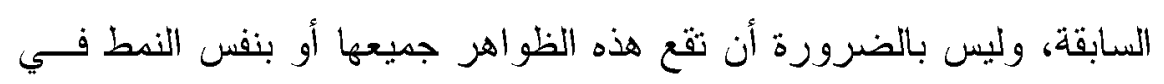

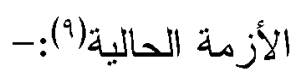

\section{أ- سقوط العقلانية الهشة الحهاكمة للتفاعلات اليومية:}

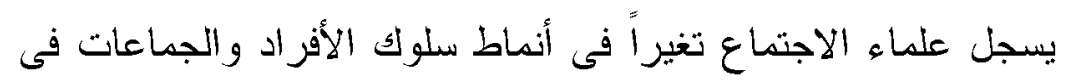

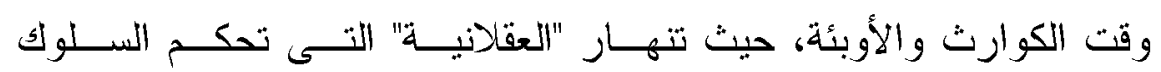

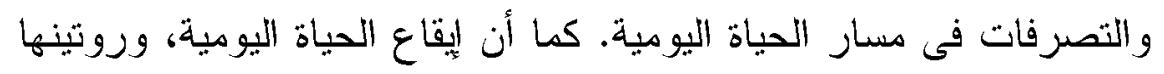

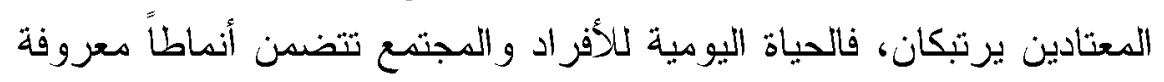

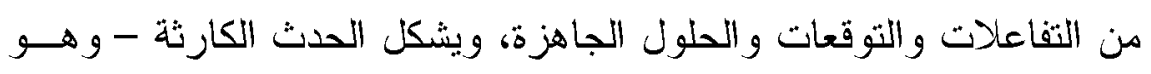

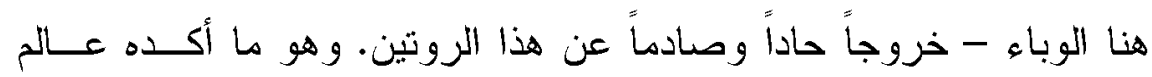

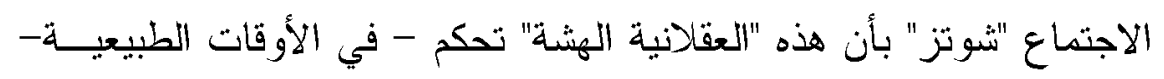

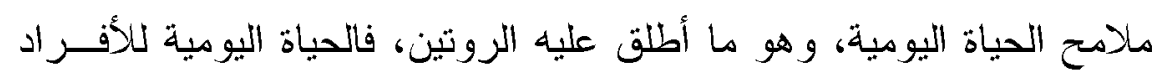

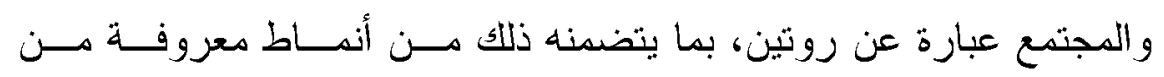

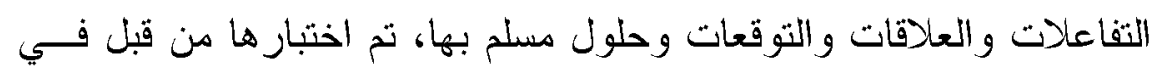

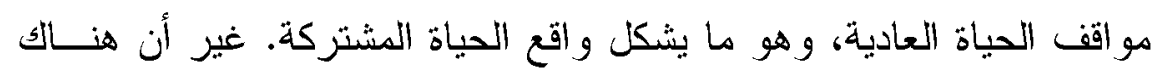

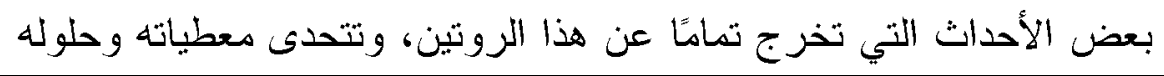


الجاهزة، وفي هذه الحالة تكون الاستجابة لهذا التهديد عبارة عن موجات من هن التهات

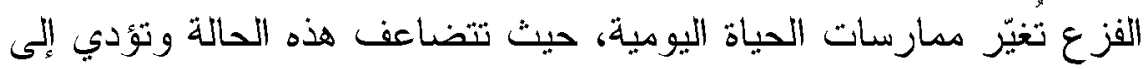

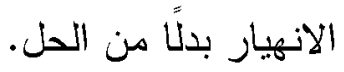

ب- تأتر منظومة القيم واختلاف الممارسيات الاجتماعية

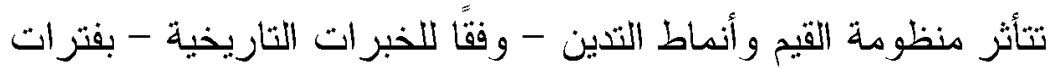

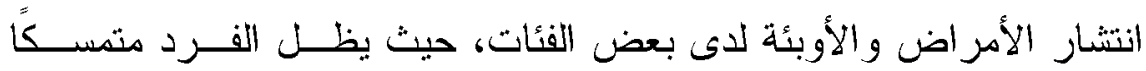

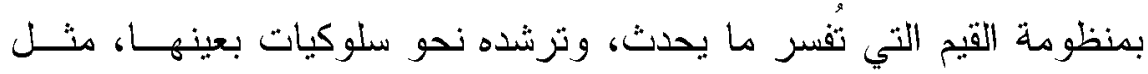

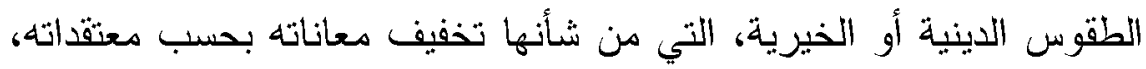

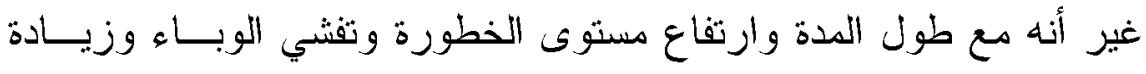
الضغط النفسي يرتبك الفرد، وقد يتتكك في معتقداته وقيمه، وقد يذهب وإلى ولى

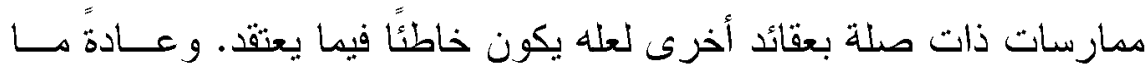

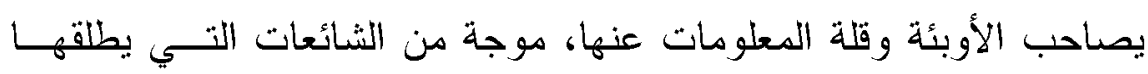

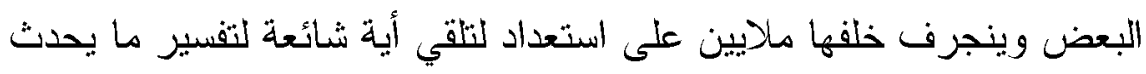

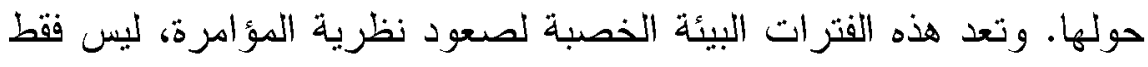

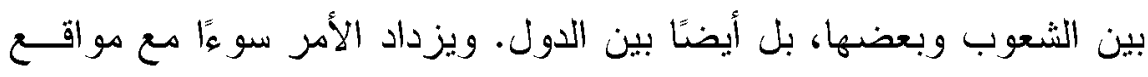

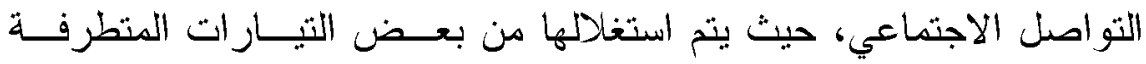

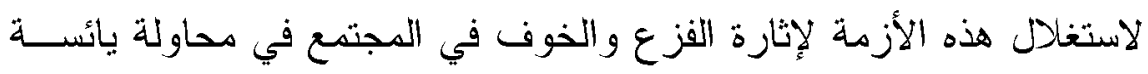

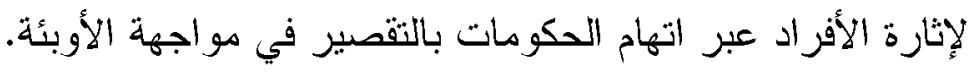

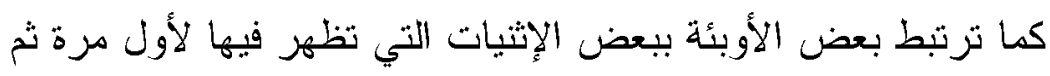

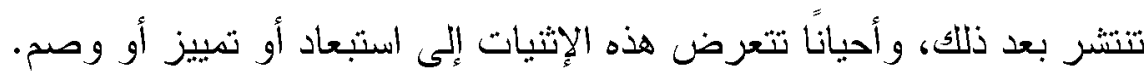

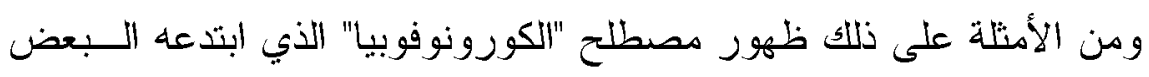
لتجسيد حالة الخوف دن كل ذوي الملامح الآسيوية وليس الصينيين فقـط.

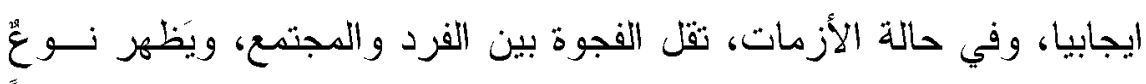

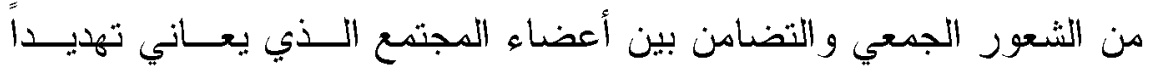

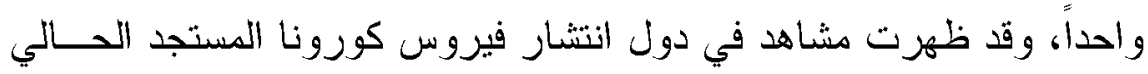

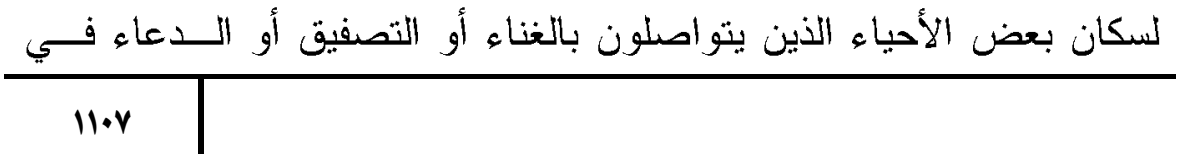


اللحظة ذاتها، والتواصل عبر النو افذ لاعم بعضهم بعضًا، وتحفيز أنفسـهـ النها

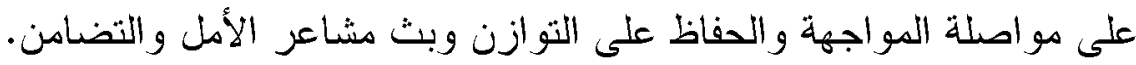

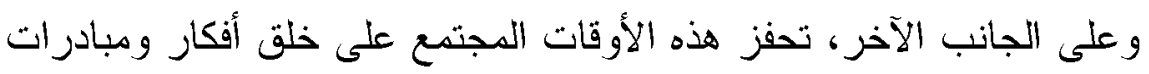

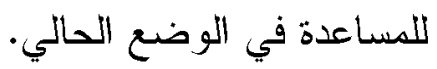

\section{ثانيا- التباعد الاجتماعى (التعريف فئف - التداعيات )}

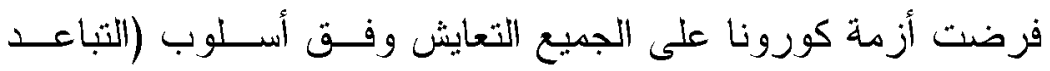

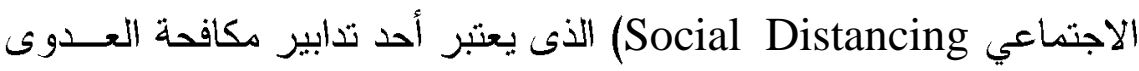

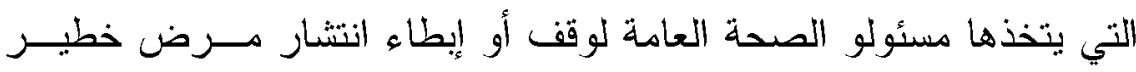

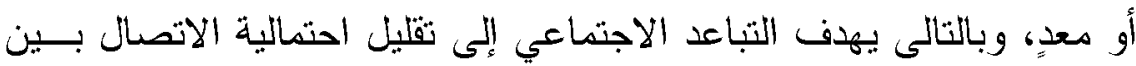

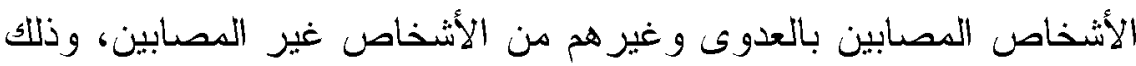

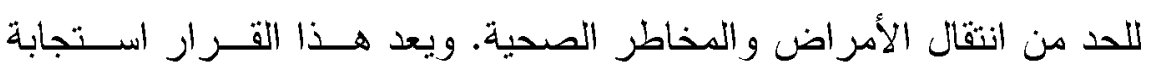

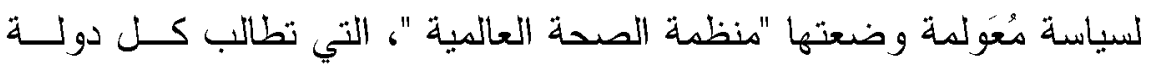

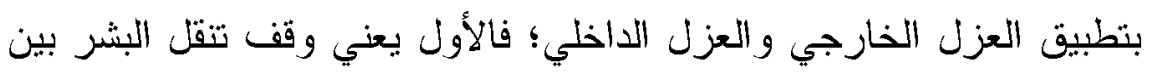

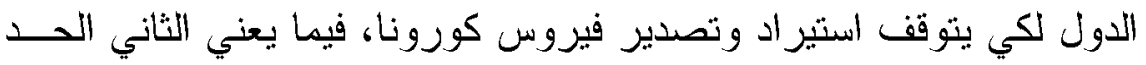

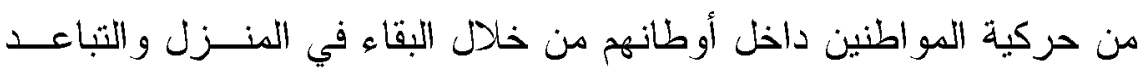
الاجتماعي، حفاظاً على صحة الأفر اد وصحة المجتمع ككل (·").

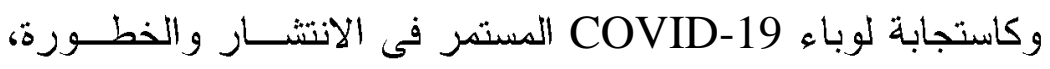

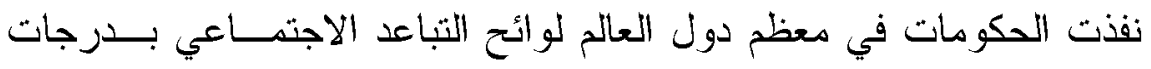

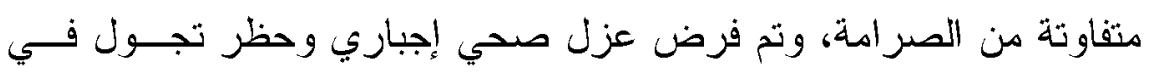

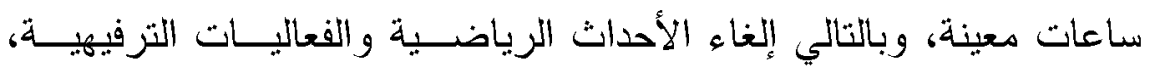

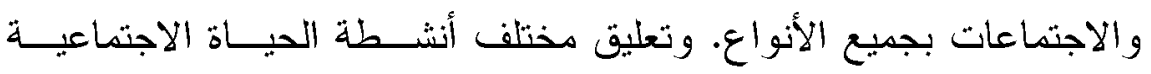

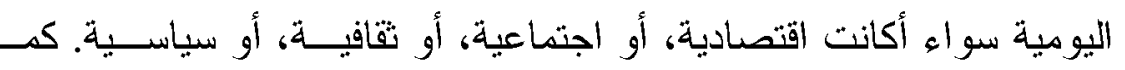

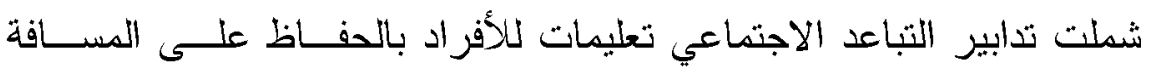

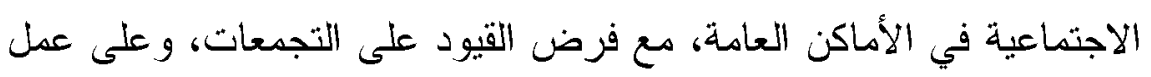

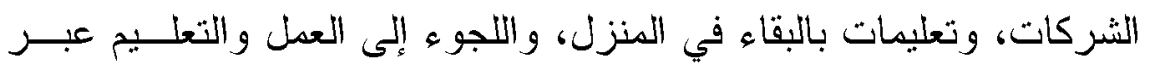

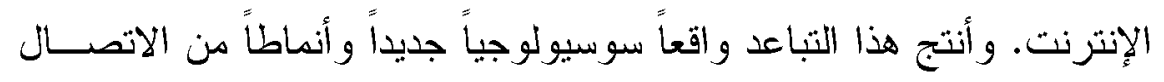




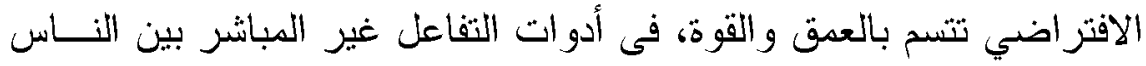

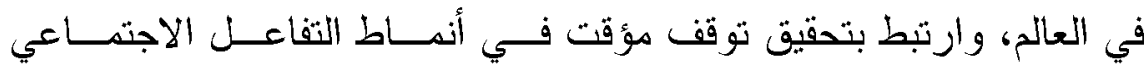

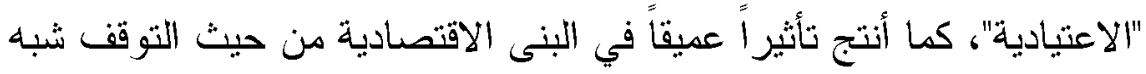

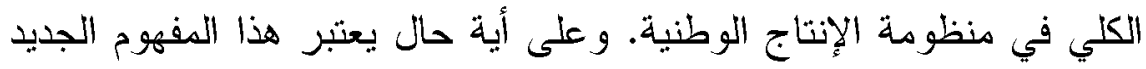

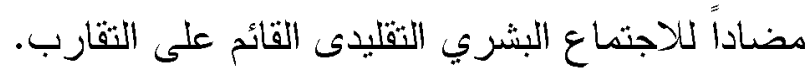

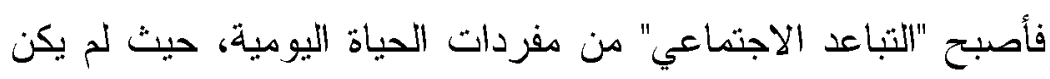

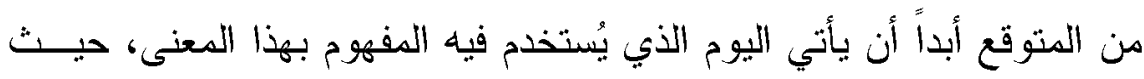

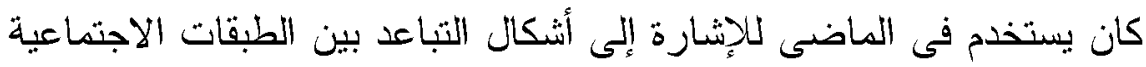

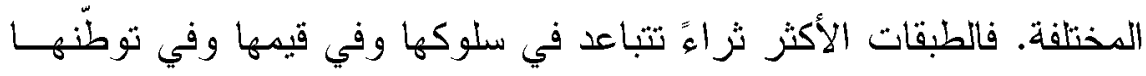

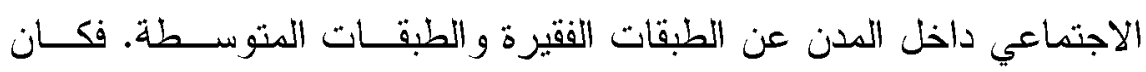

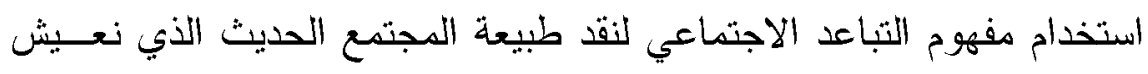

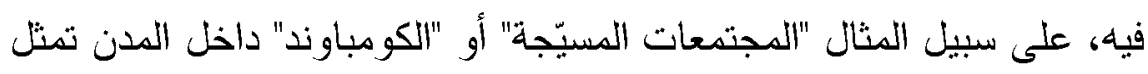

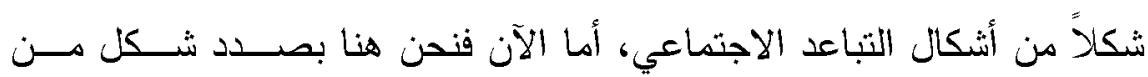

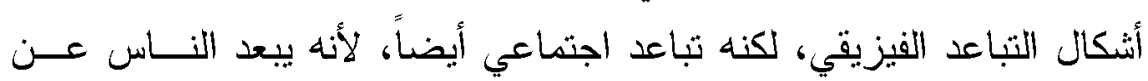

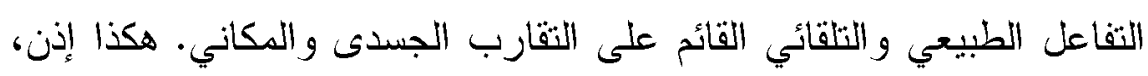

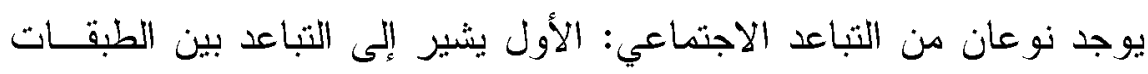

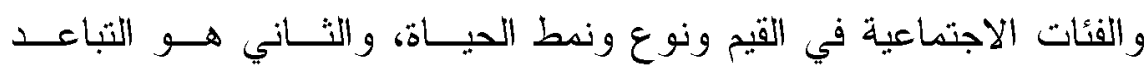

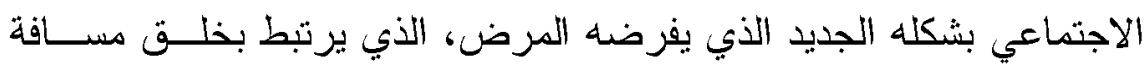

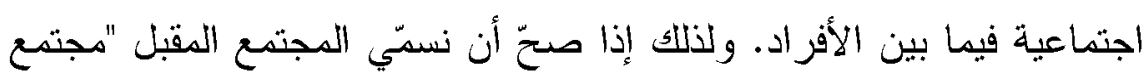
ما بعد الجائحة"، فإنه يصحّ أيضاً أن نسميه "دجتمع التباعد الاجتماعي" (11).

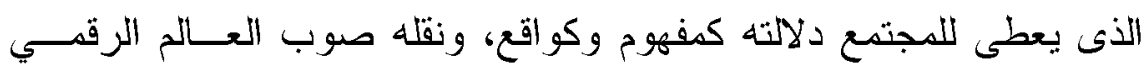

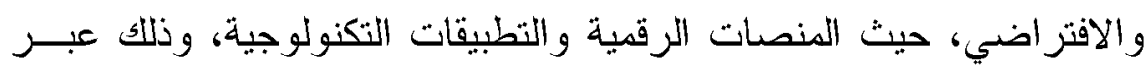

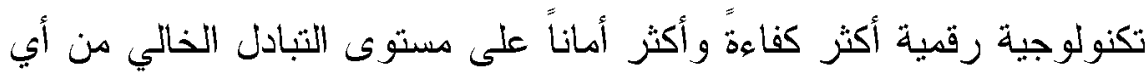
خطر انتقال للعدوى و المرض، و هكذا انطلقت دينامية وحركة متتامية بوتيرة قياسية نحو الإقبال الكثيف على الإنترنت و المو اد الرقمية. 
وعلى الرغم دن فاعلية التباعد الاجتماعى فى مواجهة الجائحسـة، إلا

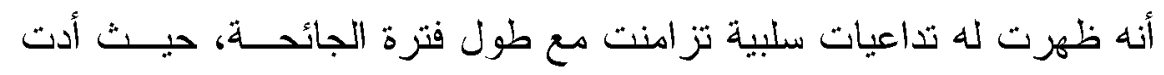

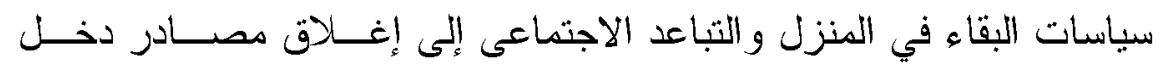

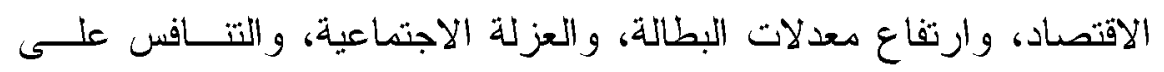

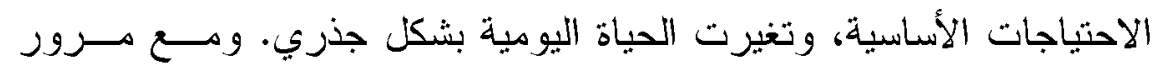

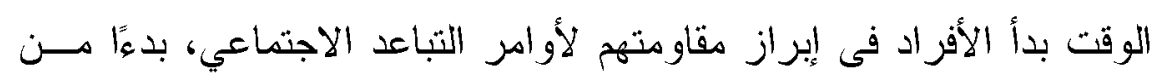

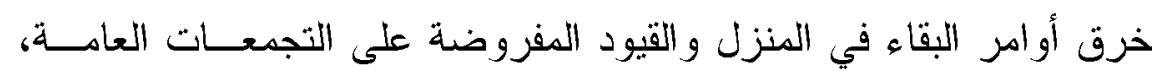
درورا بالاعتداء على العاملين في المجال الأمنى والطبي هن خلال السعال

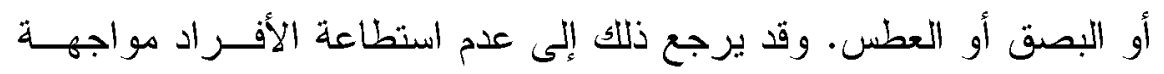

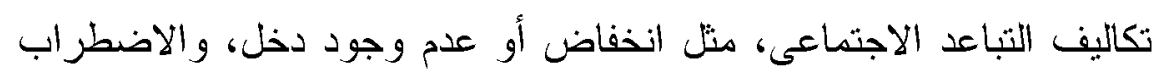

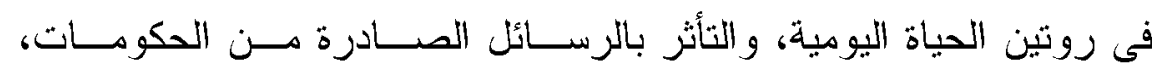

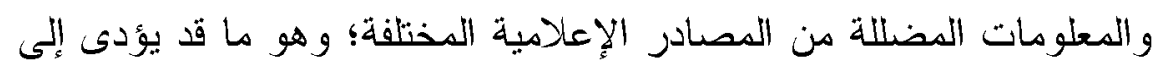
كثير من المخاطر سوف تعرض لاحقال(rا').

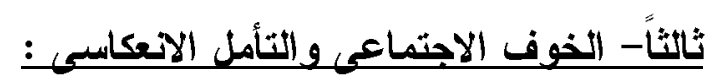

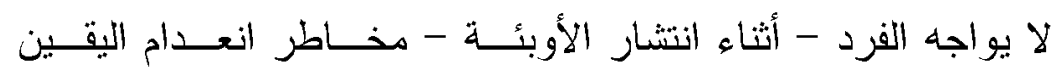

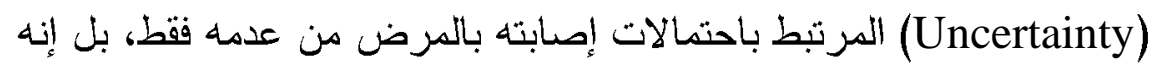

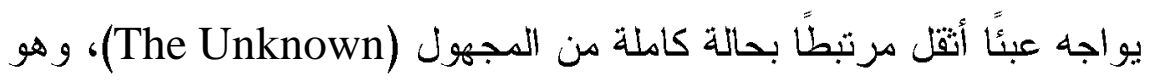
ما يتسبب في تصاعد مشاعر الخوف والقلق مقارنة بالأمر اض العادية. فهي

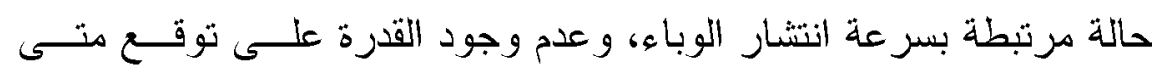

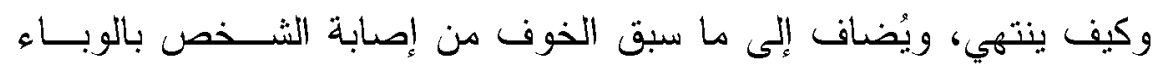

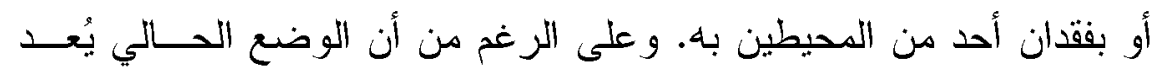

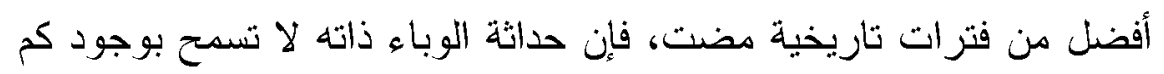

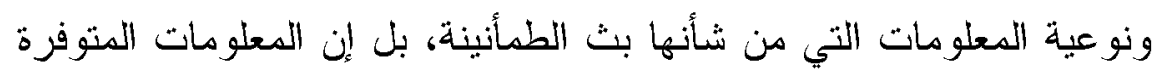

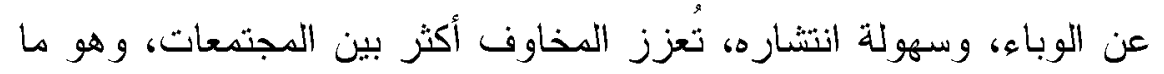

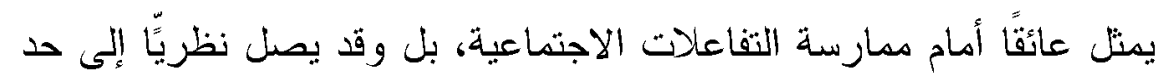

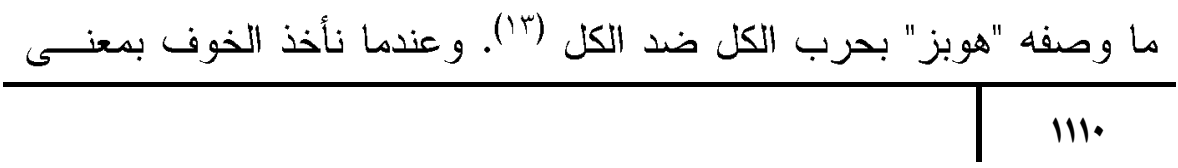


أعمق، وننظر إليه في اختلاف دفهومه لاى الفئات الاجتماعيــة المختلفــة،

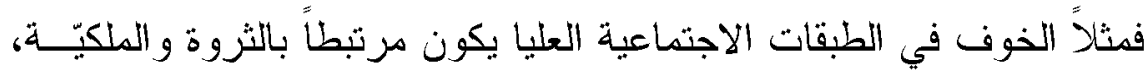

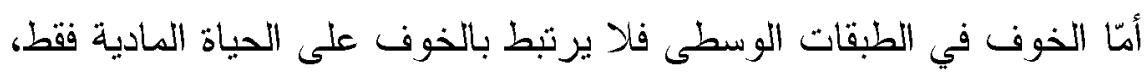

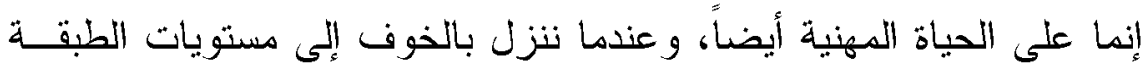

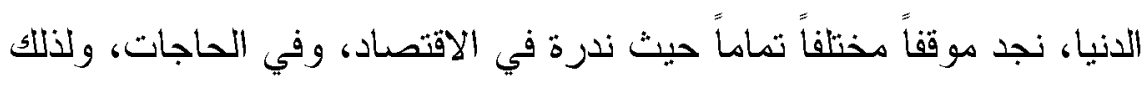

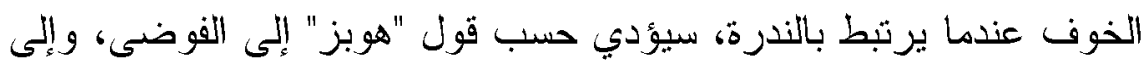

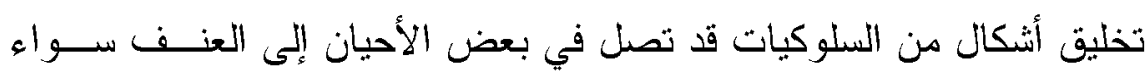

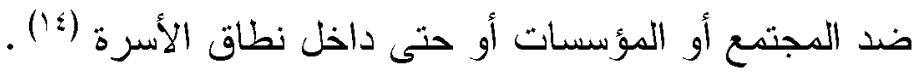

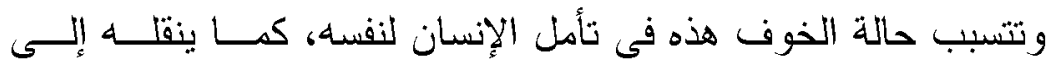
التأمل في الحياة بشكل عام، في مصيره وهصير أولاده و عائلته ومســنقبله، وطبيعة الحياة حتى فيما بعد فيروس كورونا. فمن المفيد للغاية، القيام بذلك

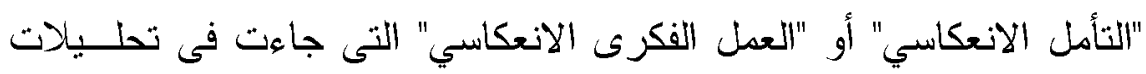

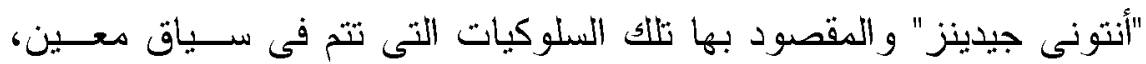

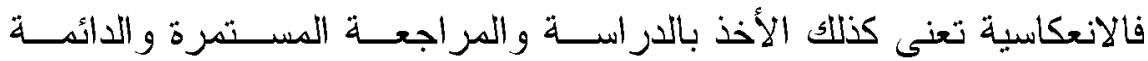

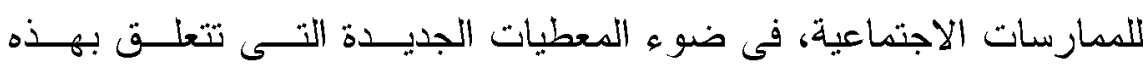

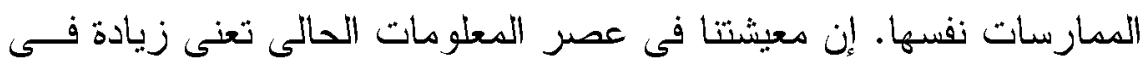

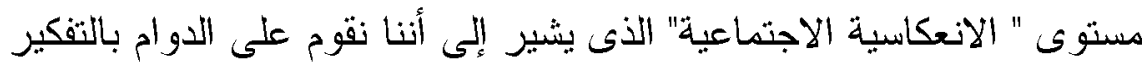

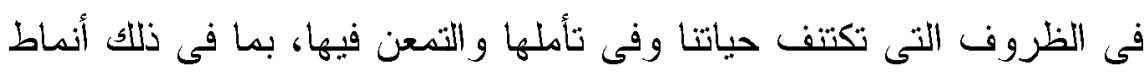

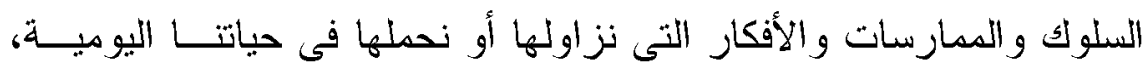
وتظل لدينا فى جميع الأحوال القدرة على التغيير والتعديل على الصـــيدين

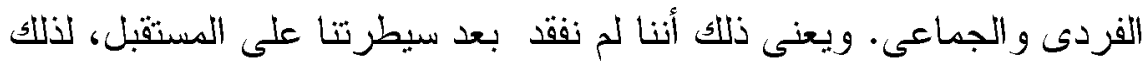

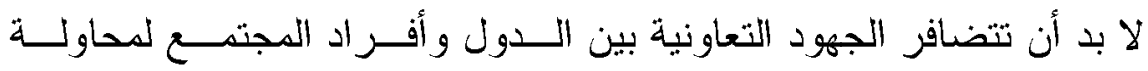
السيطرة على هذا العالم المنفلت(10). 
ع - مجتمع ما بعد الجائحة .......الترؤى المستقبلية والمخاطر المحتملة

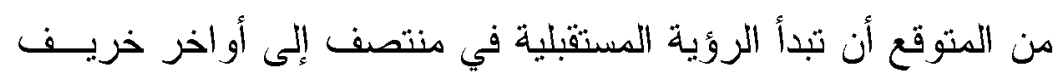

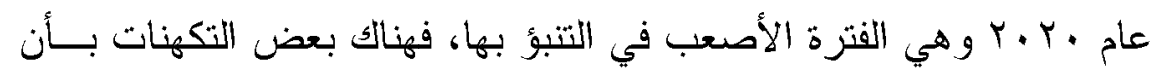

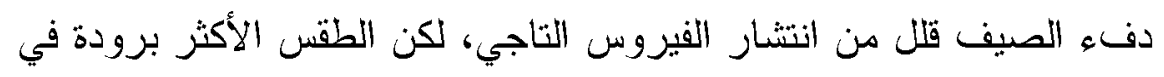

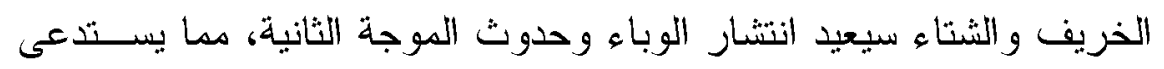

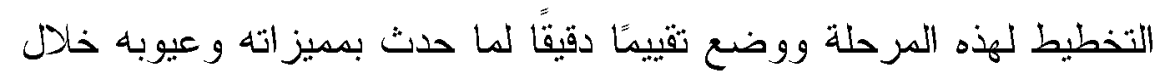

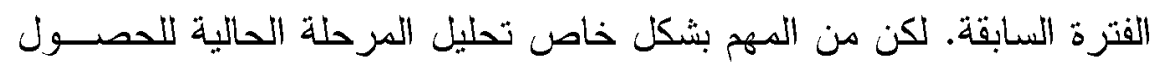

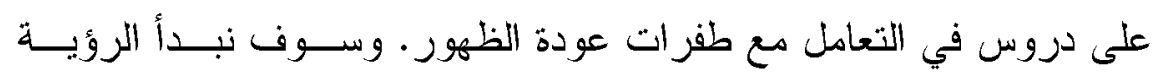

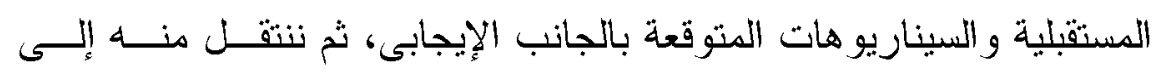

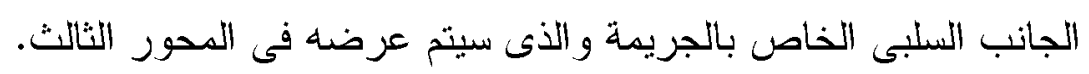

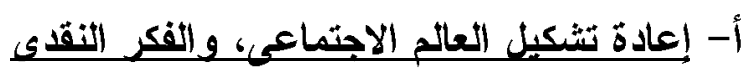

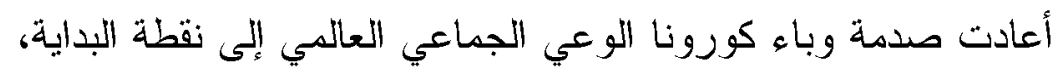

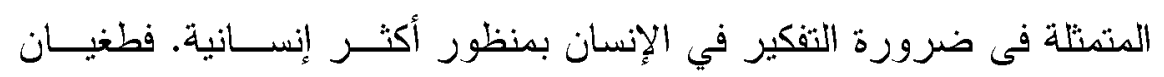

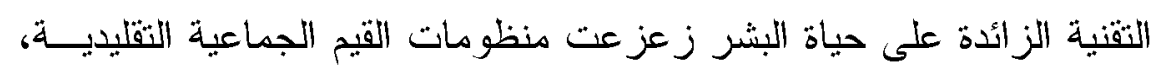

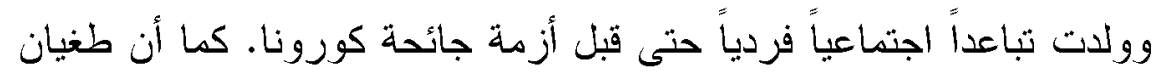

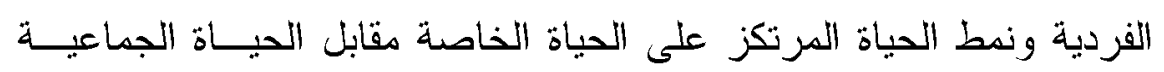

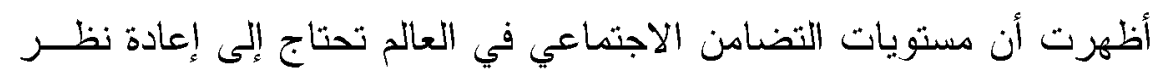

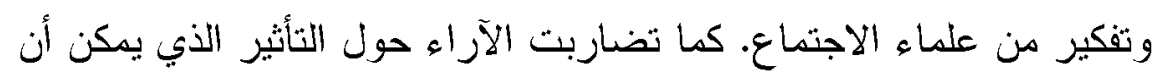

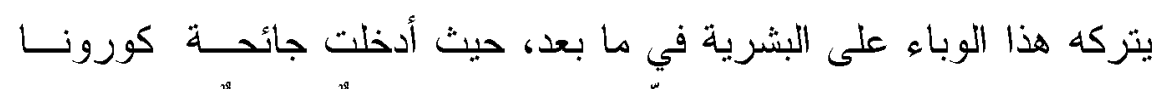

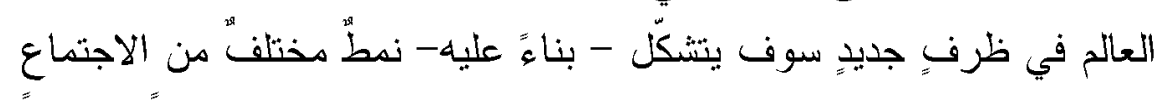

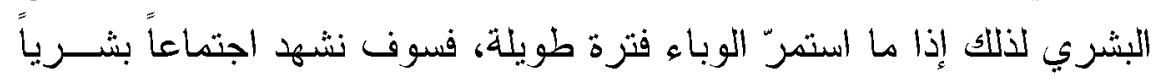

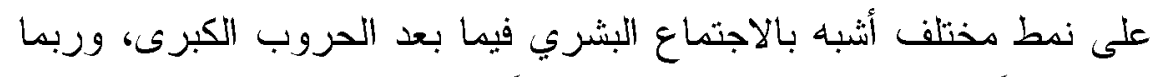

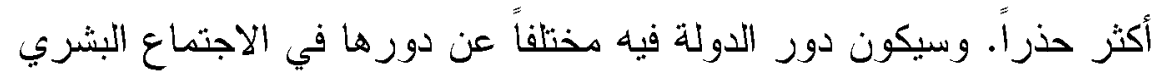

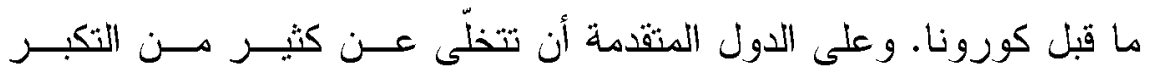

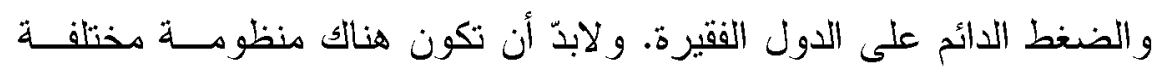

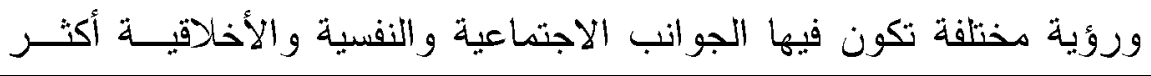


ظهوراً، وبهذا الصدد، فربما نكون بحاجة إلى الحداثة المصقولة التي تتميز

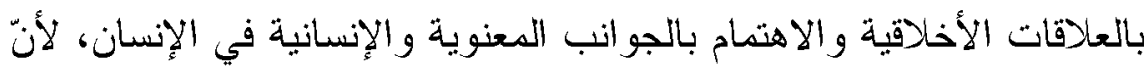

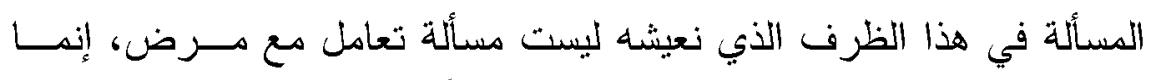

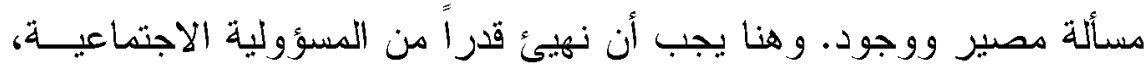

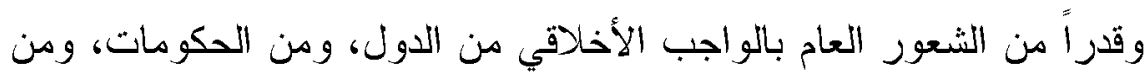

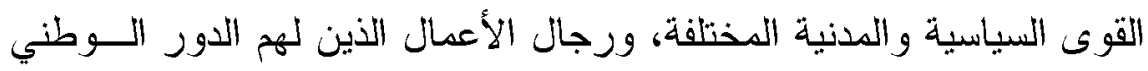

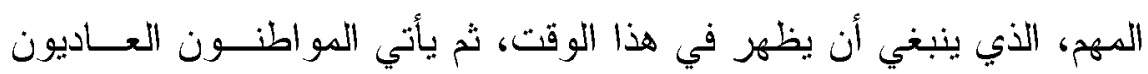

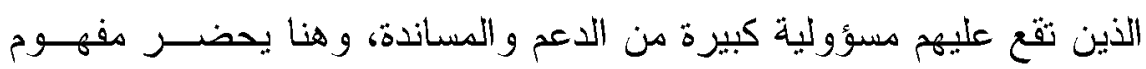

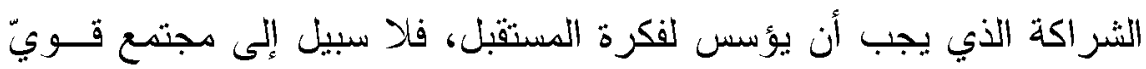

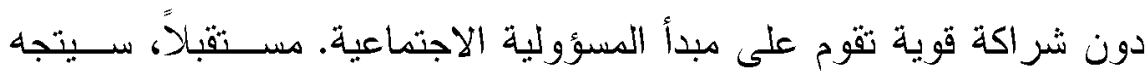

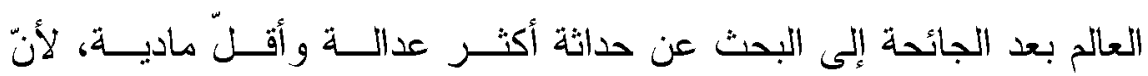

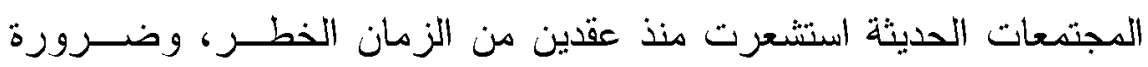

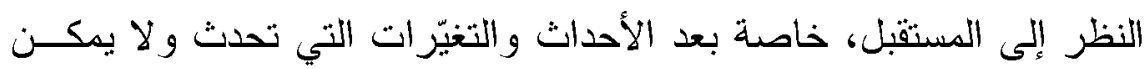

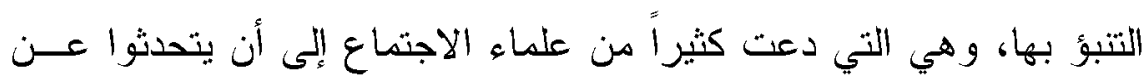

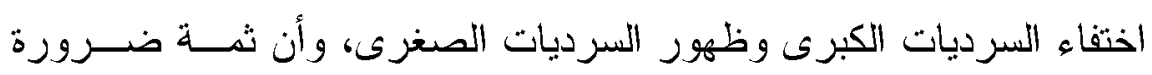

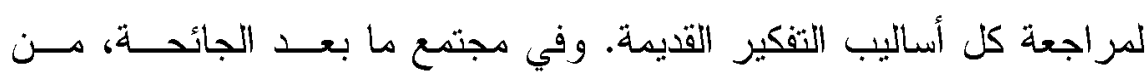

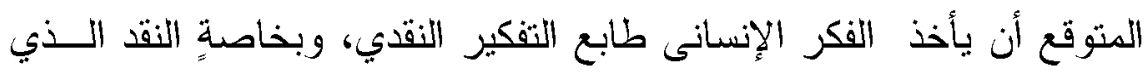

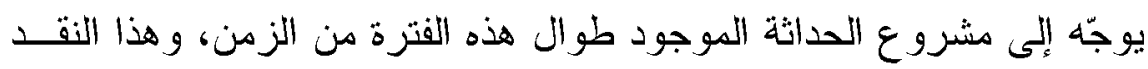

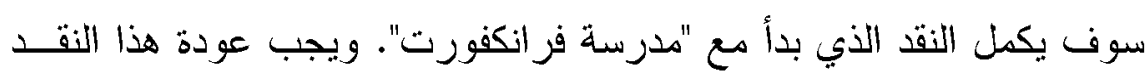

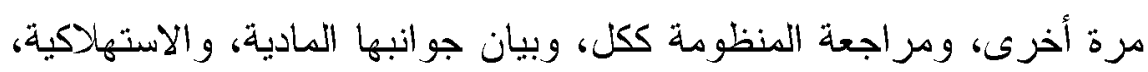

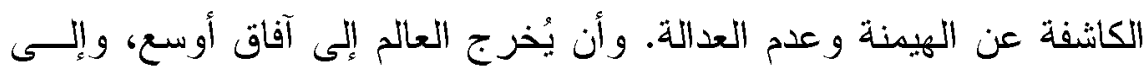

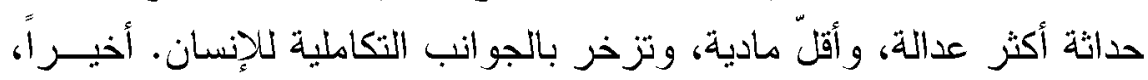

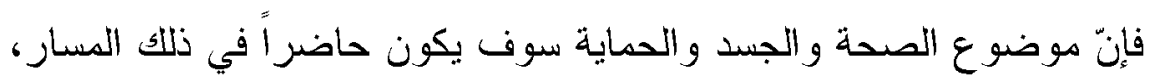
طالما أنه يشكل مصدر اً رئيساً للقلق (17"). 


\section{ب - الاتجاه نحو المجتمع الرقمى}

تزامنت إجراءات التباعد الاجتماعي التي فرضها ظهــور و انتتـــار الفيروس، في تدعيم قو اعد وأسس المجتمع الرقمي من خلاعل نعليق التفاعل

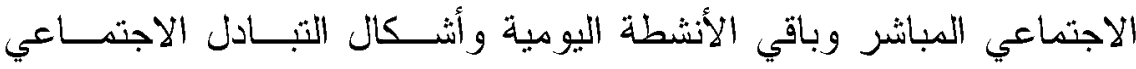

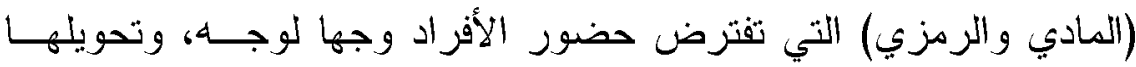

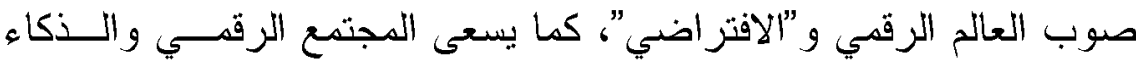

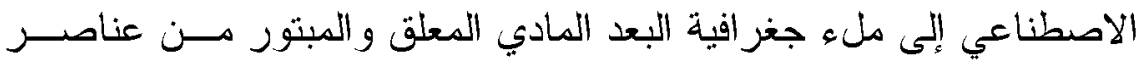

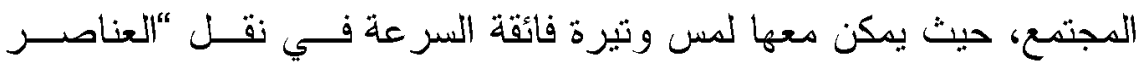

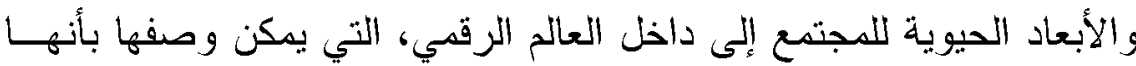

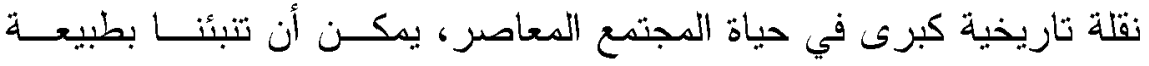

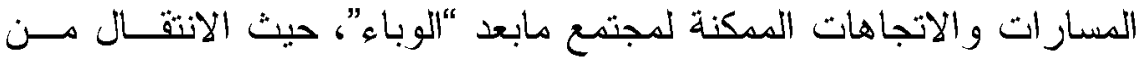
مجتمع المؤسسات إلى مجتمع المنصات. وقـــد اتجـهـه عـدد هــن الــدول

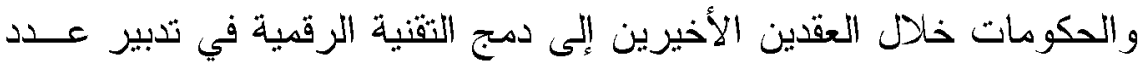

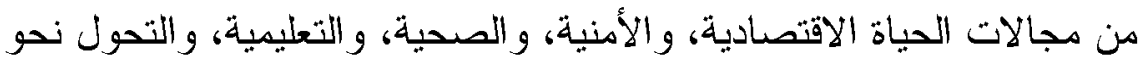

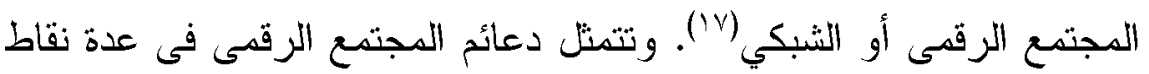
أهمها:

أو لاً: التعليم عن بعد: برغم اعتماد عمليات التعليم والتكوين عن بعـد

Educaton and formation Online)

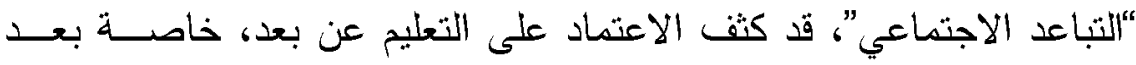
إعلان عدد دن الدول والهجتمعات الحجر الصحي وحالة الطوارئ الصحية،

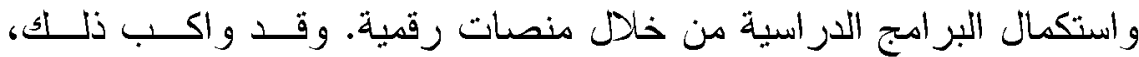

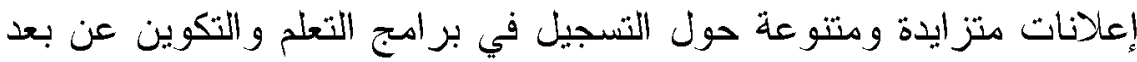

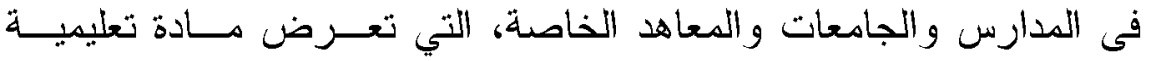
هتتو عة. ثانياً: خدمات إدارية عن بعد: سارع عاتهات عدد من المؤسسات الإدارية،

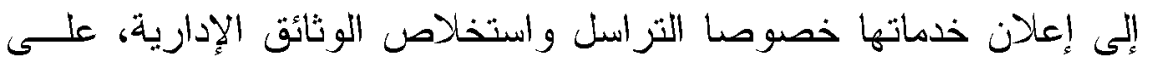

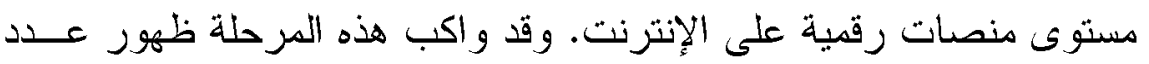


كبير من التطبيقات القابلة للتحميل على الحاسب أو الهاتف، والتـى تتكفـلـل

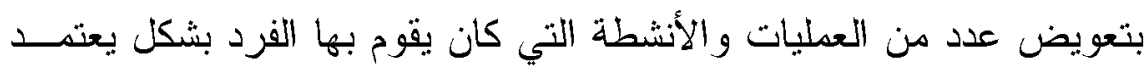

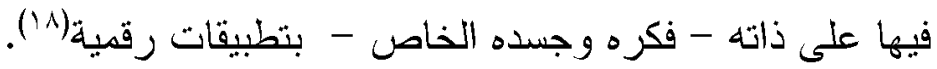

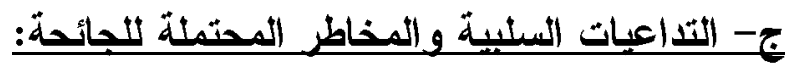

أقرت منظدة الأمم المتحدة خطورة التداعيات السلبية لجائحة كورونا

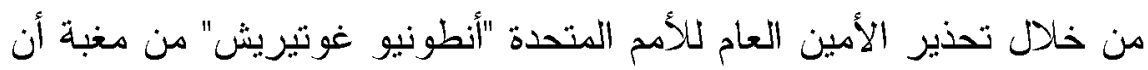
تتسبب جائحة كوفيد-19 في دمار ومعاناة لا يمكن تصور هما حول العالم.

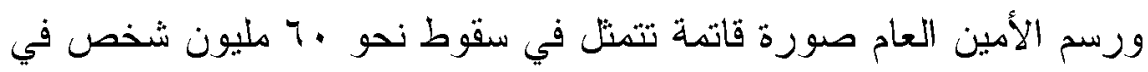

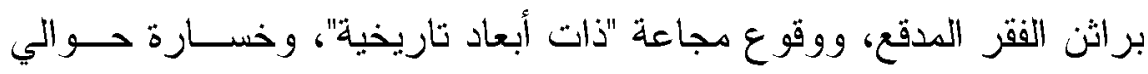

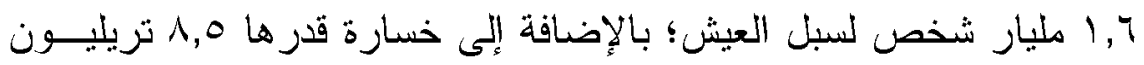
دو لار في الناتج العالمي، وهو أكبر انكماش هنذ الكساد الكبير في ثثلاثينيات

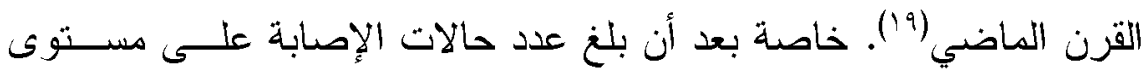

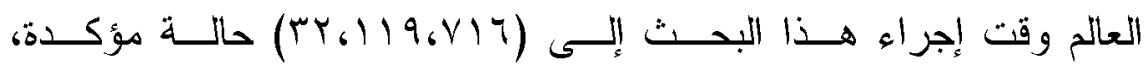

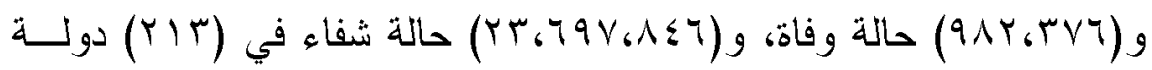
و وقاطعة (r.)

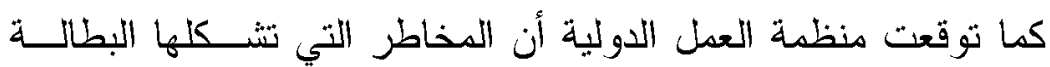

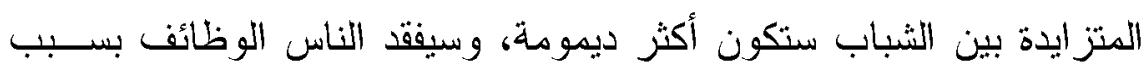

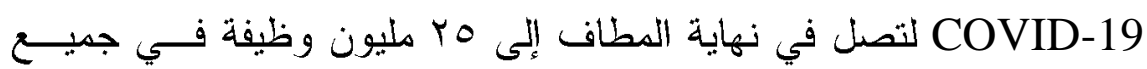
أنحاء العالم .0؛ كما سيتأثر بشكل خاص الأشخاص الذين كانت وظــائفهر

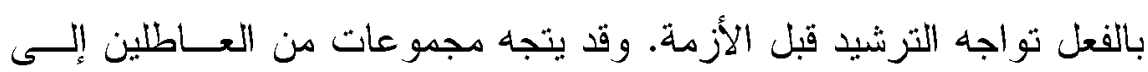

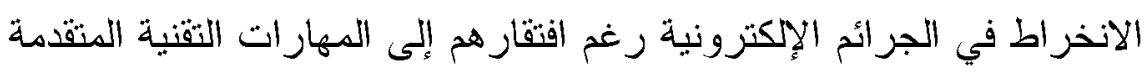

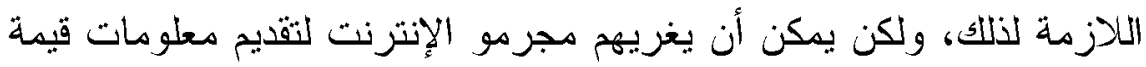

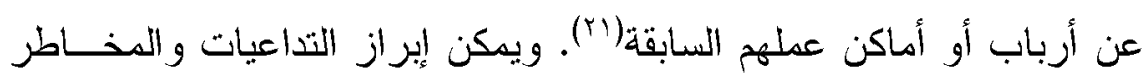
في النقاط التالية : 


\section{ا- هدم فكرة الحداثة و العولمة}

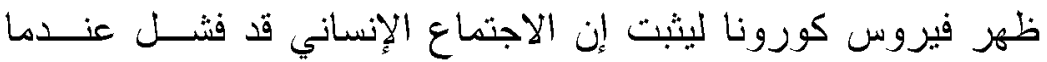

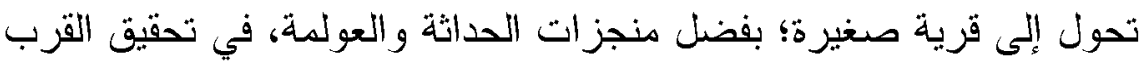

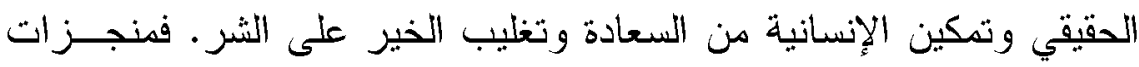
الحداثة كانت وراء انتشار المجال الحضري، وتكاثز المدن، ووسائل النقـلـل

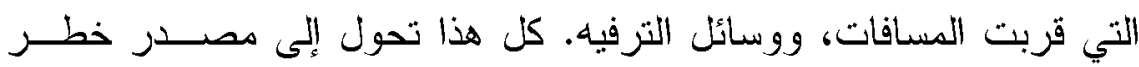

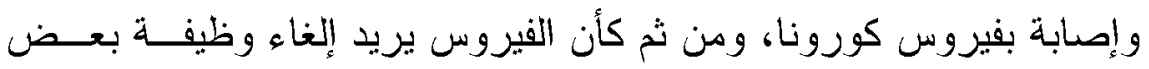

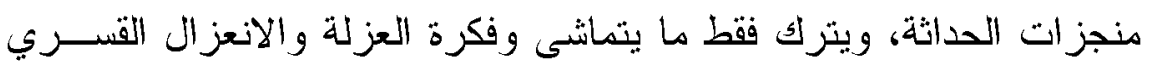

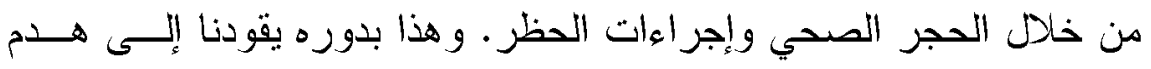
فكرة حرية الفرد التي قام عليها جوهر الحداثة وهو مدارسة الفرد لحريتــهـ

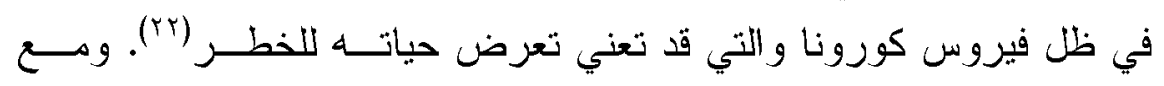

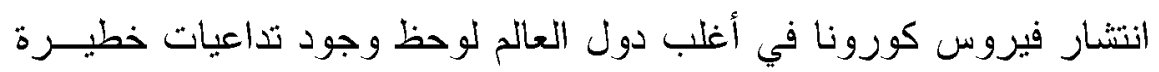

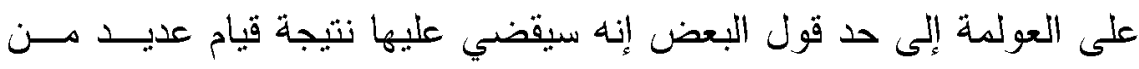
الدول بإغلاق حدودها، ووقف التبادلات التجارية ووقف حركات التنقل منها

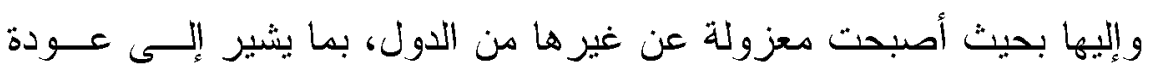

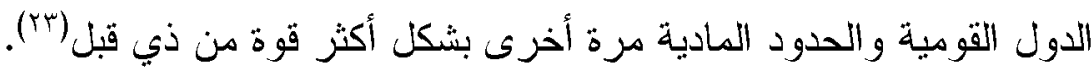

\section{r- ظهور مجتمع الثهامث}

يدرس علم الاجتماع جائحة الكورونا هن منظور الانعزال و العزلـــة

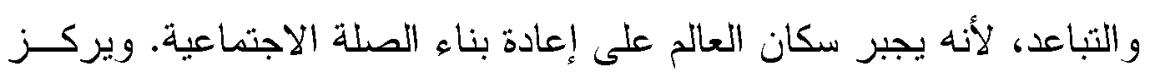

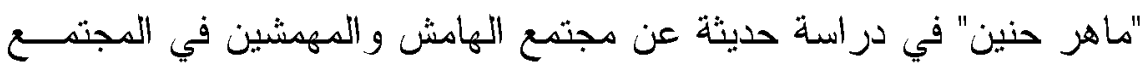

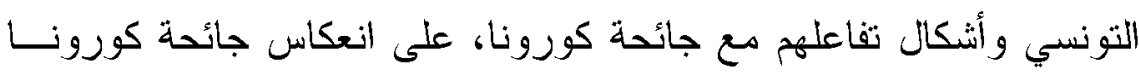

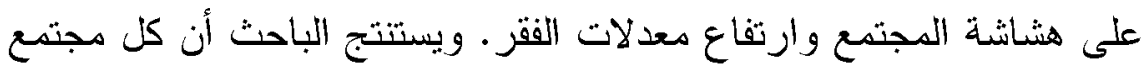

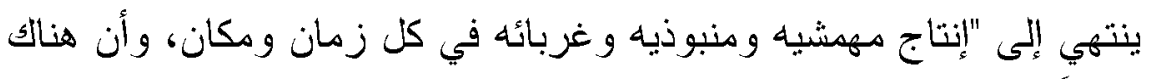

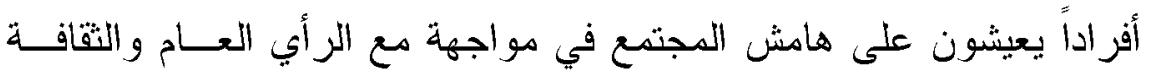

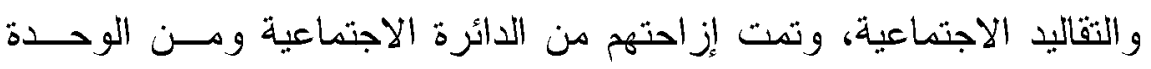

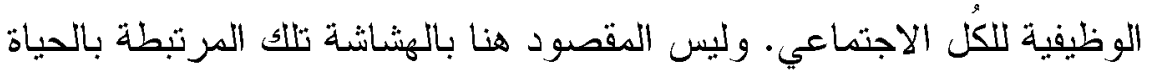




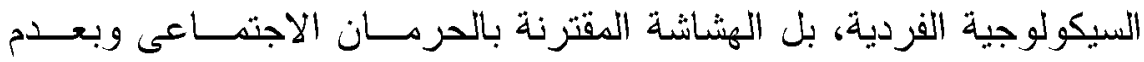

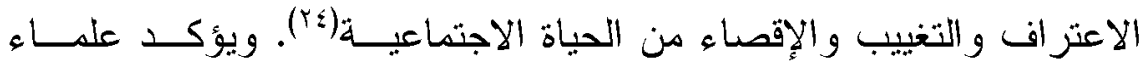

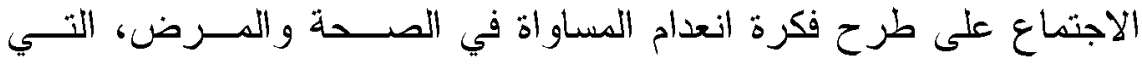

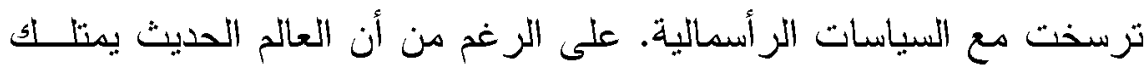

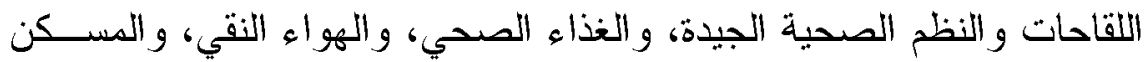

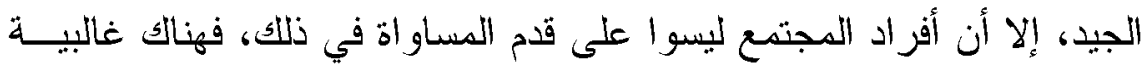

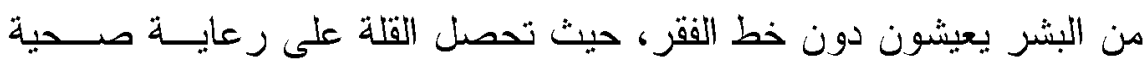

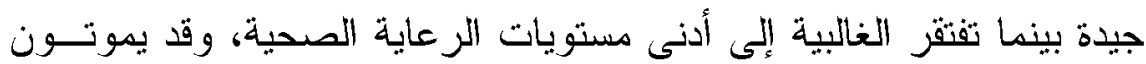
بسبب أضعف الأمر اض و أبسطها.

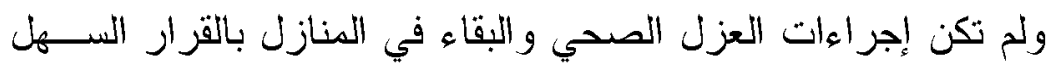

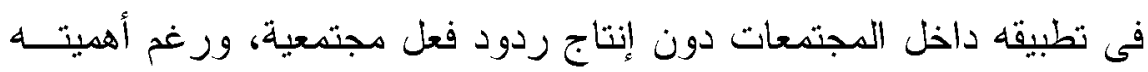

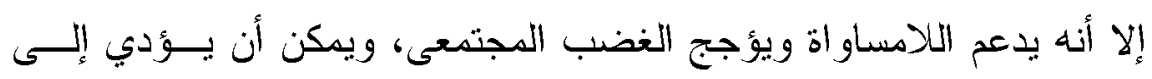

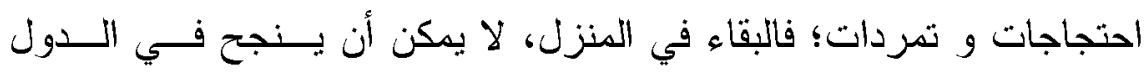

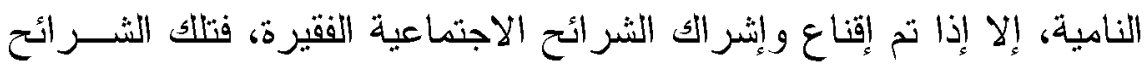
تكسب قوتها يوميا وبثكل غير منتظم بفضل نشاطها داخل الاقتصاد غيــر

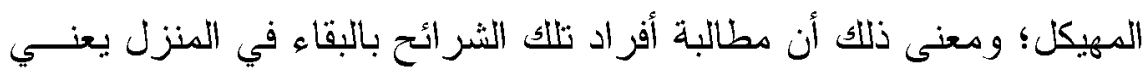

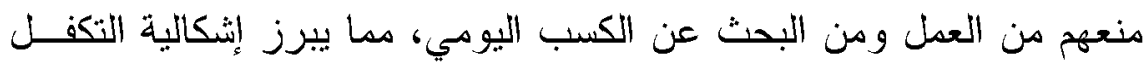

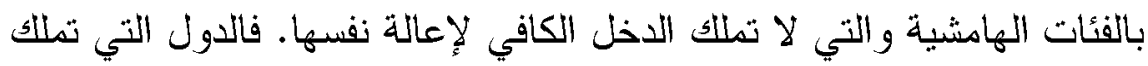

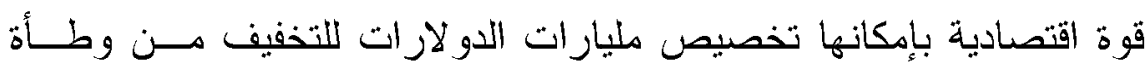

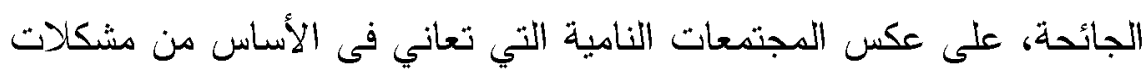

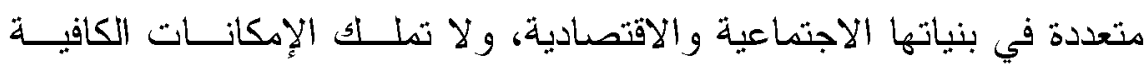

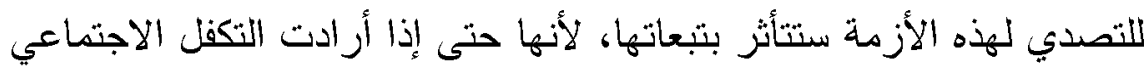

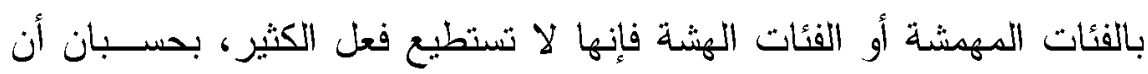

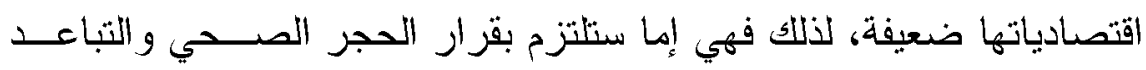

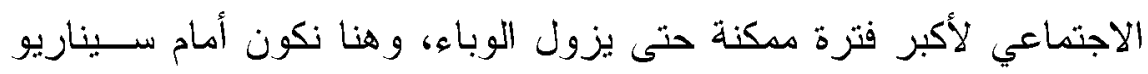

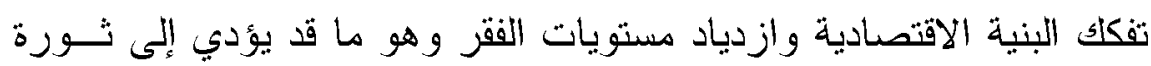


اجتماعية ضد تلك الاجر اءات، و إما أن نكون أمام سيناريو مختلـ ف تماهــا

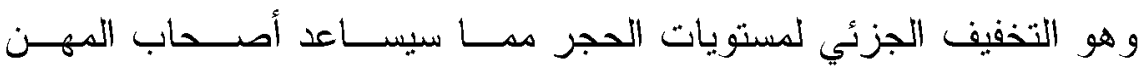
لممارسة نشاطاتهج، وهو ها سيؤدي إلى ارتفاع في دعدلات الإصابات داخل

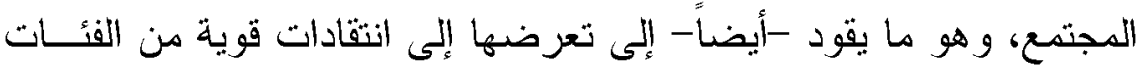

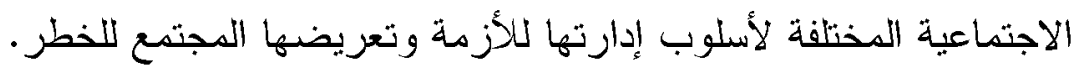

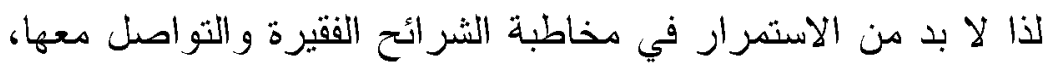

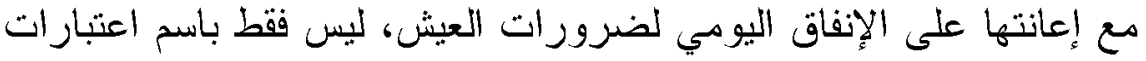

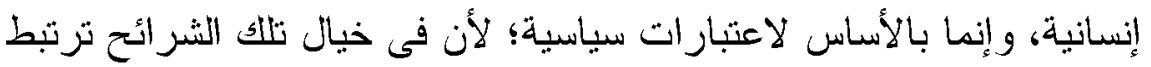

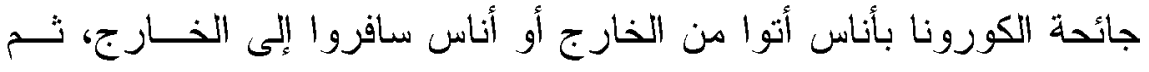

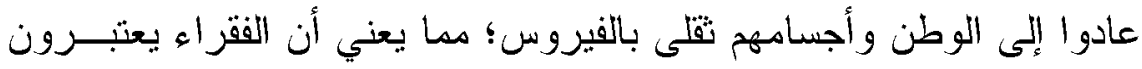

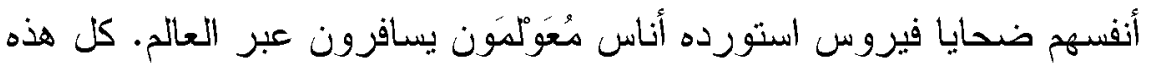

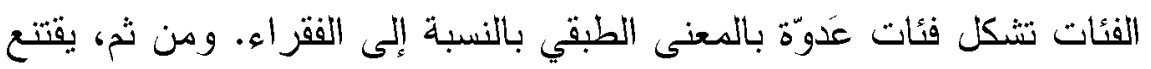

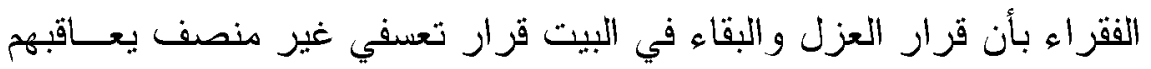

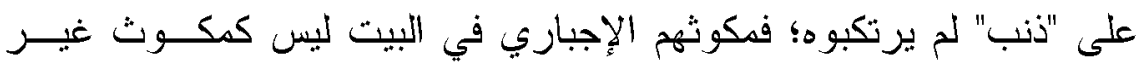

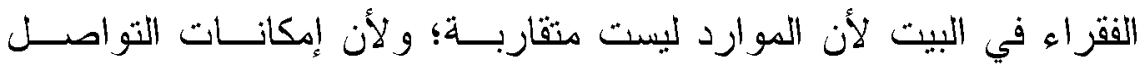

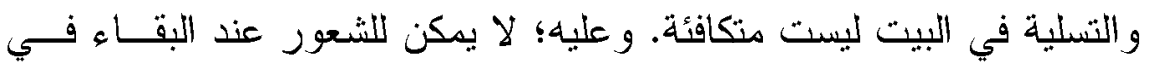
البيت أن يكون منماثلا (ro)

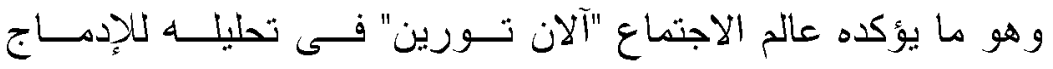

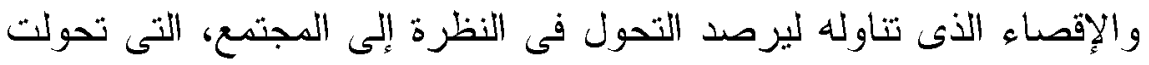

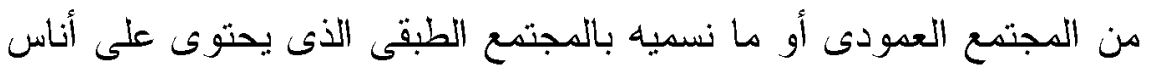

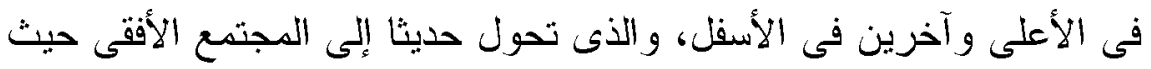

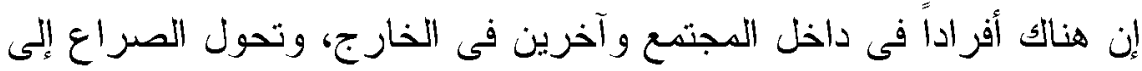

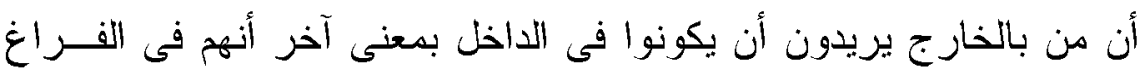

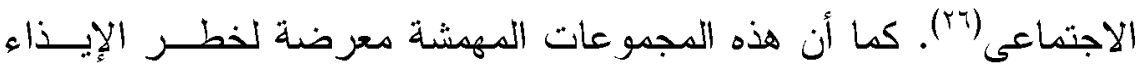

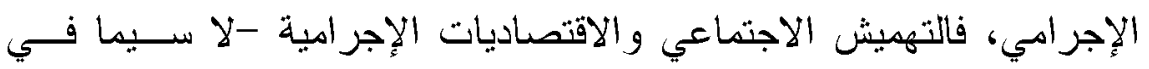

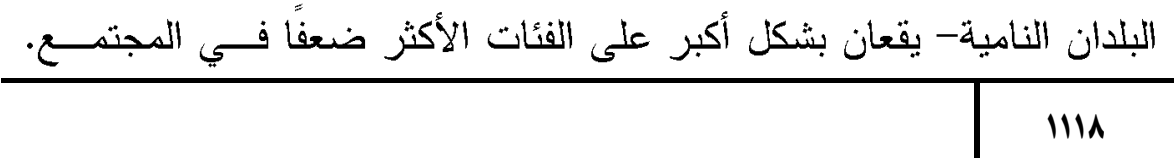


و التى يمكن استغلالها من فبل مجموعات الجريمة المنظمة لجني الأرباح من التهائ

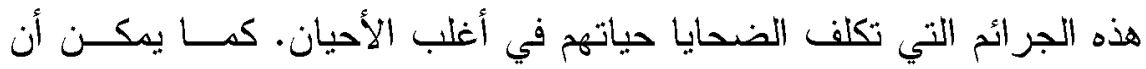
يكتسب المر \& عند إصابته بمرض هعين"وصمة" اجتماعية أى يتم فصل الفرد

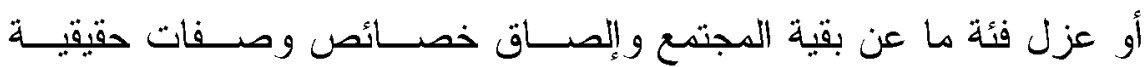

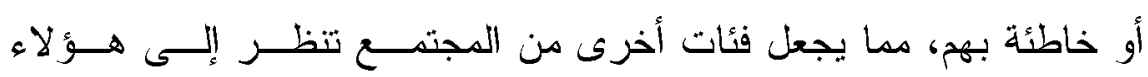
الموصومين نظرة الثكك والعداء، فتدفعهم لطريق الجريمة.

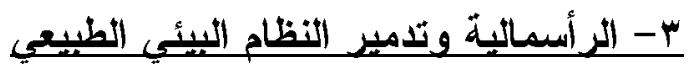

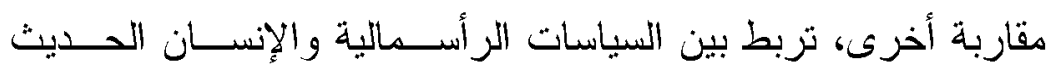

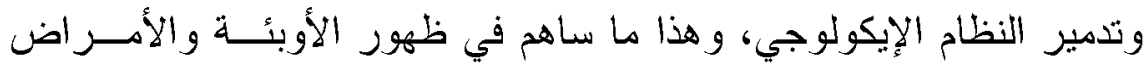

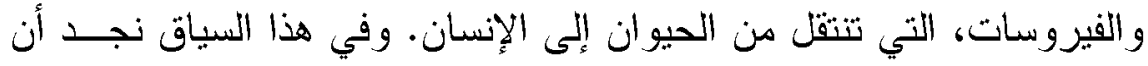

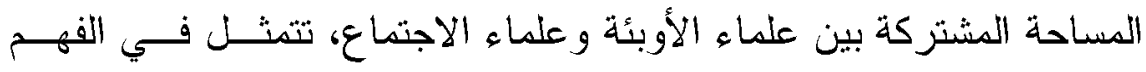

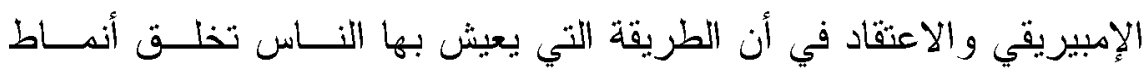

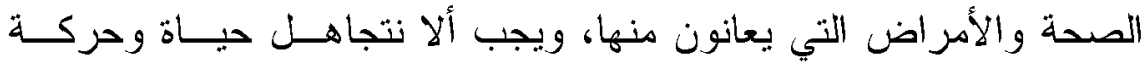

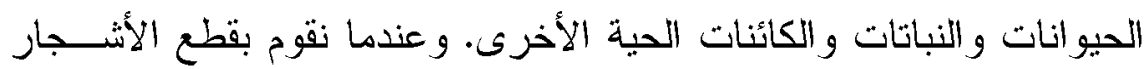

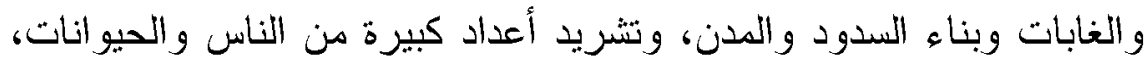
فإننا ندمر النظم الطبيعية للبيئة المستقرة. و عندما نجعل البشر على اتلى اتصــال

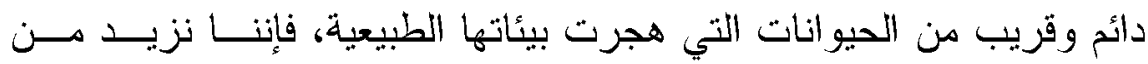

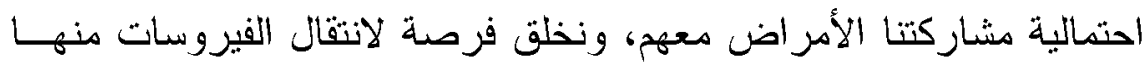

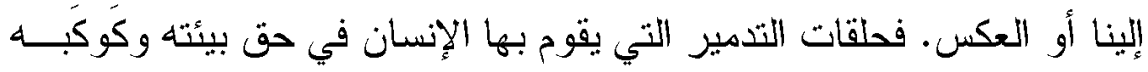

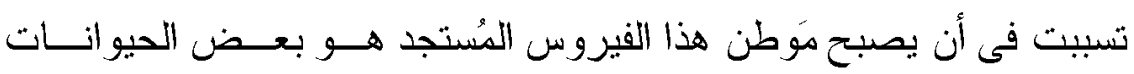

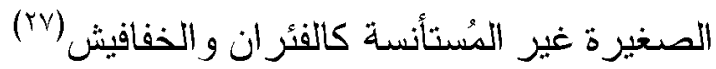

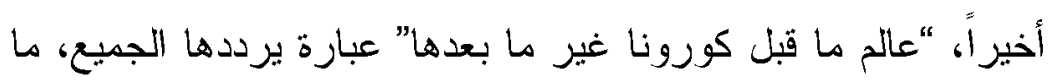

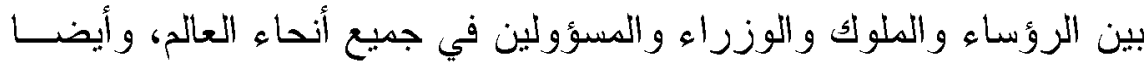

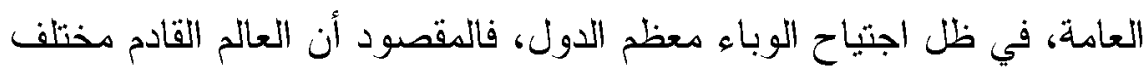

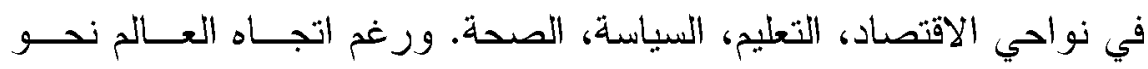

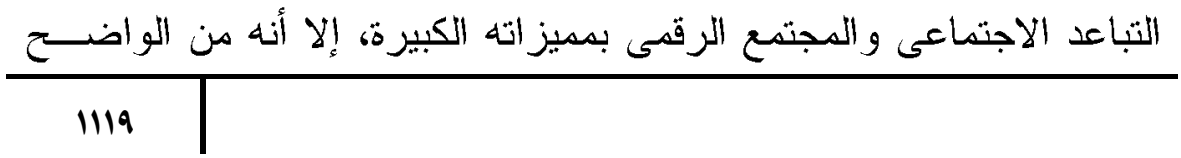


أيضا، أن هناك الكثير هن التداعيات السلبية التى فتحت الباب أهـام عـالم الجريمة والاحتيال بشكل مختلف تماها، حيث باتت الجريمة الإلكترونية في المواجهة، ويبدو أن المستقبل لها بعد مرحلة الوباء دقارنة بالجرائم التقليدية

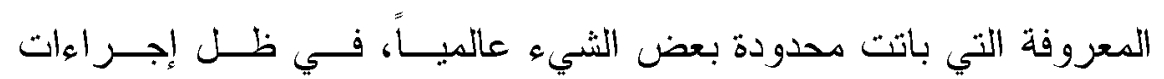
احترازية اتخذتها شتى بلدان العالم لمكافحة تفشي وانتقال الفيروس. بوان وأصبح

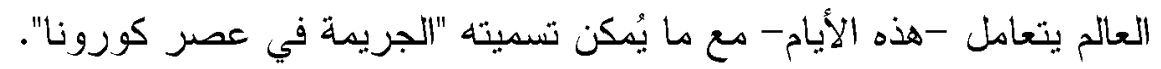

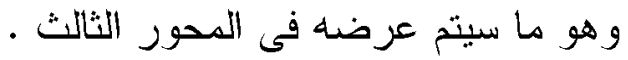
المحور الثالث : الجريمة في زمن جائمة فئحة الكورونا..... الواقع والمستقبل 1- مقدمة

رصدت منظمة الثرطة الجنائية الدولية "الإنتربول" فـى تقريرهــا،

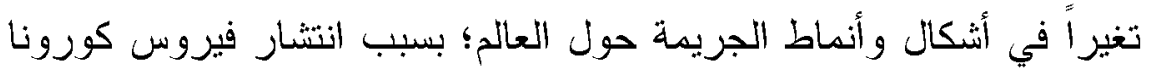

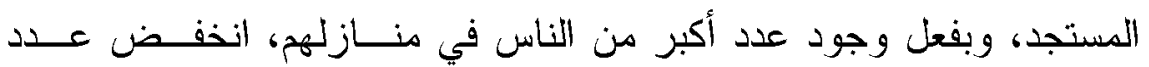

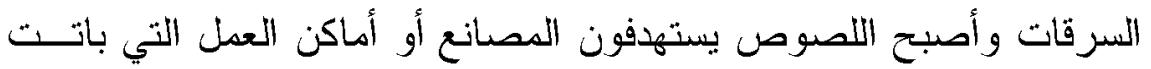

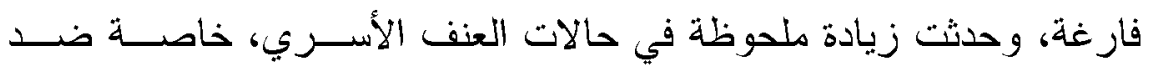

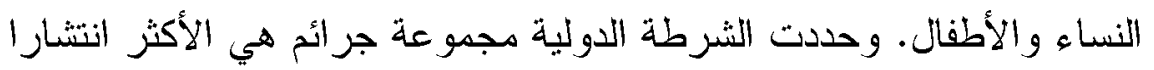
حول العالم بعد تفني فيروس كورونا المستجد، وهي: (الجرائم السيبر انية جر ائم استهداف مقدمي الخدمات الصحية - الاتجار في دعدات مزيفة للوقاية

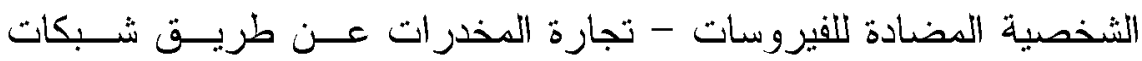
التو اصل الاجتماعي) (r^r). ويتضح ذلك من خلادل عرض الإحصاءات الدالة على ذلك:

\section{r - إحصاءات الجريمة أتناء جائحة كورونيا}

تراجعت معدلات ارتكاب الجرائم في جميع أنحاء العالم مع ظهــور

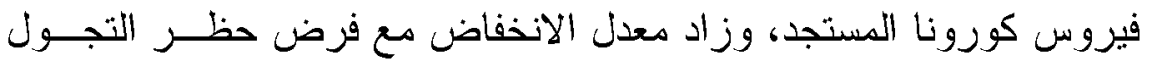

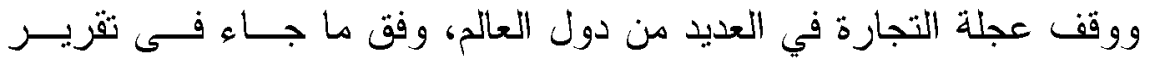

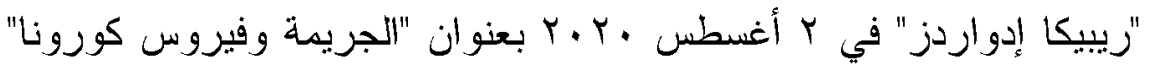

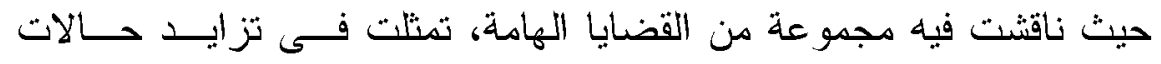


الإصابة داخل الولايات المتحدة الأكريكية، بالإضافة إلى حالة الجدل المثارة

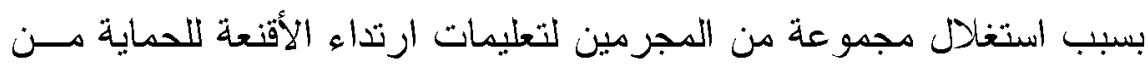

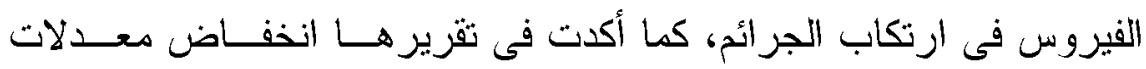

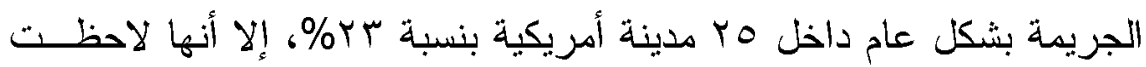

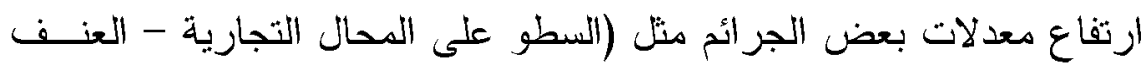

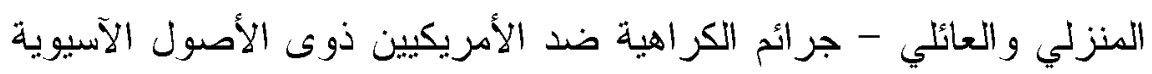

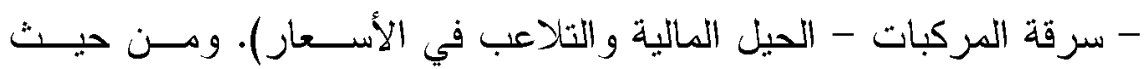

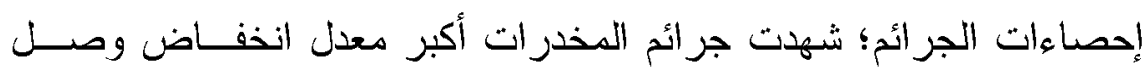
لأكثر هن با7\% مقارنة بالسنو ات الخمس الماضية، و انخفضت كل هن جرائم

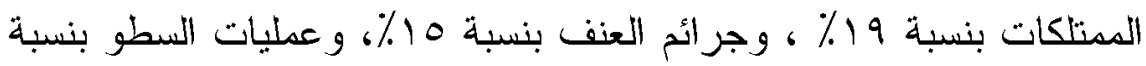

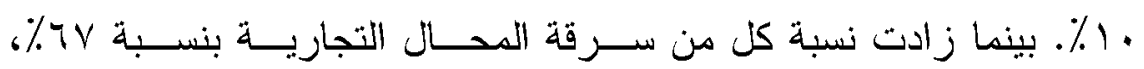

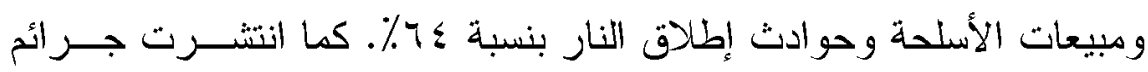

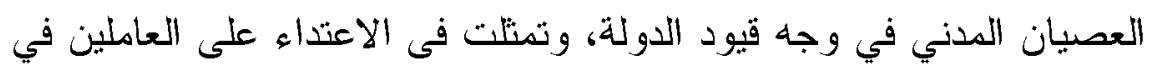

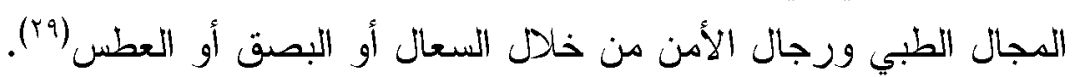

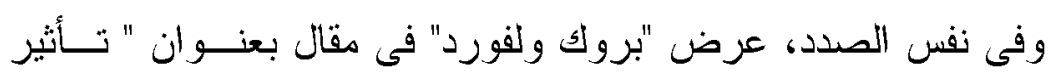

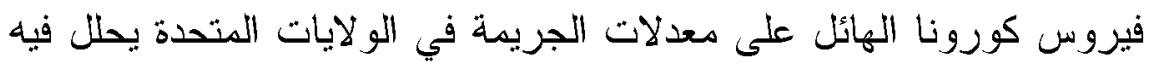

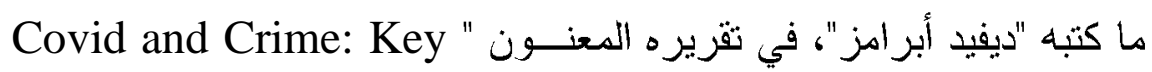
Findings الإغلاق التى تزامنت دع فيروس كورونا، في جميع الددن التي نم دراستها

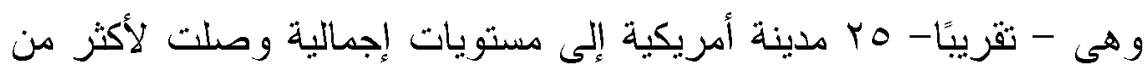
بr\% أقل من متوسط الفترة الزمنية نفسها في السنوات الخمس الماضـيـية".

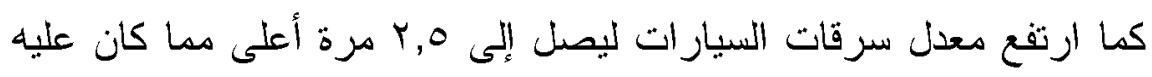

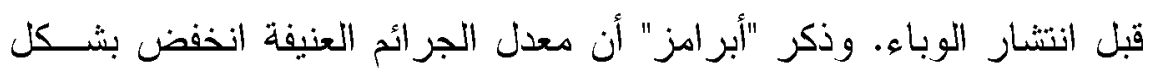

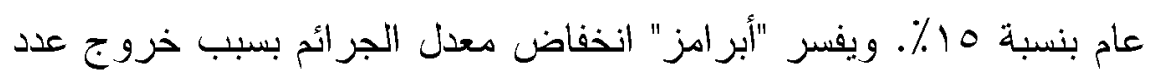

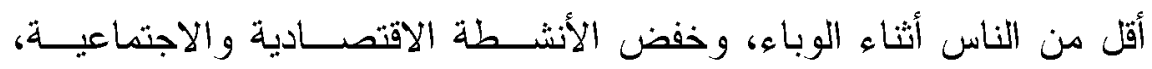
و التوقف عن الذهاب إلى العمل، وقيادة السيارت، و التجــول فـي المدينــة. 
وفسر الارتفاع فى دعدل جرائم الاعتداء على المحلات التجارية، بأنه بينما

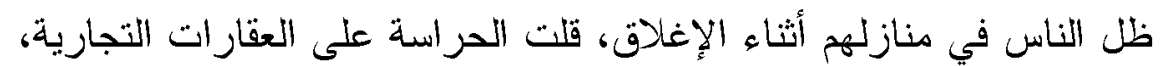

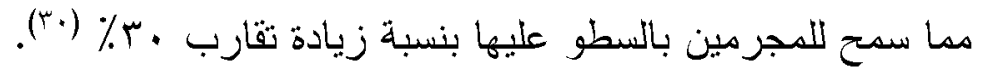

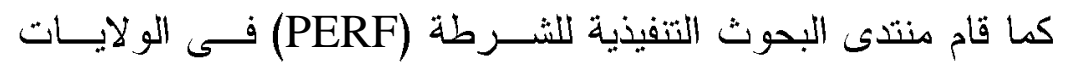

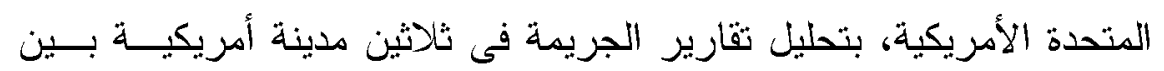

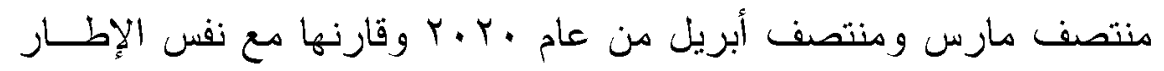

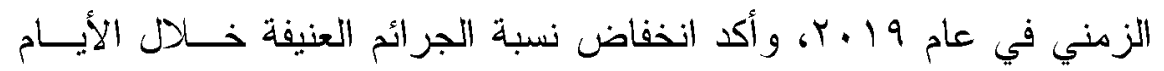

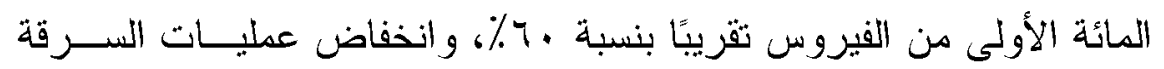

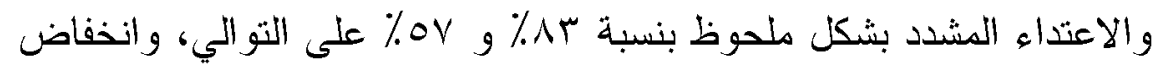

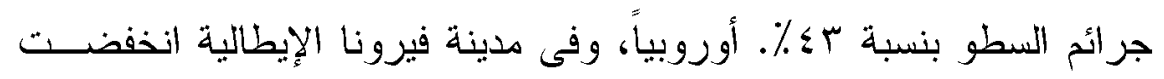

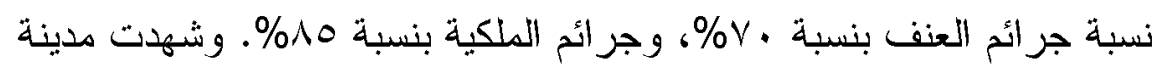

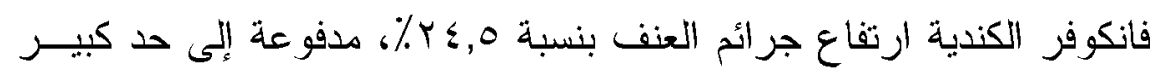

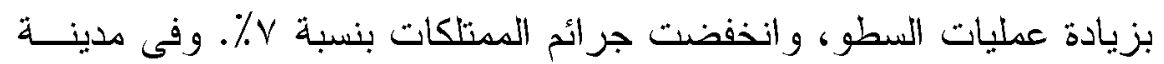

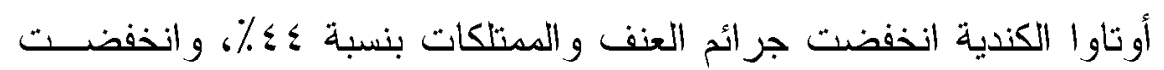

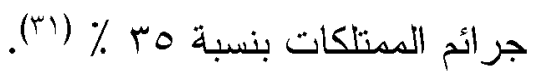

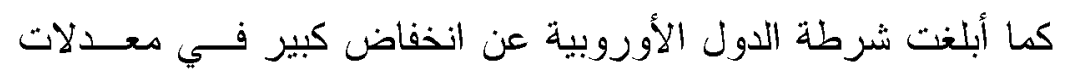

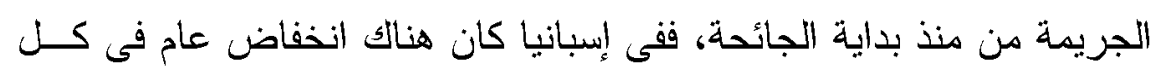

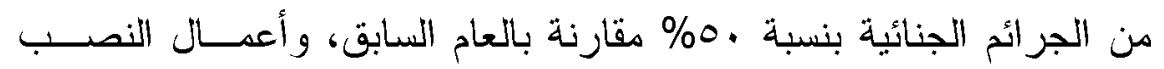

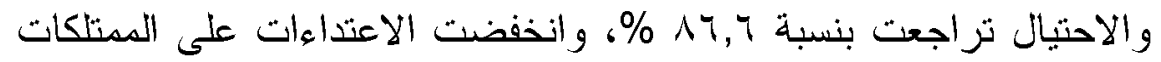

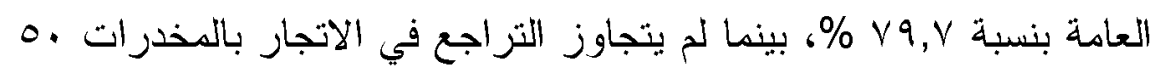

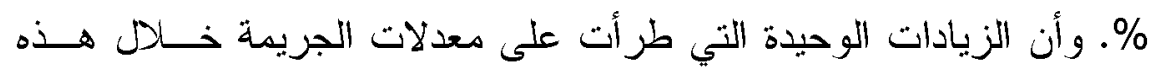

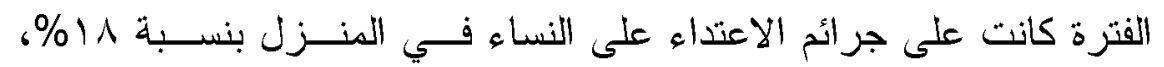

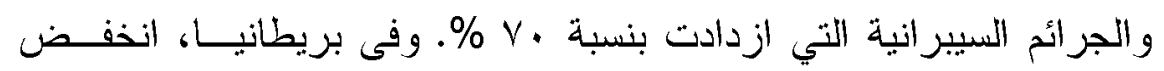

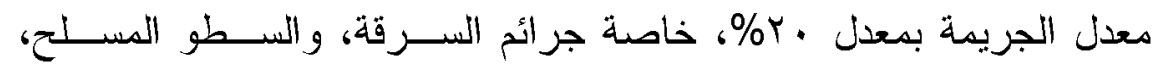

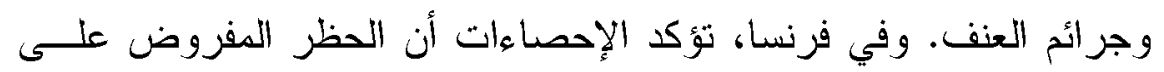

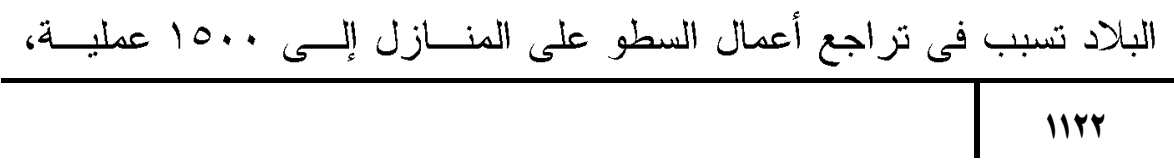




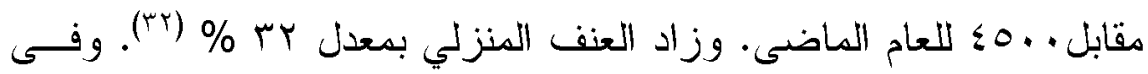

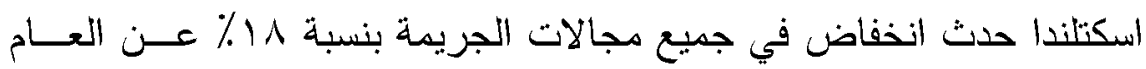

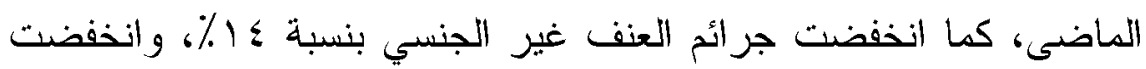

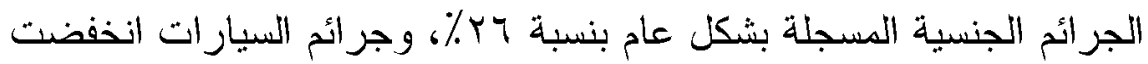
بنسبة r \% وفى أمريكا الوسطى والجنوبية، انخفض معدل الجر ائم بشكل عــام،

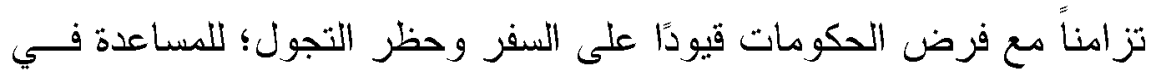

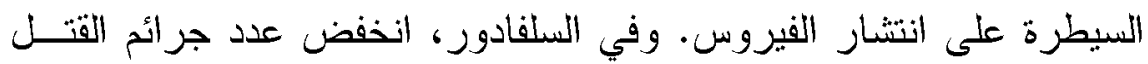

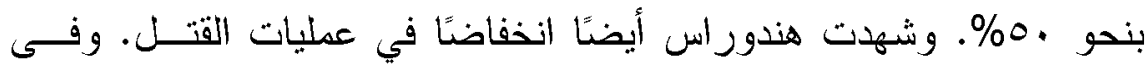

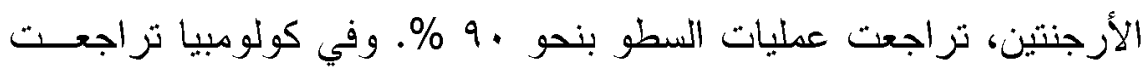

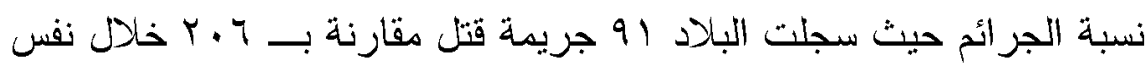

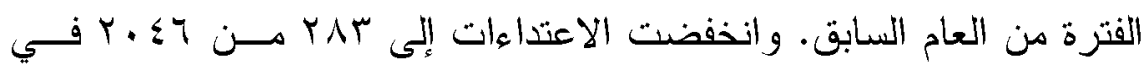

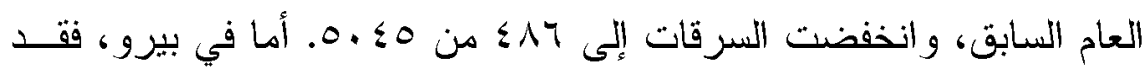

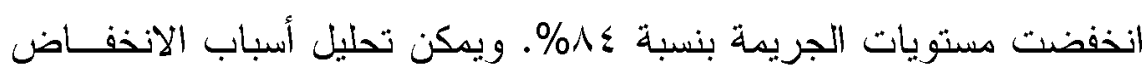

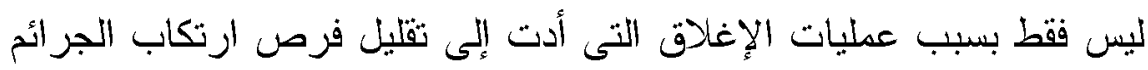

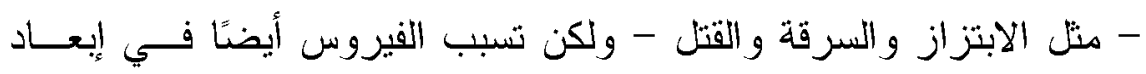

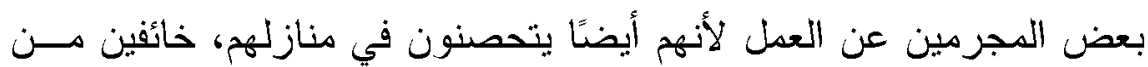

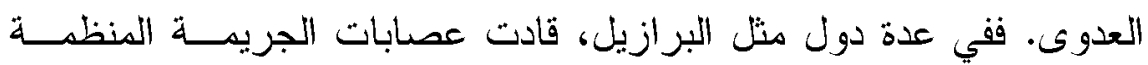

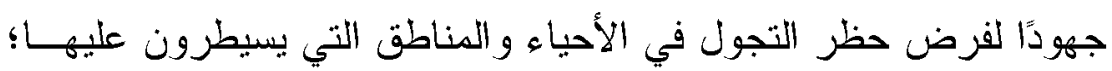

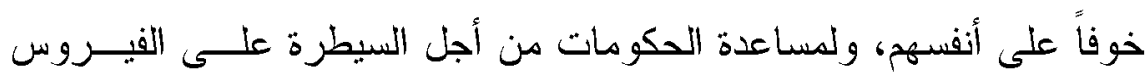
حتى يعودوا إلى نشاطهم سريعا (عَّ). عربياً، حالة دن التباين شهدتها بعض الدول، حيث تراجعت جــــــائم

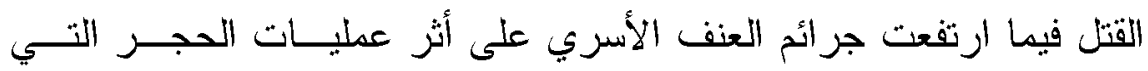
فرضت في بعض الدول بشكل متفاوت. وفي دصر ارتفعت نســبة جـر ائم

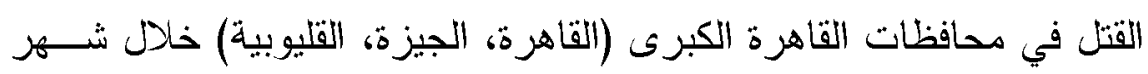

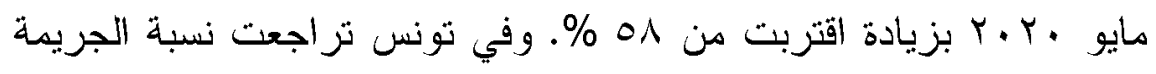




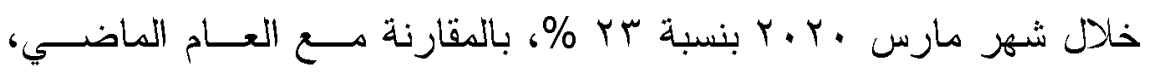

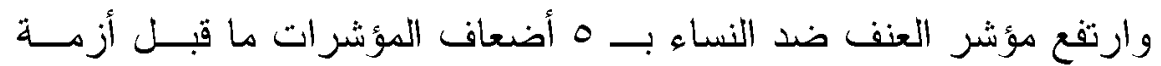

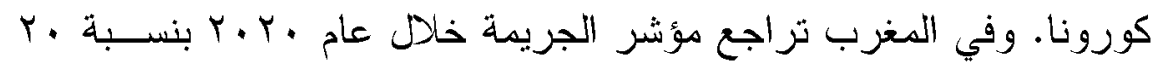

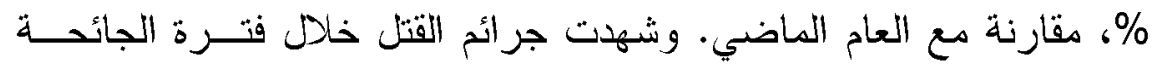

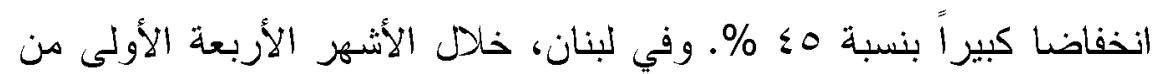

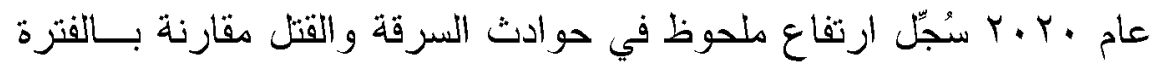

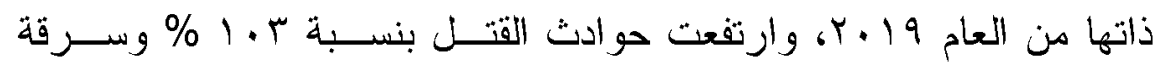

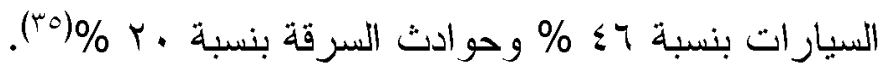
r- تغير ات البنية الاجتماعية والتحول في أنماط الجريمة كانعكاس للتباعد الاجتماعى والتحول نحو المجتمع الرقمى (تحيل الاحصاعات)

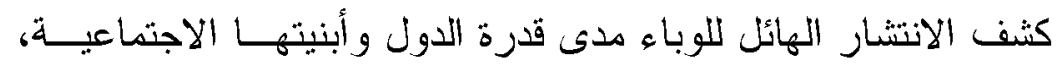

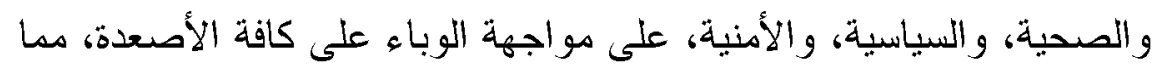

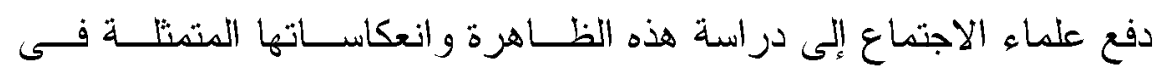

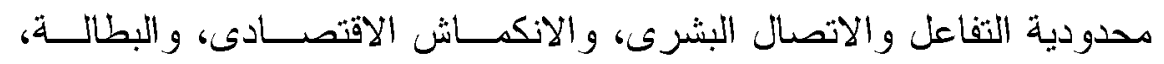
والعنف الأسرى، والتغير فى أنماط الجريمة. وتعتبر دعدلات الجرائم مؤشراً

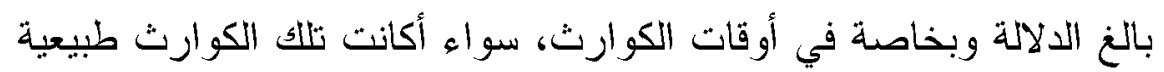

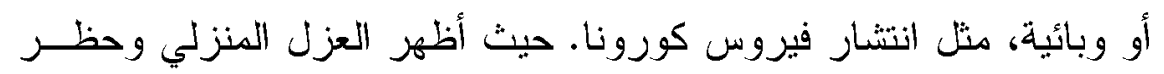

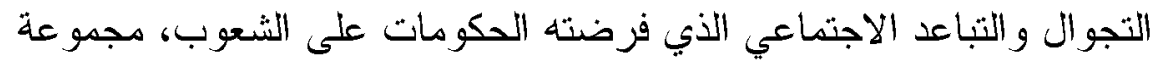

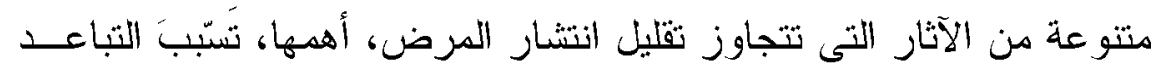

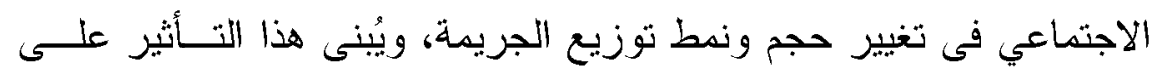

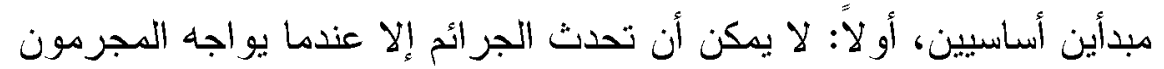

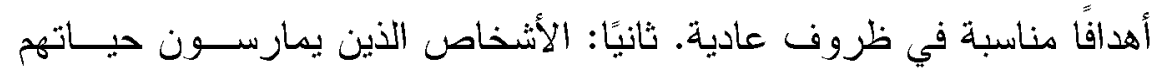

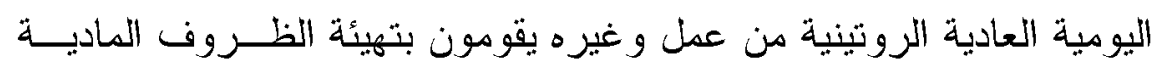

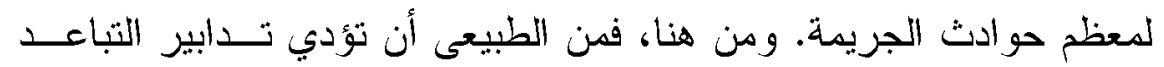

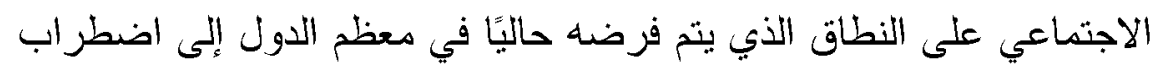


كبير في الروتين اليومي، مدا يؤدي إلى تغيير وتعطيل الظروف المادية التي

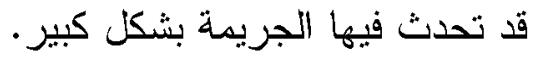

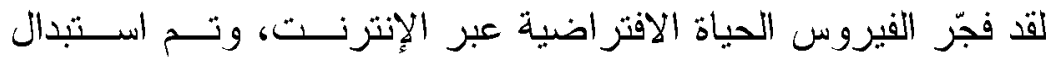

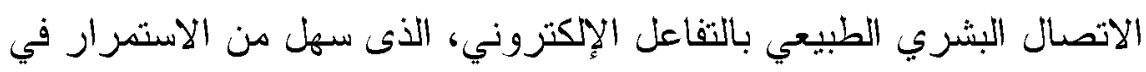

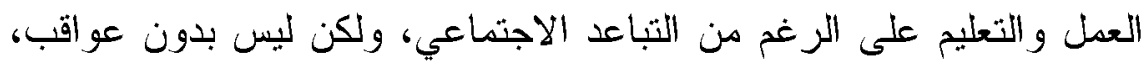

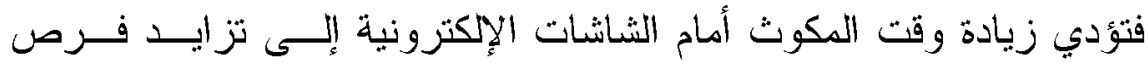

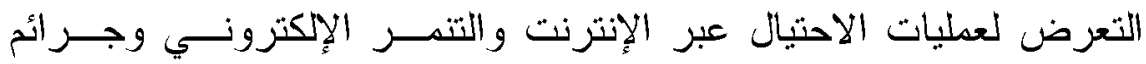
الكر اهية الخاصة بالفيروسات. وبالتالي، فإن التباعد الاجتماعي الهادف إلى الإلى

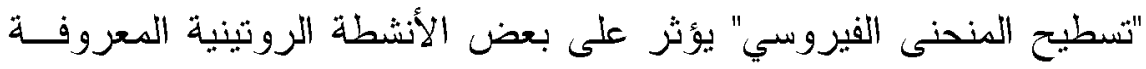

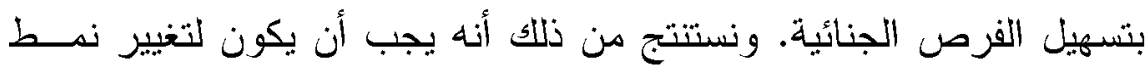

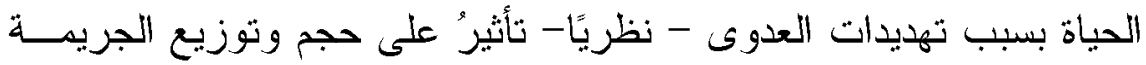

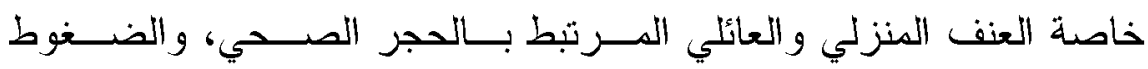

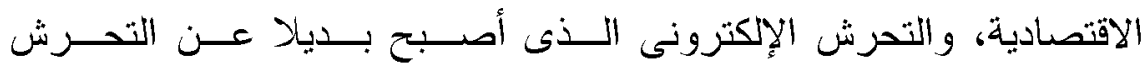

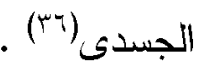

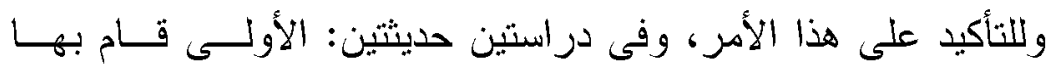
"جورج دو هليرا" بعنوان " تأثثر التباعد الاجتماعي أثناء جائحة - COVID

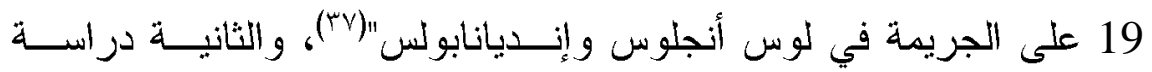

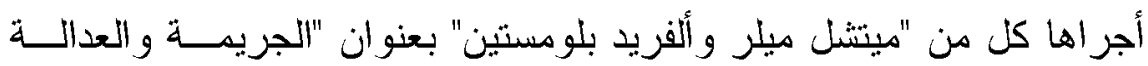

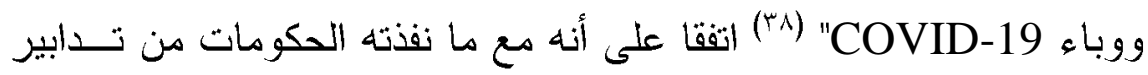

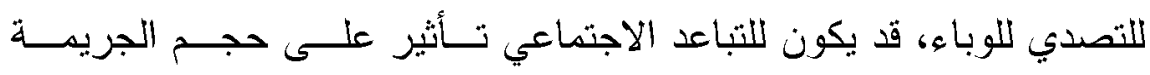

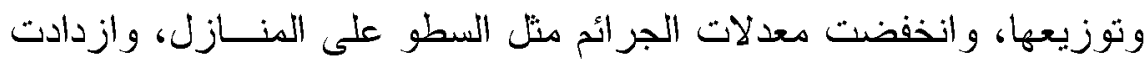
جرائم مثل العنف المنزلي، ويفسر ذللك أنه عادة ما تتم سرقة الثنازل نهاراً

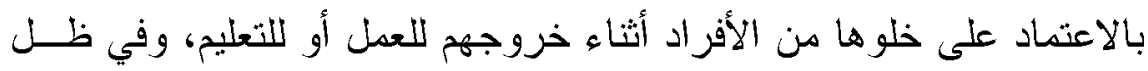

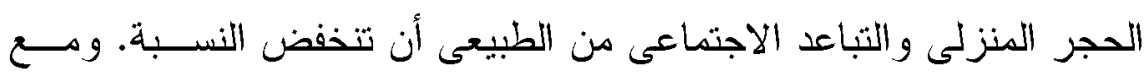

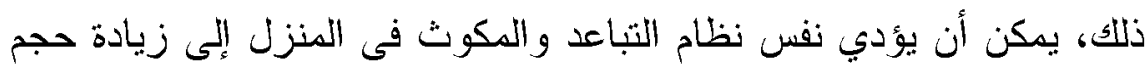
العنف المنزلي والعائلي، الذي يزدهر خلف الأبواب المغلقة، بسبب الضغطً 
الإضافي المتولا بين أفراد العائلة. ويمكن أن نخرج بنتيجة مؤداها أن روتين الحياة اليومية - دن هنظور نظرية الأنشطة الروتينية - هو الذي يتحكم فى الهى

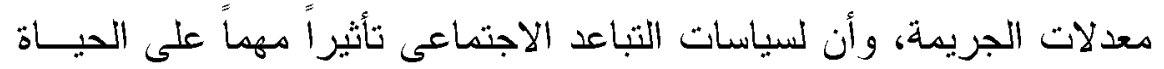

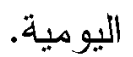

كما بدأ مجرمو الإنترنت في استغلال المخاوف حول COVID-19

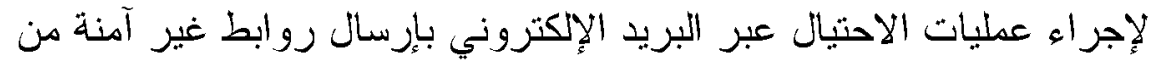

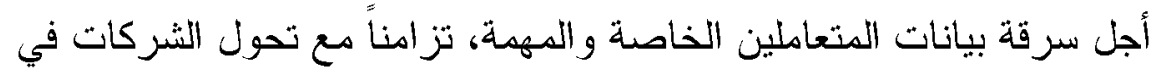

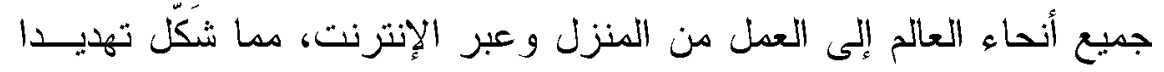

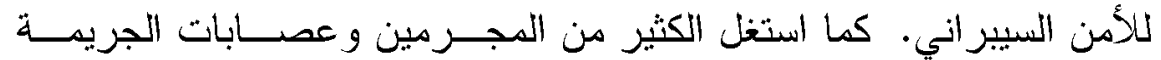
المنظمة organized crime حالة الطوارئ العالمية بسبب جائحة كورونا؛

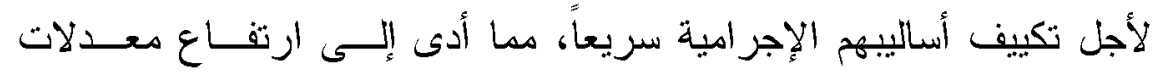

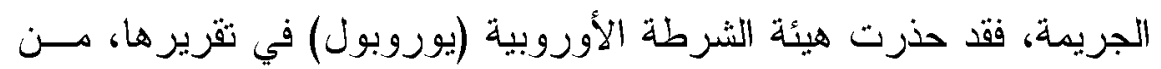

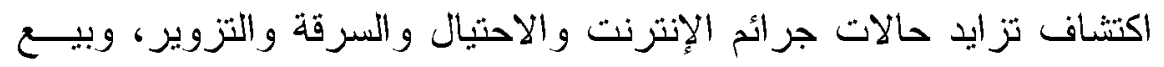

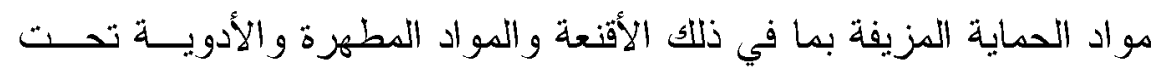

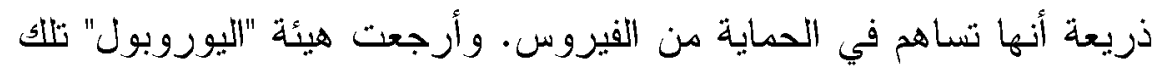

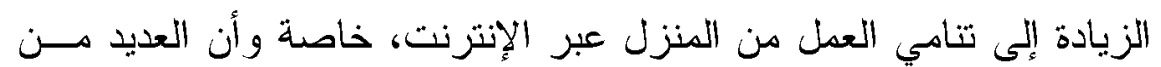

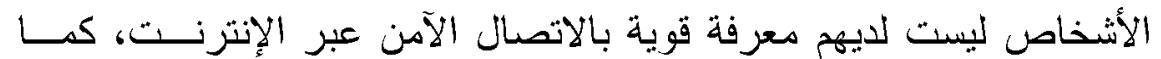

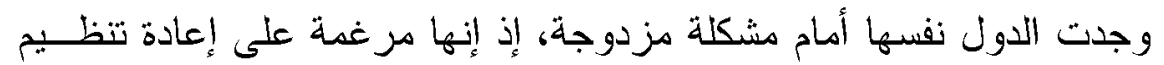

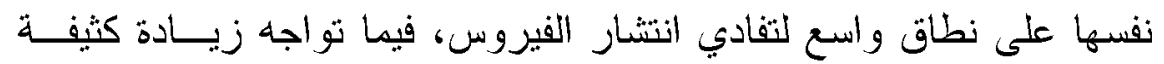

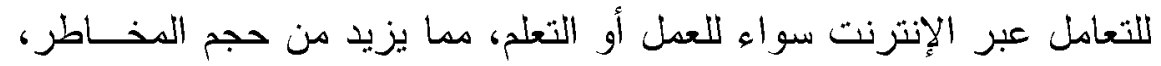

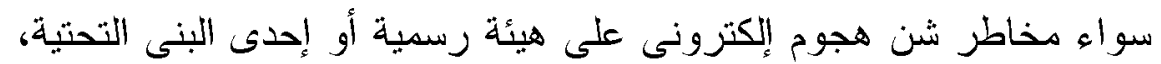

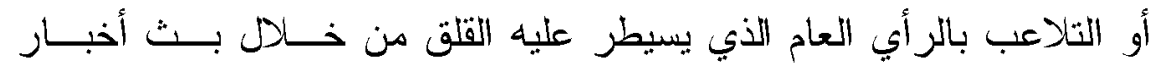

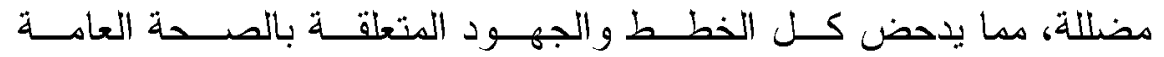

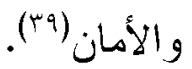

وفى هحاولة للتنبؤ ووضع سيناريو هات كستقبلية حول تأثير جائحســة COVID-19 


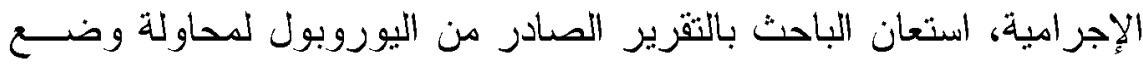

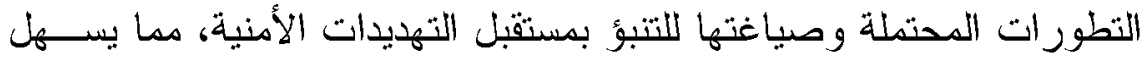
مكافحتها بشكل استباقي. حيث يرتبط الكثير هن النشــاط الإجز ائسي أنثـاء

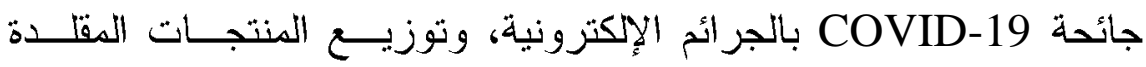

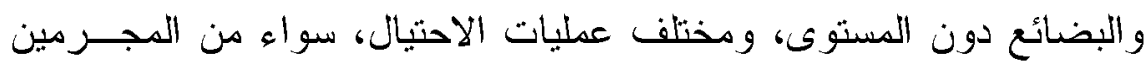

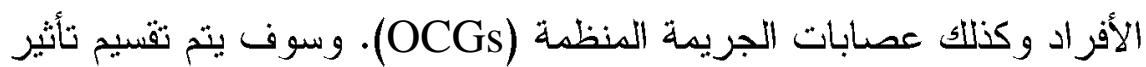

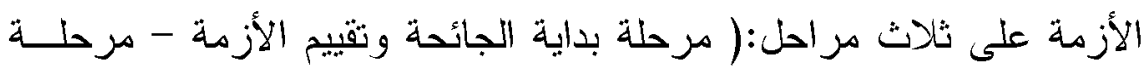

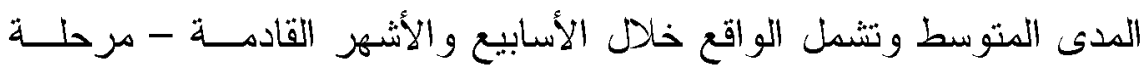
المدى الطويل وتتشل المستقبل البعيد).

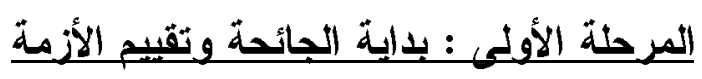

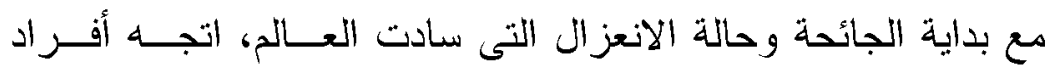
المجتمعات إلى هنصات الإنترنت والمجتمع الرقمى، ويتضح ذلك من خلال

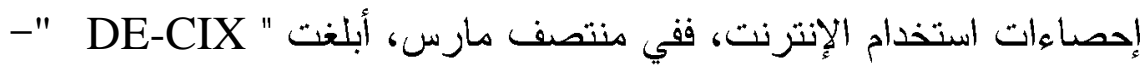

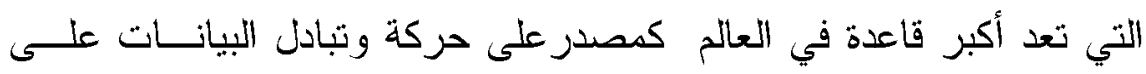

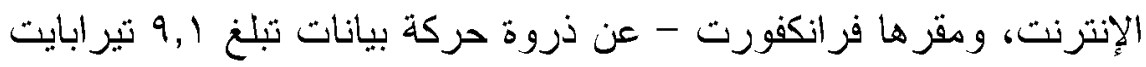
في الثانية ـ ويعتبر هذا المستوى القياسي هو القفزة الأكبر في حركة البيانات

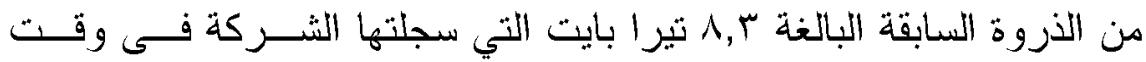

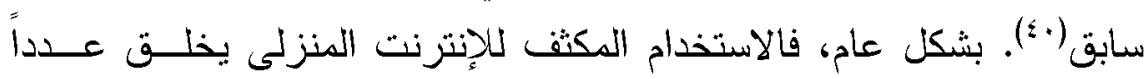

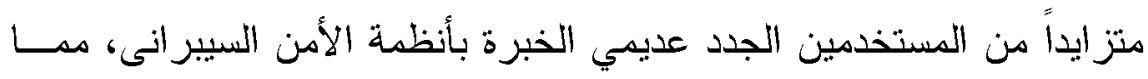
يتيح المزيد من الفرص للأنشطة الخبيثة و الجهات الإجر امية لاستغلال ذلك.

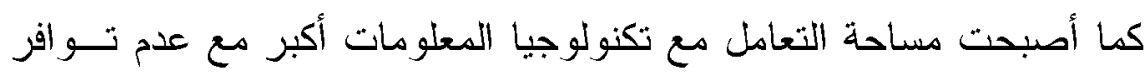

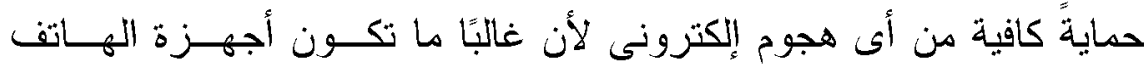

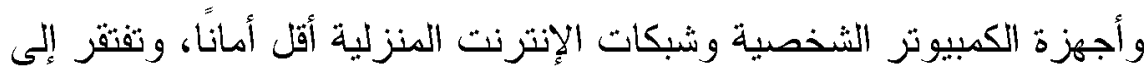

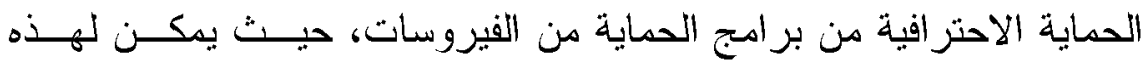

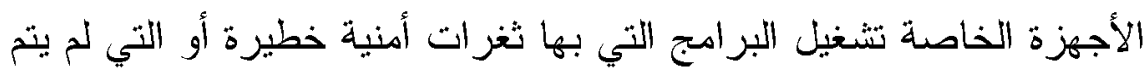

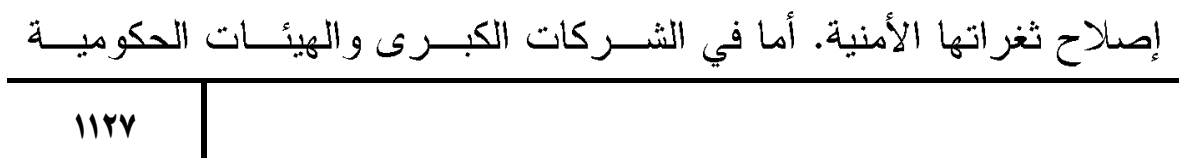


والمنظمات يكون الوضع مختلفا، فعادة ما تتمتع أنظمة تكنولوجيا المعلومات

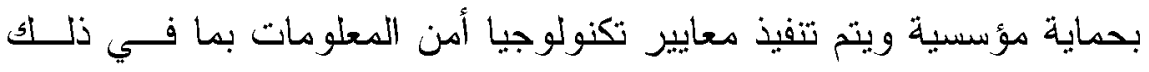
الإجر اءات المناسبة والبرهجيات، وتثبيت تحديثات الثركة المصنعة لحماية

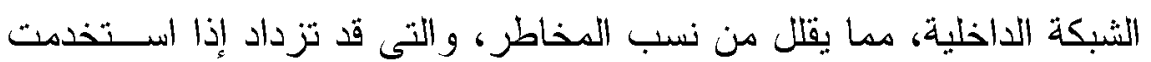

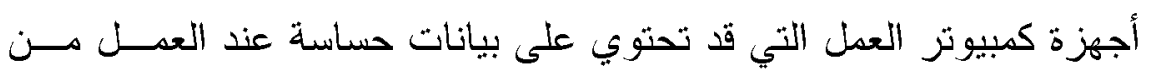

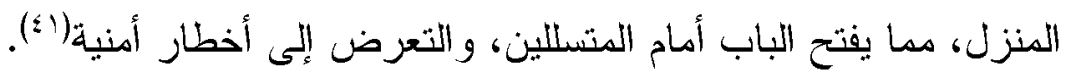

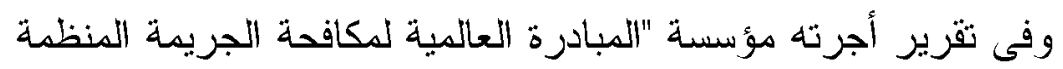
عبر الوطنية"(GI-TOC)، أكدت أن لجائحة COVID-19 تداعيات عميقة لهئة

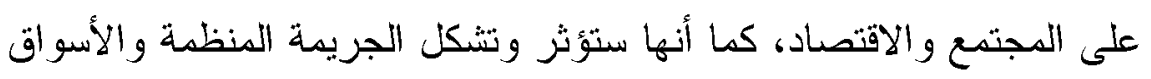

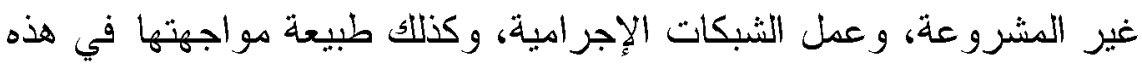

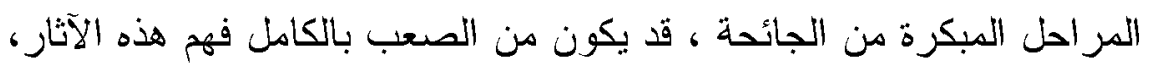

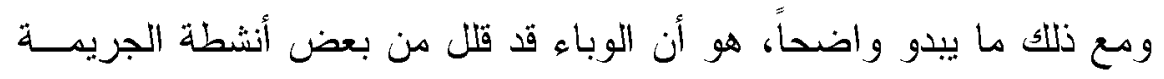

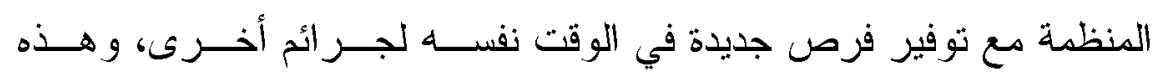

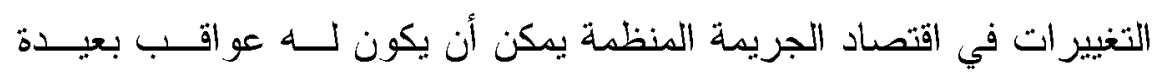

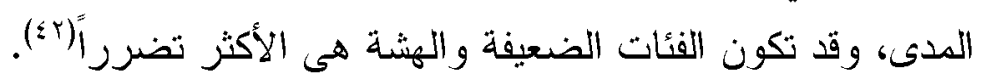

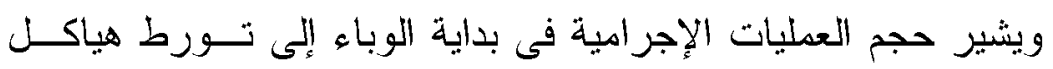

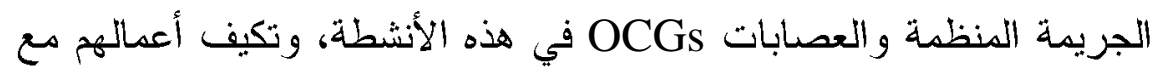
الجائحة، وتحولهم إلى أنشطة إجرامية جديدة للاستفادة من الفرص المتاحة،

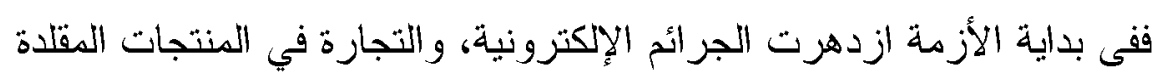
و البضائع دون المستوى المطلوب. وسنحاول هنا عرضها على التى النحو التالى:

\section{الجر ائم الإكترونية دون}

سارع دجرمو الإنترنت في ابتكار أساليب وأدوات لاســتغلال تيـار

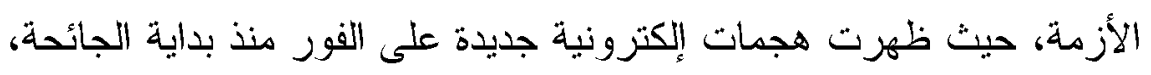

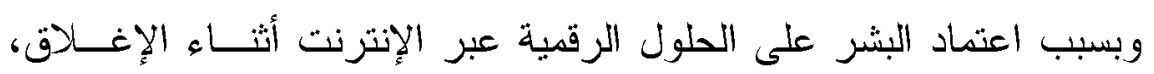

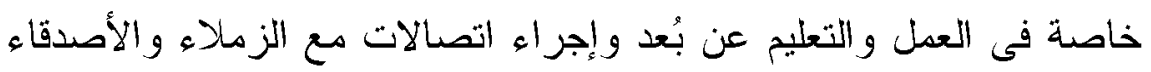

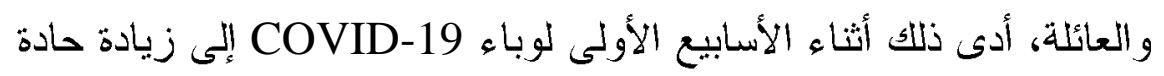


في جرائم الإنترنت المتعلقة بالجائحة. حتى طبيعــة التهديــدات بــالجرائم

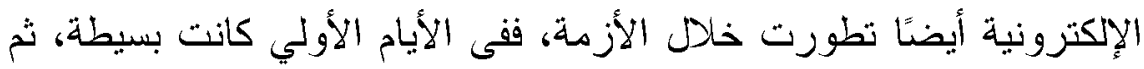

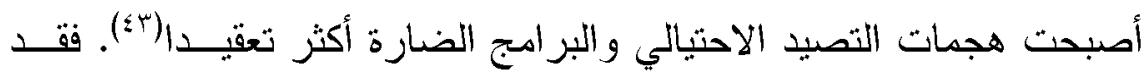

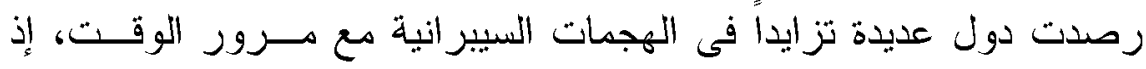

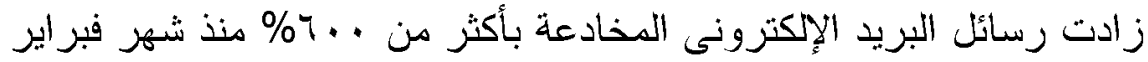

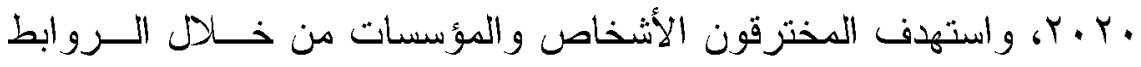

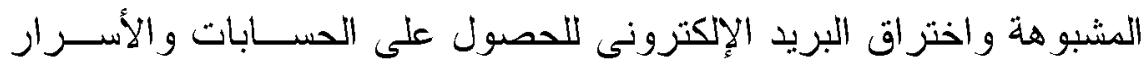

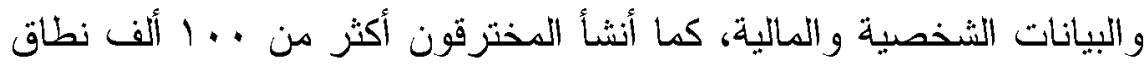

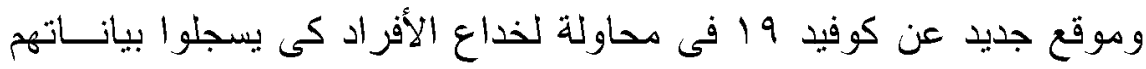
الشخصية ثم يستولوا عليها. تطور آخر مثير للقلق تمثل فى زيادة الأنشطة

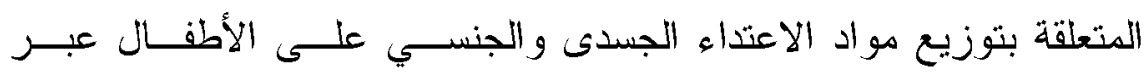

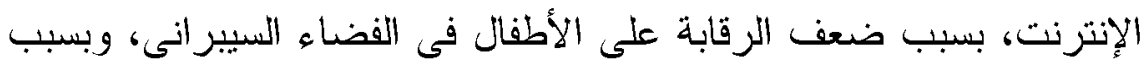

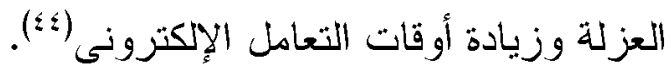
وفى تقريز أصدره مكتــب التحقيةـــات الفيــدر الي للأكسـن القــوهي الأمريكى، جاء فيه أن هع انتقال التعليم والعمل والعديد من جوانب الحيــاة

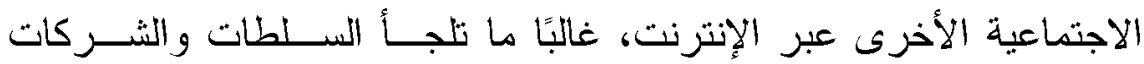

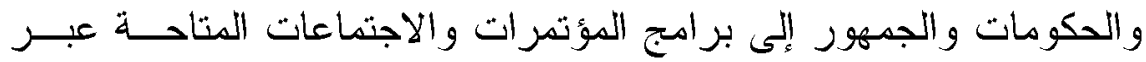
الهاتف، لصعوبة عقد الاجتماعات المادية في وقت الجائحة، وبينما تســاعد

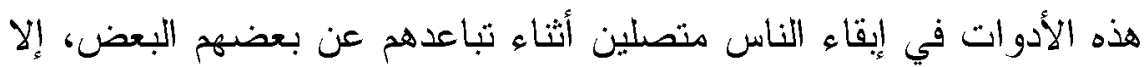

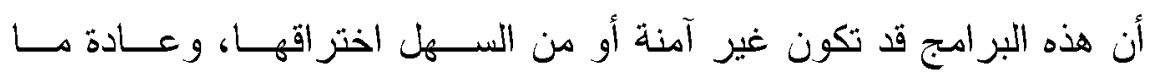
يستهدف بالأخص برنامج Zoom لأن الاعلان عن الاجتماعات و التجمعات

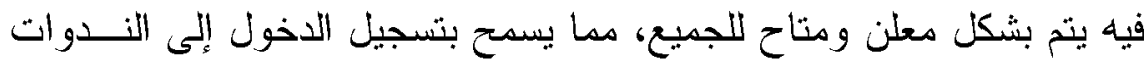

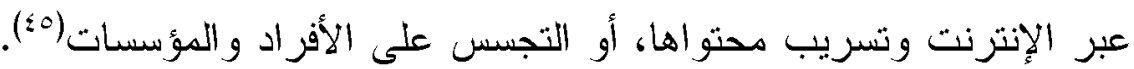

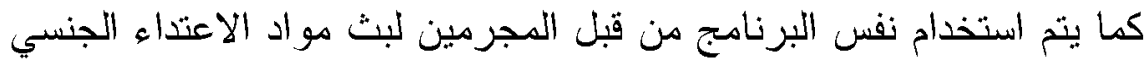

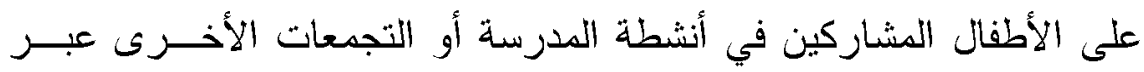

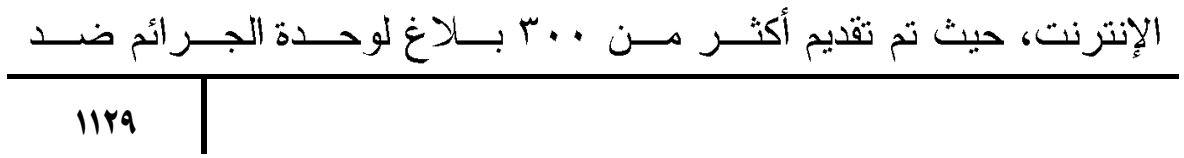




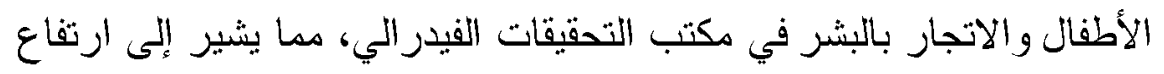

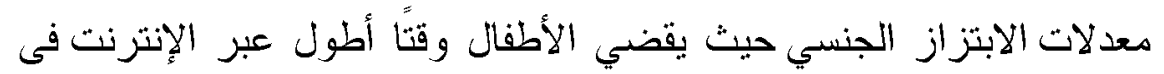

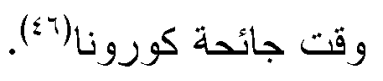

وفى هقال كتبه "يو هانس ويجين " بعنوان "تأثير COVID-19 عانه

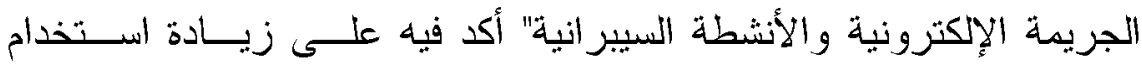

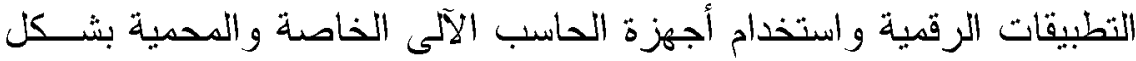
ضعيف وسئُ عند العهل من المنزل، دما يعرضها إلى اختراق المكالمــات

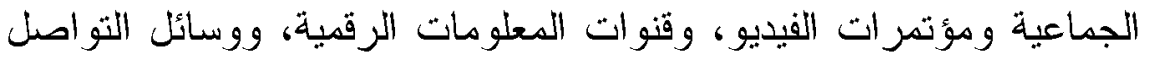

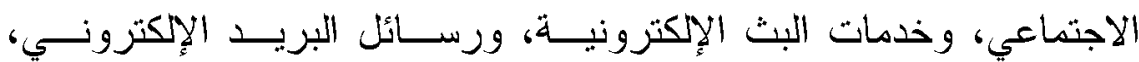

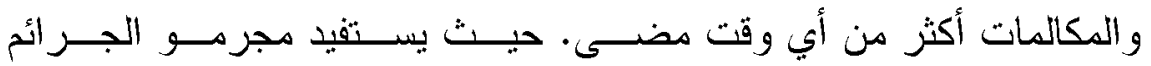

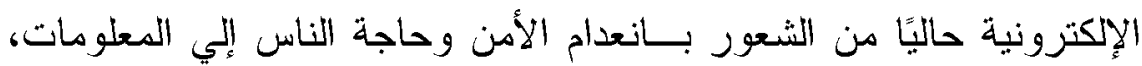

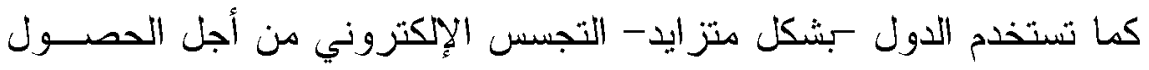

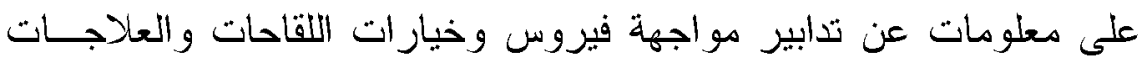

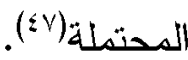

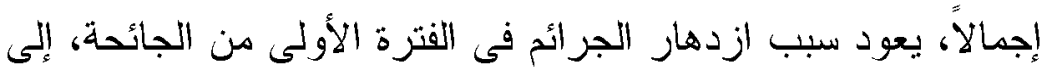

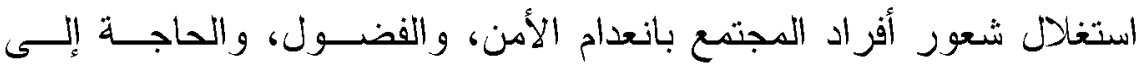

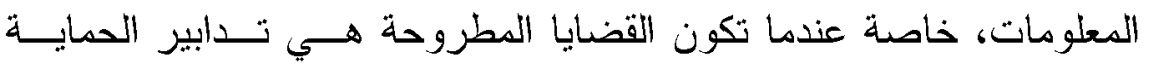
وطرق العلاج المزعومة، أو التطعيم أو الإحصاءات الخاصـــة بالمصــابين

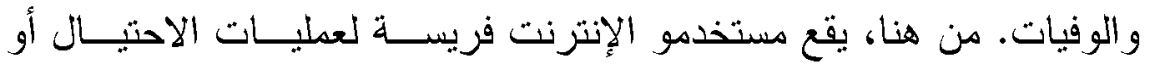

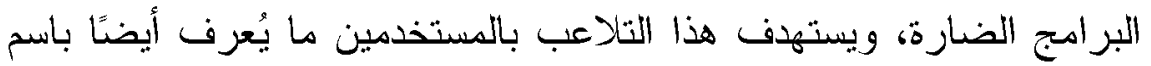

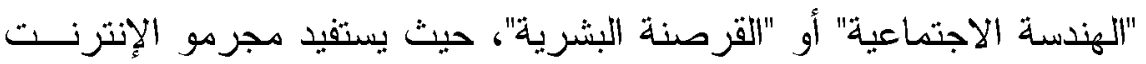

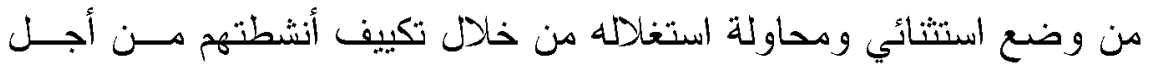

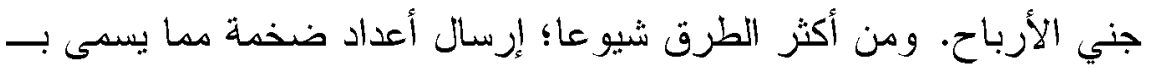

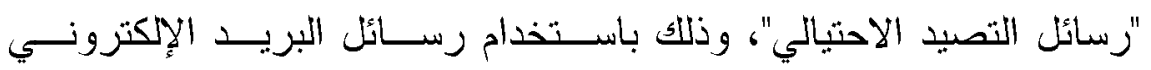
المزورة، وتقديم ذريعة مزيفة لجعلها تبدو ذات مصــداقية قـدر الإمكــان

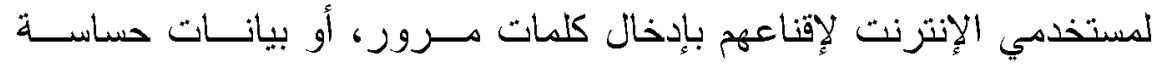




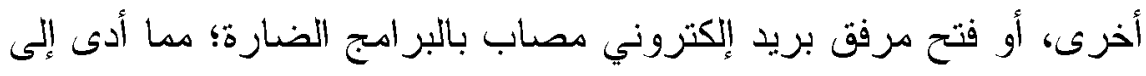

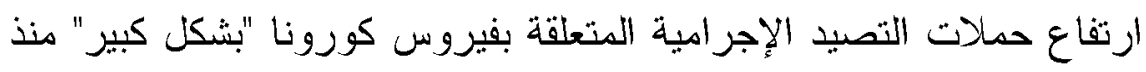

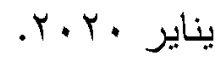

\section{جرائم قطاع الصحة وتجارة الأدوية والبلِّع المزيفة}

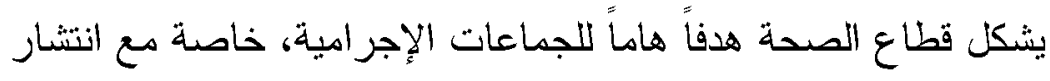

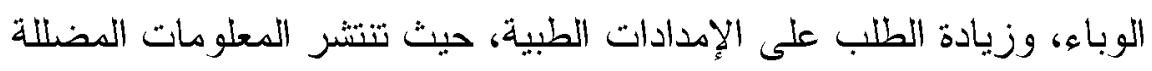

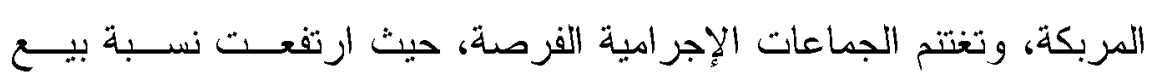

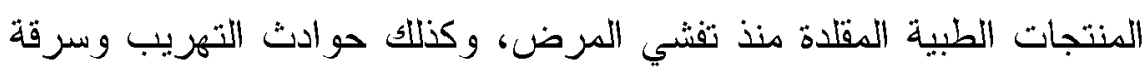

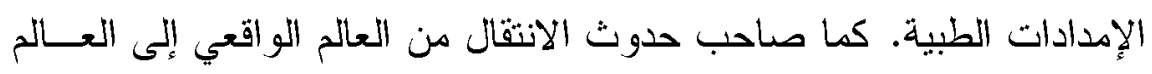

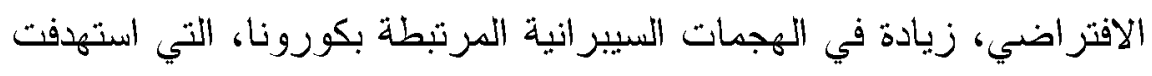

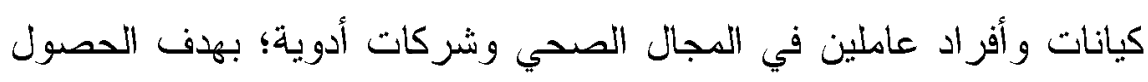

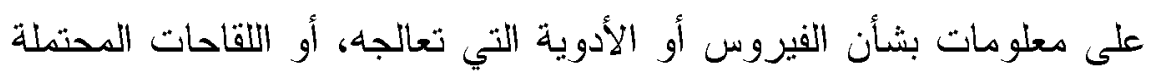

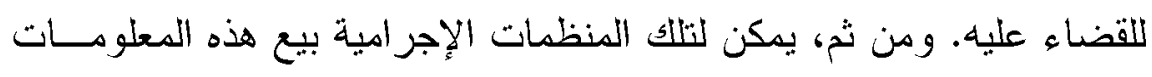

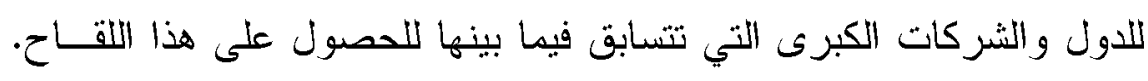

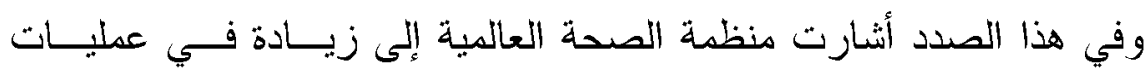

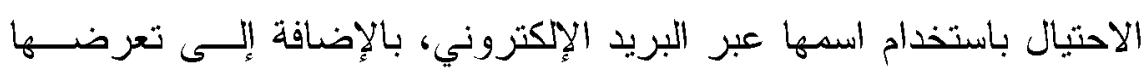

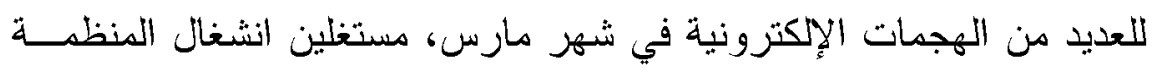
بمحاربة فيروس كورونا المستجد، واستهدفت الهجمات سرقة كلمات المرور لموظفي المنظمة (^)؛ ويدق خبراء أمن تكنولوجيا المعلومات ناقوس الخطر بثــأن زيــادة

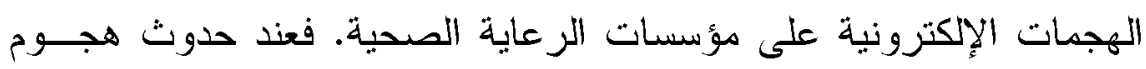

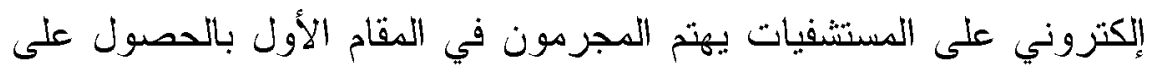

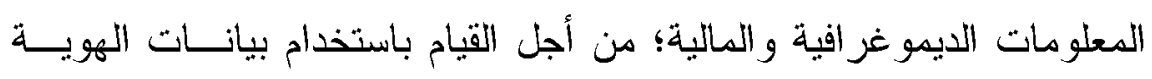

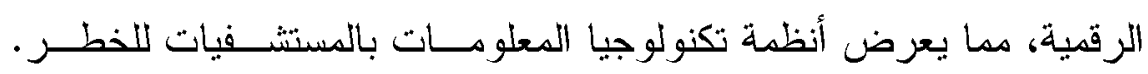

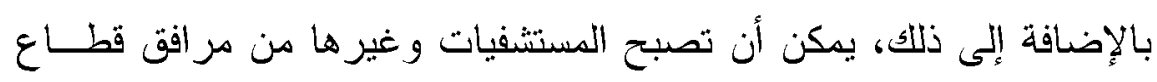

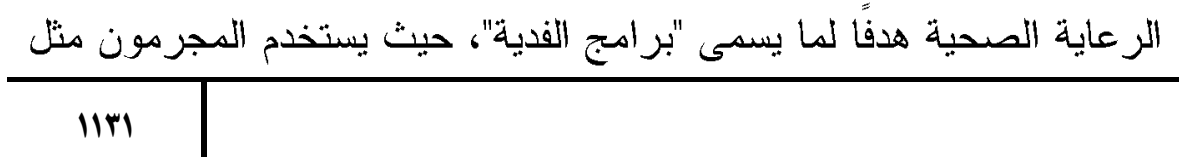


هذه البر امج الضارة لتشفير البيانات المخزنة لضحاياهم لابتزازهم بعد ذلك،

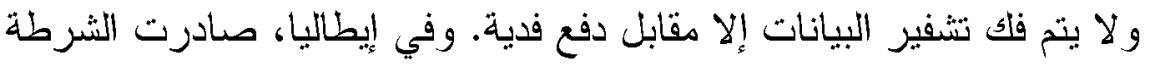

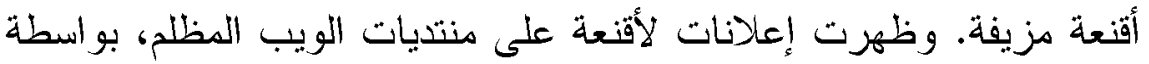

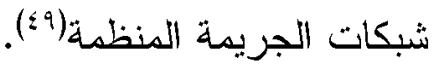
كما انتهز المجزمون الفرصة لاستغلال الطلب على الأدوية التي تقدم

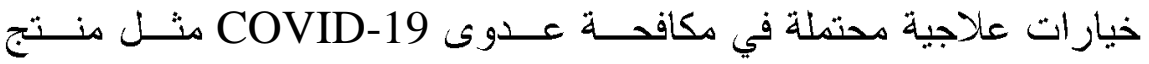

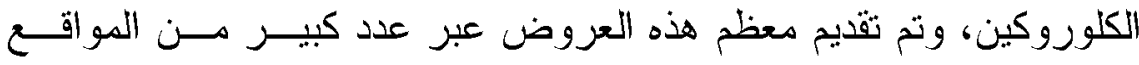

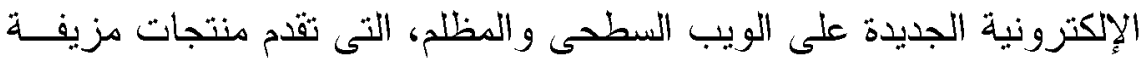

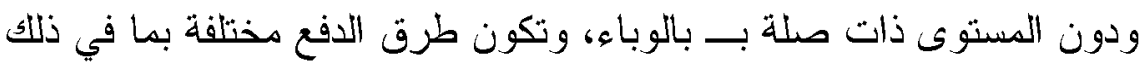

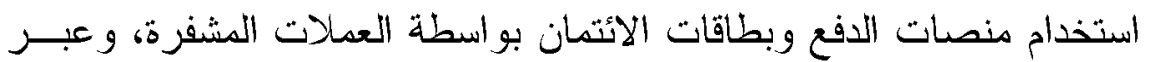

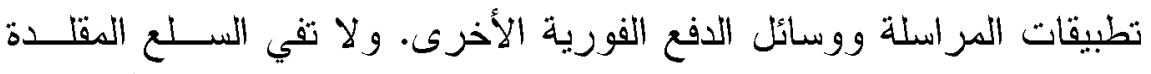

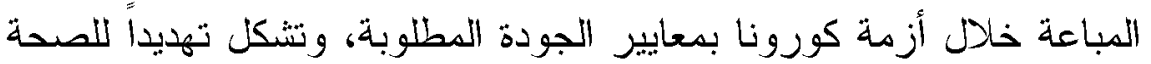

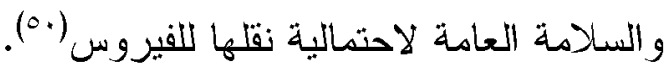
المرحلة الثانية : نظرة مستقبلية متوسطة المدىى

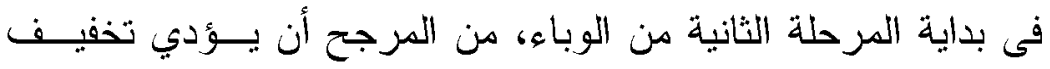
إجر اءات الإغلاق والقيود إلى عودة النشاط الإجر امي إلى دستو ياته السابقة

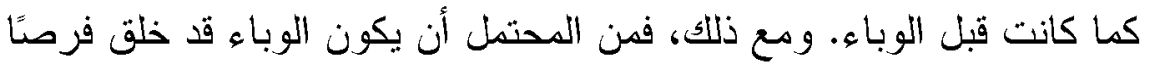
جديدة للأنشطة الإجر امية سوف تستمر خلاهل هذه المرحلة.

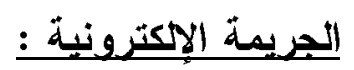

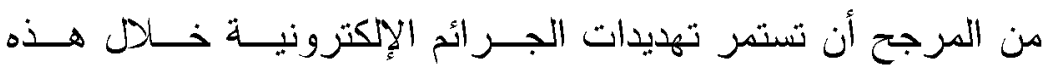

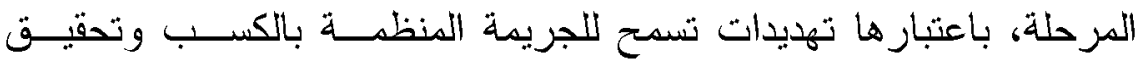

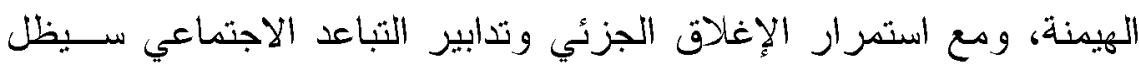

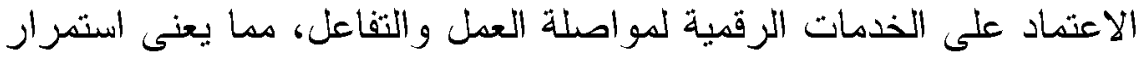
توزيع البرامج الضارة و الفيروسات التى تستهدف القطاعات الحيوية بشـــكل

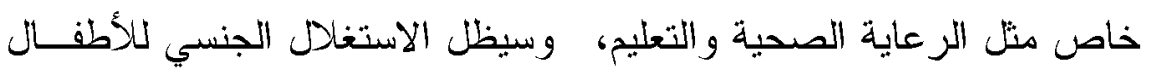

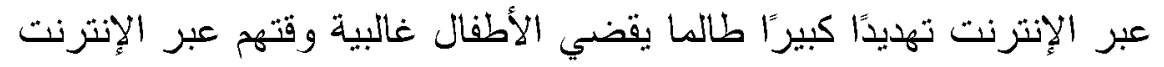




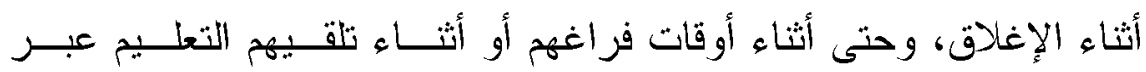
الانترنت (01)

وهع مرور الوقت، ستتحول عمليات الاحتيال الإلكترونية والمعلومات

المضللة و الجر ائم الإلكترونية إلى صناعة متتامية، متمثلة فى عمليات التصيد

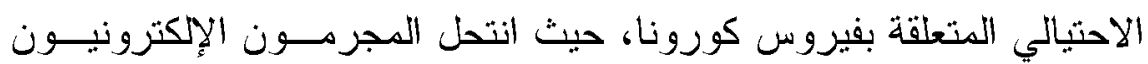

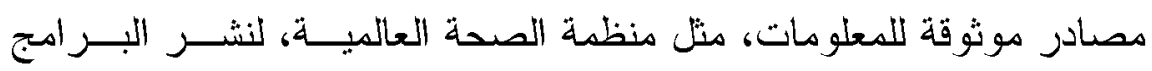

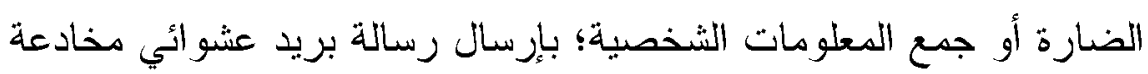

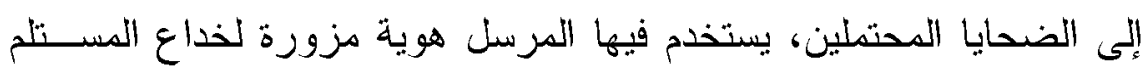

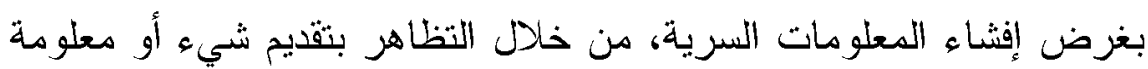

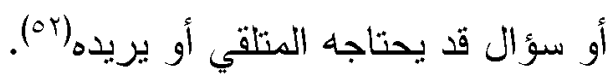

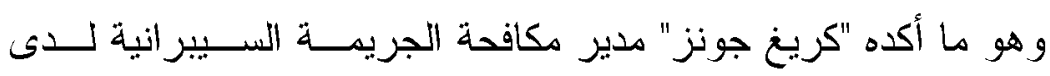

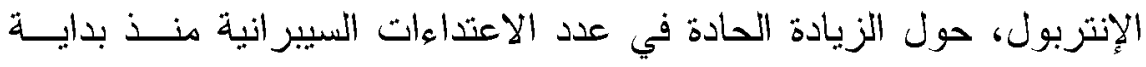

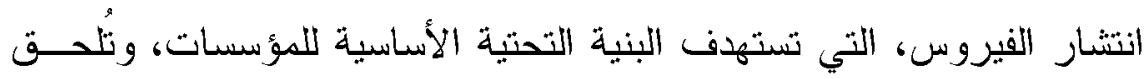

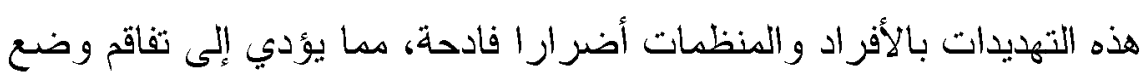

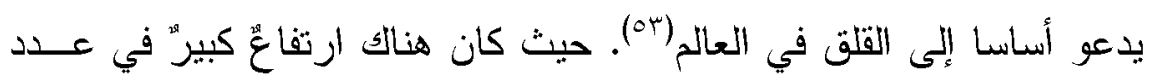

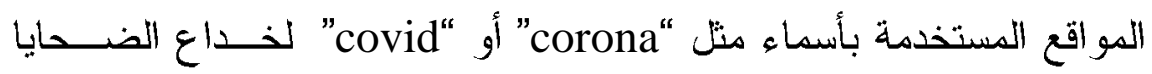

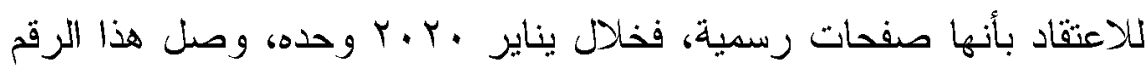

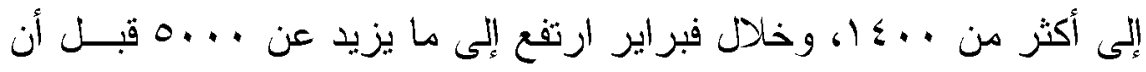

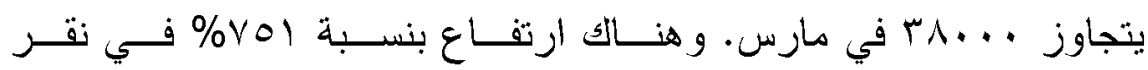

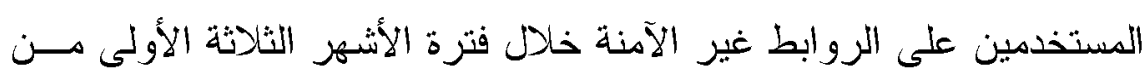

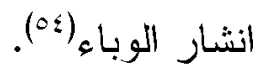

في ضوء هذه الأحداث، أصدر قسم الجرائم الإلكترونية في الإنتربول

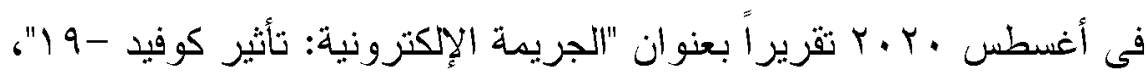

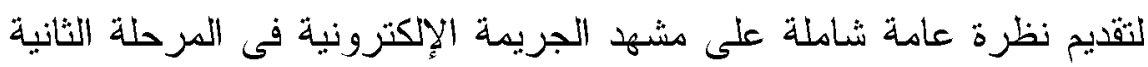
من الوباء. وأكد التقرير استمرار تأثير جائحة الفيروس التاجي غير المسبوق

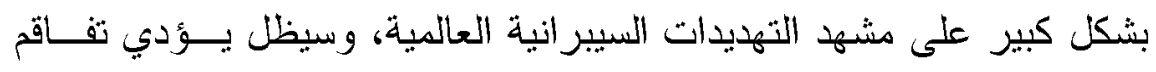


الأزمة الصحية العالمية مع الزيادة الحادة في أنشطة المجرمين الإلكترونيين المتعلقة بـ COVID-19 إلى وضع ضغط كبير لردير على حكوهات دول العالم.

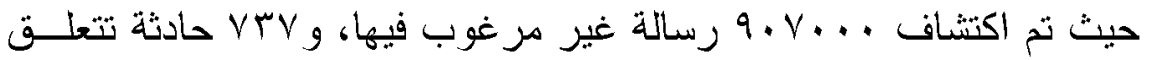

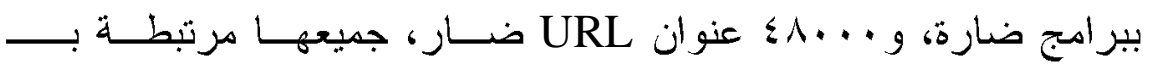
COVID-19 بين يناير و أبريل •r. +r. وسوف يتحول مجرمو الإنترنت

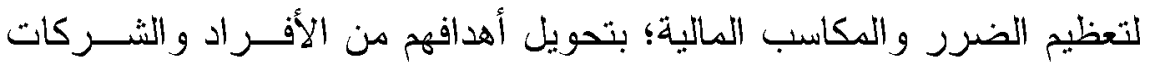

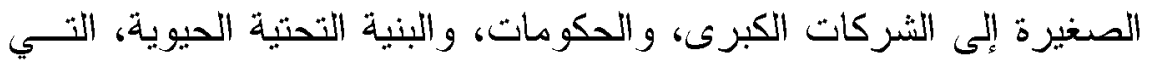

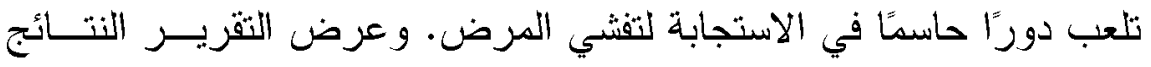

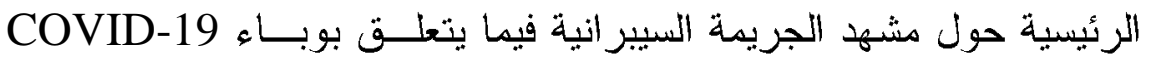
المتمثلة فى التهديدات السيبر انية الرئيسية، وتم تحليله كما يلي (00):1- عمليات الاحتيال و التصيد عبر الإنترنت: التى تتم من خلال نشر

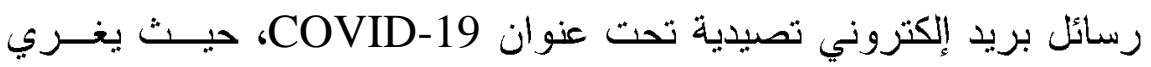

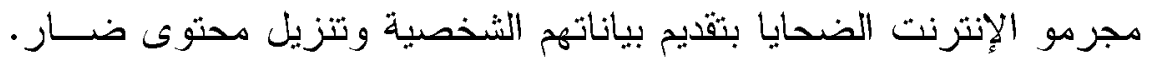

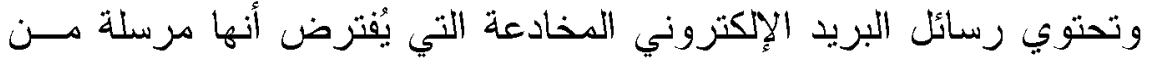

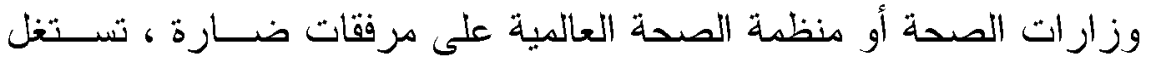

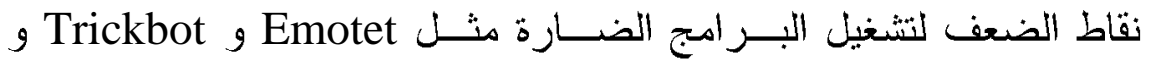
Cerberus

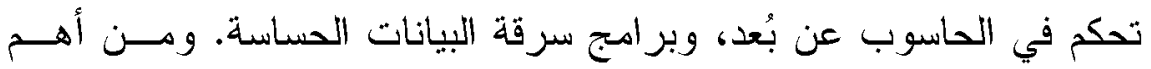
هوضوعات التصيد الاحنيالي لـ COVID-19: رسائل البريد الإكتروني هن السلطات الصحية الوطنية أو العالمية؛ و أوامر حكومية ومبادرات الدعم

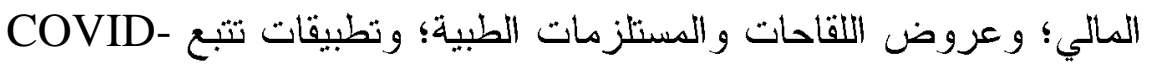

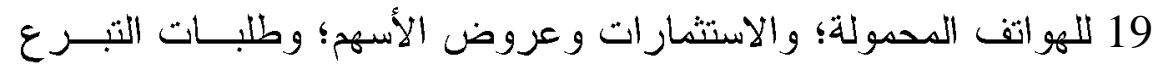

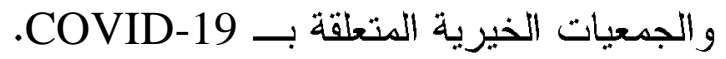

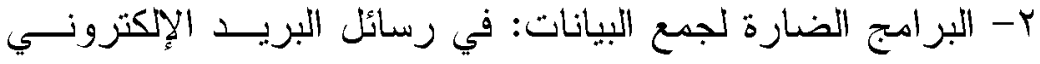

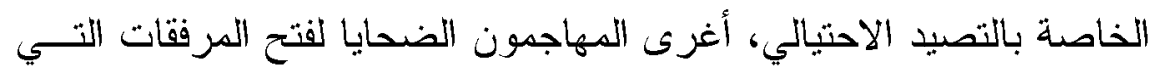

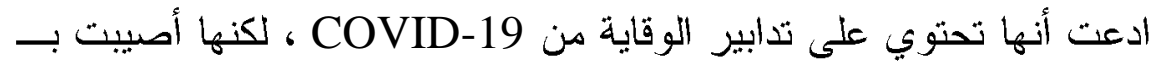


وpdf. حصان طرو ادة Emotet Trojan، الذى يتم إرساله عادةً بتنسيقات

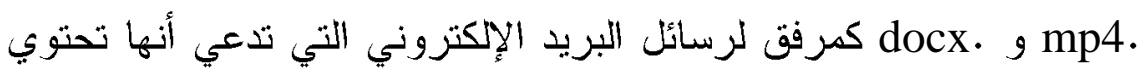

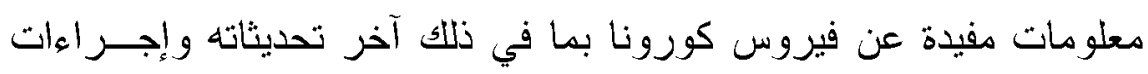

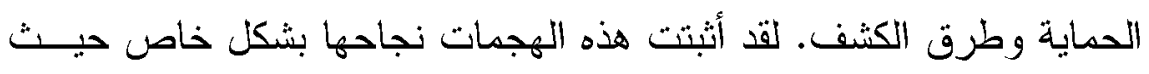

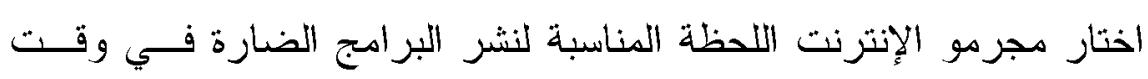
يشعر فيه الناس بالقلق و عدم الأمان.

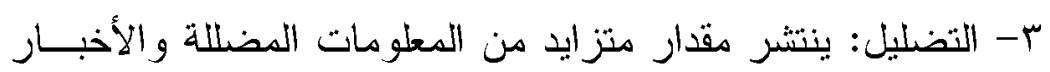

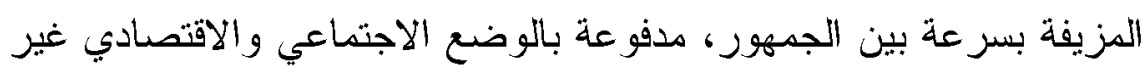

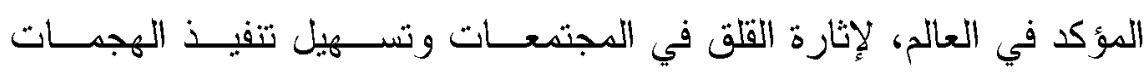

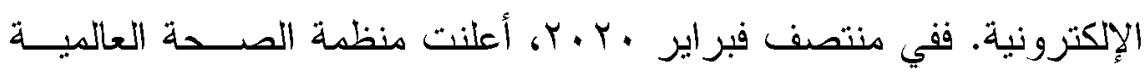
(WHO)

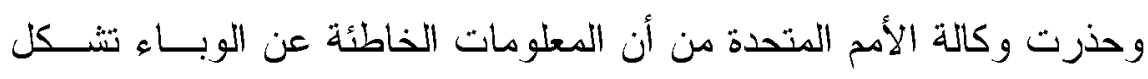

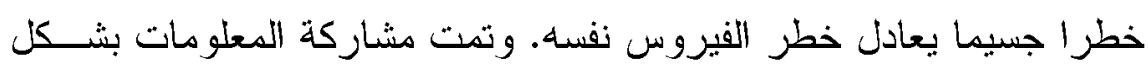

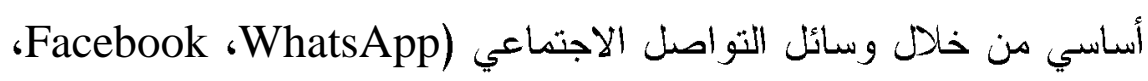

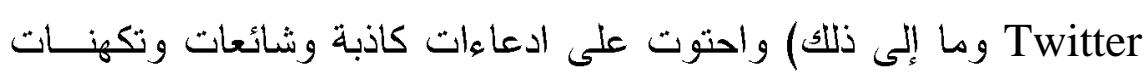

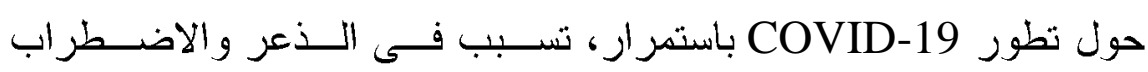
الاجتماعي الذي تفاقم بالفعل بسبب الوباء.

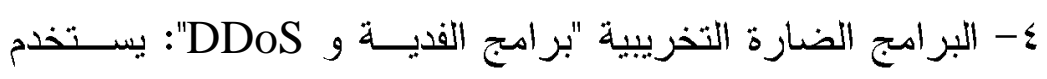

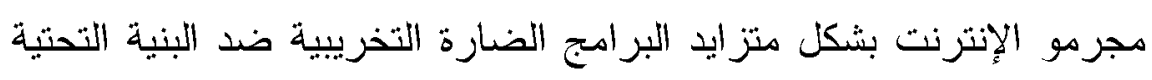

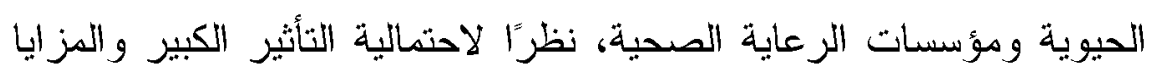

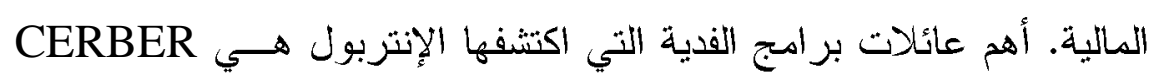

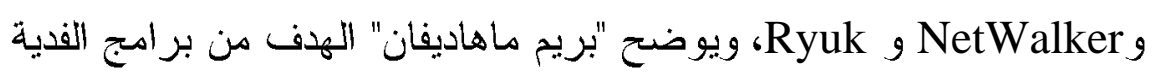

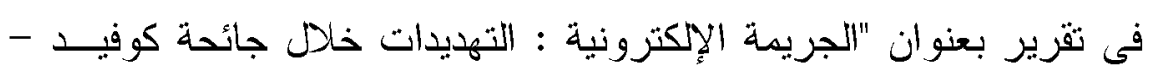

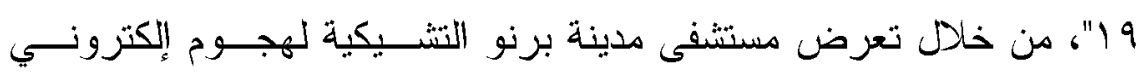

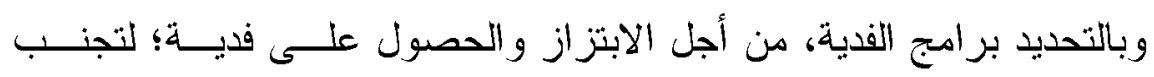

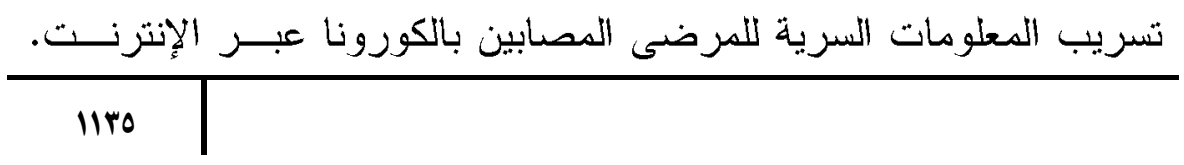


فالعو اقب لمتل هذه الهجمات قد يكون محرجًا ومكلفًا، خاصة هـــ تطــور التثفير واستخدام العملات المشفرة التى يصعب تتبعها، هما جعل هجمــات

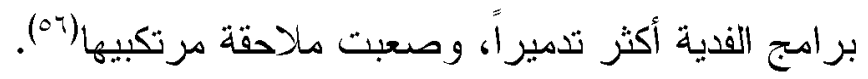

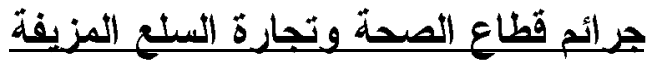

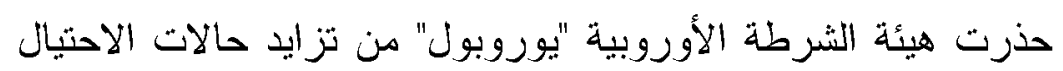

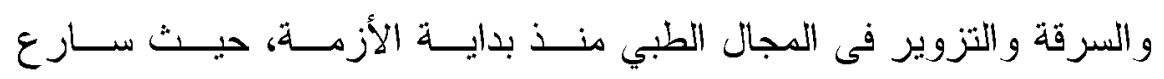

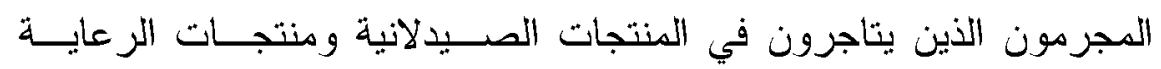

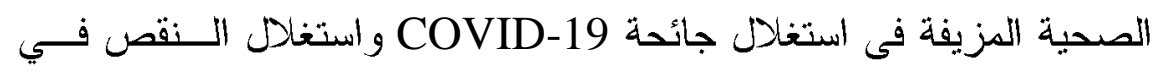

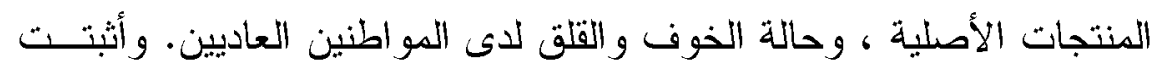

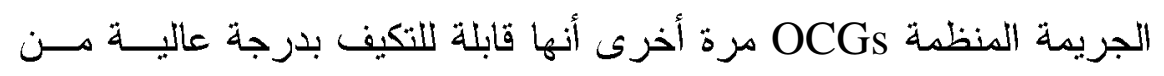

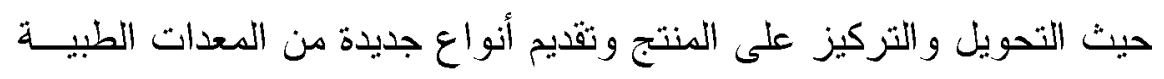

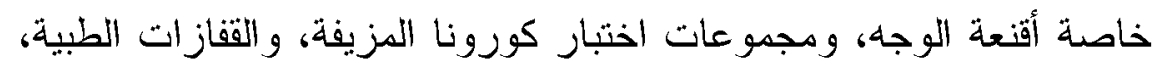

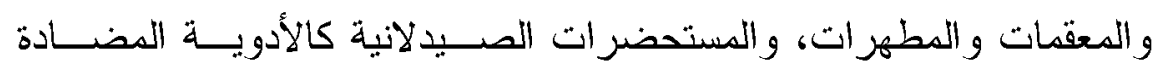

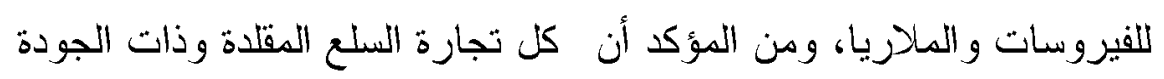
المتننية خاصة المتعلقة بالرعاية الصحية ازدهرت خلال الفترة الثانية هـن

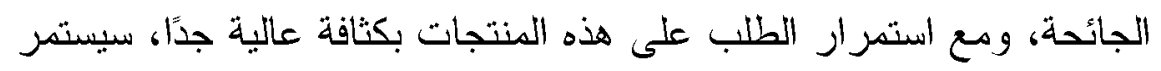

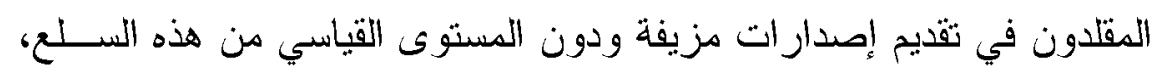

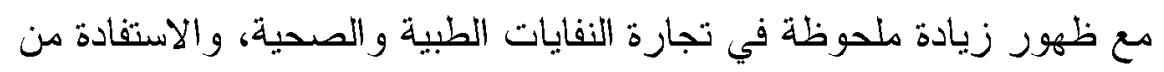

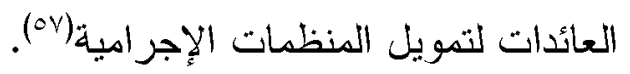

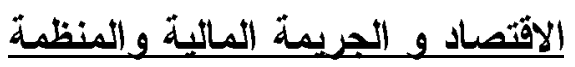

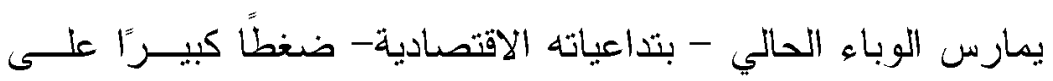

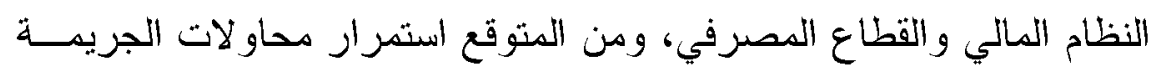
المنظمة OCGs لاستغلال الوضع الاقتصادي المتقلب في غسل الأهــو ال.

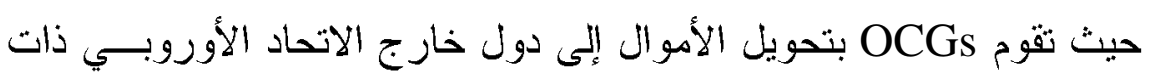

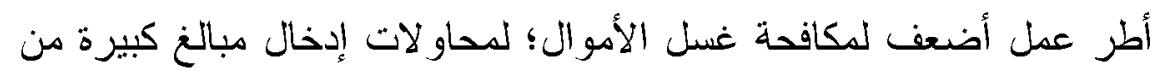

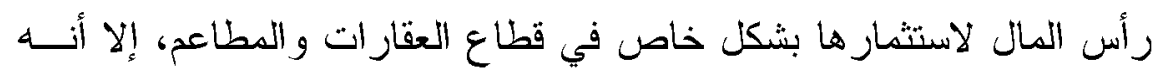


من المتوقع ظهور مجالات أخرى جديدة من غسل الأموال فــي المســتقبل.

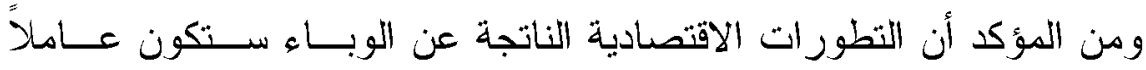

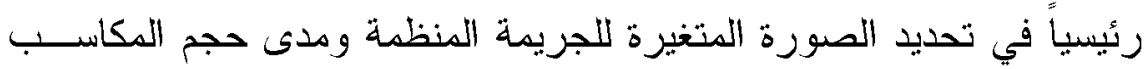

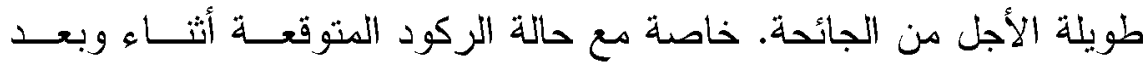

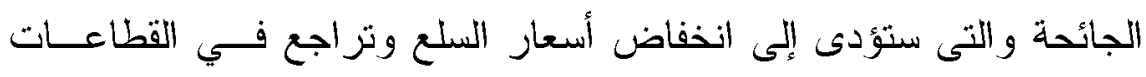

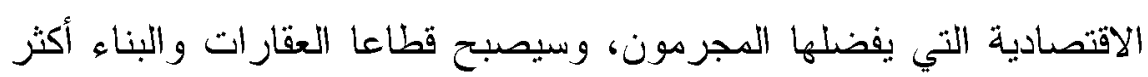
جاذبية لغسل الأهوال، سواء من حيث الاستثار أو كمبرر لحركة الأموال،

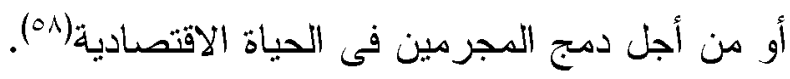

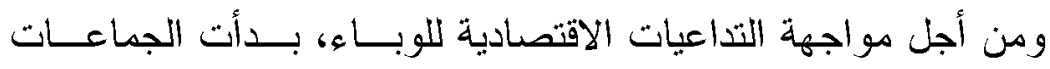

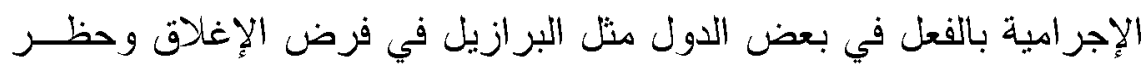

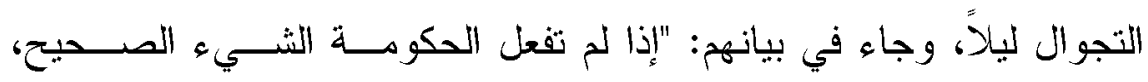

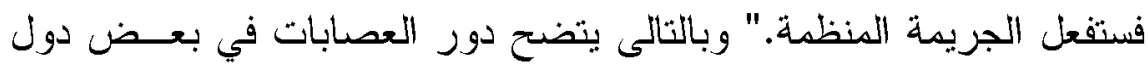

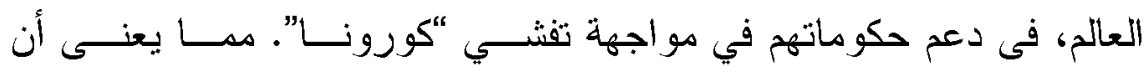

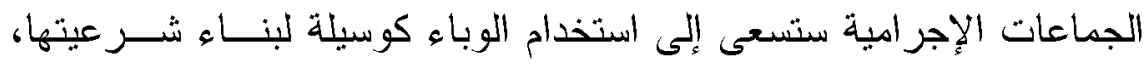

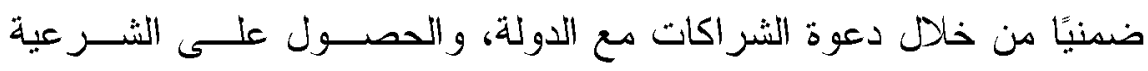

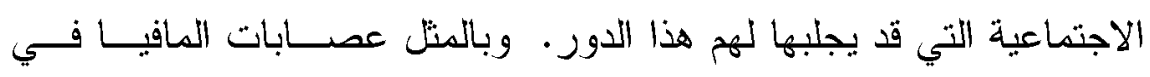

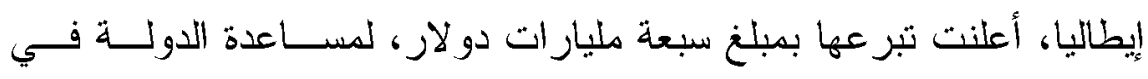

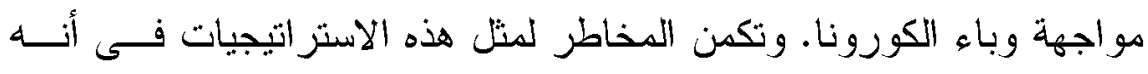

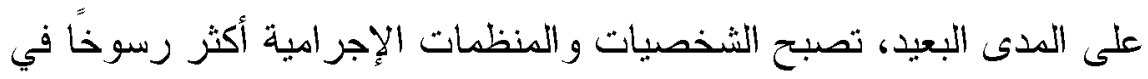

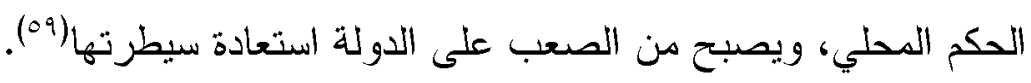

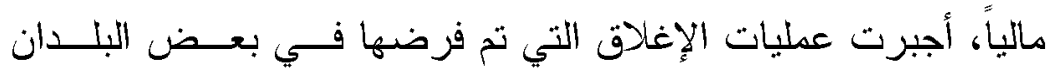

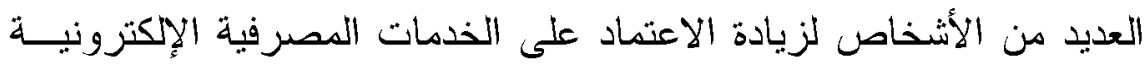

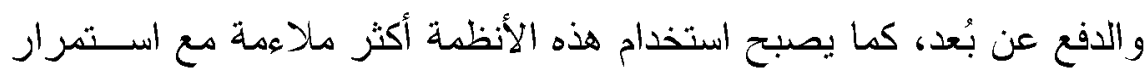

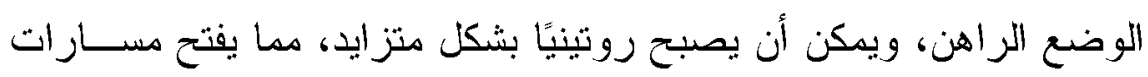

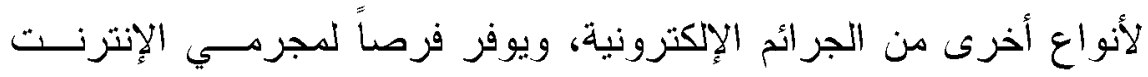

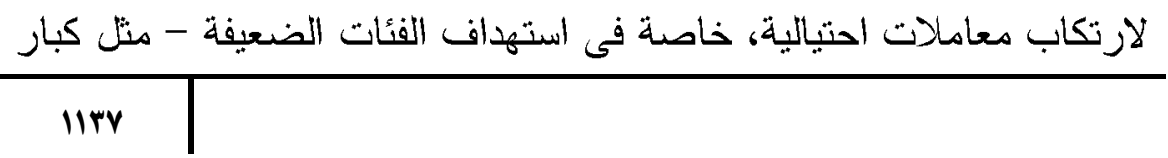


السن أو المعزولين. وبشكل عام، سيكون التأثير الاقتصادي للوبــاء عـاملاً رئيسيًا في تنكيل المشهد المستقبلي للجريمة الدنظمة.

المخردات

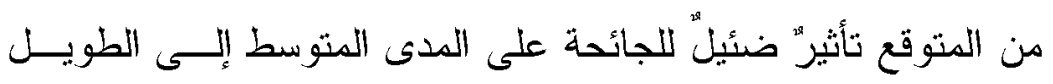

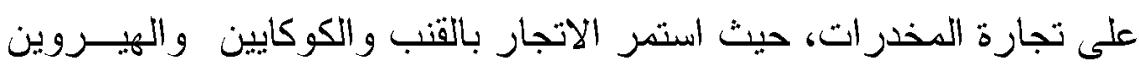

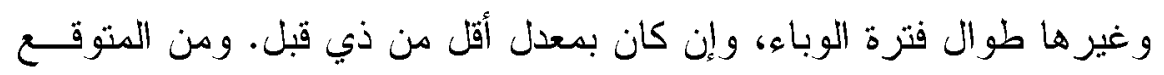

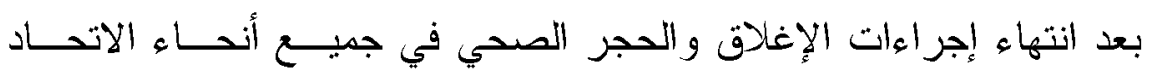

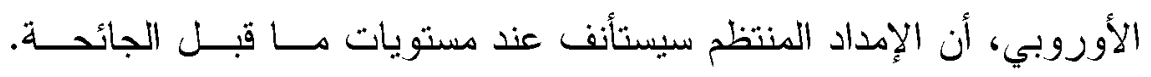

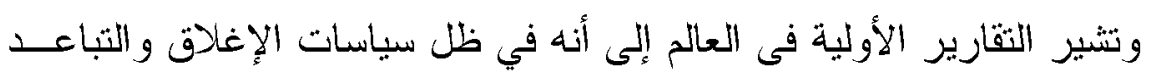

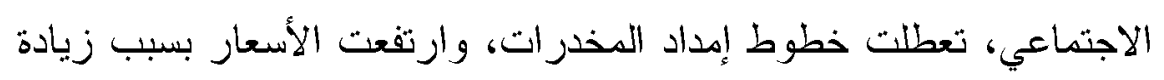

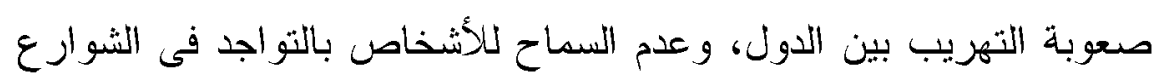

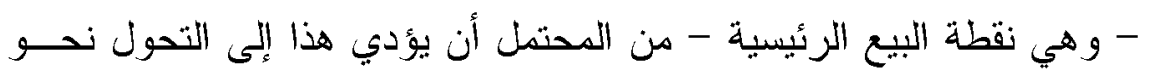

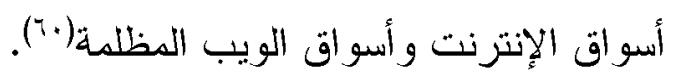

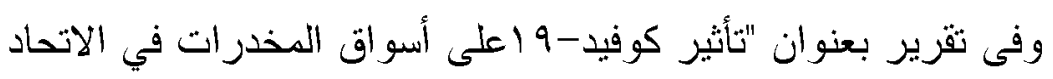

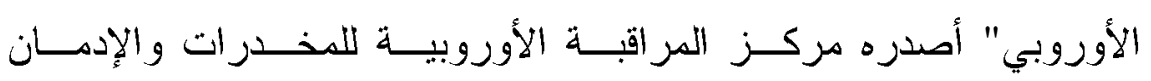

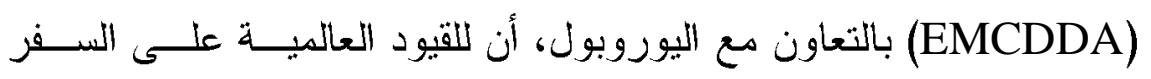

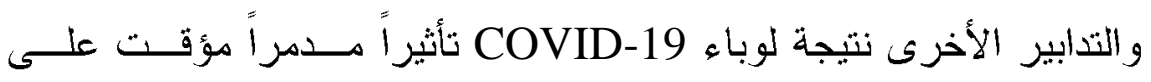

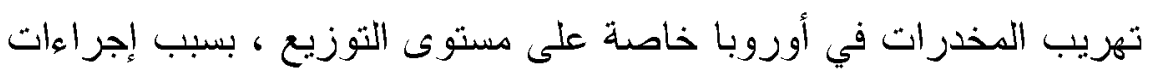

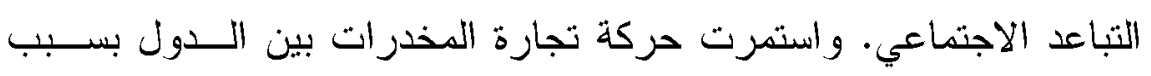

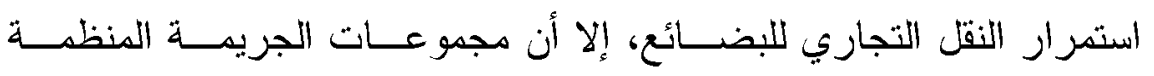
(OCGs)

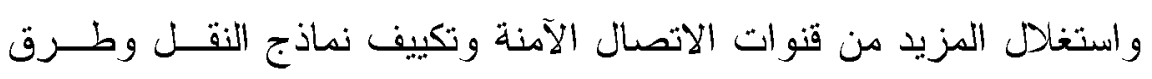

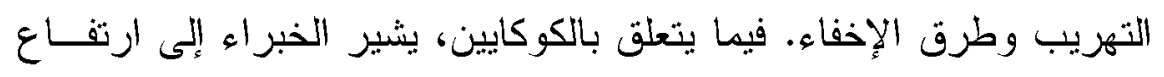

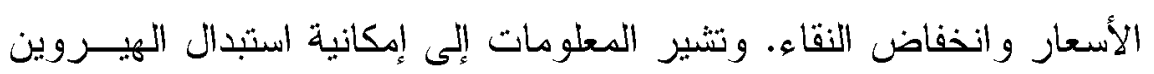

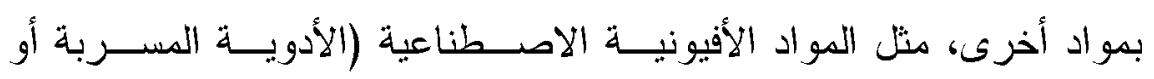

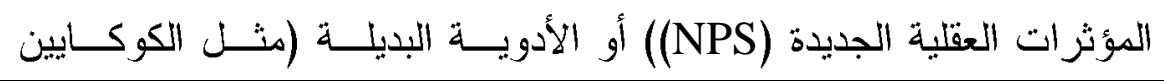


والأففيتادين و الكاثينون الاصطناعي)،. وأظهرت البيانات الأوروبية أنه تــم

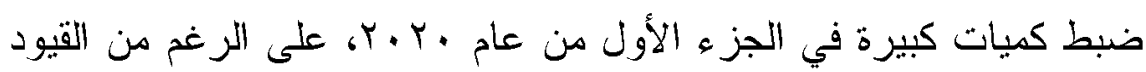
الناتجة عن وباء COVID- (19) على نحو هنزايد، يبدو أن موزعي المخدرات قد تكيفوا هع أسـاليب

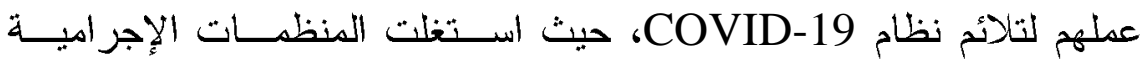
خدمات توصيل الأغذية "الديليفري" - التى انتترت بسبب بقاء المواطنين في

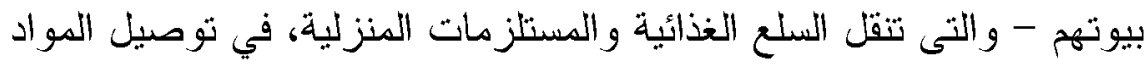
المخدرة دتل الكوكايين والماريغوانا. ويتم التعادل المالى باستخدام العملات

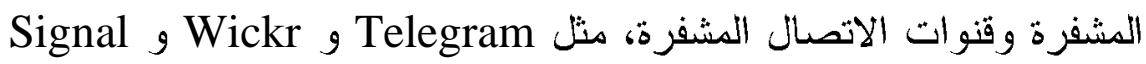
لعرض المخدرات في أسواق الثبكة المظلمة، وأكد التقرير أن عددًا متزايدًا

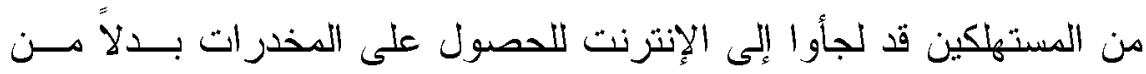

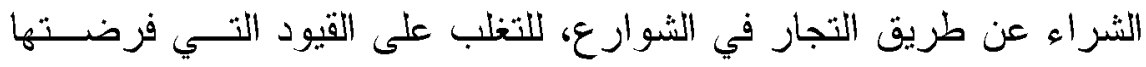

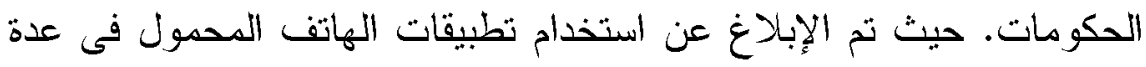

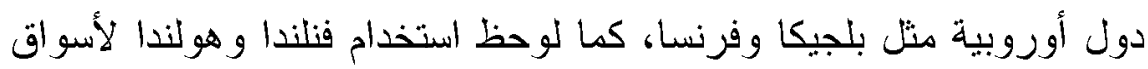

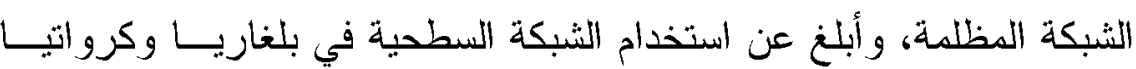

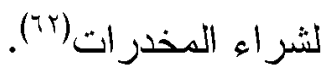

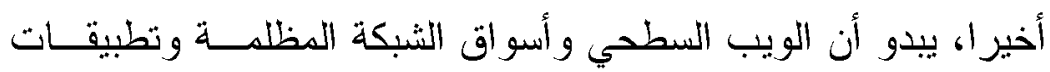

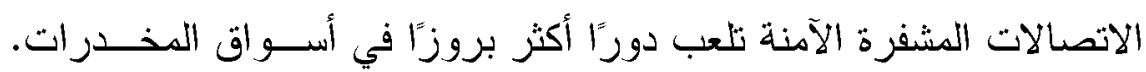

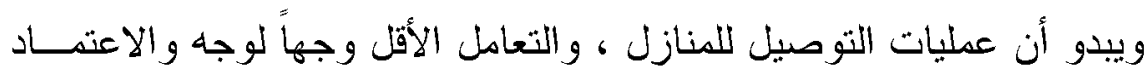

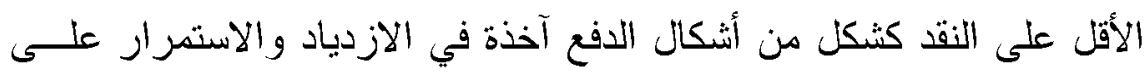

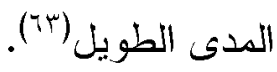

\section{المعنف المنزلمى المولئ}

تصاعد العنف المنزلي هع استمرار القيود المفروضة علــى حركـة الأشخاص بالإضافة إلى الضغوط الاقتصادية والاجتماعية في دعظم البلدان،

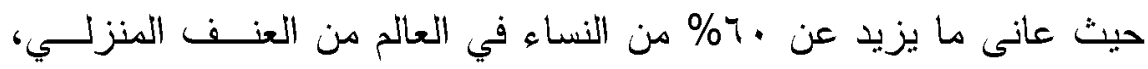

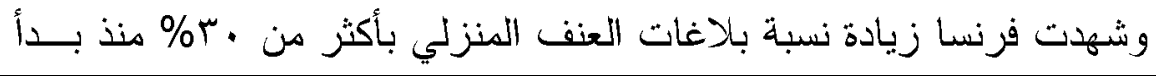


إغلاق البلاد في Vامارس، فيما سجلت قبرص وسنغافورة و البرازيل نســباً

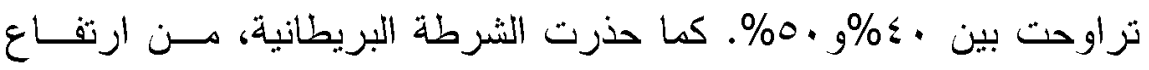

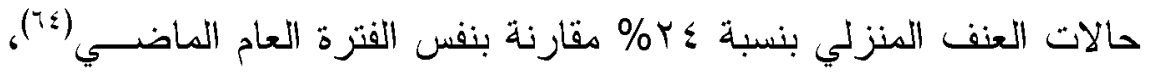

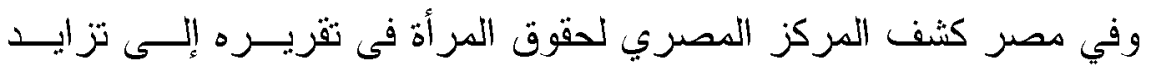

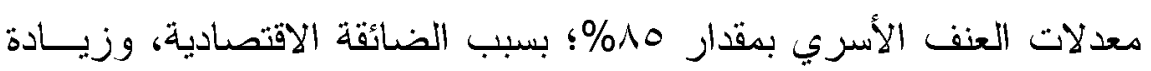

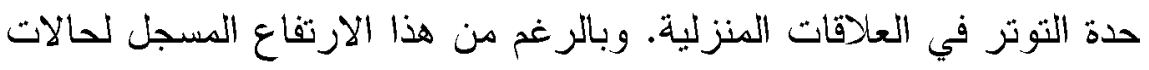

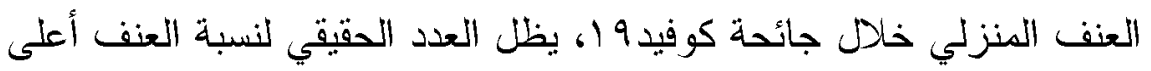

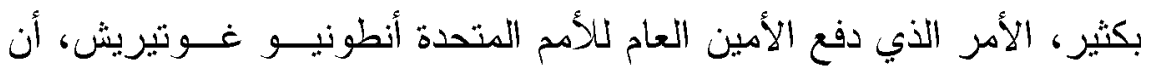

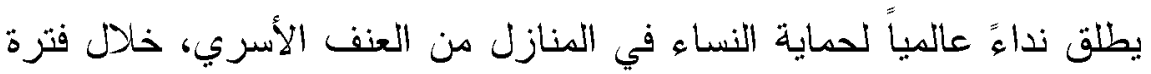

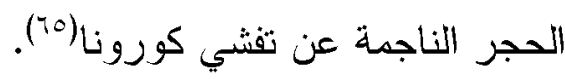

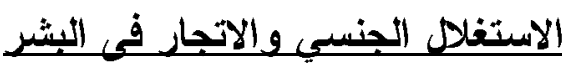
تسبب الإغلاق المطول فى ازدهار الصناعات الجنسية عبر الإنترنت،

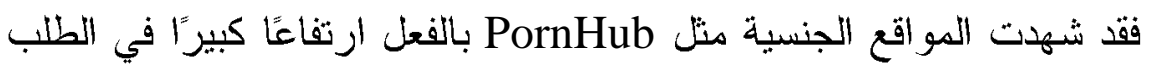

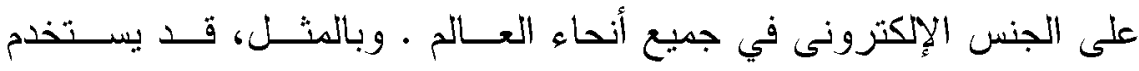

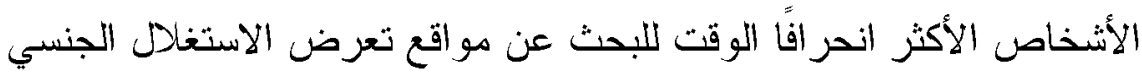

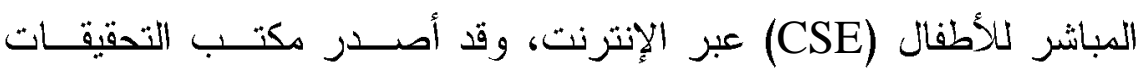
الفيدرالي (FBI) تحذيرًا من أن الأطفال الذين يدرسون في المنزل ولئر ويلعبون الألعاب عبر الإنترنت ويستخدون وسائل التواصل الاجتماعي أثناء إغلاق

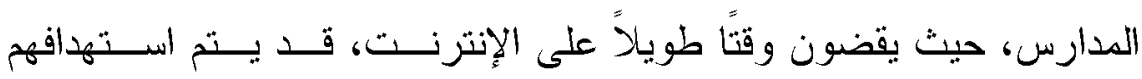

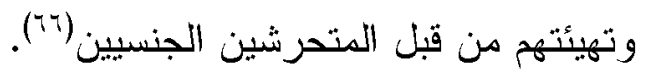

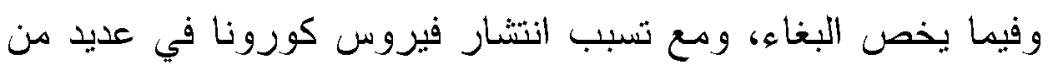

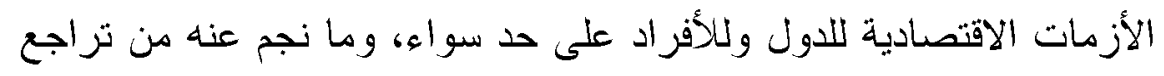

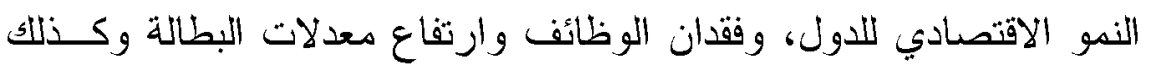

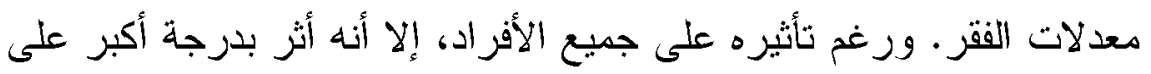

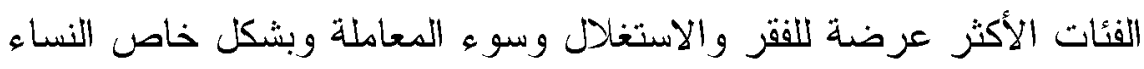
اللاتي يتم الاتجار بهن و إقحامهن في العمل في البغاء.. ومن المحتمل انهيار 
هذا القطاع كباقي القطاعات وذللك لإغــلاق النـــوادي والملاهـــي الليليــة،

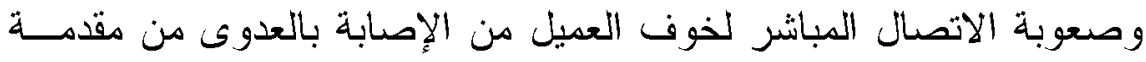

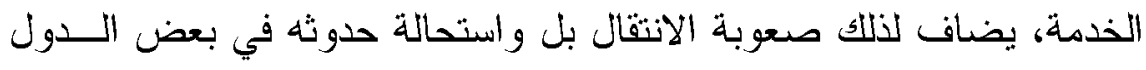

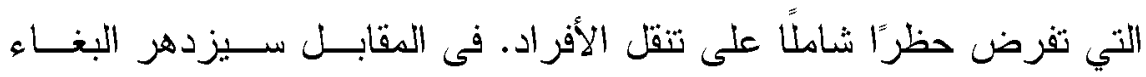

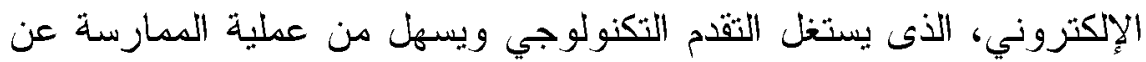
بعد بمقابل مادي عبر كاديرا الويب أو مكالمات الفيديو عبر تطبيقات وسائل

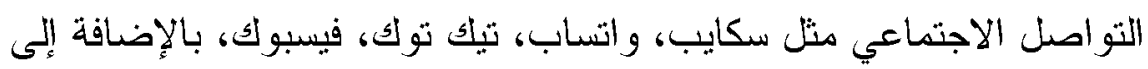

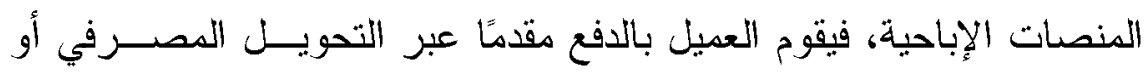

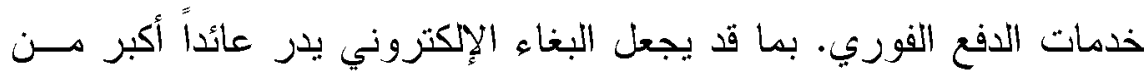

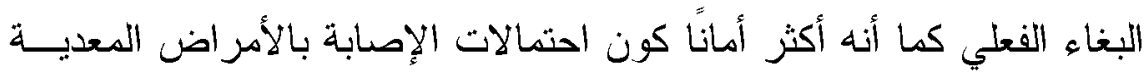

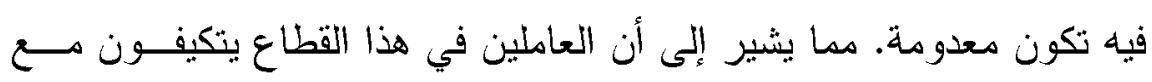

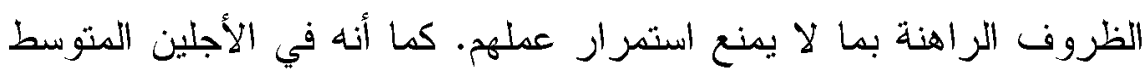

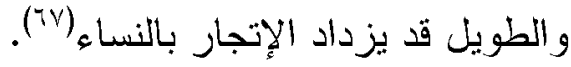

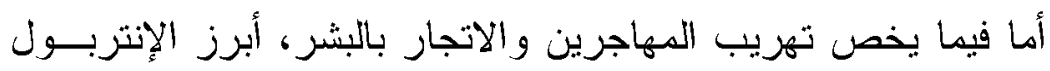

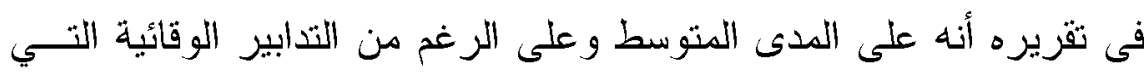
اعتمدتها الدول، فقد سعى المهربون والمتاجرون وحتى الضحايا إلى البحث البه

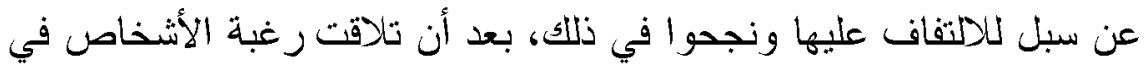

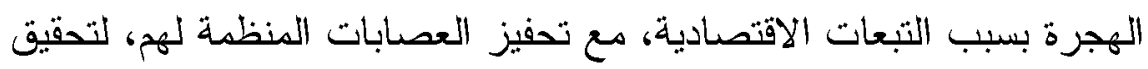

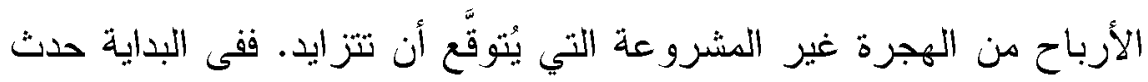

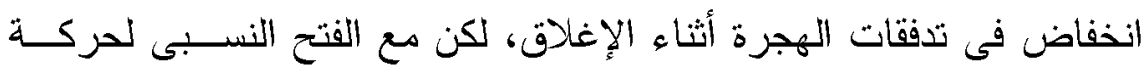

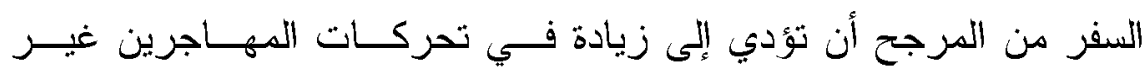

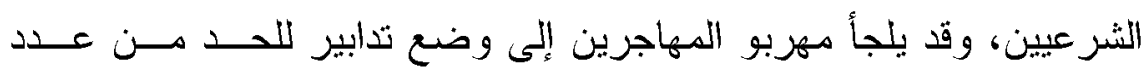

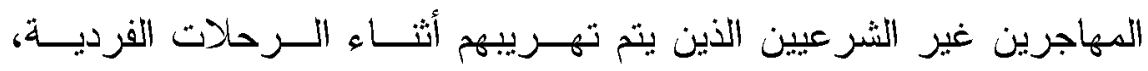

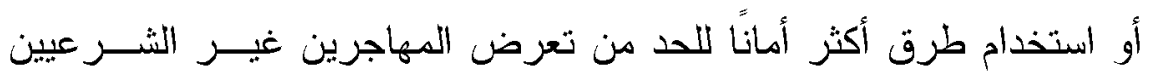

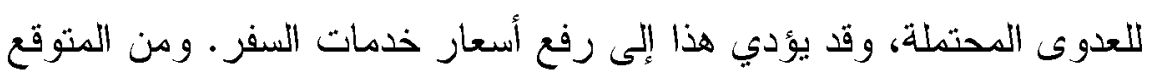

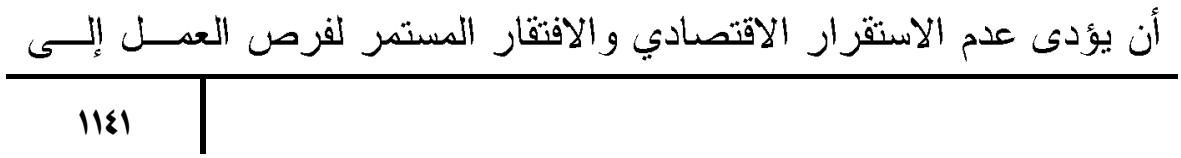


زيادة الطلب على العمالة الرخيصة التي يمكن الوصول إليها مــن خـلال

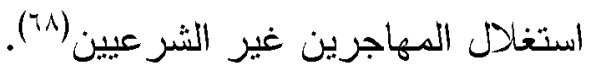
ويصعب تقييم تبعات وباء كوفيد-9 اعلى الاتجار بالبشر تقييما مؤكداً

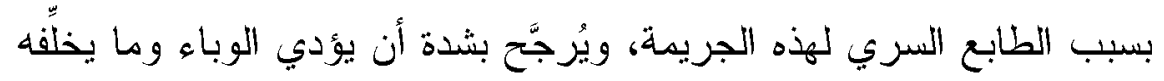

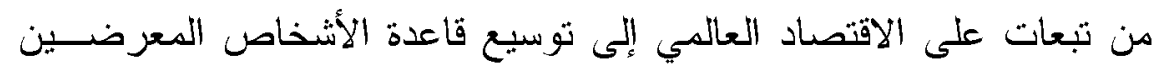

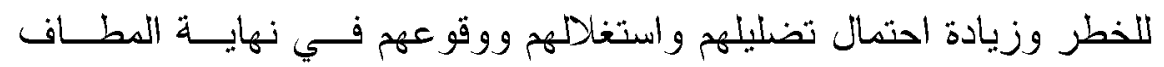

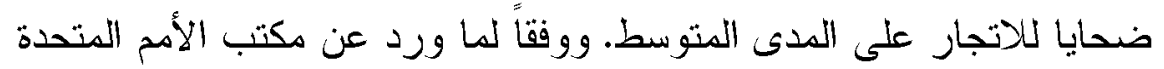

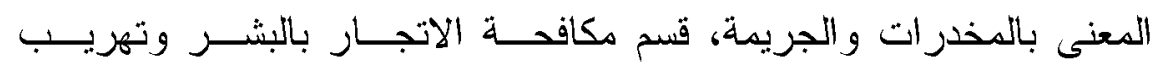

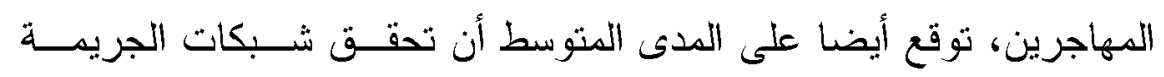

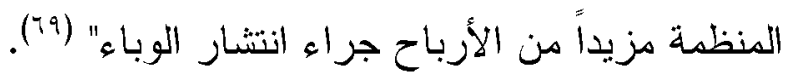

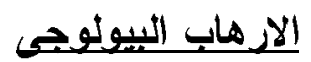

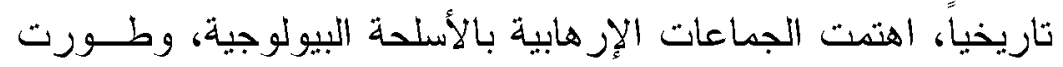

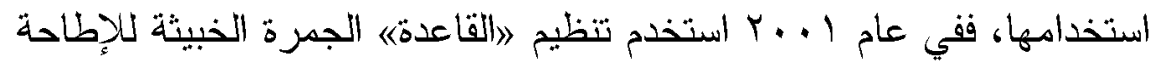
بعدد دن السياسيين الأمريكيين في الولايات المتحدة، والتى تكبدت خســائر

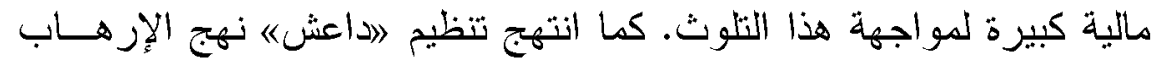

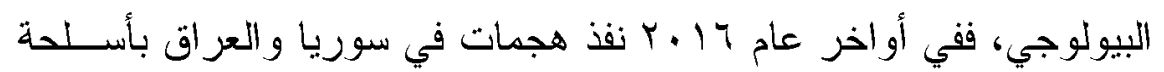

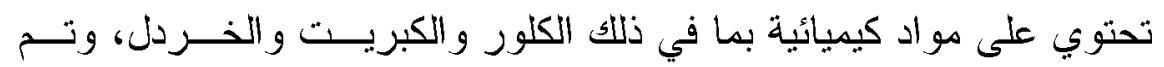

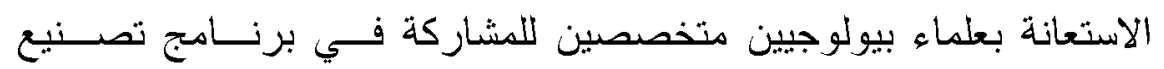

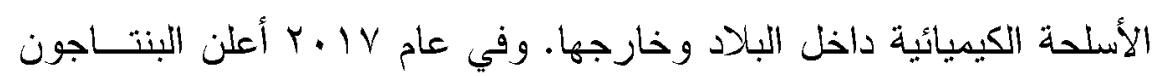

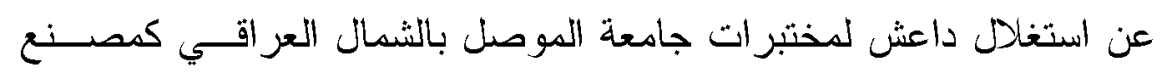

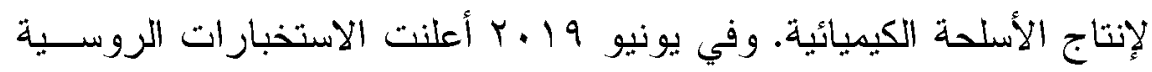

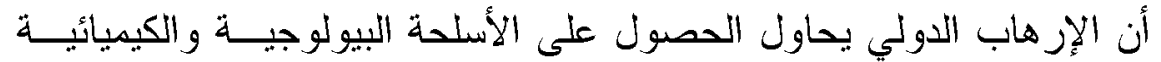

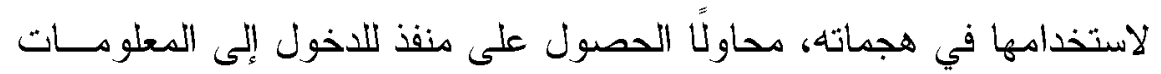

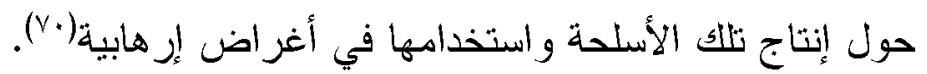

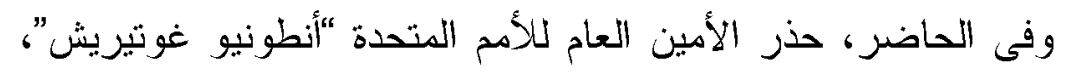

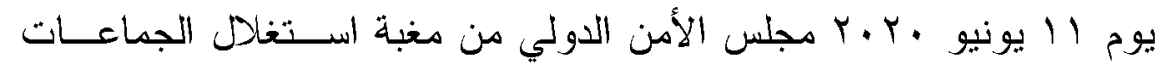


الإرهابية جائحة كورونا لتأجيج العنف في دول العالم، وأكد أنه دع تصاعد

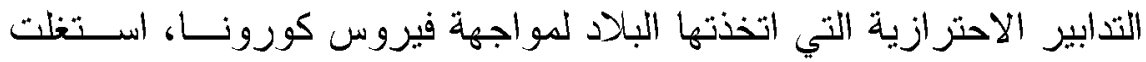

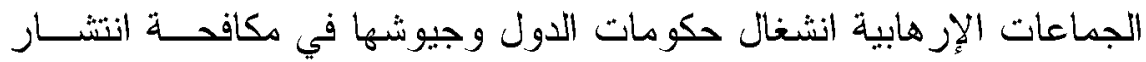

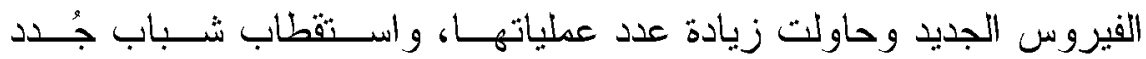

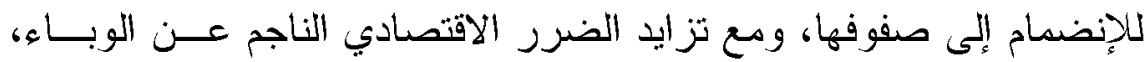

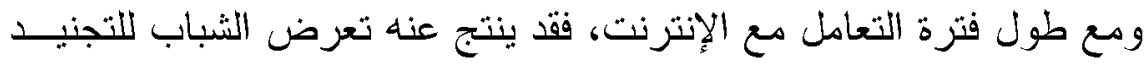

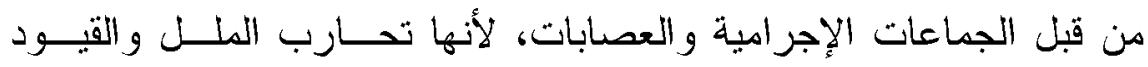
الاجتماعية للإغلاق.

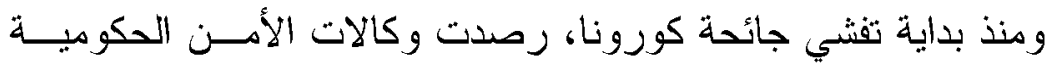
و الباحثون السياسيون تصاعداً في خطاب الكر اهية والعنصرية الذي يدفع بهان ريه المتطرفون على شبكة الإنترنت، فيما حذرت تقارير استخبار اتية هن احتمالية

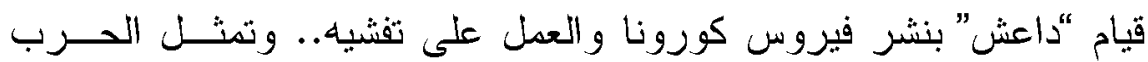

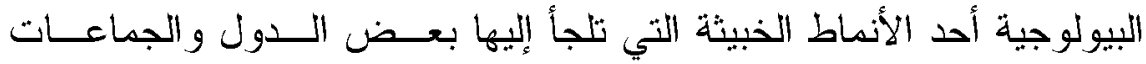

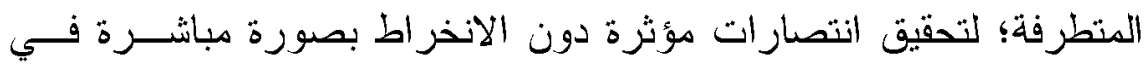

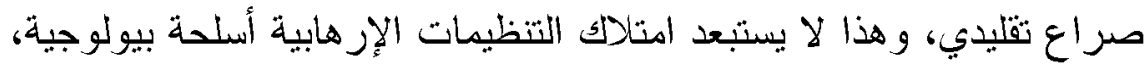

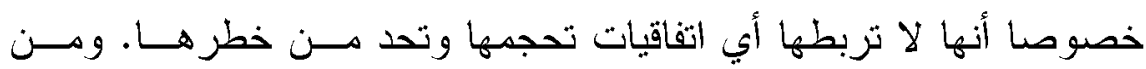

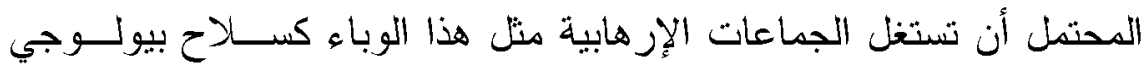

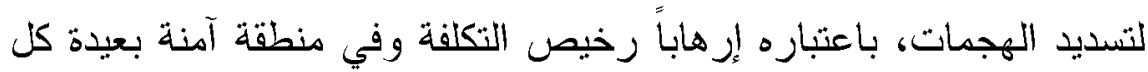

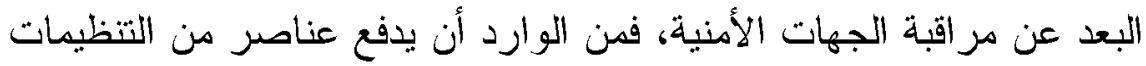

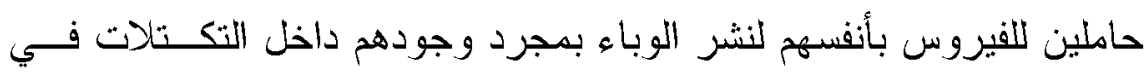
الدول، وفق استر اتيجية تخريبية مدمرة.

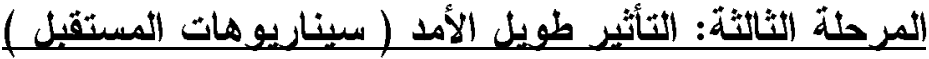

تعتبر نماذج التتبؤ بسيناريو هات الجريمة أمثلة على التقنيات الجديــدة

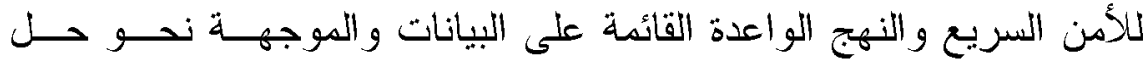
المشكلات وتسريع عملية اتخاذ القرار، وتوفر حلو لاً ذكية تساعد في تقليـلـل التحيزات البشرية وعدم الكفاءة، في عصر يتميز بالثورة التكنولوجية و الذكاء 
الاصطناعي و البيانات الضخمة المتاحة لمساعدة سـلطات إنفــاذ القـانون

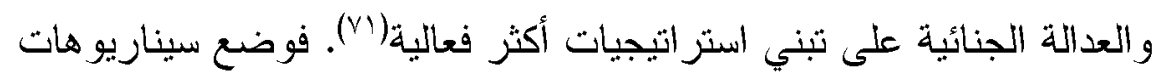

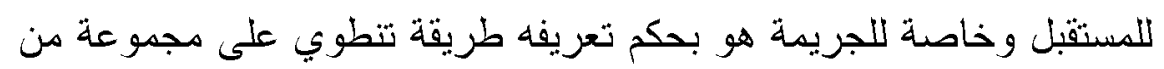

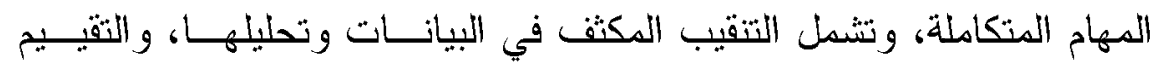

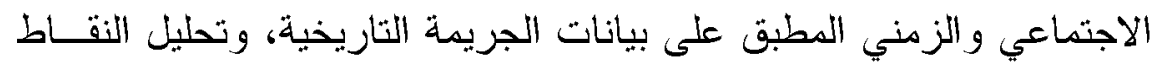

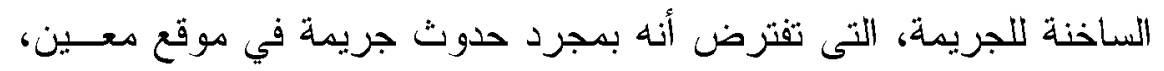

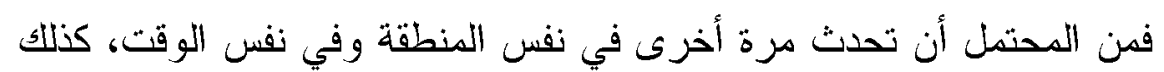

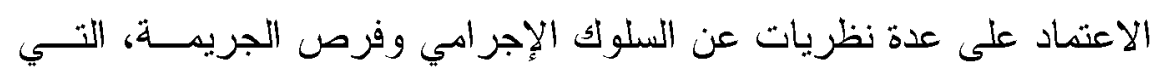

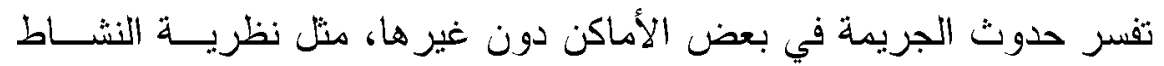

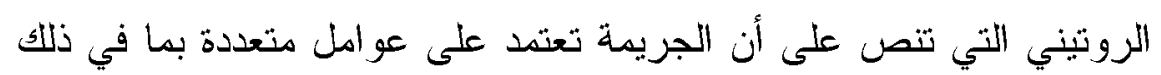

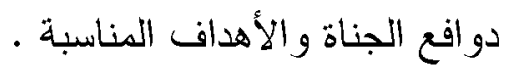

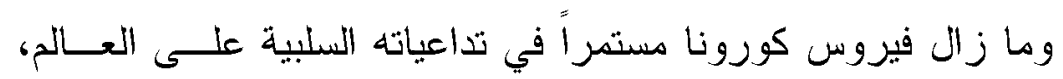
سواء على مستوى أعداد المصابين و الوفيات، أو حتى انعكاساته الاجتماعية

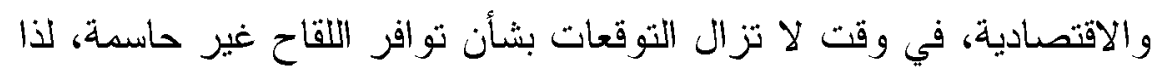

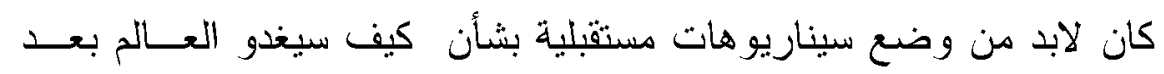

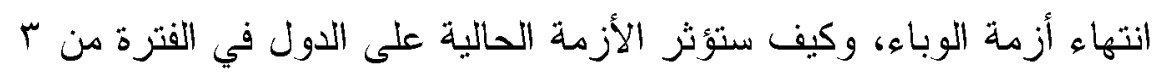

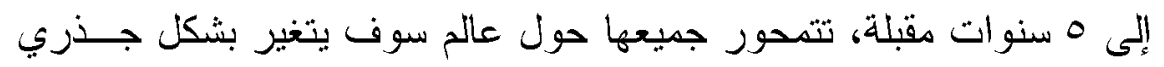

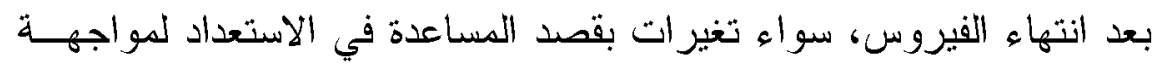

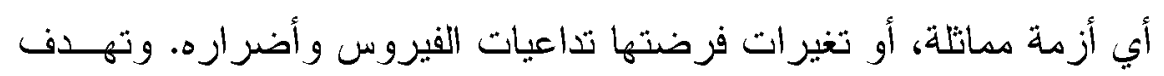

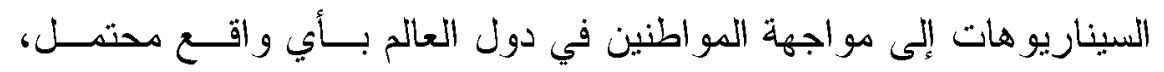

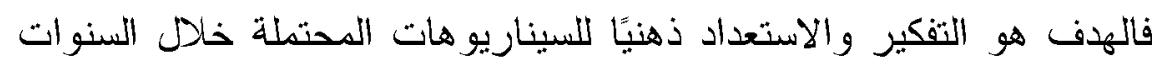
المقبلة، حتى تلك التي لا تبدو و اقعية، واحتمالية أن المستقبل سيكون مزيجًا من السيناريو هات المختلفة. 


\section{أولاً : السبناريوهات الاقتصادية والاجتماعية:}

في هذا السيناريو سوف يستعين الباحث بالتقرير الذى أعدته شـــركة

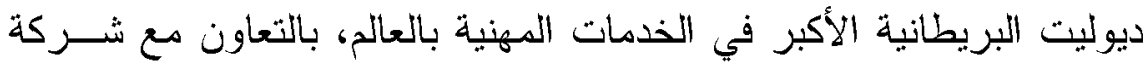

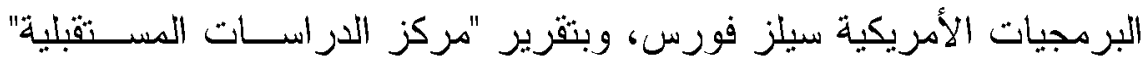

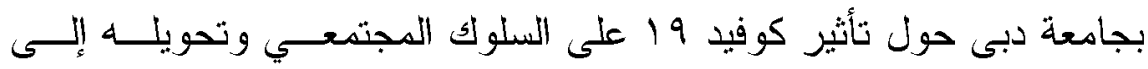

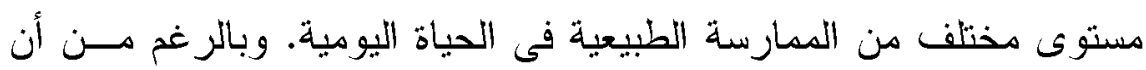

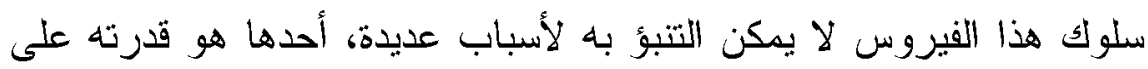

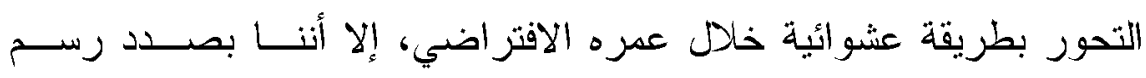
سيناريو للحياة اليودية بعد انتهاء الجائحة.

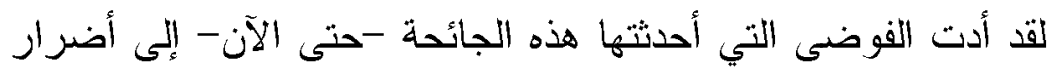

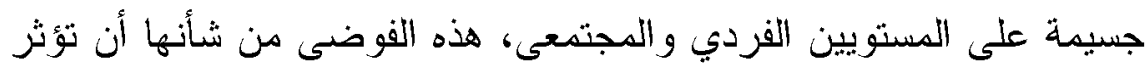

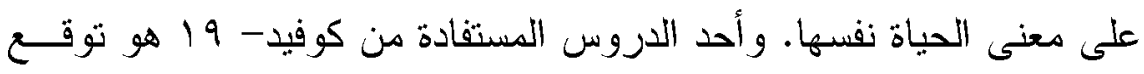

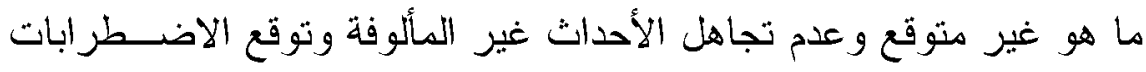
عن طريق استشر اف المستقبل و التخطيط بالسيناريو هات. (disruptions)

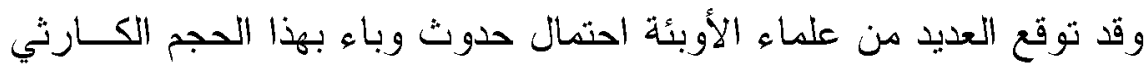

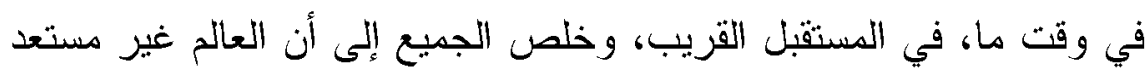

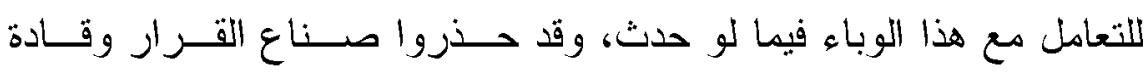
الحكومات في العالم من ضرورة التعبئة واتخاذ الإجز اءات المناسبة، ولكــن فئن

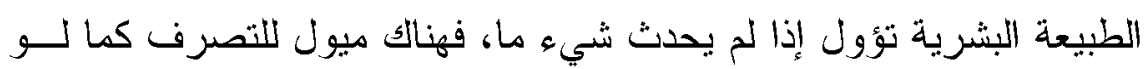

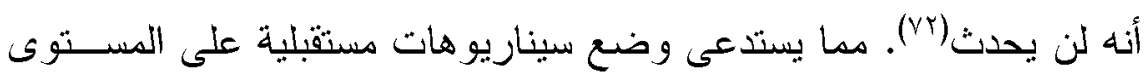

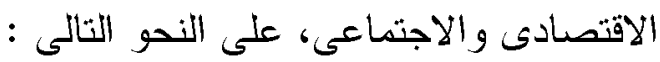

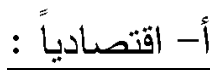

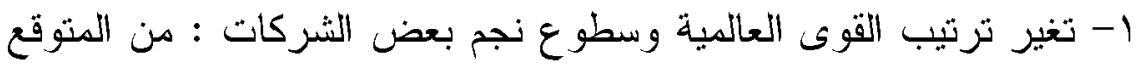

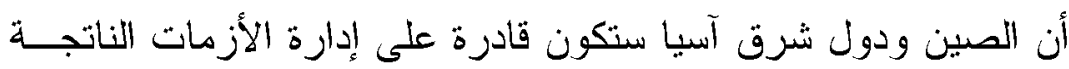

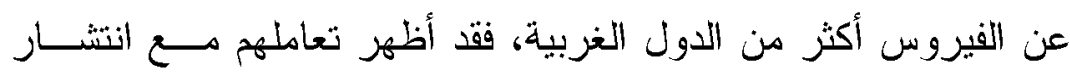

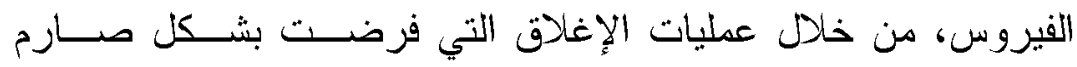


وتكنولوجيا مر اقبة الدصابين، قدر اتهم في مكافحة الوباء و التعامل مــع الده

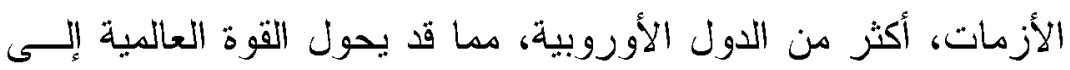

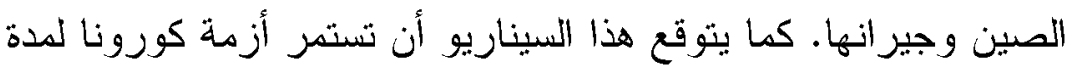

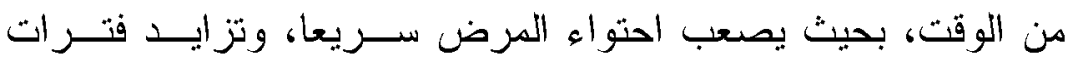

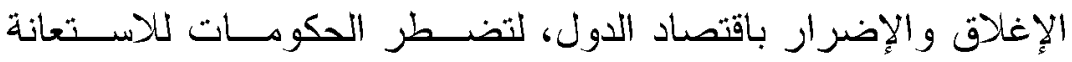

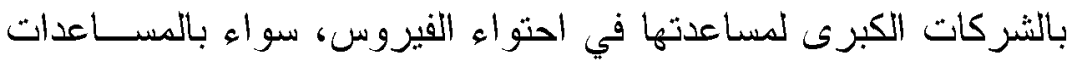

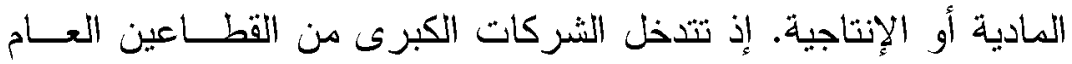

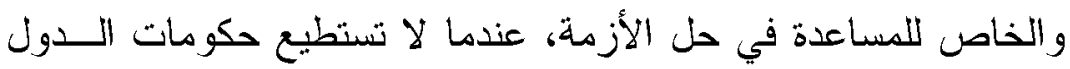

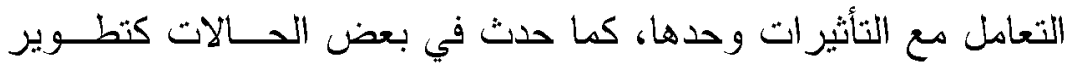

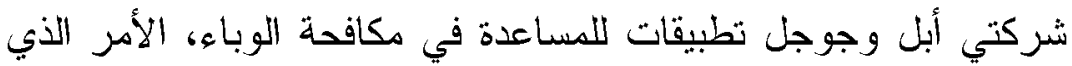

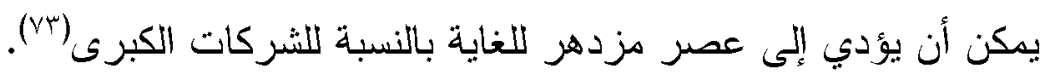

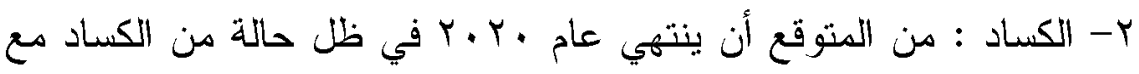

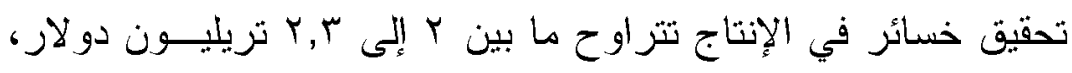

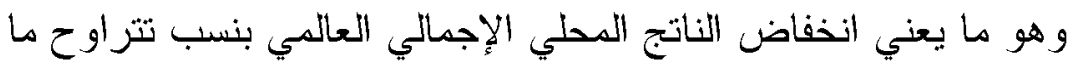

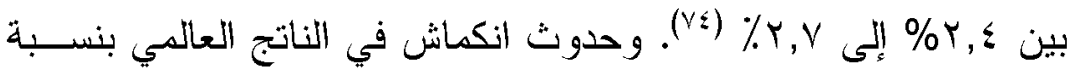
\% م مع تعافٍ بطيء للنشاط الاقتصادي؛ إلا أن مخاطر فنشل مواجهة الوباء بشكل كفء في الأسواق الناشئة والاقتصادات النامية، سيشكلان

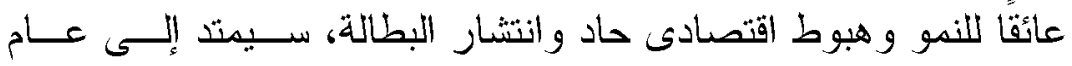

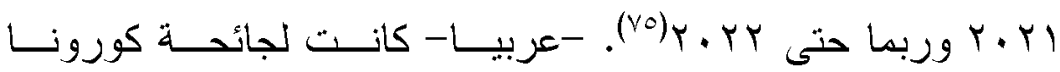

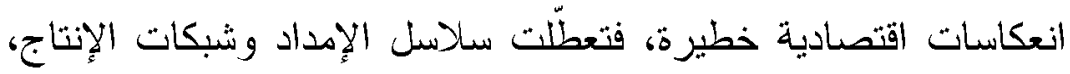

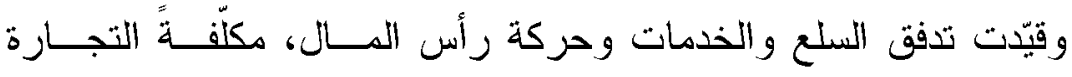

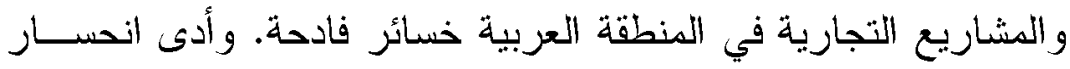

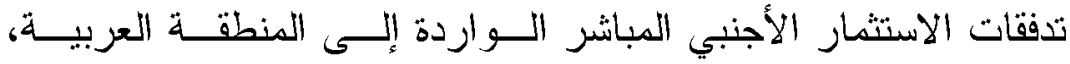

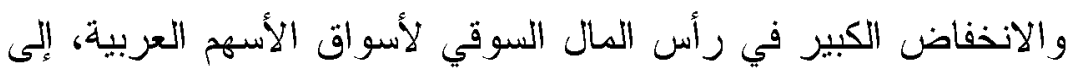

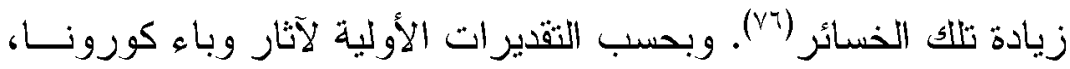

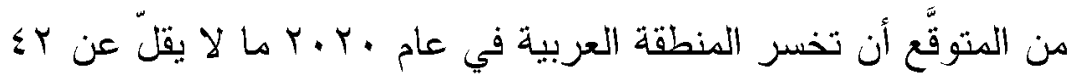


مليار دو لار • ومن المتوقّع أن تخسر المنطقة V, أمليون وظيفة في عام

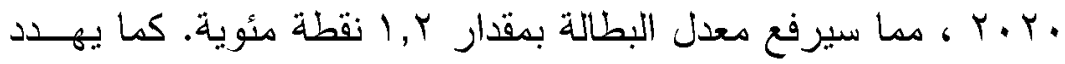
وباء كورونا حوالى 00 مليون شخص بحاجة إلى المساعدات الإنسانية

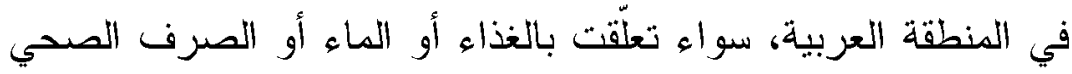

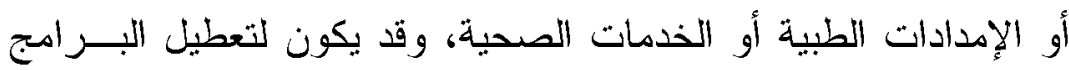

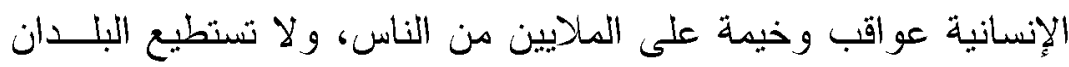

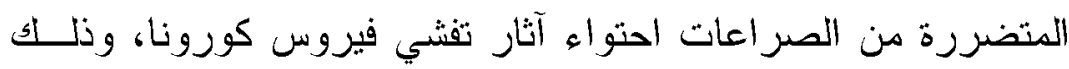

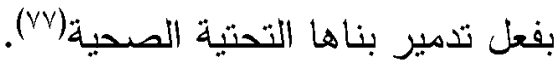
r- انخفاض الدخل وسوق العدل : من المتوقع ارتفاع مستوى التعرّض للفقر وغياب الحد الأدنى من الحماية الاجتماعية في العديد من البلدان العربية.

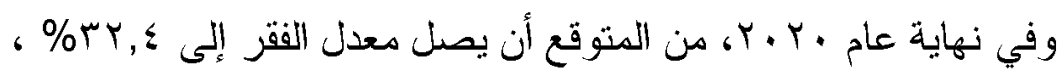
أو 110 مليون شخص في البلدان العربية المتوسطة الدخل والأقل (Vه).

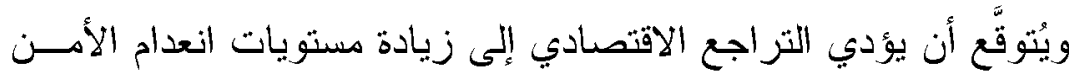

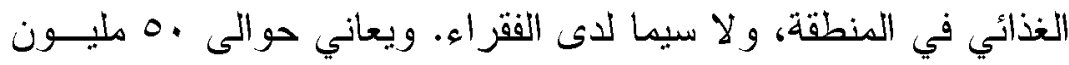

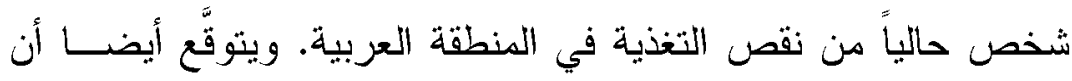

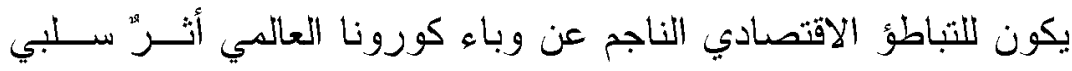

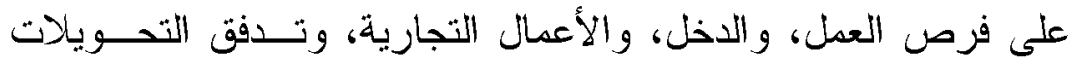

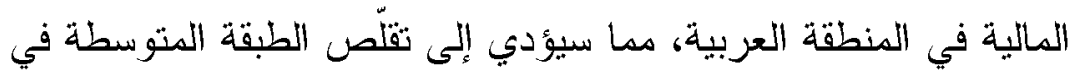

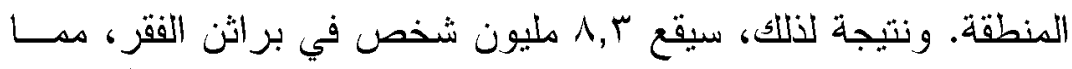

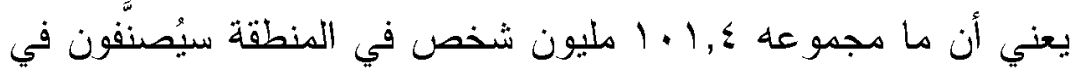

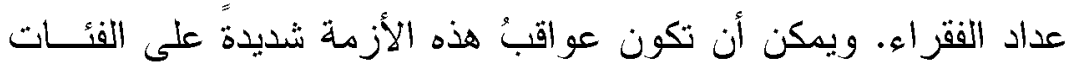

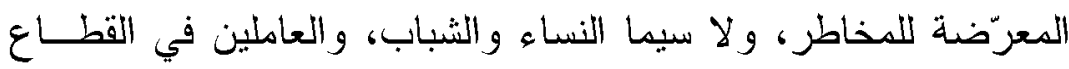

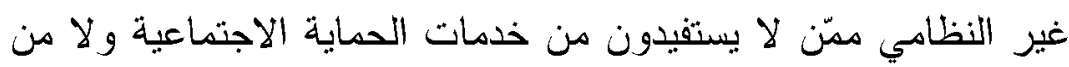
التأمين ضد البطالة (va). وسيؤدي الحجر المطوّل حتماً إلى زيادة بطالة الثـــباب، وســيواجه

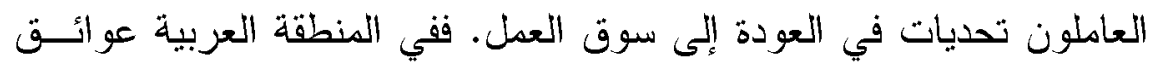




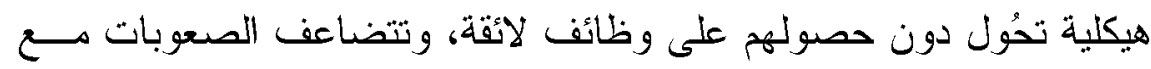

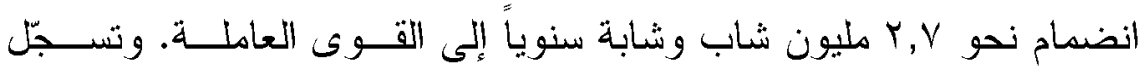
المنطقة العربية أعلى مستو يات لبطالة الثباب وأسر عها تزايداً في العالم، فقدابه

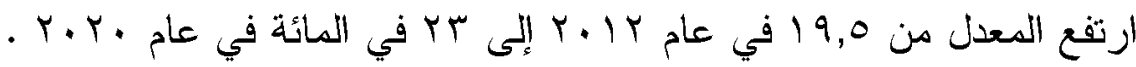
ويزيد معدّل بطالة الشابات في المنطقة عن ضعف مان ما هو عليه في صفوف

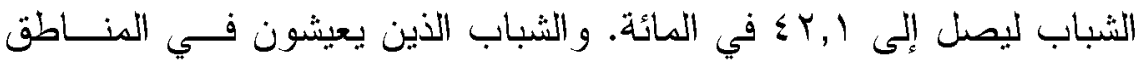

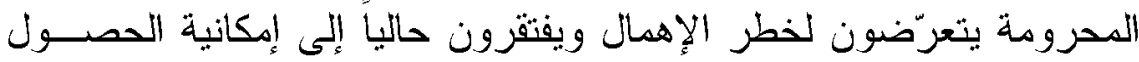

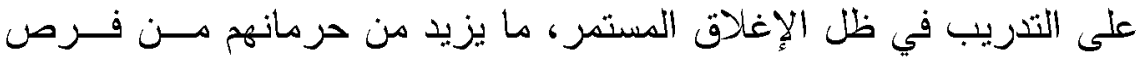

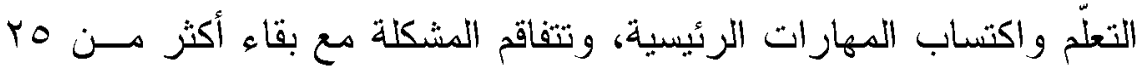
مليون شاب وشابة خار ج دائرة العمل و التعليم والتدريب(.A.).

\section{ب- اجتماعياً:}

1- التوترات الطبقية و الحياة اليومية : من المتوقع أن تسير معركة العسالم

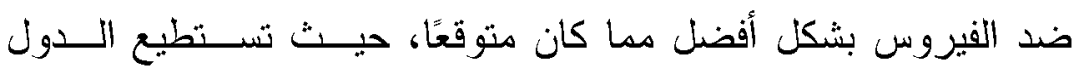

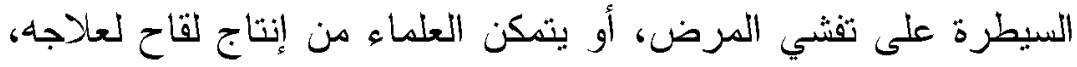

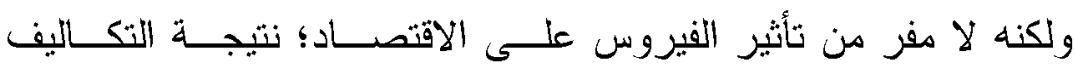

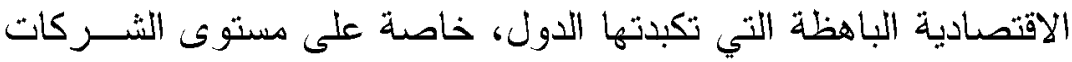

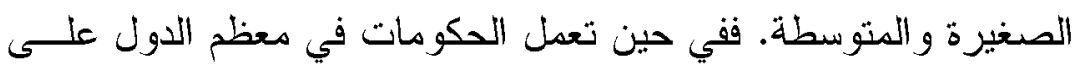

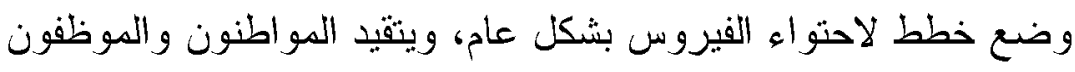

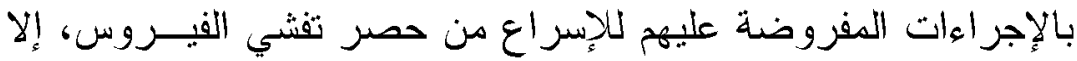

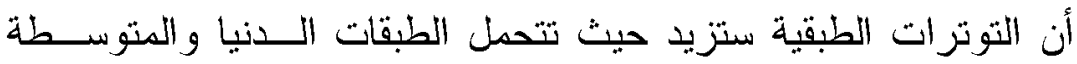

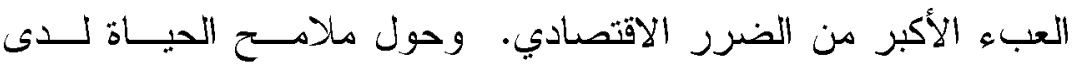
المو اطنين عامة بعد انتهاء الأزمة، فالحياة اليودية ستظل مستقرة نسبيا،

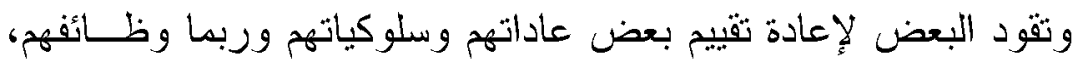

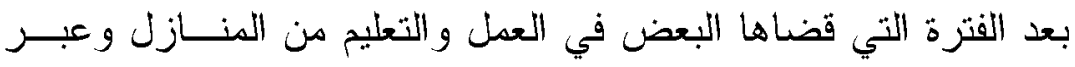
الإنترنت. 
ץ- عالم دعزول : يعد هذا السيناريو الأسوأ على الإطلاق، فهو يتخيل ثبوت

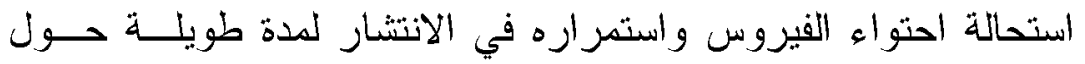

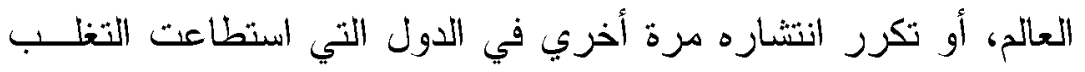

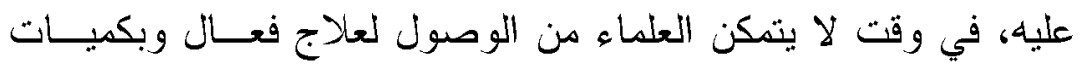

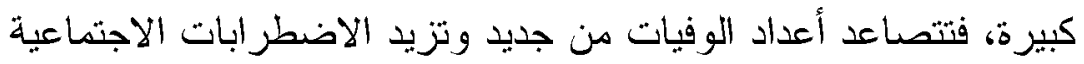

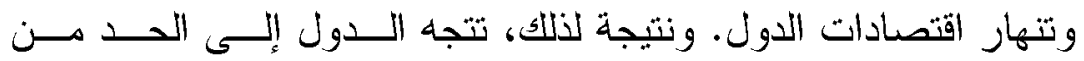

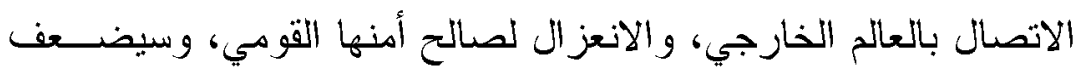

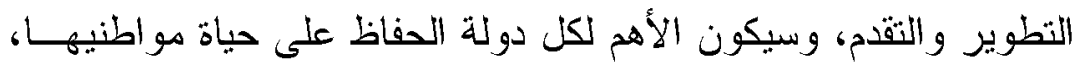
فسيكون سيناريو دظلماً، وينتشر الخوف الاجتماعى بين الجميع.

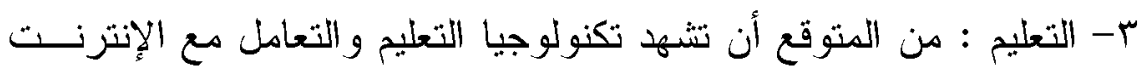

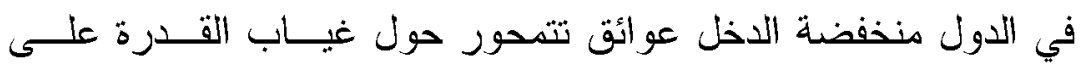

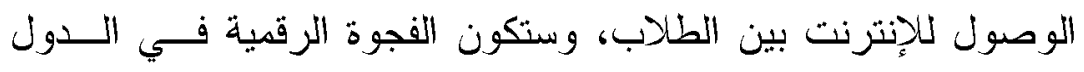
منخفضة الدخل بمثابة حجر عثرة في طريق إتمام العام الدراسي لنظام

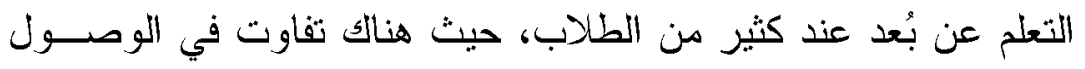

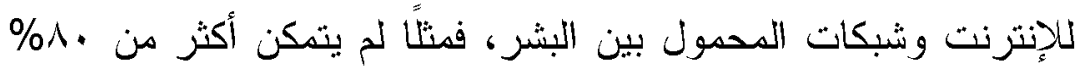

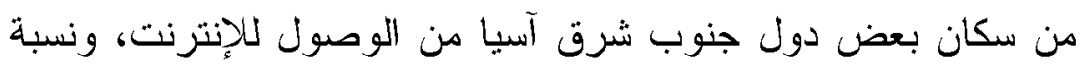

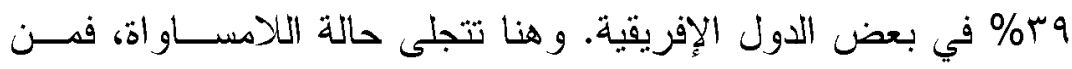

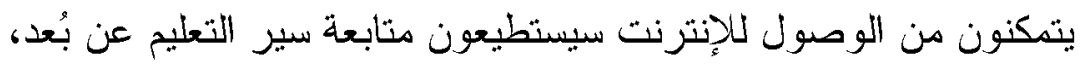

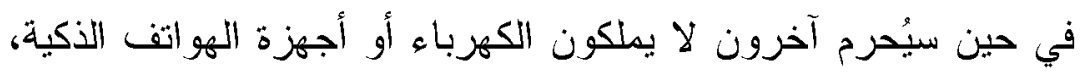
وأجهزة الكمبيوتز دن مواصلة التعليم (1).

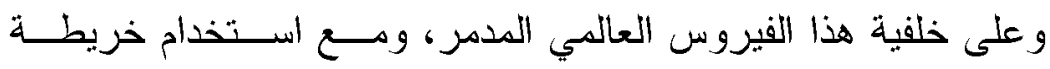

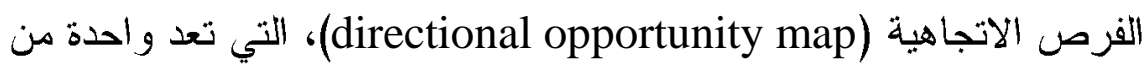

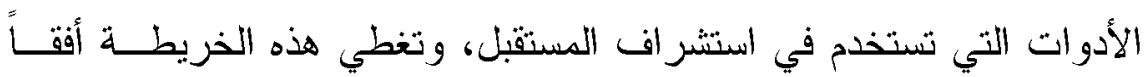

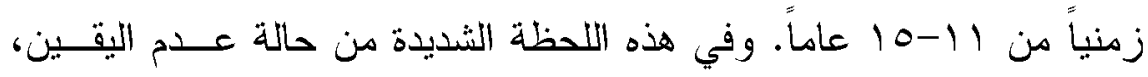

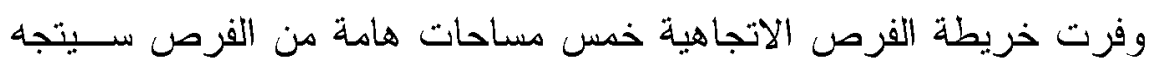

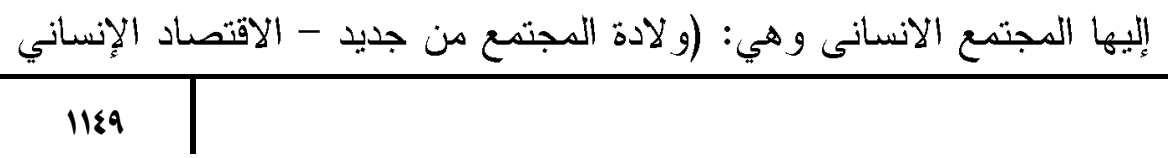


- إعادة تثغيل المعرفة - التكنولو جيا الأخلاقية - ما وراء مجتمع محسـوره

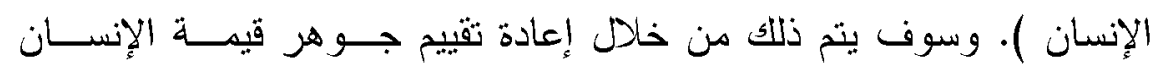

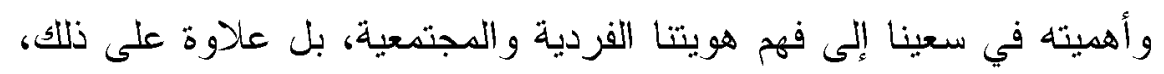

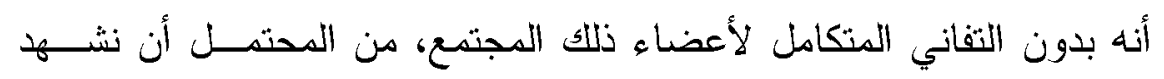

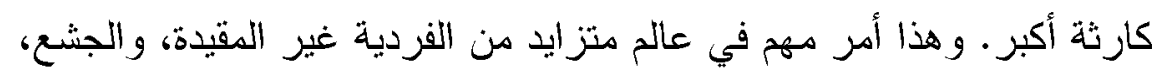

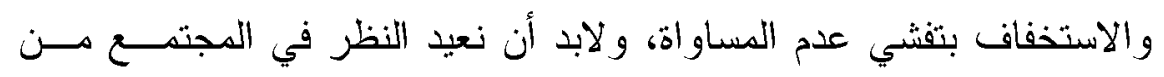

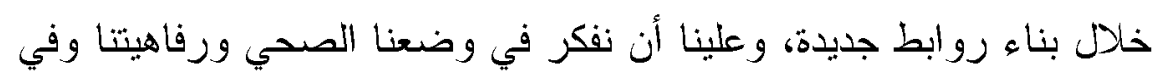

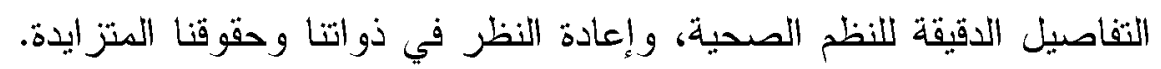
كما أن الحاجة الدفاجئة واستجابتتا السريعة للتعلم عبر الإنترنت سوف تعجل

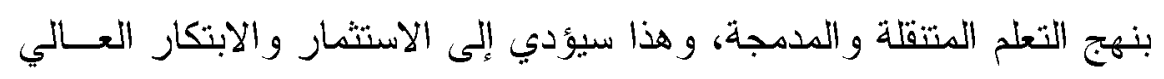

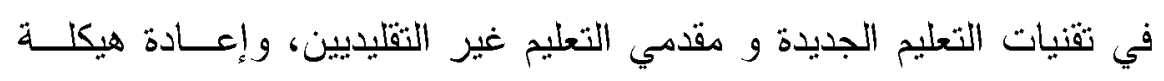
محتوى الدورة الدراسية، و اختيار المواد الدراسية والحاجة إلى أساليب تقييم

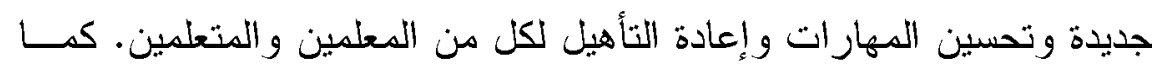
سيؤدي إلى إعادة التفكير بثكل كبير في دسار ات التعلم، وتسريع الاتجــاه

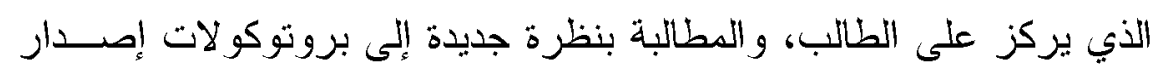

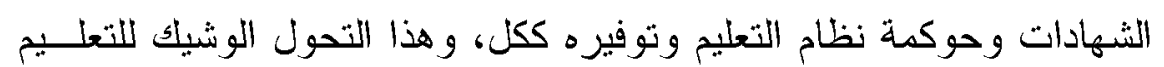

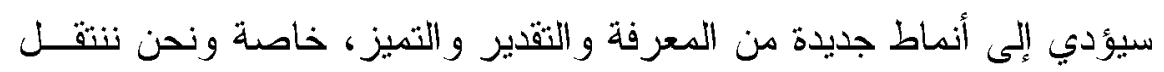

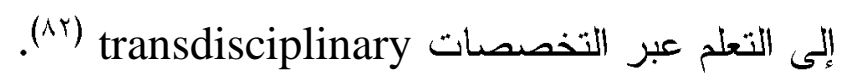

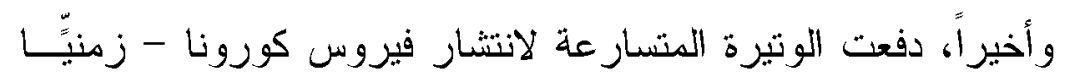

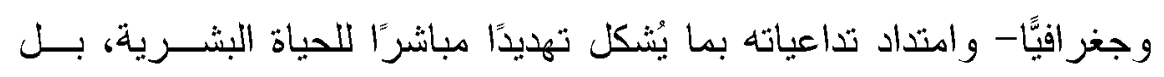

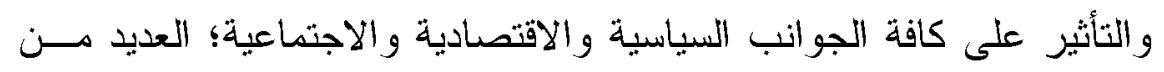

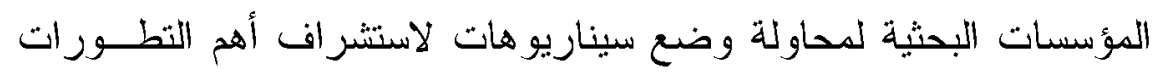

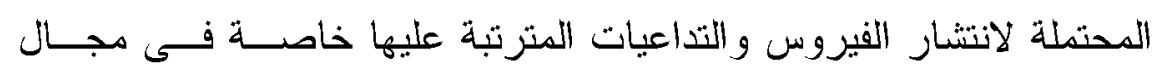

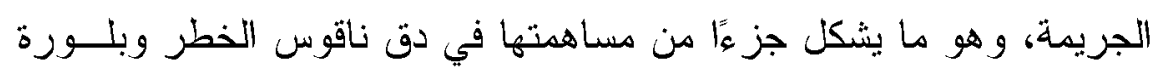

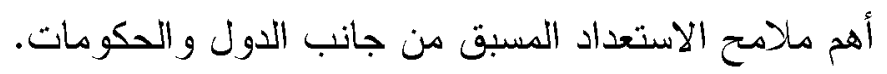




\section{ثانيا: سبناريوهات مستقبل الجريمة :}

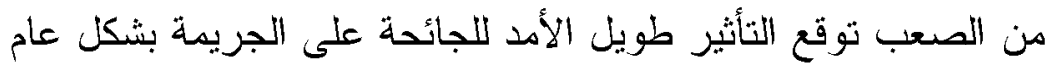

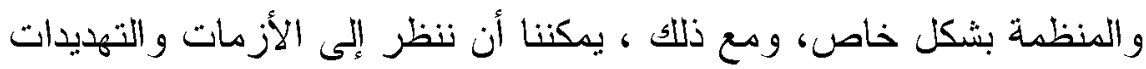

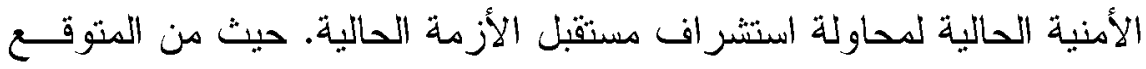

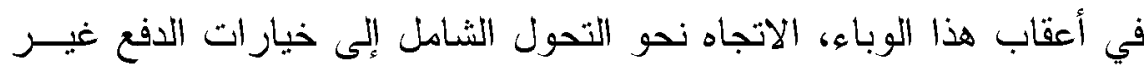

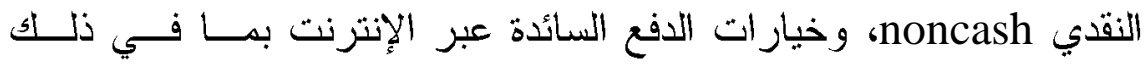
العملات المشفرة المتاحة بشكل متز ايد وفي متتاول جميع المستخدمين، بينما

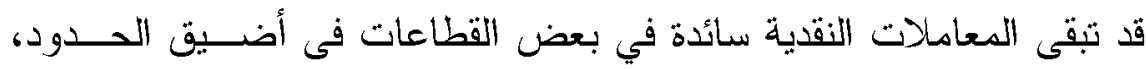

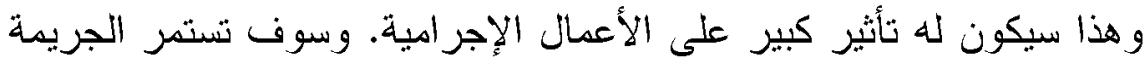

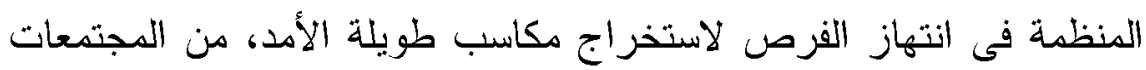

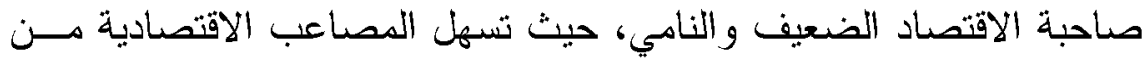

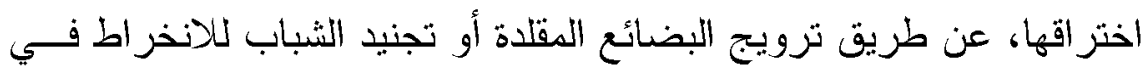

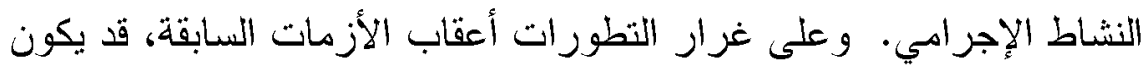
هناك توقع بزيادة مستويات الفساد في مختلف دول العالم، من خلال الأفراد

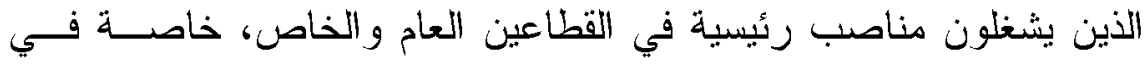

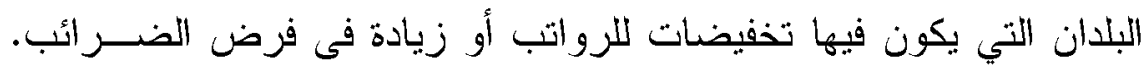
ويمكن عرض السيناريو هات المستقبلية للجريمة كالتالى :

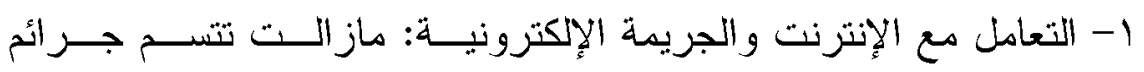

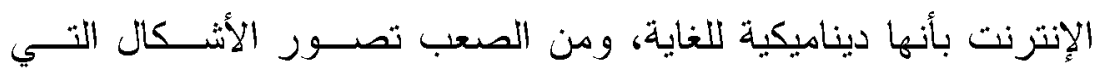

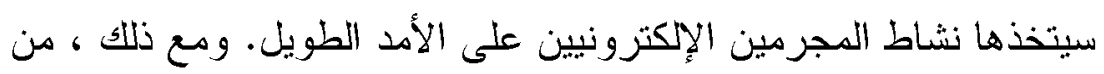
غير المرجح أن يتضاءل نشاط الجريمة السيبرانية، وستستمر التهديدات التهني الإلكترونية خلال جائحة COVID-19 في استهداف الضحايا وحتى بعد

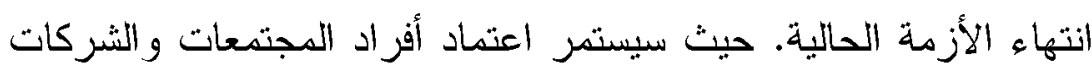

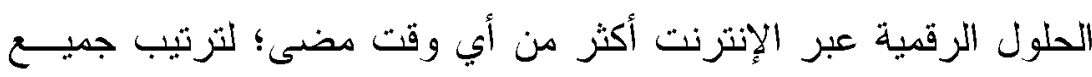

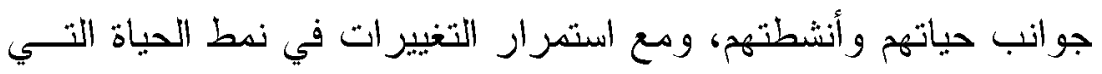
ظهرت خلال الوباء دثل العمل والتعليم والتسوق عن بُعد حتى بعد انتهاء 
الإغلاق، سيستمر مجرمو الإنترنت في البحث عن فرص لاستغلال هذه

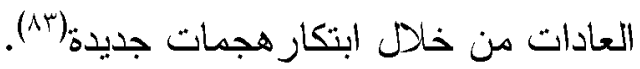

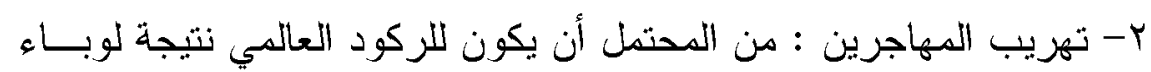

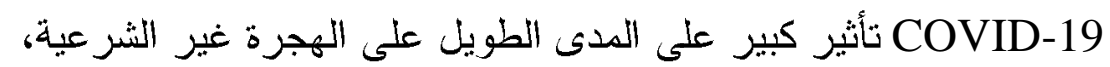

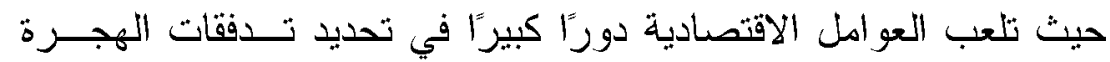
وتفضيلات المهاجرين غير الثرعيين إلى البلدان التى يسافرون إليهــا.

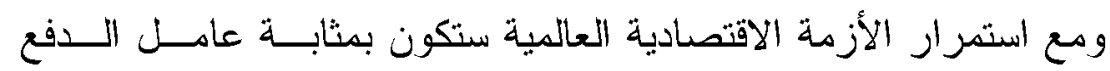
للمهاجرين غير الثرعيين القادمين من البلدان الأقل مرونـــة اقتصــاديًا

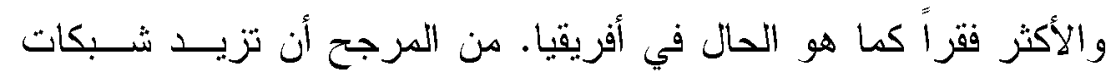
تهريب المهاجرين كن أنشطتها وتسهل تهريب عدد متز ايد من المهاجرين

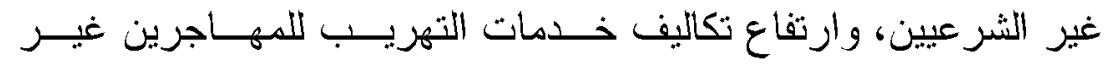

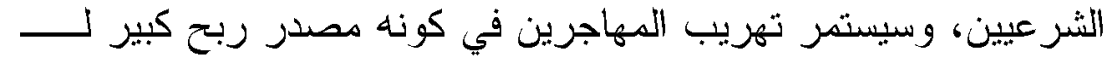

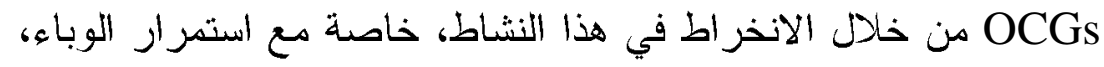

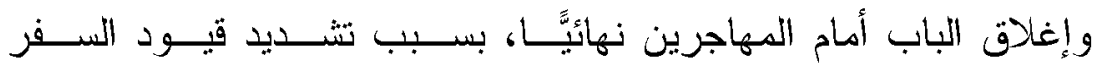
والاختبار ات الطبية المطلوبة للمهاجرين؛ بداعي الخوف دن موجة ثانية

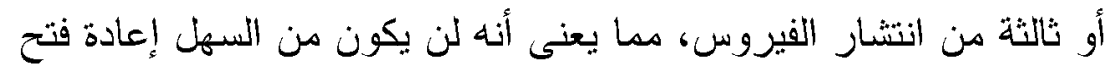

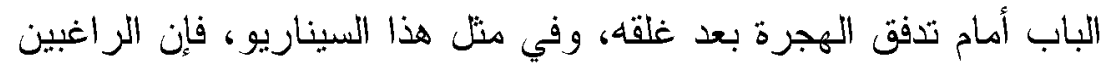

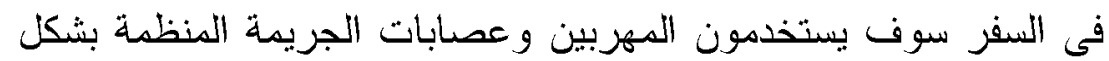
متز ايد، للهجرة وعبور الحدود الدولية دون نوثيق أو فحوصات صحية،

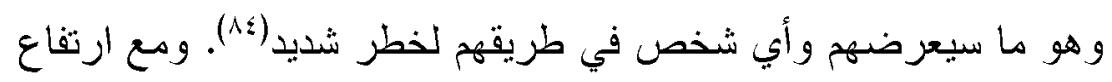

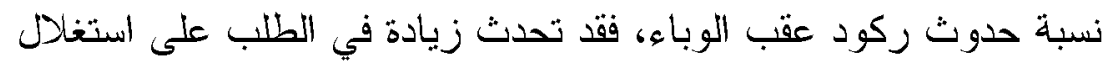

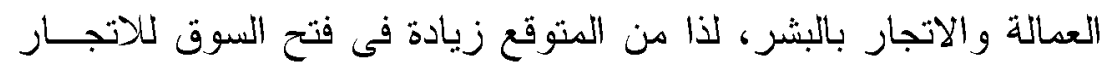
بالبشر r- الوضع الاقتصادى والجرائم المالية : دن المتوقع هع حدوث الأزهـات

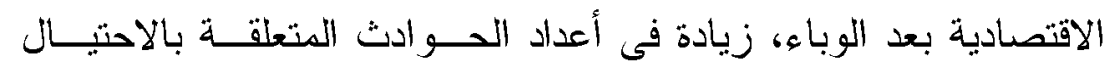

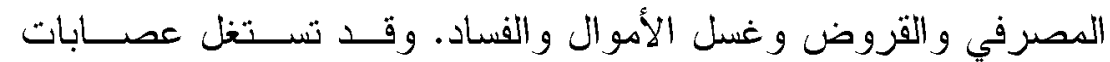


الجريمة المنظمة الموقف للاستحو اذ على شركات كثيفـة النقــــــل لغسـل

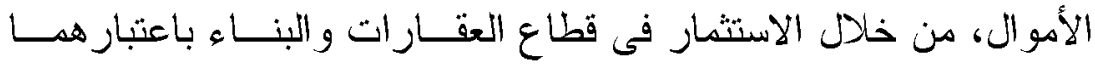
الأكثر جاذبية لغسل الأموال و مبرراً لحركة الأموال بسهولة. بالإضــافة إلى ذلك، قد يكون الاستثار في المجال الفني أيضًا جذابا بســبب عـدم وجود أسعار ثابتة، وسهولة إعادة دمج عائدات الجريمة من خلاله. وقــد تسيطر المنظمات الإجرامية الغنية بــالنقود علــى الأعدــال التجاريــة

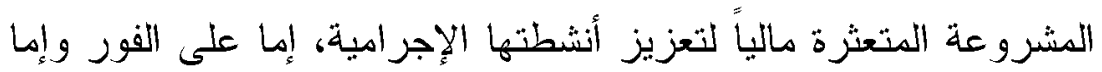
على المدى الطويل. و هذا يعنى أن الانكماش الاقتصادي المحتمل سيشكل بشكل أساسـي ملامح خطورة الجريمة المنظمة، فعندما يحدث التفاوت الاقتصادي في جميع أنحاء أوروبا، سيمنح الجريمة المنظمة قبولًا اجتماعيًا أكثر، مدا يسهل تسلل بCGs على أنهم مزودو العمل والخدمات. ومع ارتفاع معدلات البطالة، و انخفاض الاستثار المشروع، والمزيد من القيود المفروضة على مــوارد الســلطات العامة كل ذلك يمكن أن يتحد ليقدم فرصنا أكبر للجماعات الإجر امية ، كأفر اد

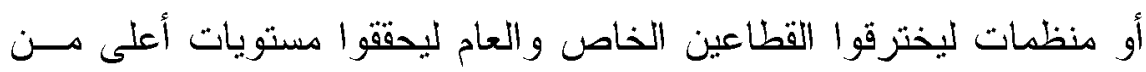
الأُرباح.

؟- تجارة المخدرات والأدوية : مع رفع القيود تدريجياً، من المحتمـل أن يزداد استخدام هنظدات الاتجار بالمخدرات للتكنولوجيات الرقمية القائمة على الاتصال و الإنترنت، وعلى الثبكة المظلمة، و على وسائل التواصل الاجتماعي، واستخدام تطبيقات الاتصالات المشفرة. وبالتالي يمكن توقع زيادة أهمية أسواق الثبكة المظلمة وقنوات الاتصال الآمنة. ودن المرجح

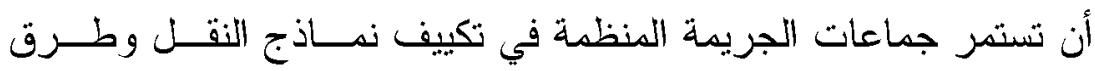
التهريب، خاصة هع استمرار تعطيل التهريب جوا، سيزداد الاعتماد على الطرق البرية وخدمات البريد والطرود لتوزيع المخدرات. 
0 - العنف و عدم المساو اة بين الجنسين: في ظل استمرار انتثــار جائحـــة

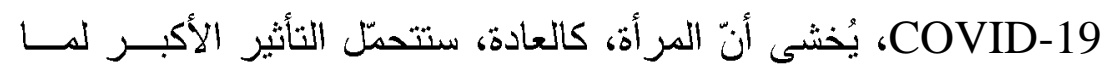
سيولْه هذا الوباء من دخاطر صحية وعنف في المنطقة العربية، وهـن المتوقع أن يطال الققر مزيداً هن النساء في المنطقة العربية، دما سيؤثًر بشدة على الأسر التي تعيلها نساء. وأن يستمر تعرض النساء و الفتيـات لمزيد من العنف الأسري، وذلك بسبب تصاعد التوترات فـي الأسـرة؛ نتيجة عدم تلبية الاحتياجات الأساسية، وتفاقم الضغوط الاقتصادية، و القلق هن التعرض لفيروس كورونا. ومن المؤسف أن عدداً قليلاً جـدًا مــن الدول العربية توثق حالات العنف الأسري، دما يعني أن النطاق الحقيةي

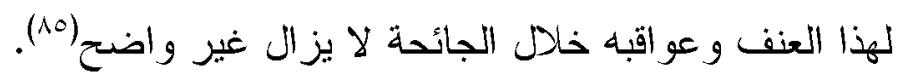




\section{الخاتمة والتوصبات}

كثفت لنا الجائحة عن مدى تطوير مجرمى الإنترنت لهجماتهج بوتيرة تنذر بالخطر، مستغلين حالة الخوف و عدم اليقين النــاجمين عـن الوضــع الاجتماعي والاقتصادي غير المستثر فى جيع دول العالم. في الوقت نفسه، يتزايد الاتجاه نحو المجتمع الرقمى والاعتماد على الاتصال و البنية التحتيـة الرقمية بسبب الإغلاق العالمي؛ مدا يضاعف من فرص الجريمة و الهجمات السيبز انية. لقد أوجد الوباء فرصًا محورية للتفكير في القـدرات والمــوارد الحالية للتحسن، وتحقيق استعداد أفضل ومرونة لأية صــدمات مسـتنقبلية. وأثبت الوباء العالمي أهمية الاستجابة العالمية السريعة لمواجهــة الجائحـــة بطريقة تعاونية و منسقة. إن الأولوية الأكثر إلحاحًا للتصدي لهذه التهديــدات السيبرانية المثز ايدة هي زيادة تعزيز التعاون الدولي وتحسين تبادل معلومات

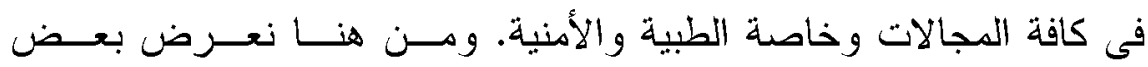
التوصيات التى من شأنها أن تساعد متخذى القرار لمو اجهة تداعيات الجائحة في كافة المجالات.

\section{أُ أقتصاديا}

1- تهدد التداعيات الاقتصادية للجائحة البلدان النامية بموجة دــن حـالات التخلف عن سداد الديون، لذلك لابد من إيجاد حلول دائدسـة، ووضــع خطط ومقترحات ملموسة لمنع الدول النامية دن الانزلاق في حـالات

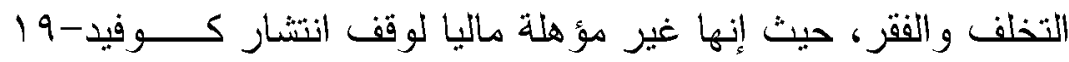
وكذلك تحمل عو اقبه الاجتماعية والاقتصادية، و أهمية خلــق مســاحة للاستثار ات لتحقيق أهداف التتمية المستدامة . م.r، دع ضرورة إعادة التفكير في أنظمتا الاقتصادية، الأمر الذى يتطلب من القيادة السياسـية

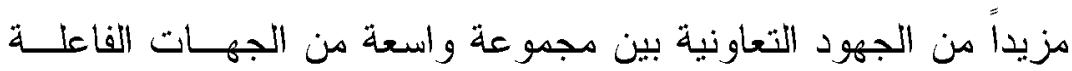
لحماية المستقبل من أجل الأجيال القادمة. ץ- ضرورة التخلص دن السباق النيو - الليبر الي المحموم نحو الهينة ونحو الربح دون حدود على حساب إنسانية الإنسـان، وضـرورة إعطـاء 
الأولوية فى ميز انيات الدول و الاستتمار ات إلى قطاعي التعليم والصحة،

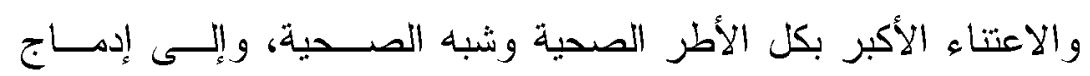
الاقتصاد غير المهيكل وتقليص الفوارق الاجتماعية.

\section{ب- اجتماعيا}

1- توحيد الجهود المحلية و العالمية لبناء مسار ات مستدامة ومرنة؛ لتــوفير

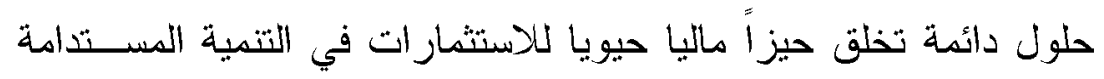

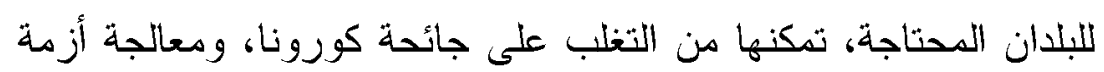

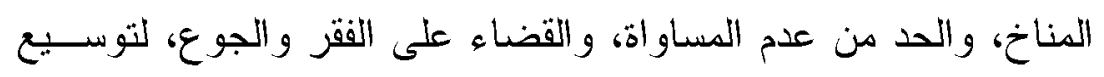

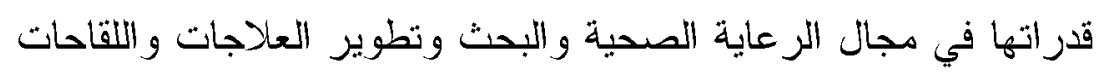

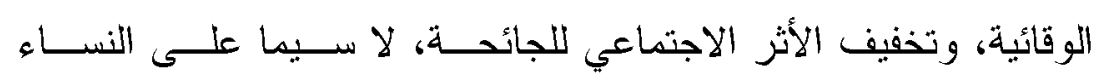
والأطفال و الفئات الاجتماعية الهشّة.

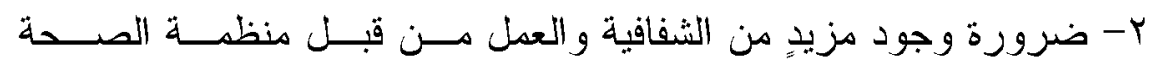

العالمية، وذللك من أجل عملها في تتبع انتشار الفيروس، وتقيبيم الثغرات

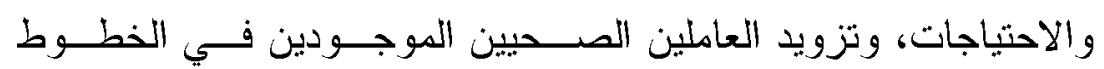

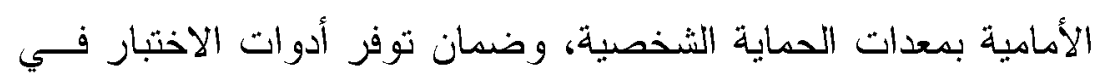

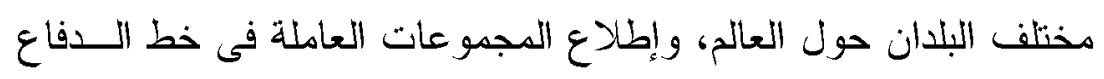
الأول على أحدث ما يتمّ التوصل إليه دن توجيه فنّي.

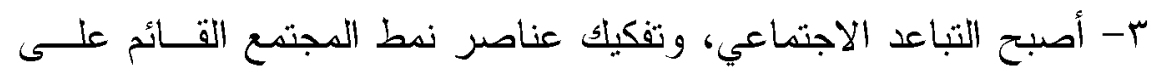

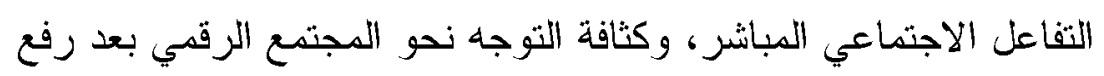

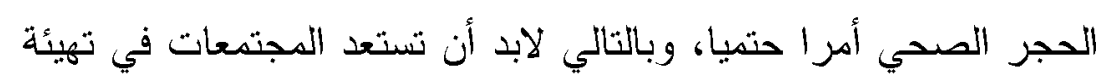

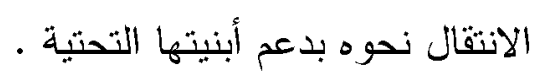

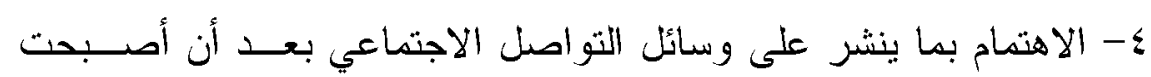

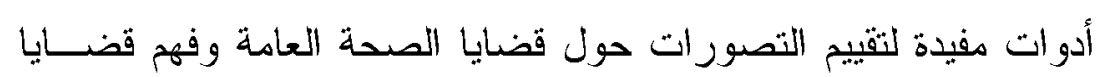

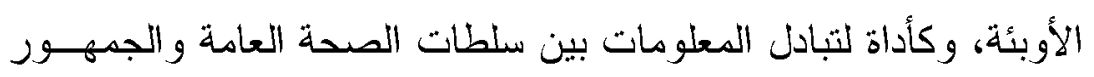

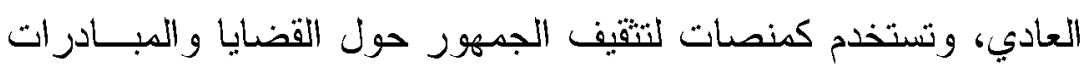

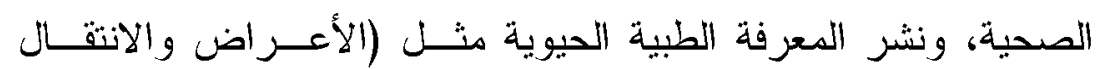




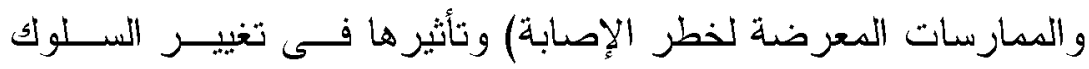
وزيادة التعبئة المجتمعية في جهود الصحة العامة.

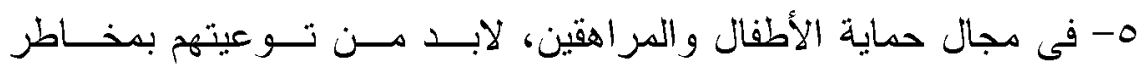

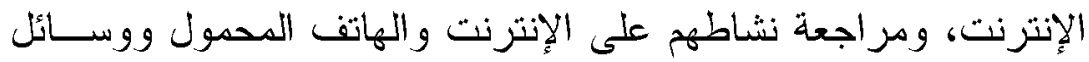
التو اصل الاجنماعي و ألعاب الفيديو.

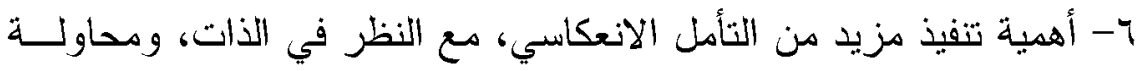

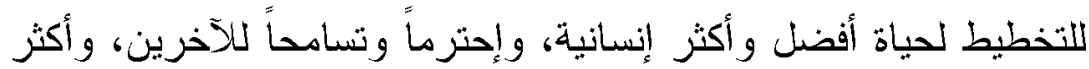

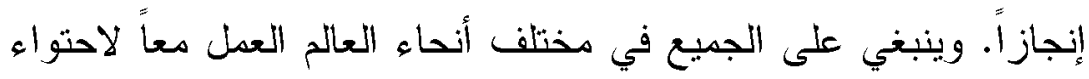

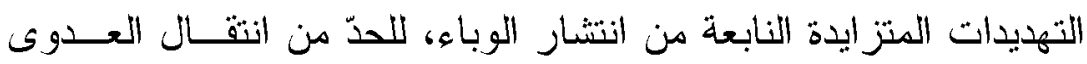

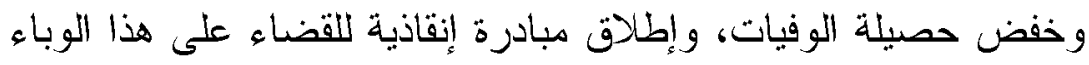

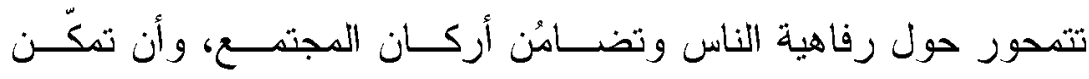

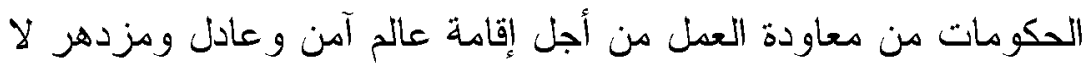
يهمل أحداً. V- يتضح جلياً الحاجة الملحة لفه المخاوف المتعلقة بالتهميش والعنف القائم

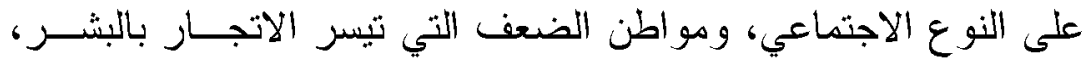
بالإضافة إلى التصدي للعقبات التي تحول دون تحديد الضحايا وحمايتهه،

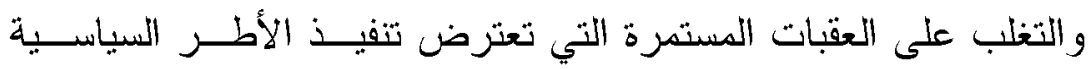

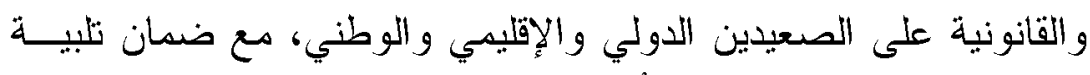

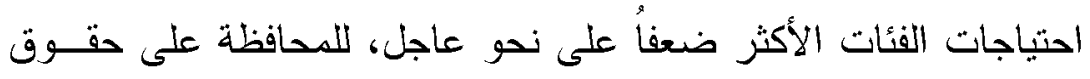
جميع الضحايا، و لا سيما النساء و الأطفال.

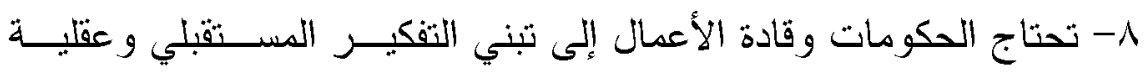

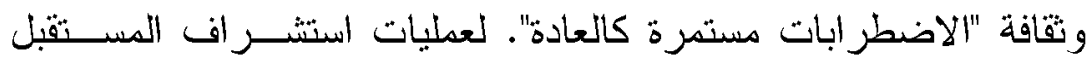
الأساسية التي تثمل استقر اء التوجهات ومسح الأفق والسيناريو الأساسي التهادي و السيناريو هات البديلة للمستقبل و الرؤية و التخطيط، هي منهجية هنظمة ونية لفهز و إدارة وقيادة الاضطر ابات، وضمان الجاهزية والاستعداد هن خلال

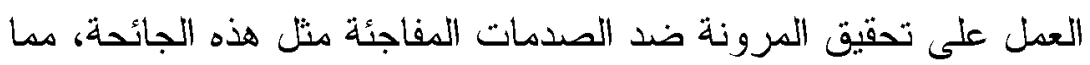


يستوجب بناء كفاءات قوية في استثر اف المســثقبل تشـــل القيــادات

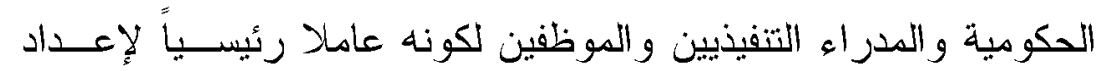

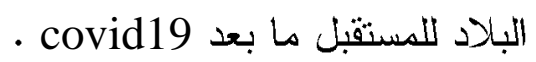

\section{جم- أمنتيا}

1- من المتوقع أن تستمر دعدلات الجريمة الإلكترونية في الازدياد هع تقدم

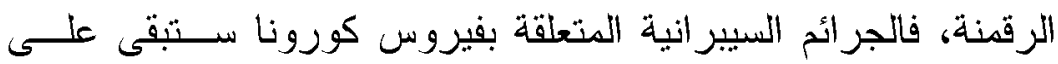

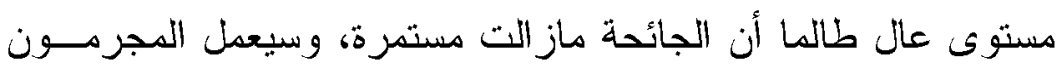

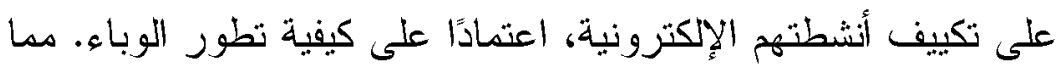

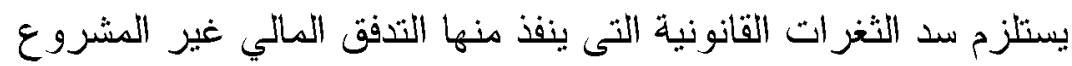

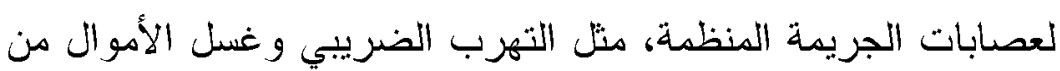

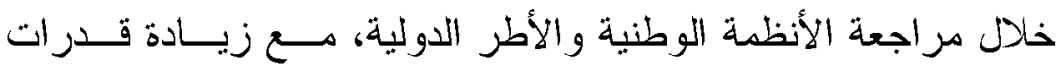
وخبرات وكالات إنفاذ القانون في مجال الوقاية، وتوسيع نطاق التحقيق

$$
\text { في الجرائم الإلكترونية. }
$$

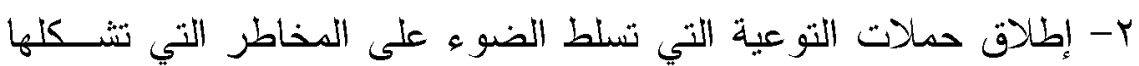

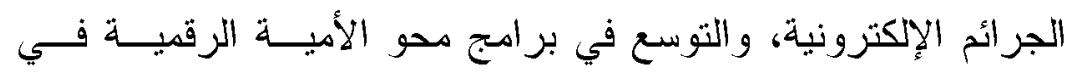

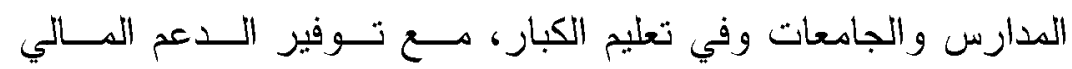

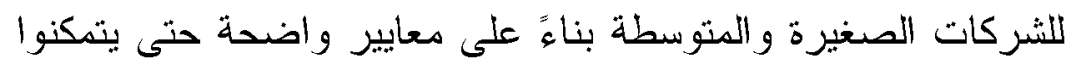

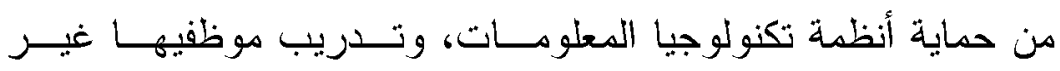

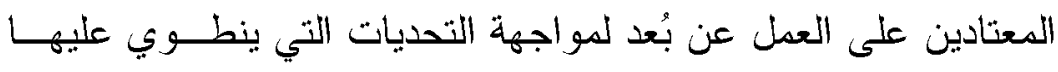
الأهر وكيفية تجنبها.

r- لا يوجد أمان بنسبة . . 1 \% في المجال السيبراني، يمكن فقط أن تكون

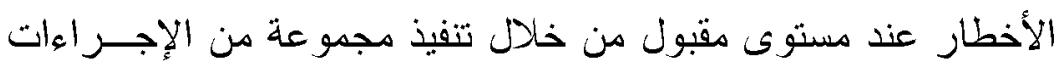

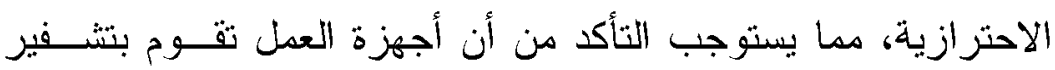

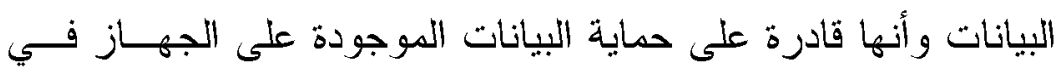

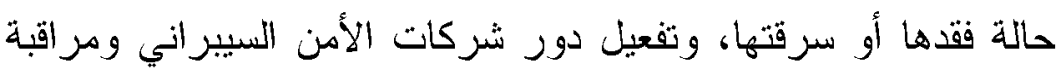

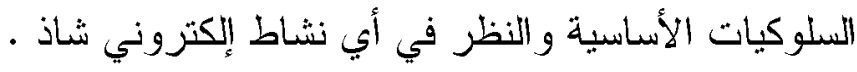


؟- أهية استمرار مر اقبة التأثير الأمني للفيروس عن كثب، لا سيما عندها

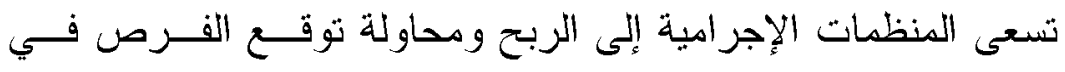

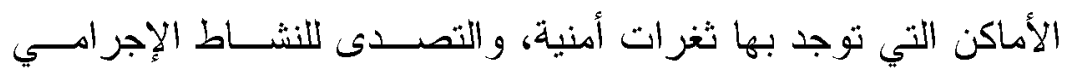

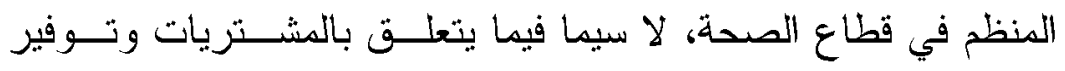
الإمدادات الطبية المزيفة.

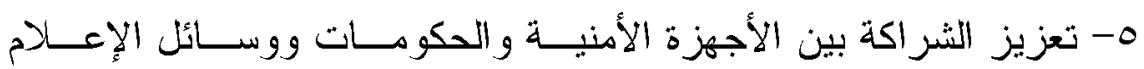

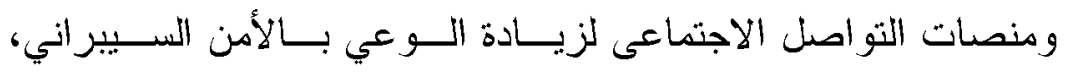

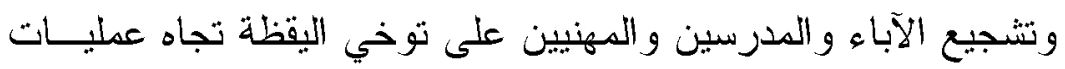

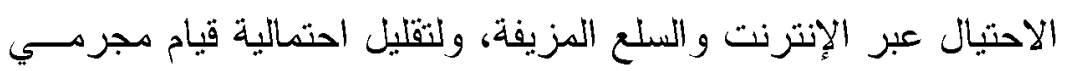

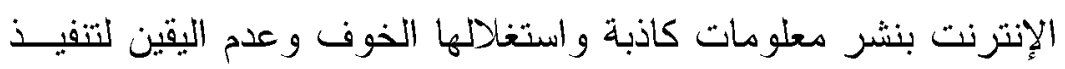

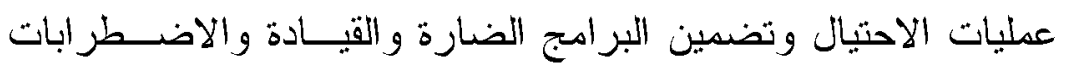

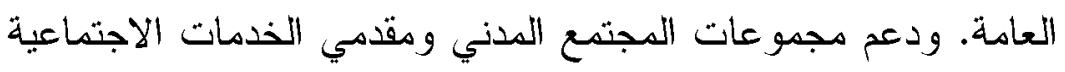

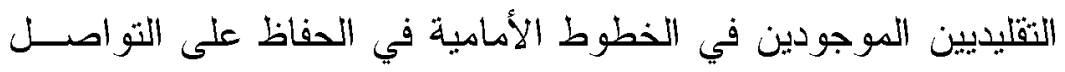

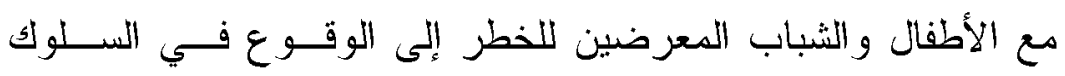

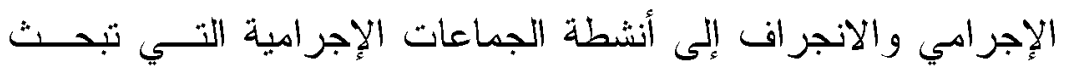

$$
\text { لتجنيد أعضاء جدد. }
$$

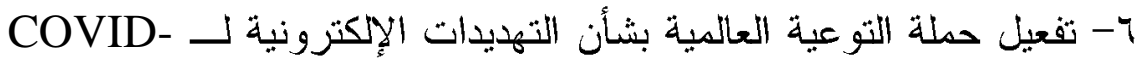
\#WashYourCyberHands

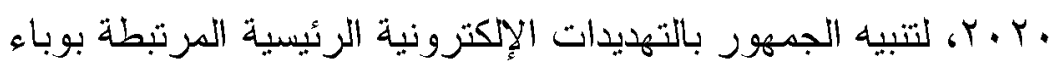

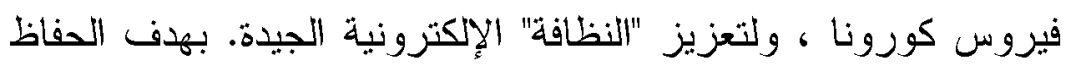

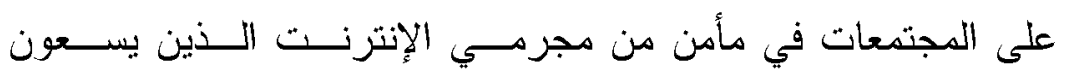

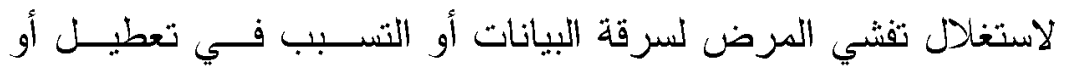

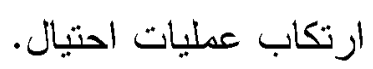

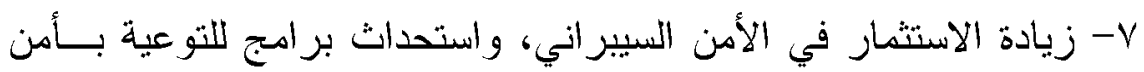

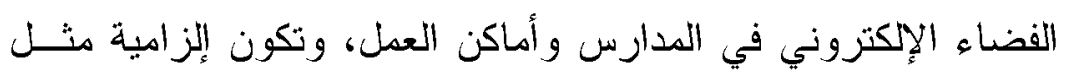

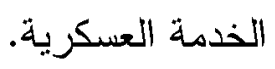


1- هن المهج أن يتوصل العالم إلى وضع قو انين ملزمة، وخطـ طـ عمليــة

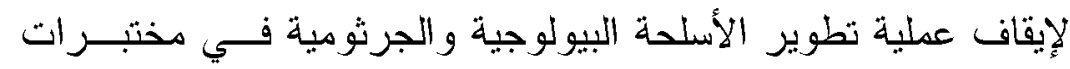

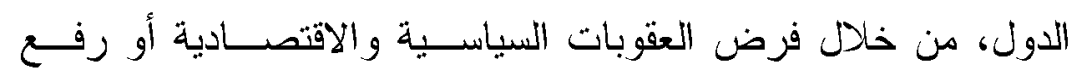
الدعاوى القانو نية ضد الدول وكذلك دن خلال الدبلو ماسية السيبر انية.

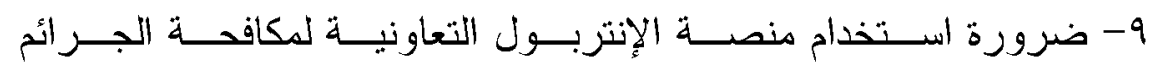

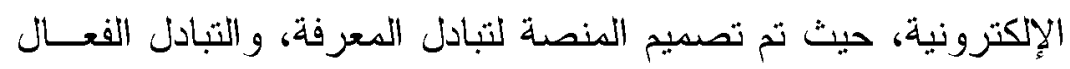

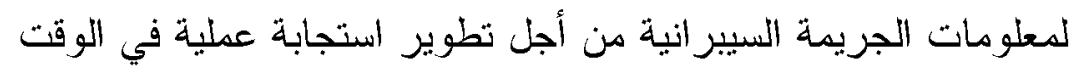

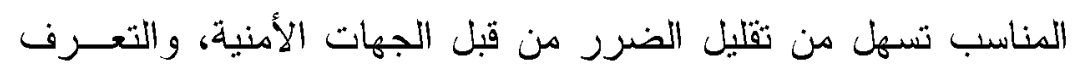

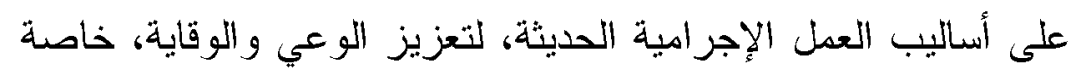
فيما يتعلق بحالات هجمات برامج الفدية ضد الحكومات والبنية التحتية

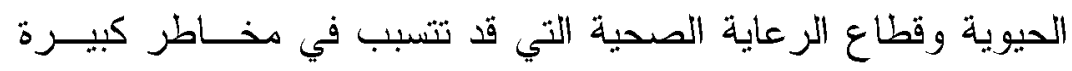
وتضر بالسلامة العامة و الأمن.

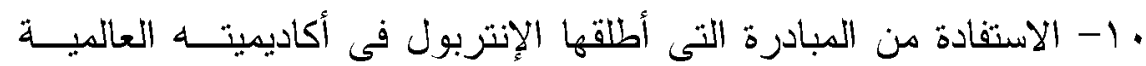

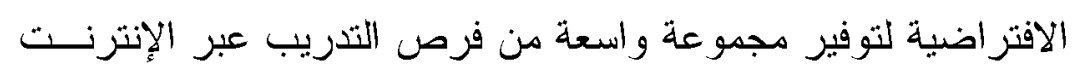

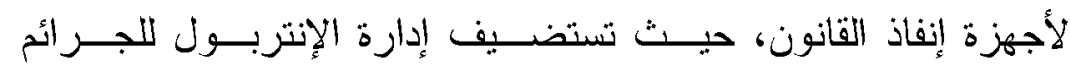

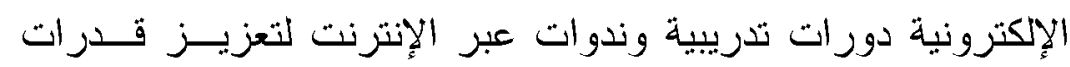

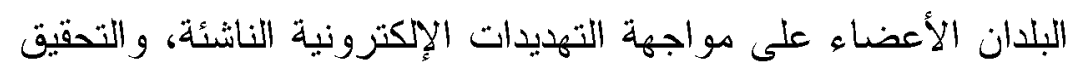

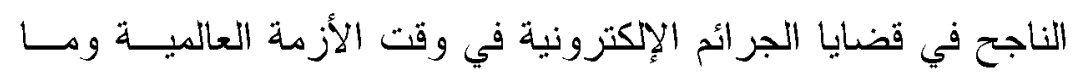
بعدها. 


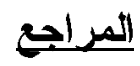

1-Cohen, L. E., \& Felson, M. (1979). Social change and crime rate trends: A routine activity approach. American Sociological Review, 44, 588-608.

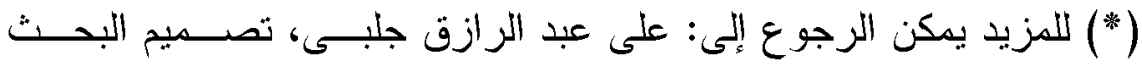
الاجتماعى"الأسس و الاستراتيجيات"، دار المعرفة الجامعية، الاسكندرية، . . . .

r- تم الرجوع إلى الصفحة الخاصة بكوفيد-9 اعلى موقع منظمة الصــحة

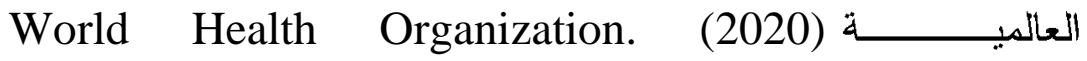
/https://www.who.int/csr/disease/coronavirus_infections/ar https://www.who.int/ar/emergencies/diseases/novelcoronavirus-2019/advice-for-public/q-a-coronaviruses https://www.who.int/epi-win

r- ماهر حنين، سوسيولوجيا الهامش زمن الكورونا الخوف - الهنشآشة الانتظار ات "، المنتدى التونسي للحقوق الاجتماعية والاقتصادية، ابريل

$$
\leq, v, r \cdot r \text {. }
$$

¿- Laura Spinney, How pandemics shape social evolution, VOL 574 , NATURE 325,17 OCTOBER 2019. https://www.nature.com/articles/d41586-019-03048-8

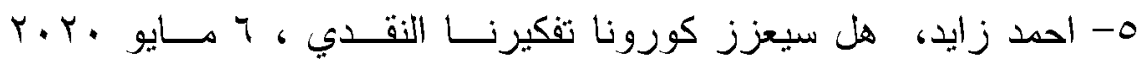
IT:YV

https://www.independentarabia.com/node/116971/

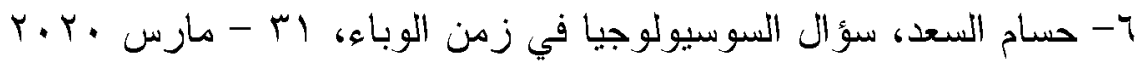
https://www.alquds.co.uk/

- V انتوني جيدينز، علم الاجتماع، ترجمة: فايز الصياغ، الصنظمة العربية

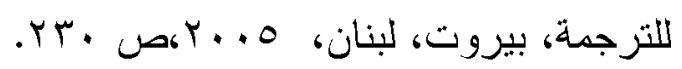

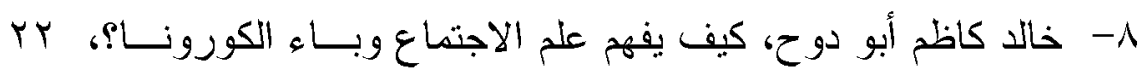
http://aswatonline.com/2020/04/22 $\quad$ Y.r.r. أبريل 
* للمزيد يمكن الرجوع إلى كتاب أو رليش بيك ، مجتمع المخاطرة، ترجمة

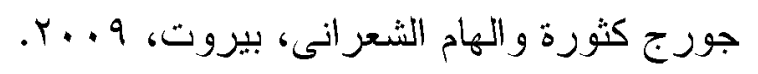

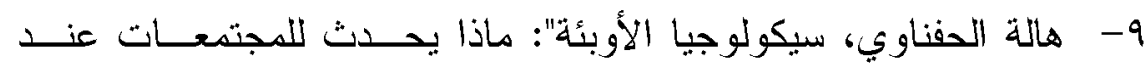

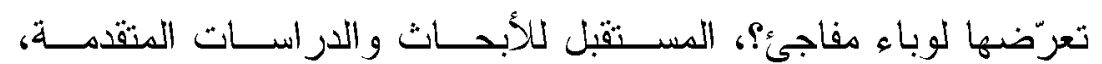

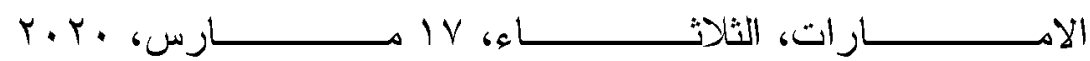
https://futureuae.com/ar-AE/Mainpage/Item/5379

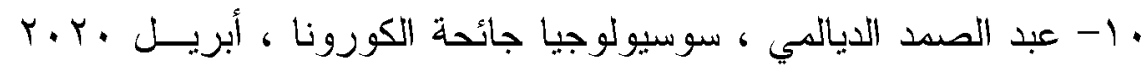
https://www.mominoun.com/articles/ 11 - احد زايد، درجع سابق.

Ir-George Mohlera and others, Impact of social distancing during COVID-19 pandemic on crime in Los Angeles and Indianapolis, Journal of Criminal Justice,Volume 68, May-June 2020.

$$
\begin{aligned}
& \text { זו- هالة الحفناوي، درجع سابق. }
\end{aligned}
$$

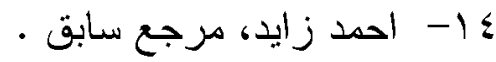

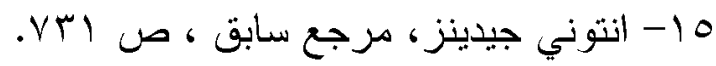

$$
\begin{aligned}
& 7 \text { آ آحد زايد، مرجع سابق. }
\end{aligned}
$$

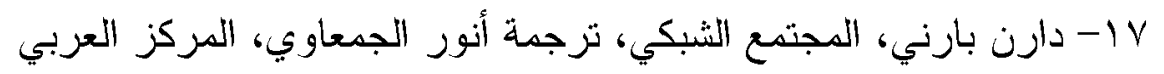

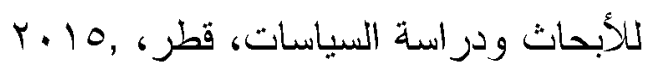

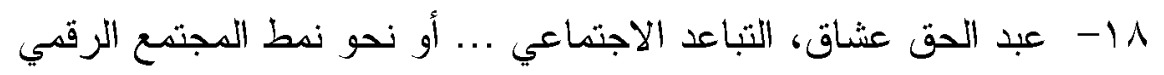

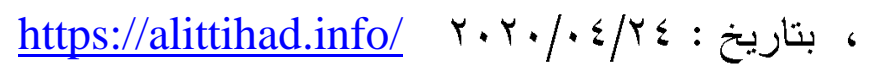

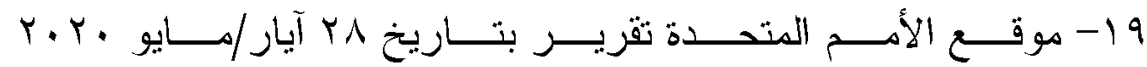
https://news.un.org/ar/story/2020/05/1055632

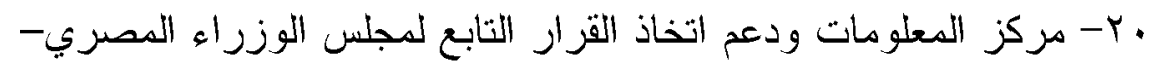

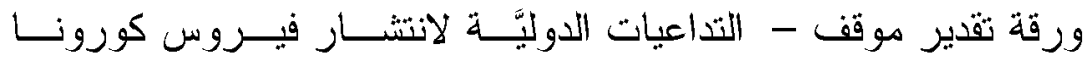

$$
\text { المُستجد - العدد }
$$


(I) -Prem Mahadevan, CYBER CRIME Threats during the COVID-19 pandemic. www. globalinitiative.net. APRIL 2020

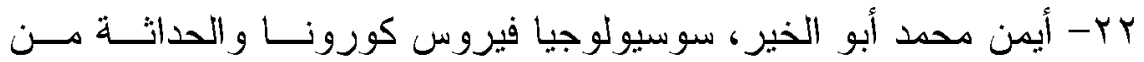

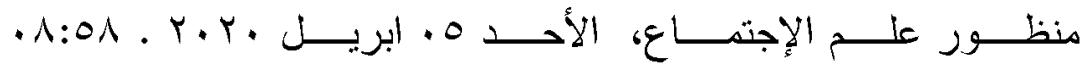
https://shms.ps/post/98037/

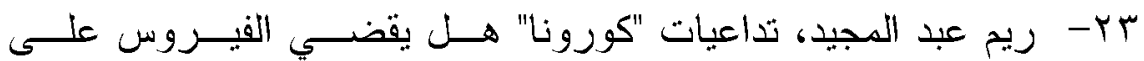

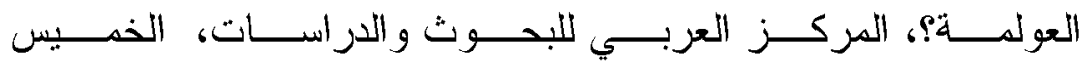
http://WwW.acrseg.org/41534 r.r.r/ • 9

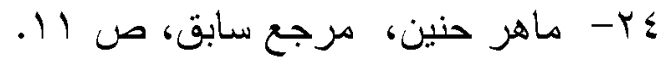

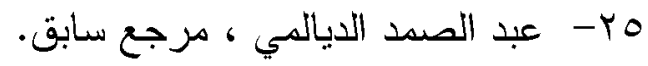
Tr- ماهر حنين، درجع سابق، ص

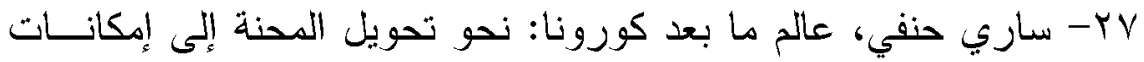

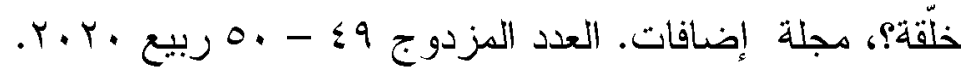

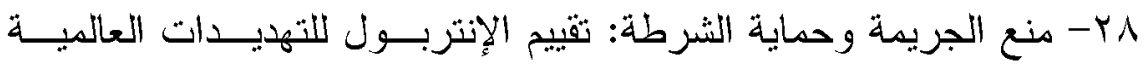

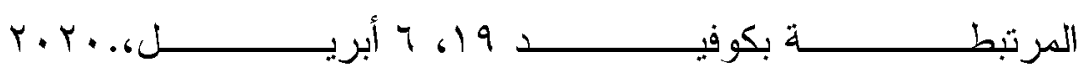
.https://www.interpol.int/ar/1/1/2020/193

rq- Rebecca Edwards, Crime and the Coronavirus: What You Need to Know ,August 3, 2020. https://www.safewise.com/blog/covid-19-crimes/

r.- Brooke Wolford, Coronavirus has 'massive' impact on US crime rates: Here are some of the big changes. JULY 21 2020 $08: 23$

PM https://www.miamiherald.com/news/coronavirus/article 244393022.html

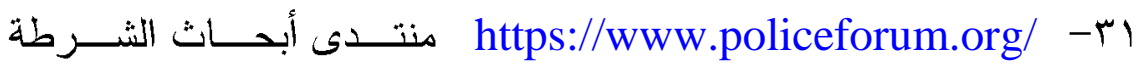
التنفيذية (PERF)، تأسس في عام 19 أكمنظمة غير ربحية مقرهـا

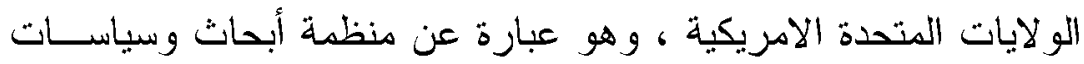


شرطية ومزود للخدمات الإدارية و المساعدة الفنية والتعليم على المستوى التنفيذي لدعم وكالات إنفاذ القانون.

ب ب- هبة القدسي، جريمة تتسلل إلى نواة العائلة في العالم الغربي، الأربعاء

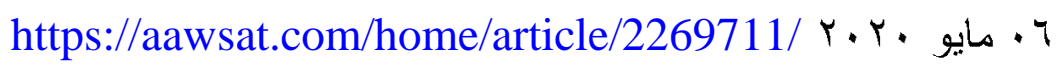

rr- Impact of COVID-19 on crime, Published: 04 Jun 2020 09:38

https://www.gov.scot/news/impact-of-covid-19-oncrime/

$r$ ¿-Murder Rates Were Staggering. The Virus Has Brought Some

Quiet, for Now. https://www.nytimes.com/2020/04/11/world/americas/c oronavirus-murder-latin-america-crime.html هr- محدد عبد الغنى، أرقام... كيف أثرت جائحة كورونا على مؤشرات

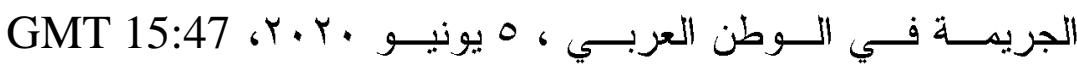
https://arabic.sputniknews.com/arab_world/2020060510 45632668-

rา-Bradbury-Jones, C., \& Isham, L. (2020). The pandemic paradox: The consequences of COVID-19 on domestic violence. Journal of Clinical Nursing., 29, 2047-2049 rv- George Mohlera and others, op.cit.,p 12.

r^- J. Mitchell Miller \& Alfred Blumstein, Crime, Justice \& the COVID-19 Pandemic: Toward a National Research Agenda ,American Journal of Criminal Justice volume 45, 09 July 2020. pages515-524. https://link.springer.com/article/10.1007/s12103-020$\underline{09555-\mathrm{Z}}$

qب- هنع الجريمة وحماية الشرطة: تقييم الإنتربول للتهديـــات العالميــة

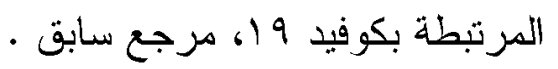

¿- DE CIX: Highest jump ever: DE-CIX Frankfurt reaches 9.1 Tbps, 11.03.20, retrieved from: https://www.de- 
جائحة كورونا وانعكاسها على تغير معدلات وأنماط الجرية رؤى الواقع وسيناريوهات المستقبل

cix.net/de/news-events/news/de-cix-frankfurt-reaches-91 -tbps.

¿- Johannes Wiggen, The impact of COVID-19 on cyber crime and state-sponsored cyber activities, KonradAdenauer-Stiftung e. V., Berlin, No 391 / June 2020 https://www.kas.de/de/ueber-uns

$\{r$ - Lucia Bird,CRIME AND CONTAGION, The impact of a pandemic on organized crime https://globalinitiative.net/ MARCH 2020

\&r- Beyond the pandemic "how COVID-19 will shape the serious and organised crime" landscape in the EU. 30 April 2020. www.europol.europa.eu

ะ - Muncaster, P., "\#COVID19 Drives Phishing Emails Up $667 \%$ in Under a Month", InfoSecurity, 2020. Google, 2020.

¿o- Kari Paul, 'Zoom is malware': Why experts worry about the video conferencing platform, The

Guardian, 2 April 2020. https://www.theguardian.com/technology/2020/apr/02/z oom-technologysecurity-

coronavirus-video-conferencing.

క7- Michael Sullivan, "Child Sex Abuse Live streams Increase During Coronavirus Lockdowns," NPR, 8\4\2020, available at: https://n.pr/3c8HWgT.

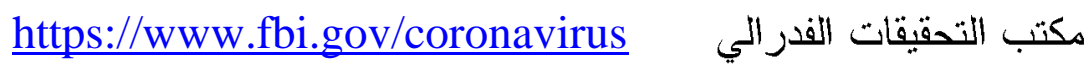
COVID-19 يحث على اليقظة أثناء جائحة

$\leqslant \vee-$ Johannes Wiggen, The impact of COVID-19 on cyber crime and state-sponsored cyber activities,op.cit.,p3. 
^ـ- هايدي الثافعي ، أشكال وهعدلات الجريمة في زهن كورونا، المركز

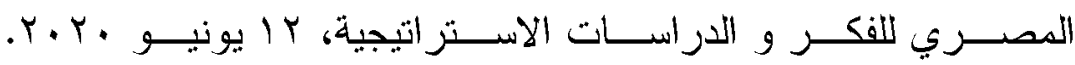
https://marsad.ecsstudies.com/32507/

s $9-$ Europol (2020b), Beyond the pandemic: How

COVID-19 will shape the serious and organised crime landscape in the EU, Europol, The Hague, 30 April (https://www.europol.europa.eu/sites/default/files/docu ments/report_beyond_the_pandemic.pdf).

o. - Viral marketing - counterfeits, substandard goods and intellectual property crime in the COVID-19 pandemic, 17 April 2020. www.europol.europa.eu

01- Beyond the pandemic "how COVID-19 will shape the serious and organised crime" landscape in the EU.op.cit., p 2.

or-Prem Mahadevan, CYBER CRIME Threats during the COVID-19 pandemic. op.cit., p 5.

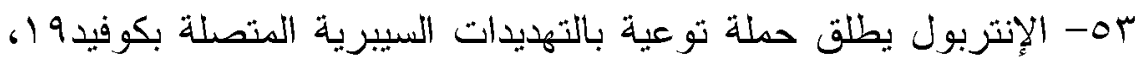

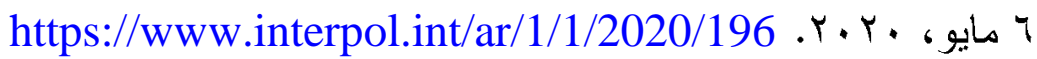
؛ - استغلال بr- استغلال الأزمة" ما أبرز توجهات الجرائم الســيبرانية

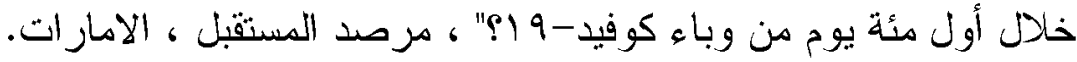

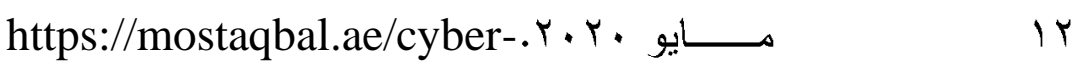
/crimes-100-days-covid-19

00- CYBERCRIME: COVID-19 IMPACT . AUGUST 2020. www.interpol.int 07- Prem Mahadevan, CYBER CRIME Threats during the COVID-19 pandemic. op.cit., p 5.

ov-Beyond the pandemic "how COVID-19 will shape the serious and organised crime" landscape in the EU.op.cit., p 4. 
o^- EU Drug Markets" Impact of COVID-19". May 2020. www.emcdda.europa.eu

يعد EMCDDA هومركز المراقبة الأوروبية للمخدرات والإدمان فـى اوروبا

09- Lucia Bird,CRIME AND CONTAGION, The impact of a pandemic on organized crime. op.cit., p 7.

7.-Interpol (2020), 'Dealers using food delivery services to transport drugs during COVID-19 lockdowns', 30 April (https://www.interpol.int/en/News-and-

Events/News/2020/Dealers-using-food-delivery-

services-to-transport-drugs-during-COVID-19-

lockdowns).

ఛ-EU Drug Markets" Impact of COVID-19". May 2020. op.cit., p 5. www.emcdda.europa.eu.

7 r - EMCDDA (2020), COVID-19 and drugs: Drug supply via darknet markets, European Monitoring Centre for Drugs and Drug Addiction, Lisbon (www.emcdda.europa.eu/publications/ad-hoc/covid-19and-drugs-drug-supply-via-darknet-markets).

با- تقرير أمدي جديد يشير إلى تأثير جائحة فيروس كورونا الكبير على أنى

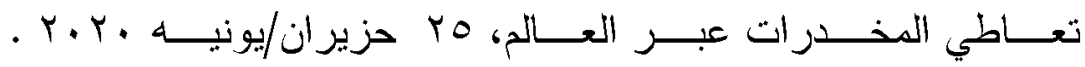
https://news.un.org/ar/story/2020/06/1057232

7 ร- Bradbury-Jones, C., \& Isham, L. (2020). The pandemic paradox: The consequences of COVID-19 on domestic violence. Journal of Clinical Nursing., 29, 2047-2049.

$$
\text { 0-7 - هايدي الشافعي ، مرجع سابق. }
$$

77- Lucia Bird,CRIME AND CONTAGION, The impact of a pandemic on organized crime. op.cit., p 8. 


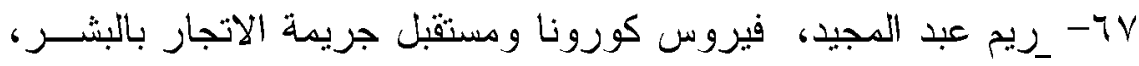

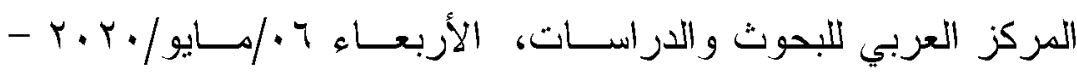

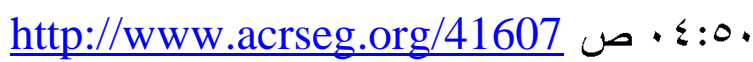

T^- COVID-19 impact on migrant smuggling and human trafficking. $11 \quad$ June 2020. https://www.interpol.int/ar/1/1/2020/198

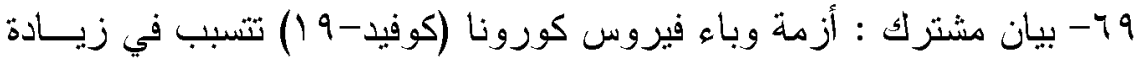

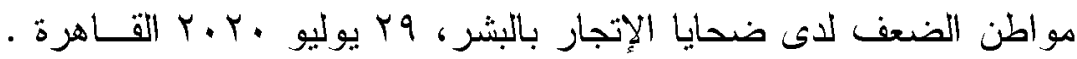
https://www.unodc.org/middleeastandnorthafrica/ar/webstories/dclaration-commune-la-pandmie-covid-19exacerbe-les-vulnrabilits-des-victimes-de-la-traite-despersonnes.html

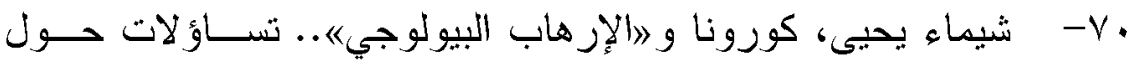

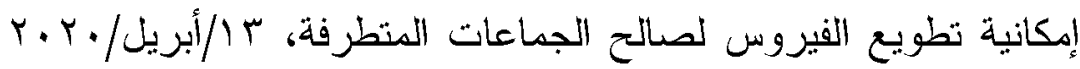

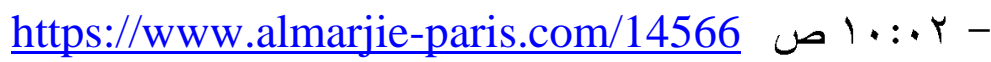
v)- Katherine Aguirre, Emile Badran and Robert Muggah, FUTURE CRIME ; Assessing twenty first century crime prediction, Igarapé Institute . Brasil. Www.igarape.org.br

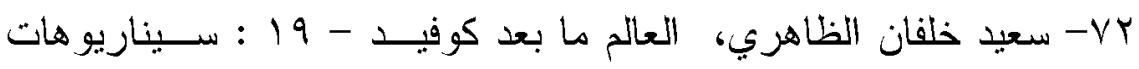

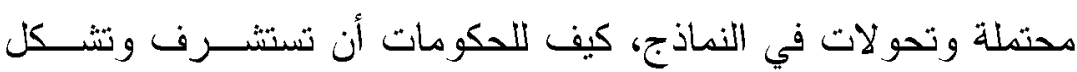

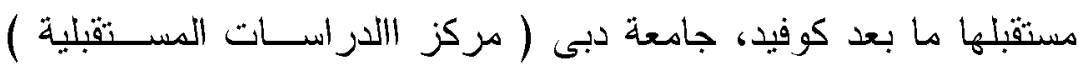
https://www.ud.ac.ae/cfs

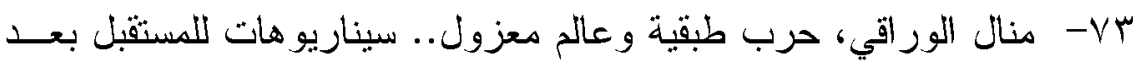

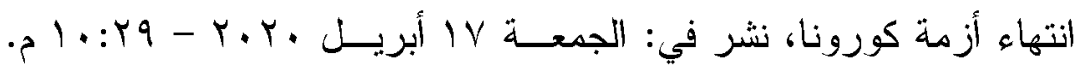
https://www.shorouknews.com/news/view.aspx?cdate=170 42020\&id=e1d3993f-0ab3-4c77-bfa5-aae921c99d43

乏 سارة عبدالعزيز، دحددات الضرر: السيناريوهات الدحتملة لتطــور

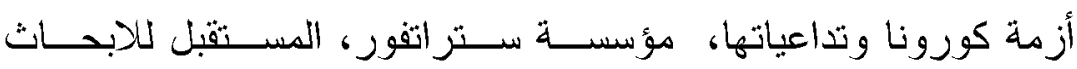

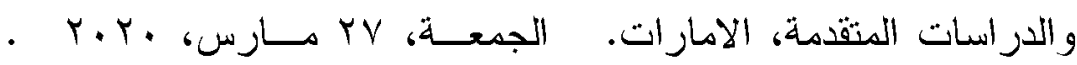
https://futureuae.com/ar/Mainpage/Item/5428/ 


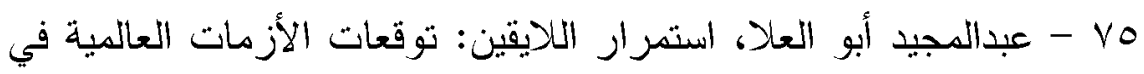

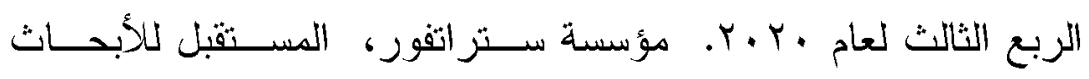

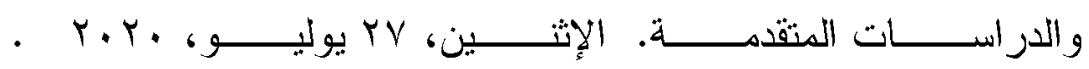
https://futureuae.com/arAE/Mainpage/Item/5719/-2020

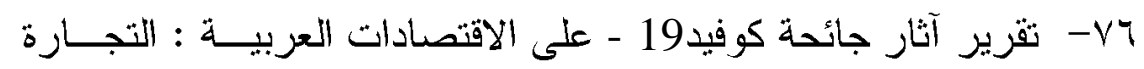

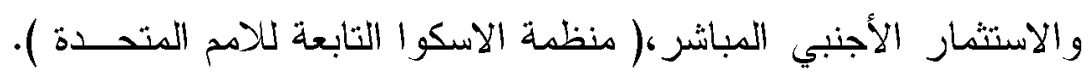
WWw.unescwa.org تقرير هيئة الامم المتحدة للمر أة : آثار جائحسـة كوفيــ- VV

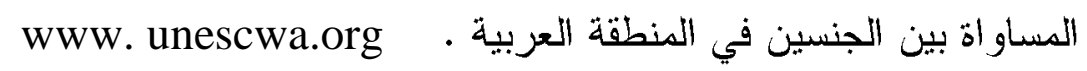

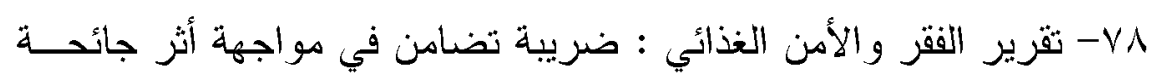

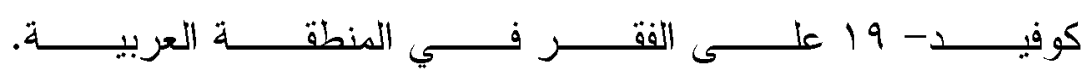
www.unescwa.org. E/ESCWA/2020/POLICY BRIEF.7 تو - تقرير فيروس كورونا :التخفيف من أثر الوباء على الفقر وانعدام الأمن

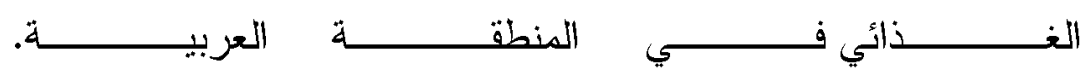
www.unescwa.org. E/ESCWA/CL3.SEP/2020/Policy Brief.2 . www.unescwa.org . E/ESCWA/2020/POLICY BRIEF.9

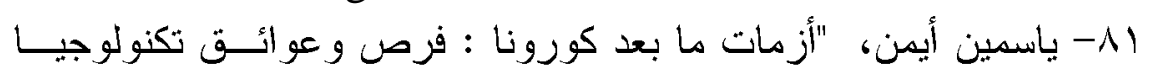

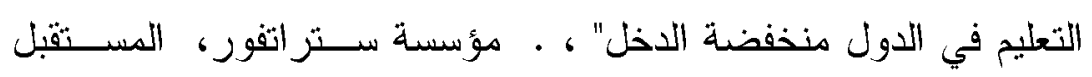

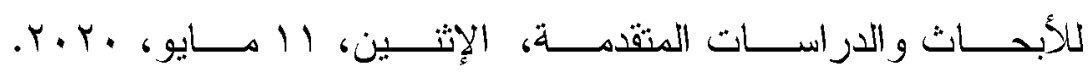
/https://futureuae.com/ar-AE/Mainpage/Item/5579 r - سعيد خلفان الظاهزي، درجع سابق. $\lambda r-$ Beyond the pandemic "how COVID-19 will shape the serious and organised crime" landscape in the EU.op.cit., p 6. 
مجلة كلية الدراسات الإسلامية والعربية للبنات بدمنهور العدد الخامس الجزء الثالث عشر •r.rم

ء - باسم راتد، اتساع الفجوات: اتجاهات تأثير وباء كورونا على الهجرة

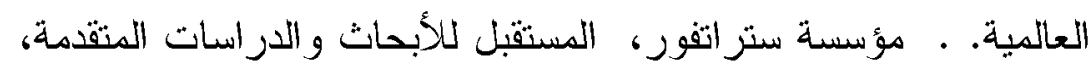

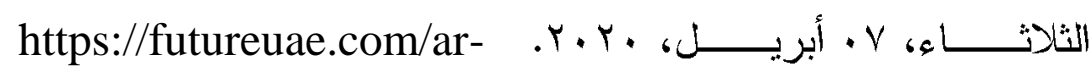
/AE/Mainpage/Item/5490 هـ- تقرير هيئة الامم المتحدة للمر أة، مرجع سابق. 